\title{
Scoping Analyses on Tritium Permeation to VHTR Integrated Industrial Application Systems
}

Chang $\mathrm{H}$. Oh Eung S. Kim

March 2011

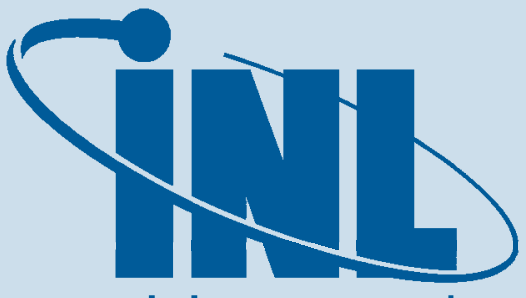

Idaho National Laboratory

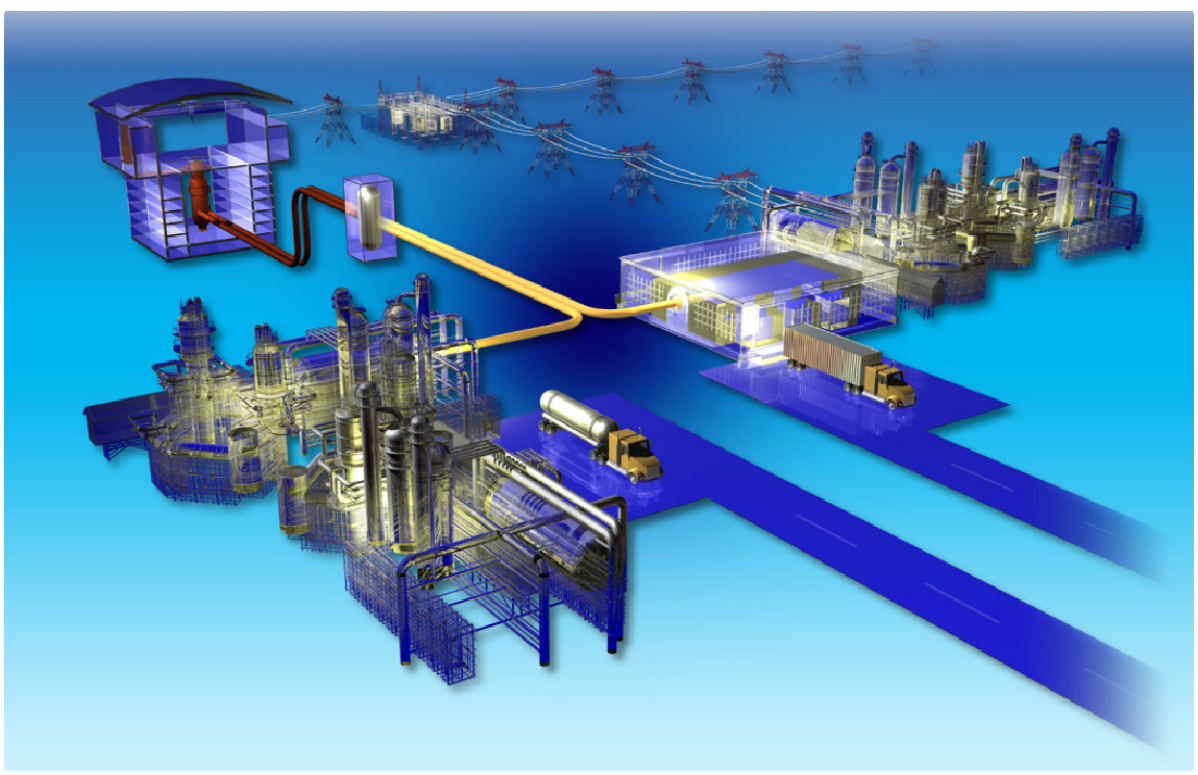




DISCLAIMER
This information was prepared as an account of work sponsored by an
agency of the U.S. Government. Neither the U.S. Government nor any
agency thereof, nor any of their employees, makes any warranty, expressed
or implied, or assumes any legal liability or responsibility for the accuracy,
completeness, or usefulness, of any information, apparatus, product, or
process disclosed, or represents that its use would not infringe privately
owned rights. References herein to any specific commercial product,
process, or service by trade name, trade mark, manufacturer, or otherwise,
does not necessarily constitute or imply its endorsement, recommendation,
or favoring by the U.S. Government or any agency thereof. The views and
opinions of authors expressed herein do not necessarily state or reflect
those of the U.S. Government or any agency thereof.


INL/EXT-10-19607

Revision 1

\section{Scoping Analyses on Tritium Permeation to VHTR Integrated Industrial Application Systems}

Chang H. Oh

Eung S. Kim

March 2011

Idaho National Laboratory

Next Generation Nuclear Plant Project

Idaho Falls, Idaho 83415

Prepared for the

U.S. Department of Energy

Office of Nuclear Energy

Under DOE Idaho Operations Office

Contract DE-AC07-05ID14517 



\section{Next Generation Nuclear Plant Project}

\section{Scoping Analyses on Tritium Permeation to VHTR Integrated Industrial Application Systems}

INL/EXT-10-19607

Revision 1

March 2011
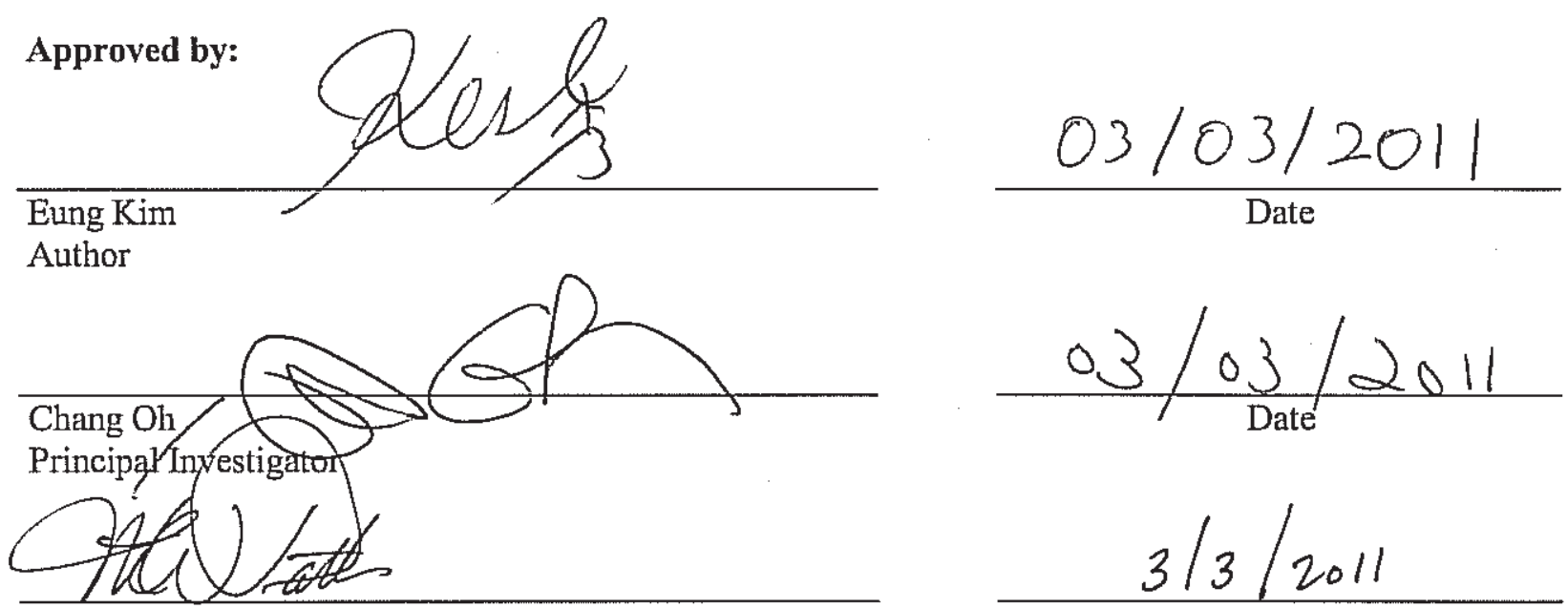

Mike Patterson

Engineering Technical Manager

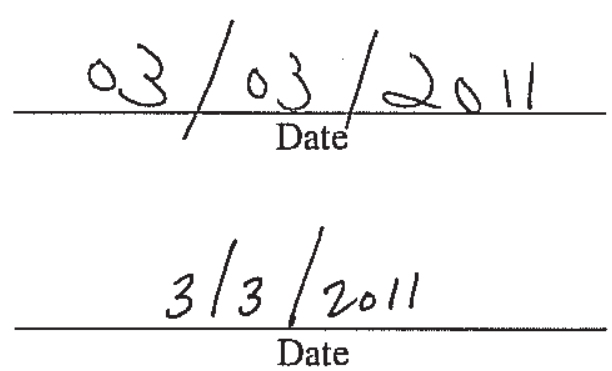





\section{EXECUTIVE SUMMARY}

Tritium permeation is currently an important issue in the development of the Very High Temperature Reactor (VHTR) because tritium is easily permeated through high temperature metallic surfaces. Tritium permeation in VHTR-integrated systems was investigated in this study using the tritium permeation analysis code (TPAC) that was developed by Idaho National Laboratory (INL). The INL TPAC is a numerical tool based on the mass balance equations of tritium-containing species and hydrogen (i.e., $\mathrm{HT}, \mathrm{H}_{2}$, and HTO) coupled with a variety of tritium sources, sink, and permeation models. In the TPAC, ternary fission and thermal neutron caption reactions with ${ }^{6} \mathrm{Li},{ }^{7} \mathrm{Li}{ }^{10} \mathrm{~B}$, ${ }^{3} \mathrm{He}$ were taken into consideration as tritium sources. Purification and leakage models were implemented as main tritium sinks. Permeation of tritium and $\mathrm{H}_{2}$ through pipes, vessels, and heat exchangers were considered as main tritium transport paths. In addition, electrolyzer and isotope exchange models were developed for analyzing hydrogen production systems including high-temperature steam electrolysis (HTSE) and sulfur-iodine processes.

Three different systems were considered in this study: (1) the VHTR (gas Brayton cycle)/HTSE system, (2) the high-temperature gas-cooled reactor (HTGR) (steam Rankin cycle)/HTSE system, and (3) the HTGR (steam Rankin cycle)/methanol-to-gasoline (MTG) System. The VHTR/HTSE system is based on the VHTR design with a $900^{\circ} \mathrm{C}$ core outlet temperature and a Brayton cycle. The VHTR provides heat and electricity to the HTSE system for generating hydrogen. The HTGR/HTSE system is based on the HTGR design with a $750^{\circ} \mathrm{C}$ core outlet temperature and steam Rankin power cycle. The HTGR provides heat and electricity to the HTSE system for hydrogen production. As part of the nuclear-assisted industry process application, the VHTR was coupled with the MTG process. The VHTR/MTG system is also based on the $750^{\circ} \mathrm{C}$ core outlet temperature and the steam Rankin cycle. However, the VHTR provides only heat to the MTG system for generating gasoline and natural gas. This scoping study is focused on the following areas without tritium barriers:

- Tritium concentrations in the industrial final products

- Tritium distributions in the entire coupled system

- Identification of important factors affecting tritium permeation and distributions.

Global sensitivity analysis techniques were used in this study based on the variance decomposition and the Monte Carlo method. Two sensitivity indices were considered as importance measures: the first order index and the total index. The first order index was used for quantifying the main effect, and the total index was used for quantifying the total effect including interactions. More than 15,000 random samples were used for each case. As a result, important parameters were identified and well quantified with their rankings.

This report presents preliminary results along with the Monte Carlo-based sensitivity for three nuclear-assisted process applications: VHTR/HTSE, HTGR/HTSE, HTGR/MTG, and HTGR/Improved MTG; also included are discussions on the efficient methods to reduce model uncertainties and to mitigate tritium permeations in the system. 


\section{CONTENTS}

EXECUTIVE SUMMARY

ACRONYMS

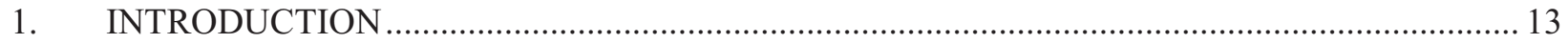

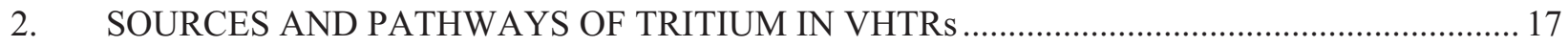

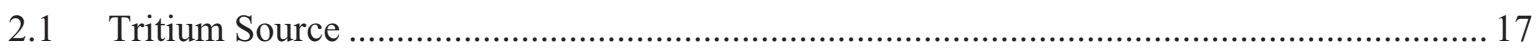

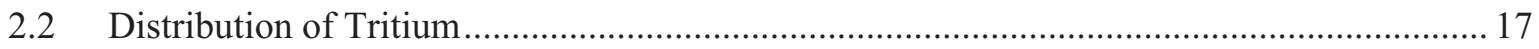

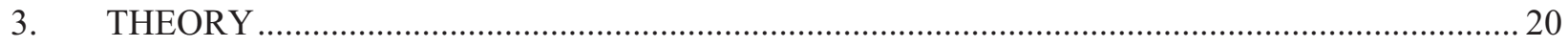

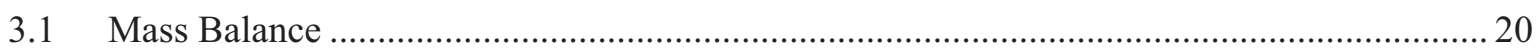

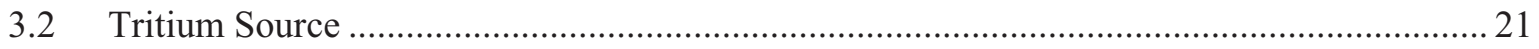

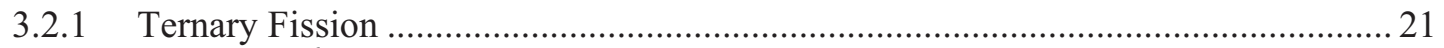

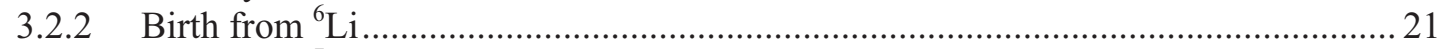

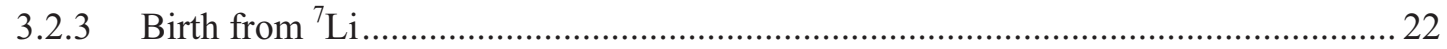

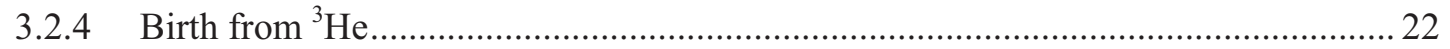

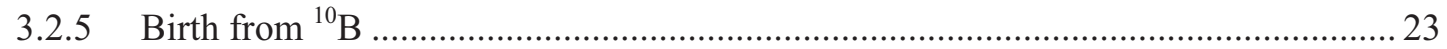

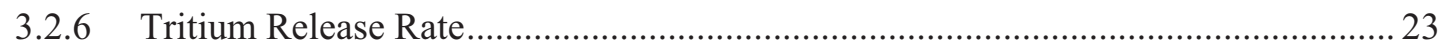

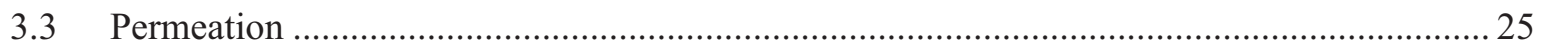

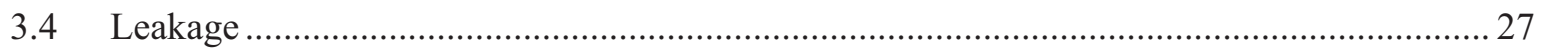

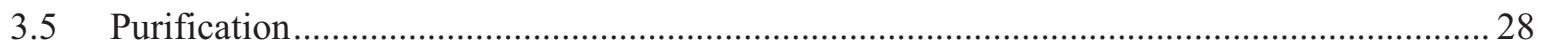

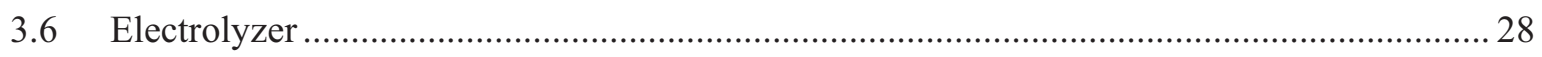

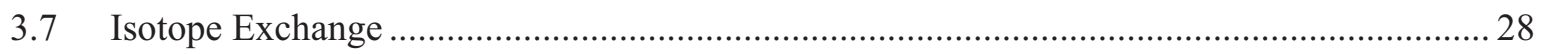

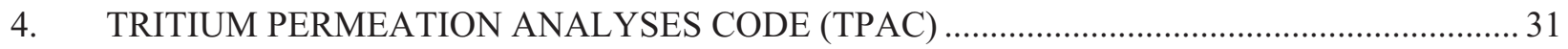

5. ANALYSIS OF TRITIUM BEHAVIORS IN VHTR INTEGRATED INDUSTRIAL

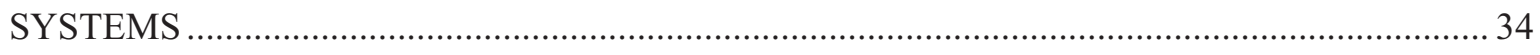

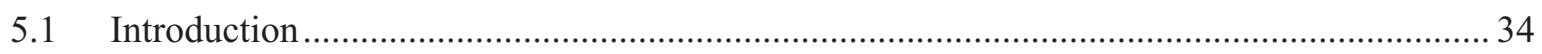

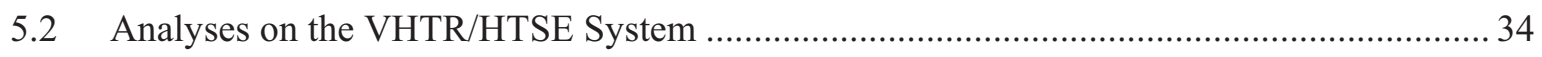

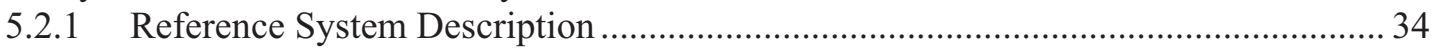

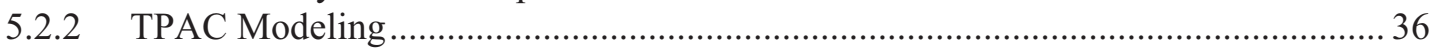

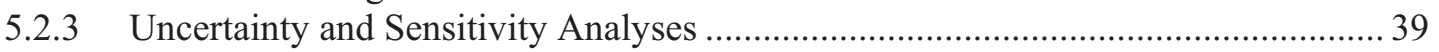

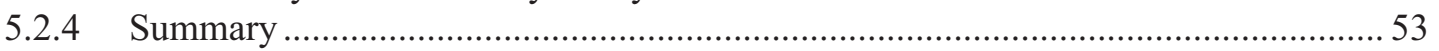

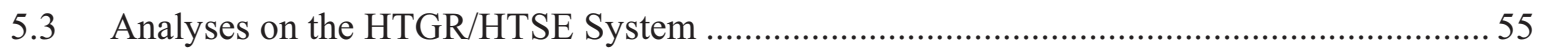

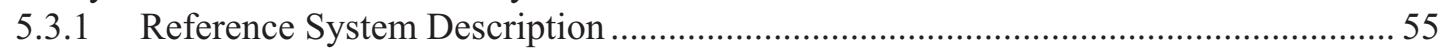

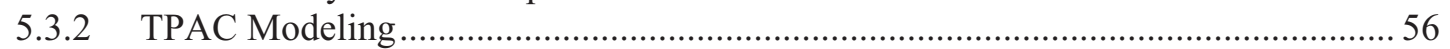

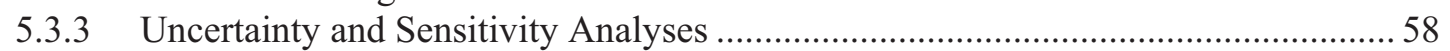

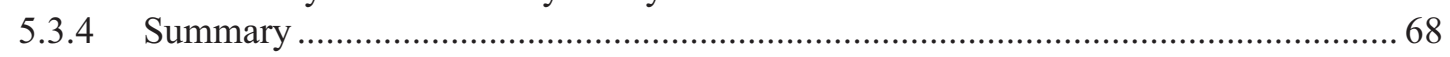

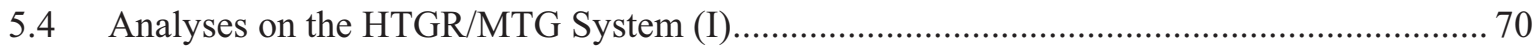

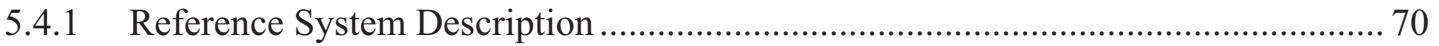

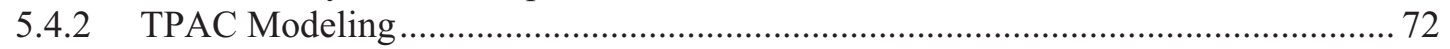

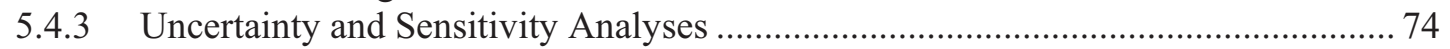

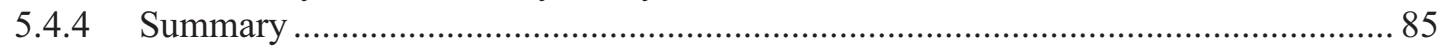


5.5 Analyses on the HTGR/MTG System (II) - Improved Flowsheet ................................... 87

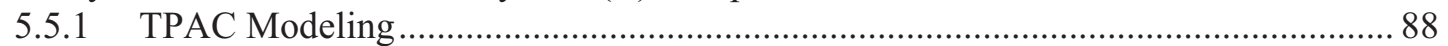

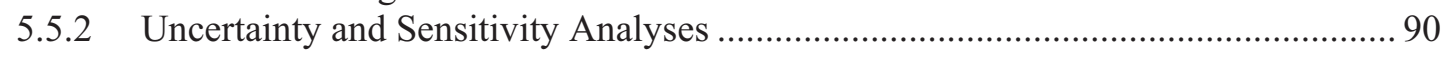

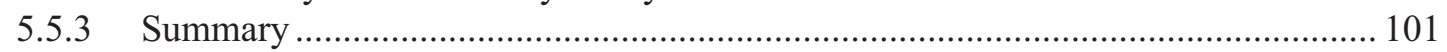

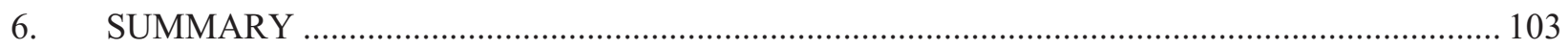

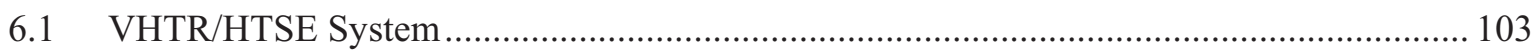

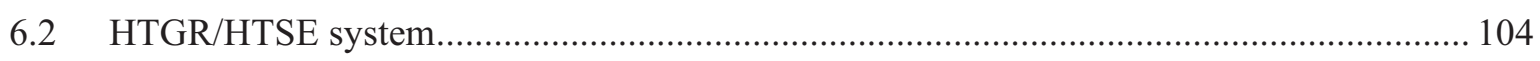

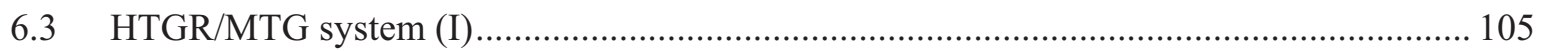

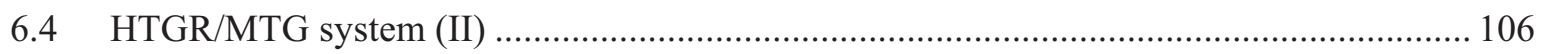

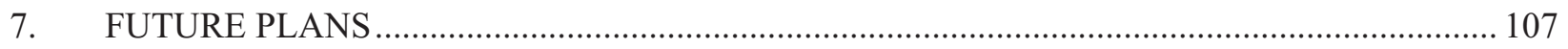

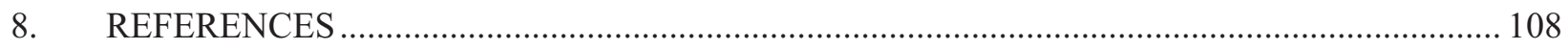

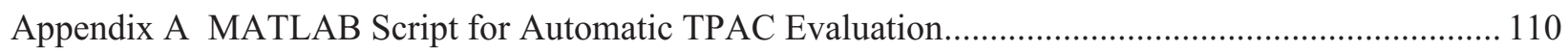

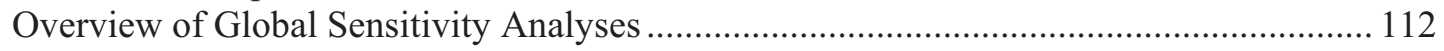

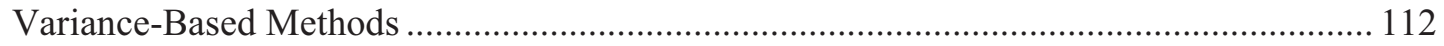

General Analysis Procedure for Global Sensitivity Analyses and SIMLAB ..................... 113

General Strengths and Weaknesses of Global Sensitivity Analyses.................................... 114

\section{FIGURES}

Figure 1-1. Diffusion, bulk transport, and permeation pathways of tritium in a heat transport loop system (Sherman and Adams, 2008).

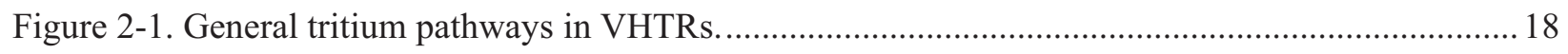

Figure 2-2. Tritium distribution in the VHTR system (Ohashi and Sherman (2007))............................. 19

Figure 3-1. Cross-sectional picture of a PCHE (Dewson and Grady, 2003). ........................................... 26

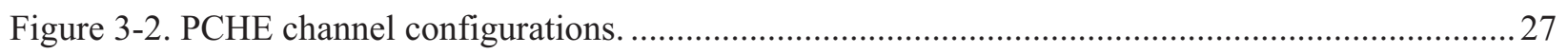

Figure 4-1. General TPAC modeling sample and GUI..................................................................... 31

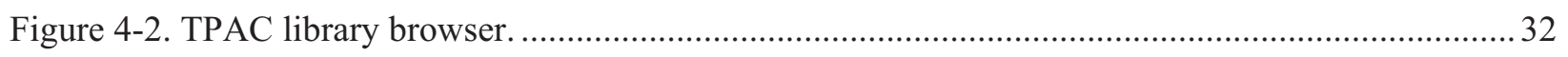

Figure 5-1. Indirect parallel configuration of VHTR/HTSE system (VHTR part) ................................... 35

Figure 5-2. Indirect parallel configuration of VHTR/HTSE system (HTSE part)................................... 36

Figure 5-3. TPAC modeling for the reference VHTR/HTSE system. .................................................... 37

Figure 5-4. Uncertainty/sensitivity analysis procedure and methods (or software) utilized.......................3

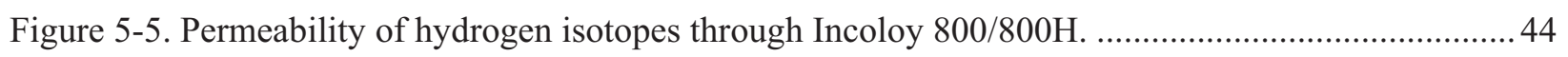

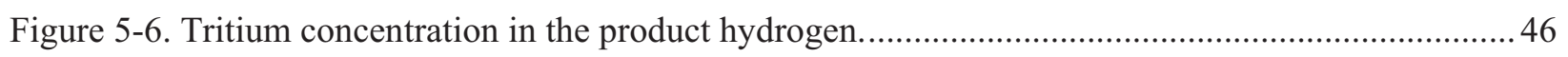

Figure 5-7. Frequency distribution of the tritium concentrations in the hydrogen product $(15,360$

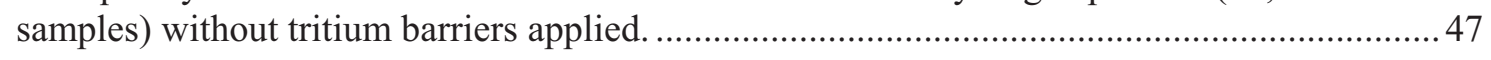

Figure 5-8. Cumulative distribution function (CDF) of tritium concentrations in the hydrogen

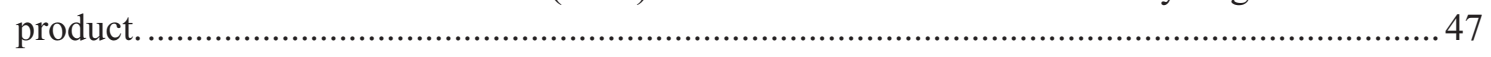

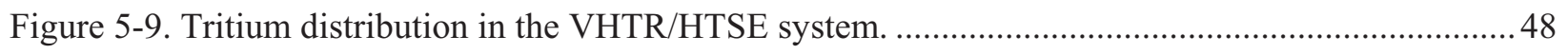




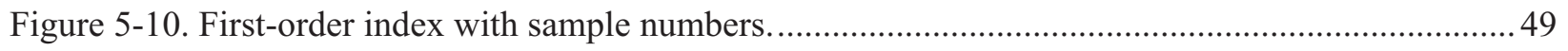

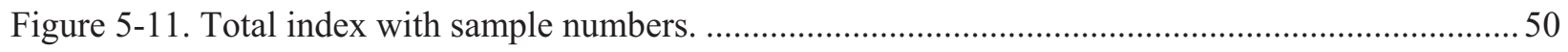

Figure 5-12. First-order index (tritium concentration in the product hydrogen). ................................... 51

Figure 5-13. Total index (tritium concentration in the product hydrogen). ...........................................5 52

Figure 5-14. First-order indices and total indices for six major parameters. ..........................................5

Figure 5-15. Process flow diagram of HTSE (Mckellar et al. 2009). ........................................................ 55

Figure 5-16. HYSYS modeling for HTSE system (Mckellar et al. 2009). ................................................ 56

Figure 5-17. TPAC modeling for the reference HTGR/HTSE system. ................................................... 57

Figure 5-18. Convergence of TPAC results (tritium concentration in the product hydrogen). .................. 61

Figure 5-19. Frequency distribution of the tritium concentrations in the hydrogen product $(15,360$

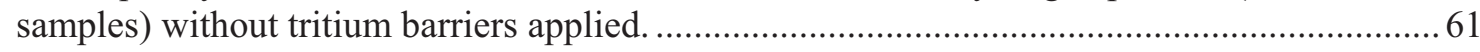

Figure 5-20. CDF of tritium concentrations in the hydrogen product. ................................................... 62

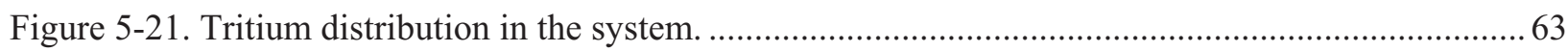

Figure 5-22. First-order index of tritium concentrations in the product hydrogen with sample

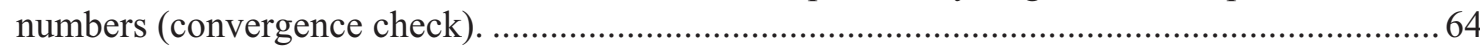

Figure 5-23. First-order index (tritium concentration in the product hydrogen). ................................... 65

Figure 5-24. Total index of tritium concentrations in the product hydrogen with sample numbers

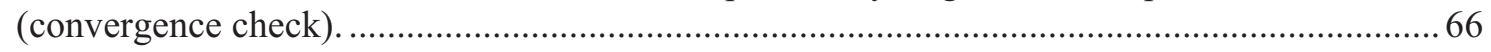

Figure 5-25. Total index (tritium concentration in the product hydrogen). ............................................. 67

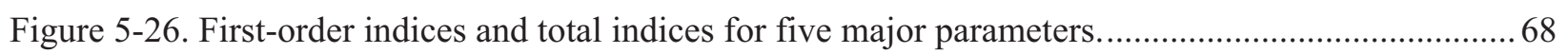

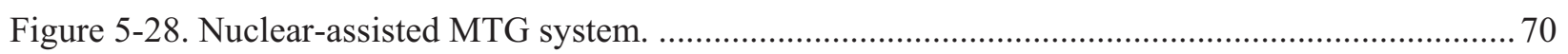

Figure 5-29. TPAC modeling for the nuclear-assisted MTG system.................................................... 73

Figure 5-30. Frequency distribution of the tritium concentration (LPG) without tritium barriers

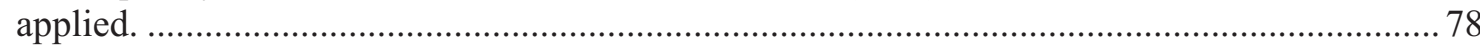

Figure 5-31. Frequency distribution of the tritium concentration (gasoline) without tritium

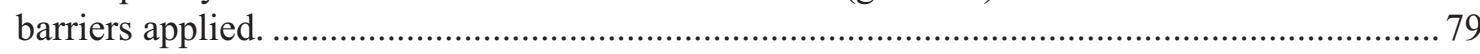

Figure 5-32. Frequency distribution of tritium concentration $\left(\mathrm{MTG}-\mathrm{H}_{2} \mathrm{O}\right)$ without tritium barrier

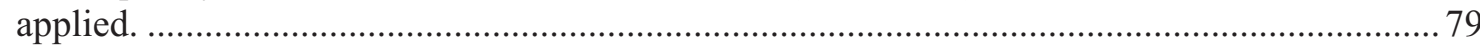

Figure 5-33. Tritium distribution in the nuclear-assisted MTG system................................................ 80

Figure 5-34. First-order indices for different sample numbers (tritium concentration in the MTG

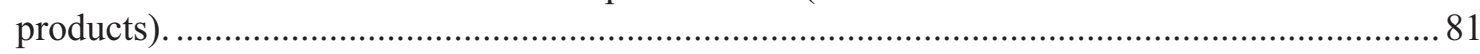

Figure 5-35. First-order indices (tritium concentration in the MTG system). ........................................ 82

Figure 5-36. Total indices for different sample numbers (tritium concentration in the MTG

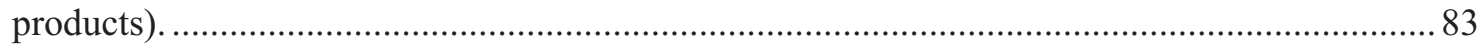

Figure 5-37. Total indices (tritium concentration in the MTG system) ............................................. 84

Figure 5-38. First-order indices and total indices (tritium concentration in the MTG system)................85

Figure 5-39. Nuclear-assisted methanol-to-gasoline (MTG) system (II)................................................ 87 
Figure 5-40. TPAC modeling for the nuclear-assisted MTG system (II).

Figure 5-41. Frequency distribution of the tritium concentration (LPG) without tritium barrier applied.

Figure 5-42. Frequency distribution of the tritium concentration (gasoline) without tritium barrier applied. .95

Figure 5-43. Frequency distribution of tritium concentration $\left(\mathrm{MTG}-\mathrm{H}_{2} \mathrm{O}\right)$ without tritium barrier applied. .95

Figure 5-44. Tritium distribution in the nuclear-assisted MTG system. .96

Figure 5-45. First-order indices for different sample numbers (tritium concentration in the MTG products). 97

Figure 5-46. First-order indices (tritium concentration in the MTG system). 98

Figure 5-47. Total indices for different sample numbers (tritium concentration in the MTG products). .99

Figure 5-48. Total indices (tritium concentration in the MTG system). 100

Figure 5-49. First-order indices and total indices (tritium concentration in the MTG system). 100

\section{TABLES}

Table 1-1. Radioactive properties of tritium. 14

Table 1-2. Regulatory constraints on tritium in the U.S. (Ohashi and Sherman, 2007). .14

Table 3-1. Sources of tritium production in VHTRs. 21

Table 3-2. Basic data for THYTAN evaluation of ternary fission. 21

Table 3-3. Tritium production reaction and cross section (Wichner 1979). .22

Table 4-1 Comparisons of TPAC code with other tritium analyses codes. .33

Table 5-1. Summary of modeling component blocks in the VHTR loops. 38

Table 5-2. Summary of modeling component blocks in the HTSE loops. .38

Table 5-3. List of input parameters for uncertainty and sensitivity analysis. .39

Table 5-4. List of input parameters and ranges for uncertainty and sensitivity analyses...... .40

Table 5-5. Calculation results for the tritium birth rate in the HTGR (Ohashi and Sherman 2007). 42

Table 5-6. Additional calculation results for the tritium birth rate in the HTGR (Ohashi and Sherman 2007). 43

Table 5-7. Means, standard deviations, and percentiles of the tritium concentrations $\left(\mathrm{Bq} / \mathrm{cm}^{3}\right)$ in the product hydrogen. 46

Table 5-8. First-order sensitivity index (for the tritium concentration in the product hydrogen). 49

Table 5-9. Total index (for the tritium concentration in the product hydrogen). .50

Table 5-10. List of input parameters for uncertainty and sensitivity analysis. .58

Table 5-11. List of input parameters and ranges for sensitivity analyses. .59

Table 5-12. Tritium concentrations in the hydrogen product $\left(\mathrm{Bq} / \mathrm{cm}^{3}\right)$. 60 
Table 5-13. First-order sensitivity indices for tritium concentration of the hydrogen product...................64

Table 5-14. Total indices for tritium concentration of the hydrogen product........................................... 66

Table 5-17. List of input parameters for uncertainty and sensitivity analysis. ....................................... 74

Table 5-18. List of input parameters and ranges for sensitivity analyses. ............................................ 75

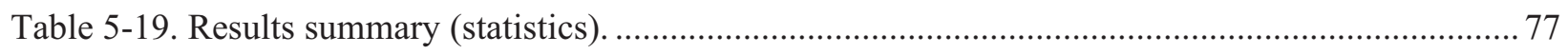

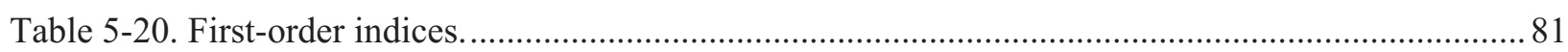

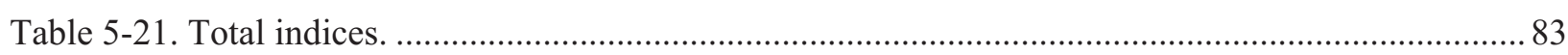

Table 5-22. Comparisons of the new MTG system with the original one. ............................................... 88

Table 5-23. List of input parameters for uncertainty and sensitivity analysis. ......................................... 90

Table 5-24. List of input parameters and ranges for sensitivity analyses. ............................................... 91

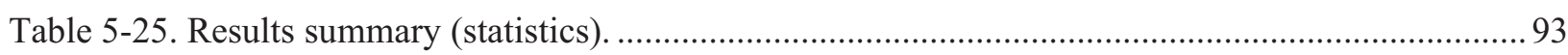

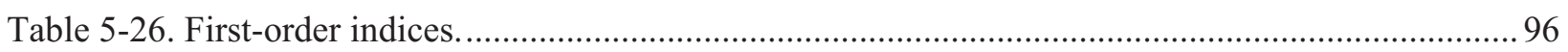

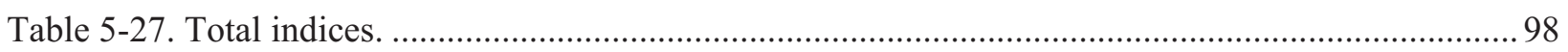




\section{ACRONYMS}

ALARA as low as reasonably achievable

ASME American Society of Mechanical Engineers

ASU air separation unit

AVR Arbeitsgemeinschaft Versuchsreaktor

BLR Boiler

BLDN Blowdown

CDF cumulative distribution function

CFD computational fluid dynamics

CFR Code of Federal Regulations

CTL

DME dimethyl ether

DOE Department of Energy

EPA Environmental Protection Agency

EX Exhaust

FAST Fourier Amplitude Sensitivity Test

$\mathrm{FF} \quad$ factor fixing

FP factor prioritization

FY fiscal year

GA General Atomics

GUI graphical user interface

HRSG Heat recovery steam generator

HTR-10 High Temperature Reactor (10 MW)

HTGR high temperature gas-cooled reactor

HTSE high temperature steam electrolysis

HTSG-ST heat recovery steam generator ??

HTTR high temperature test reactor

HX heat exchanger

IHTL intermediate heat transfer loop

IHX intermediate heat exchanger

INL Idaho National Laboratory

JAEA Japan Atomic Energy Agency

LPG ??

MEOH-SYN methanol synthesis 


$\begin{array}{ll}\text { MTG } & \text { methanol to gasoline } \\ \text { NGNP } & \text { Next Generation Nuclear Plant } \\ \text { NG-RFMR } & \text { natural gas purification and reforming } \\ \text { NRC } & \text { Nuclear Regulatory Commission } \\ \text { ORNL } & \text { Oak Ridge National Laboratory } \\ \text { PCU } & \text { power conversion unit } \\ \text { PCHE } & \text { printed circuit heat exchanger } \\ \text { PDF } & \text { probability distribution function } \\ \text { PEAR } & \text { Person Product moment coefficient } \\ \text { PHX } & \text { process heat exchangers } \\ \text { PSA } & \text { pressure swing absorption } \\ \text { SA } & \text { sensitivity analysis } \\ \text { SHX } & \text { secondary heat exchanger } \\ \text { SPEAR } & \text { Spearman coefficient } \\ \text { SRC } & \text { standard regression coefficient } \\ \text { ST } & \text { Steam turbine } \\ \text { TPAC } & \text { tritium permeation analysis code } \\ \text { TRISO } & \text { tri-structural isotropic } \\ \text { TS } & \text { tritium source } \\ \text { UA } & \text { uncertainty analysis } \\ \text { VHTR } & \text { Very High Temperature Gas-Cooled Reactor } \\ & \end{array}$




\section{Scoping Analyses on Tritium Permeation to VHTR Integrated Industrial Application Systems}

\section{INTRODUCTION}

The Very High Temperature Reactor (VHTR) is a helium-cooled, graphite moderated, thermal neutron spectrum nuclear reactor that will operate at about $8 \mathrm{MPa}$ and an outlet temperature above $750^{\circ} \mathrm{C}$. The VHTR is one of six reactor concepts recommended by the Generation IV Technology Roadmap for further development (Department of Energy [DOE] 2002). This reactor is envisioned as one of the most promising future energy technologies as it combines high efficiency, inherited passive safety features, with high-temperature energy applications, including massive hydrogen production.

One potential problem of VHTRs is tritium permeation from the primary coolant to the industry product via heat transfer surfaces that couple the VHTR and industrial processes such as MTG, ammonia production, and others. In VHTRs, tritium is generated from ternary fission of the fuel and neutron reactions with lithium impurities in the graphite, boron control materials in the reflector block, and naturally occurring ${ }^{3} \mathrm{He}$ in the helium coolant. Tritium diffused from the reactor core and formed in the helium primary coolant by ${ }^{3} \mathrm{He}$ reaction with neutron $\left({ }^{3} \mathrm{He}(\mathrm{n}, \mathrm{p}){ }^{3} \mathrm{H}\right)$ will be circulated or permeated to the secondary coolant and the intermediate heat transfer loop. Finally, the permeated tritium enters the product hydrogen in the HTSE through heat exchange surfaces. The main mechanisms of tritium transport are diffusion, bulk transport, and permeation (See Figure 1-1).

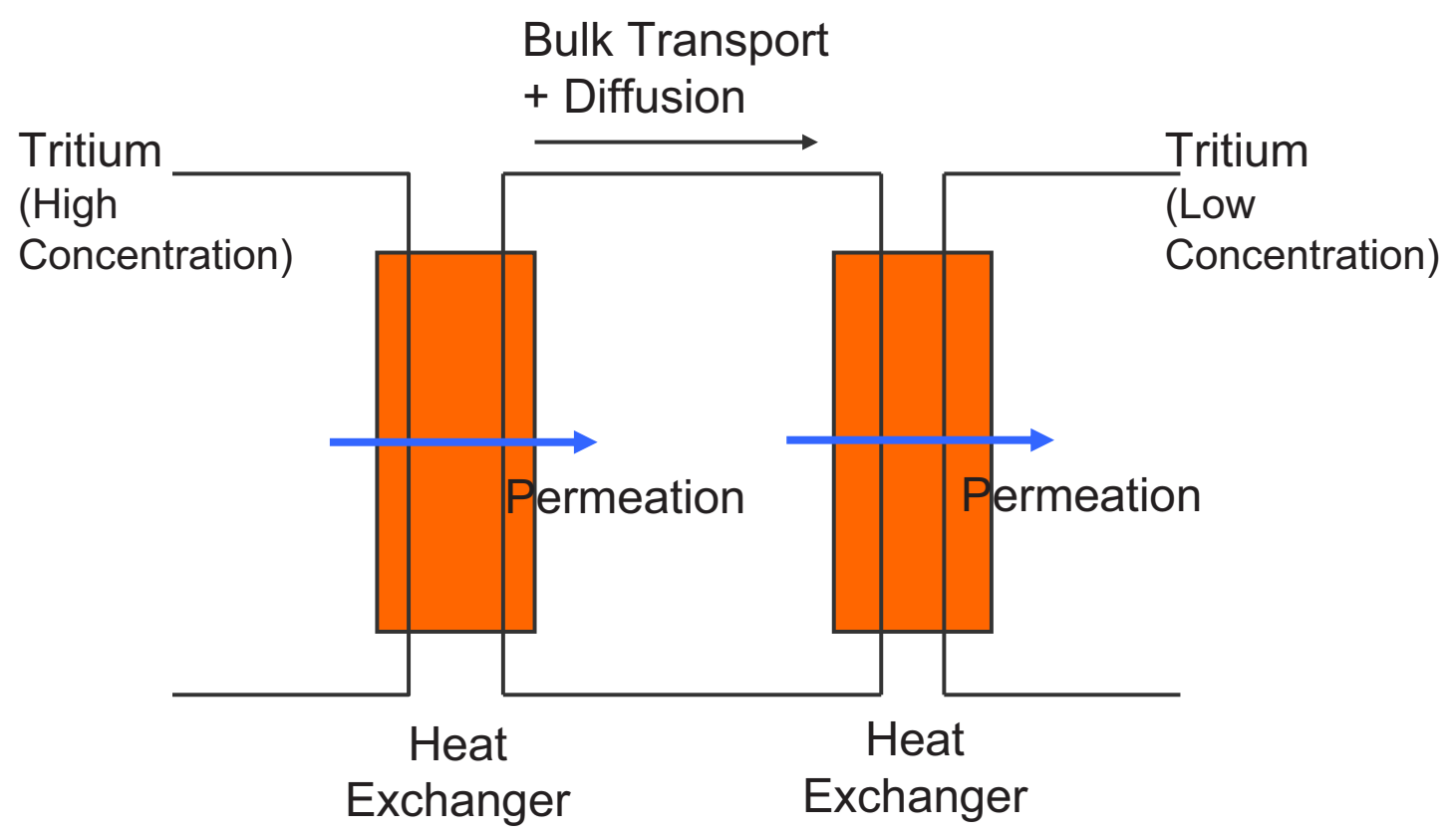

Figure 1-1. Diffusion, bulk transport, and permeation pathways of tritium in a heat transport loop system (Sherman and Adams, 2008).

Tritium is a radioactive isotope of hydrogen with the half-life of 12.32 years, which is mainly generated in the reactor core (Compare et al. 1974). Table 1-1 summarizes the radioactive properties of tritium. The nucleus of a tritium atom consists of a proton and two neutrons. This contrasts with the nucleus of an ordinary hydrogen atom and a deuterium atom. Ordinary hydrogen comprises over $99.9 \%$ of all naturally occurring hydrogen. Deuterium comprises $0.02 \%$ and tritium comprises about a $10^{-16} \%$ of natural hydrogen. The chemical properties of tritium are essentially the same as ordinary hydrogen. Typically, tritium exists as a form of $\mathrm{HT}\left({ }^{1} \mathrm{H}-{ }^{3} \mathrm{H}\right)$ because of an isotope exchange reaction between $\mathrm{T}_{2}$ 
$\left({ }^{3} \mathrm{H}-{ }^{3} \mathrm{H}\right)$ and $\mathrm{H}_{2}$ (Wichner and Dyer 1979). Tritiated water is another common form of tritium. In the tritiated water, a tritium atom replaces one of the hydrogen atoms so the chemical form is HTO rather than $\mathrm{H}_{2} \mathrm{O}$.

Table 1-1. Radioactive properties of tritium.

\begin{tabular}{|c|c|c|c|c|c|c|c|}
\hline & & & & \multicolumn{3}{|c|}{ Radiation Energy (MeV) } \\
\cline { 7 - 9 } Isotope & $\begin{array}{c}\text { Half-life } \\
(\mathrm{yr})\end{array}$ & $\begin{array}{c}\text { Natural } \\
\text { Abundance }\end{array}$ & $\begin{array}{c}\text { Specific } \\
\text { Activity }\end{array}$ & $\begin{array}{c}\text { Decay } \\
\text { Mode }\end{array}$ & $\begin{array}{c}\text { Alpha } \\
(\alpha)\end{array}$ & $\begin{array}{c}\text { Beta } \\
(\beta)\end{array}$ & $\begin{array}{c}\text { Gamma } \\
(\gamma)\end{array}$ \\
\hline H-3 & 12 & $<<1$ & 9,800 & Beta $(\beta)$ & - & 0.0057 & - \\
\hline
\end{tabular}

The effect of radiation from tritium on health is relatively small. Tritium is hazardous only if it is taken into the body, because tritium decays by emitting a low-energy beta particle with no gamma radiation. This beta particle cannot penetrate deeply into tissue or travel far in air. The most likely form of uptake is tritiated water. Uptake of tritium in a gas form is typically very low (less than 1\%). Nevertheless, tritium uptake can cause cell damage due to ionizing radiation that results from radioactive decay, with the potential for subsequent cancer induction. Nearly all (up to 99\%) inhaled tritium can be taken into the body from the lungs, and circulating blood then distributes it to all tissues. Ingested tritium oxide is almost completely absorbed, moving quickly from the gastrointestinal tract to the bloodstream. Within minutes it is found in varying concentrations in body fluids, organs, and other tissues. Generally, tritium is uniformly distributed through all biological fluids within one to two hours. Tritium is eliminated from the body with a biological half-life of 10 days, the same as water.

In the U.S., tritium emissions are regulated by the Nuclear Regulatory Commission (NRC) and Environmental Protection Agency (EPA). Table 1-2 summarizes the regulatory limits in air and water effluents on tritium.

Table 1-2. Regulatory constraints on tritium in the U.S. (Ohashi and Sherman, 2007).

\begin{tabular}{|c|c|c|c|c|c|c|c|}
\hline & & Ann & & & Effluent Con & entration & \\
\hline & & Radiatic & Dose & & Air & $\mathrm{Wa}$ & \\
\hline & Regulation & (mrem) & $(\mathrm{mSv})$ & $(\mu \mathrm{Ci} / \mathrm{ml})$ & $(\mathrm{Bq} / \mathrm{ml})$ & $(\mu \mathrm{Ci} / \mathrm{ml})$ & $(\mathrm{Bq} / \mathrm{ml})$ \\
\hline Limit & 10 CFR 20.1301(a)1 & 100 & 1 & . & . & - & - \\
\hline & $\begin{array}{c}\text { Table } 2 \text { of } \\
\text { Appendix B to } \\
10 \text { CFR } 20\end{array}$ & 50 & 0.5 & $1 \times 10^{-7}$ & $3.7 \times 10^{-3}$ & $1 \times 10^{-3}$ & 37 \\
\hline Standard & 10 CFR 20.1301(e) & 25 & 0.25 & $\left(5 \times 10^{-8}\right)^{\mathrm{a}}$ & $\left(1.85 \times 10^{-3}\right)^{\mathrm{a}}$ & $\left(5 \times 10^{-4}\right)^{\mathrm{a}}$ & $(18.5)^{\mathrm{a}}$ \\
\hline ALARA & Appendix I to & 15 & 0.15 & $\left(3 \times 10^{-8}\right)^{\mathrm{a}}$ & $\left(1.11 \times 10^{-3}\right)^{\mathrm{a}}$ & - & - \\
\hline & 10 CFR 50 & 3 & 0.03 & - & - & $\left(6 \times 10^{-5}\right)^{\mathrm{a}}$ & $(2.22)^{\mathrm{a}}$ \\
\hline $\begin{array}{l}\text { Drinking } \\
\text { Water }\end{array}$ & EPA standard & 4 & 0.04 & - & - & $2 \times 10^{-5}$ & 0.74 \\
\hline $\begin{array}{r}\text { a. Calcula } \\
10 \mathrm{C}\end{array}$ & assuming the linear rele & hip bet & he a & dose of 5 & $\mathrm{n}$ and the val & Table 2 of & endix B of \\
\hline $\begin{array}{l}\text { ALAR } \\
\text { CFR }= \\
\mathrm{EPA}=\end{array}$ & $\begin{array}{l}\text { as low as reasonably achi } \\
\text { de of Federal Regulations } \\
\text { S. Environmental Protectio }\end{array}$ & $\begin{array}{l}\text { able } \\
\text { Agency }\end{array}$ & & & & & \\
\hline
\end{tabular}

Tritium is a very small atom and therefore it easily penetrates through high-temperature metals. Especially in the VHTRs, a large portion of tritium in the primary coolant permeates through the HX surfaces of the intermediate heat exchanger (IHX) and process heat exchanger (PHX) and is mixed into 
the process chemicals of the hydrogen plant, eventually contaminating the hydrogen products (Ohashi and Sherman 2007).

Tritium behavior in HTGRs was evaluated for several countries in the 1970s (e.g., the Dragon reactor in England [Forsyth 1972], the Peach Bottom HTGR in the U.S. [Wichner and Dyer 1979], and the Arbeitsgemeinschaft Versuchsreaktor (AVR) in Germany [Steinwarz, Rohrig, and Nieder 1980]). Data from the operation of HTGRs and from laboratory experiments revealed the mechanisms of tritium production, transport, and release to the environment. In his review of tritium behavior in an HTGR system, Gainey's (1976) calculations show that tritium releases should be well within current federal guidelines for the nuclear plant. For example, the estimated maximum dose to an average adult for a typical 3,000-MWt HTGR with a cooling tower is 0.38 milligram/year, which is slightly more than one tenth of the maximum annual dose allowed (Gainey 1976). For this reason, no further laboratory-scale work on tritium was required at that time. However, their tritium calculations were only concerned with general tritium release and did not examine questions related to a nuclear reactor integrated with industrial systems. The Next Generation Nuclear Plant (NGNP) project will use the HTGR as a heat source to produce hydrogen or industrial products for industry or individual users.

Ohashi and Sherman (2007) recently estimated steady-state tritium movement and accumulation in an NGNP coupled with a hydrogen plant using a HTSE process and a thermochemical water-splitting sulfuriodine process by using the numerical code THYTAN. Estimated tritium concentrations in product hydrogen and in process chemicals in the hydrogen plant of the NGNP using the HTSE process were slightly higher than the drinking water limit defined by the EPA and the limit in the effluent at the boundary of an unrestricted area of a nuclear plant as defined by the NRC. However, modified designs and operations could bring these concentrations within specified limits. Tritium concentrations in the NGNP using the sulfur iodine process were calculated to be significantly higher and were affected by parameters with large uncertainties (tritium permeability of the process heat exchanger, the hydrogen concentration in the heat transfer and process fluids, and the equilibrium constant of the isotope exchange reaction for the sulfur-iodine (SI) process between $\mathrm{HT}$ and $\mathrm{H}_{2} \mathrm{SO}_{4}$ ). These parameters, including tritium generation and the release rate in the reactor core, should be more accurately estimated to improve the calculations for the SI process. Decreasing the tritium permeation through the HX between the primary and secondary circuits may be an effective measure for decreasing tritium concentrations in product hydrogen, the hydrogen plant, and the tertiary coolant.

In Fiscal Year (FY)-08 and -09, INL developed a computer code called the "tritium permeation analysis code" (TPAC) in order to analyze tritium behaviors in the VHTR systems. The TPAC was written by the MATLAB/SIMULINK software package, and it can solve generations of tritium source and tritium transport equations, including the penetration of tritium through the HX wall. This code was originally developed for analyses of tritium production and distribution in VHTRs and hydrogen production systems. However, the capability is not limited only to VHTR systems. TPAC is flexible enough to extend to general industrial plants or systems by simple modifications.

In FY-10, tritium analyses were performed for various industrial application systems integrated with VHTRs (or HTGRs). The systems include (1) two hydrogen production systems at $900^{\circ} \mathrm{C}$ and $750^{\circ} \mathrm{C}$, (2) the MTG system, and (3) the improved MTG system. This report describes the FY-10 work and summarizes the results; its major sections are:

- Introduction (Section 1): This section provides introductory information about this project with background information

- Source and Pathways of Tritium in VHTR (Section 2): This section explains major tritium sources and their pathways in VHTR systems

- $\quad$ Theory (Section 3): This section presents governing equations and models associated with tritium transport in VHTR systems 
- $\quad$ Tritium Permeation Analysis Code (TPAC) (Section 4): This section presents the TPAC code that INL developed in FY-08 and FY-09

- Analyses of Tritium Behaviors in the VHTR Integrated Industrial Systems (Section 5): This section presents the TPAC modeling of various VHTR integrated industrial application systems and their results with discussions

- Summary (Section 6): This section summarizes FY-10 accomplishments and discusses remaining issues. 


\section{SOURCES AND PATHWAYS OF TRITIUM IN VHTRS \\ 2.1 Tritium Source}

The tritium generation mechanism in VHTRs is well described by Gainey (1976) and Ohashi and Sherman (2006). The primary tritium birth mechanism is ternary fission of fuel (e.g. ${ }^{233} \mathrm{U},{ }^{235} \mathrm{U},{ }^{239} \mathrm{Pu}$, and ${ }^{241} \mathrm{Pu}$ ) by thermal neutrons. Tritium is also generated in VHTR from ${ }^{6} \mathrm{Li},{ }^{7} \mathrm{Li},{ }^{3} \mathrm{He}$, and ${ }^{10} \mathrm{~B}$ by the following neutron capture reactions:

${ }^{6} \mathrm{Li}(\mathrm{n}, \alpha){ }^{3} \mathrm{H}$

${ }^{7} \mathrm{Li}(\mathrm{n}, \mathrm{n} \alpha){ }^{3} \mathrm{H}$

${ }^{3} \mathrm{He}(\mathrm{n}, \mathrm{p}){ }^{3} \mathrm{H}$

${ }^{10} \mathrm{~B}(\mathrm{n}, 2 \alpha){ }^{3} \mathrm{H}$

${ }^{10} \mathrm{~B}(\mathrm{n}, \alpha){ }^{7} \mathrm{Li}$.

${ }^{6} \mathrm{Li}$ and ${ }^{7} \mathrm{Li}$ are impurities in the core graphite material such as the sleeve, spine, reflector, and fuel matrix. ${ }^{3} \mathrm{He}$ is an impurity in the reactor coolant helium. Because helium coolant leaks from the primary loop to the containment vessel, helium is supplied to the primary coolant as a make-up with an impurity of ${ }^{3} \mathrm{He} .{ }^{10} \mathrm{~B}$ exists in control rods, burnable poisons, and reflectors. Tritium is produced directly from ${ }^{10} \mathrm{~B}$ via Equation (2-4) or via the chain reaction in Equations (2-2) and (2-5).

\subsection{Distribution of Tritium}

Tritium generated in the fuel particles by ternary fissions can escape into a primary coolant, permeating several barriers of the fuel particles. In addition, tritium born from ${ }^{10} \mathrm{~B}$ and ${ }^{6} \mathrm{Li}$ can pass into the primary coolant. The principal chemical form for tritium in the reactor coolant was reported as HT $\left({ }^{1} \mathrm{H}-{ }^{3} \mathrm{H}\right)$ because of the isotope exchange reaction between $\mathrm{T}_{2}\left({ }^{3} \mathrm{H}-{ }^{3} \mathrm{H}\right)$ and $\mathrm{H}_{2}$ (Wichner and Dyer 1979). Some tritium in the primary coolant is removed by a purification system installed in the primary loop, and some can escape outside the coolant by permeation through the components and piping and by leakage with the primary helium coolant. The remaining tritium in the primary coolant permeates through the heat transfer tubes or surfaces of the IHX and gets mixed in with the secondary coolant.

In the secondary loop, some of the tritium is removed by the purification system or escapes outside, just as in the primary loop. The remainder of the tritium in the secondary coolant permeates through heat transfer surfaces and gets mixed into the tertiary coolant. Transport of tritium into the tertiary coolant is the same as for the secondary coolant. It permeates through the heat transfer surfaces of the PHXs and is mixed into the process chemicals of the hydrogen plant.

Tritium that permeates the tertiary loop going to the hydrogen plant can react with hydrogen-containing process chemicals through isotopic exchange reactions. For example, the HTSE process contains $\mathrm{H}_{2} \mathrm{O}$. Therefore, $\mathrm{HTO}$ (tritiated water) is produced by the isotope exchange reaction between $\mathrm{HT}$ and $\mathrm{H}_{2} \mathrm{O}$. Gaseous HTO and HT escape from the HTSE process with the product hydrogen and oxygen. A part of the liquid HTO flows out from the hydrogen plant with the drain water. The remainder of the liquid HTO circulates into the plant with the recycling water and accumulates in the water of the HTSE process. The SI process used in hydrogen production also contains $\mathrm{H}_{2} \mathrm{O}, \mathrm{H}_{2} \mathrm{SO}_{4}$, and $\mathrm{HI}$ chemicals from which $\mathrm{HTO}, \mathrm{HTSO}_{4}$, and TI may be produced through isotope exchange reactions. These tritium-containing chemicals circulate with and accumulate in process the chemicals. Only gaseous HT and HTO can escape from the SI process with the product hydrogen and oxygen.

The above tritium pathways in VHTRs are well illustrated in Figure 2-1. All of the production mechanisms lead to either retention in solids or entry into coolant systems. The tritium in the primary coolant can be adsorbed on the graphite surface, leaked out of the primary circuit, removed in the purification system, or permeated to the process heat application system like hydrogen production. 


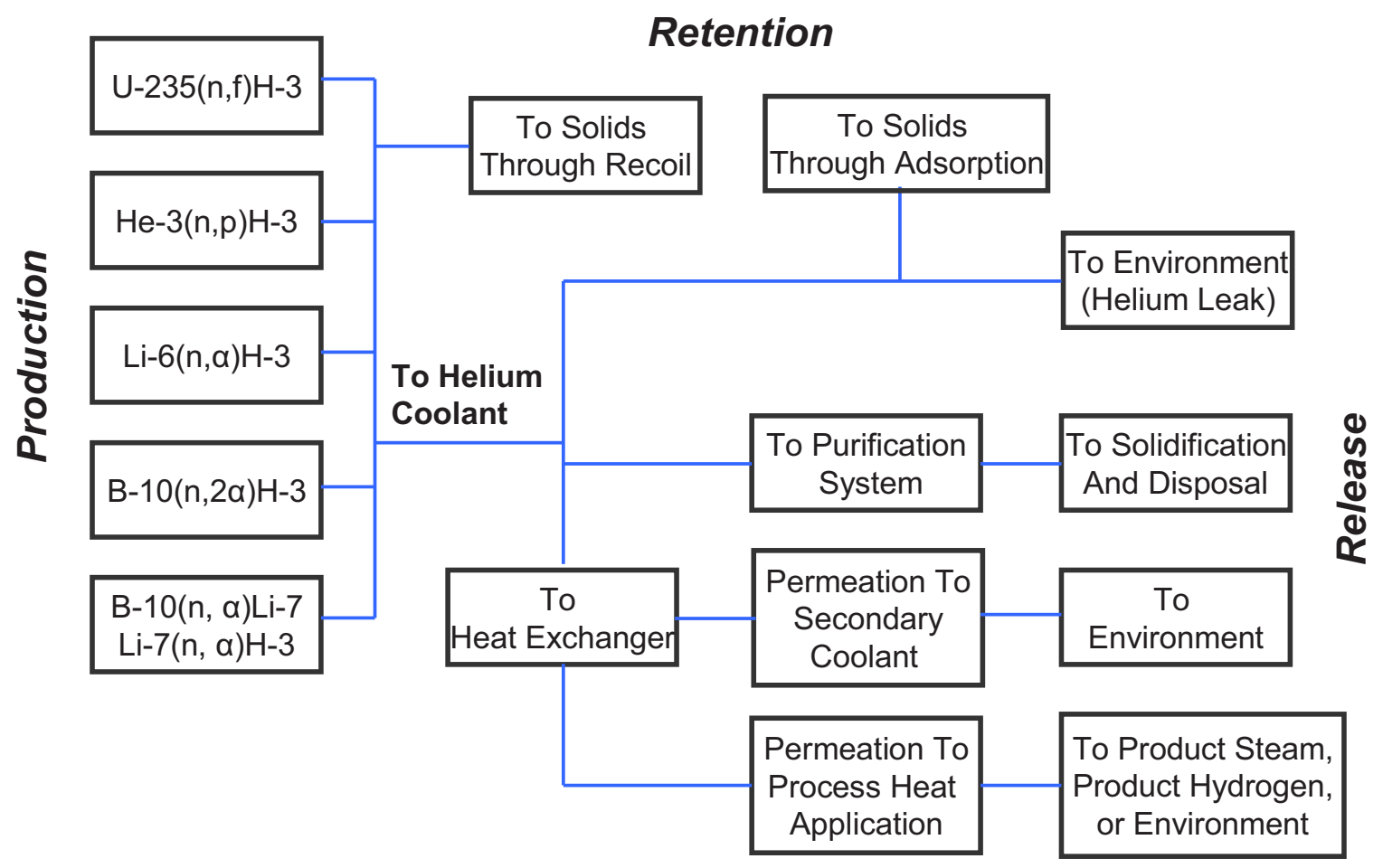

Figure 2-1. General tritium pathways in VHTRs.

Figure 2-2 shows the tritium distribution calculated by Ohashi and Sherman (2007) for a VHTR/HTSE system at steady state. The calculation was performed by the THYTAN code, which was developed by Japan Atomic Energy Agency (JAEA) (Ohashi and Sherman 2007). According to their calculations, $30.742 \%$ of the tritium released from the core is removed by the purification system in the primary loop. A small portion of the tritium $(0.106 \%)$ leaks to the outside from the primary loop with helium leakage. The remainder of the tritium (69.152\%) permeates into the secondary loop through a HX. For the secondary loop, $30.341 \%$ of the tritium, which is about half of the permeated tritium from the primary loop, is removed by the purification system. Consequently, $38.705 \%$ of the tritium permeates from the secondary helium loop to the tertiary loop through the secondary heat exchanger (SHX). In the tertiary loop, almost all of the tritium permeated from the secondary loop is removed by the purification system. Tritium permeation rates from the tertiary loop to the main line and to the sweep line of the HTSE process are $0.946 \%$ and $2.499 \%$, respectively. However, depending on the system designs and operating conditions, the specified values can be completely different from their base calculations. 


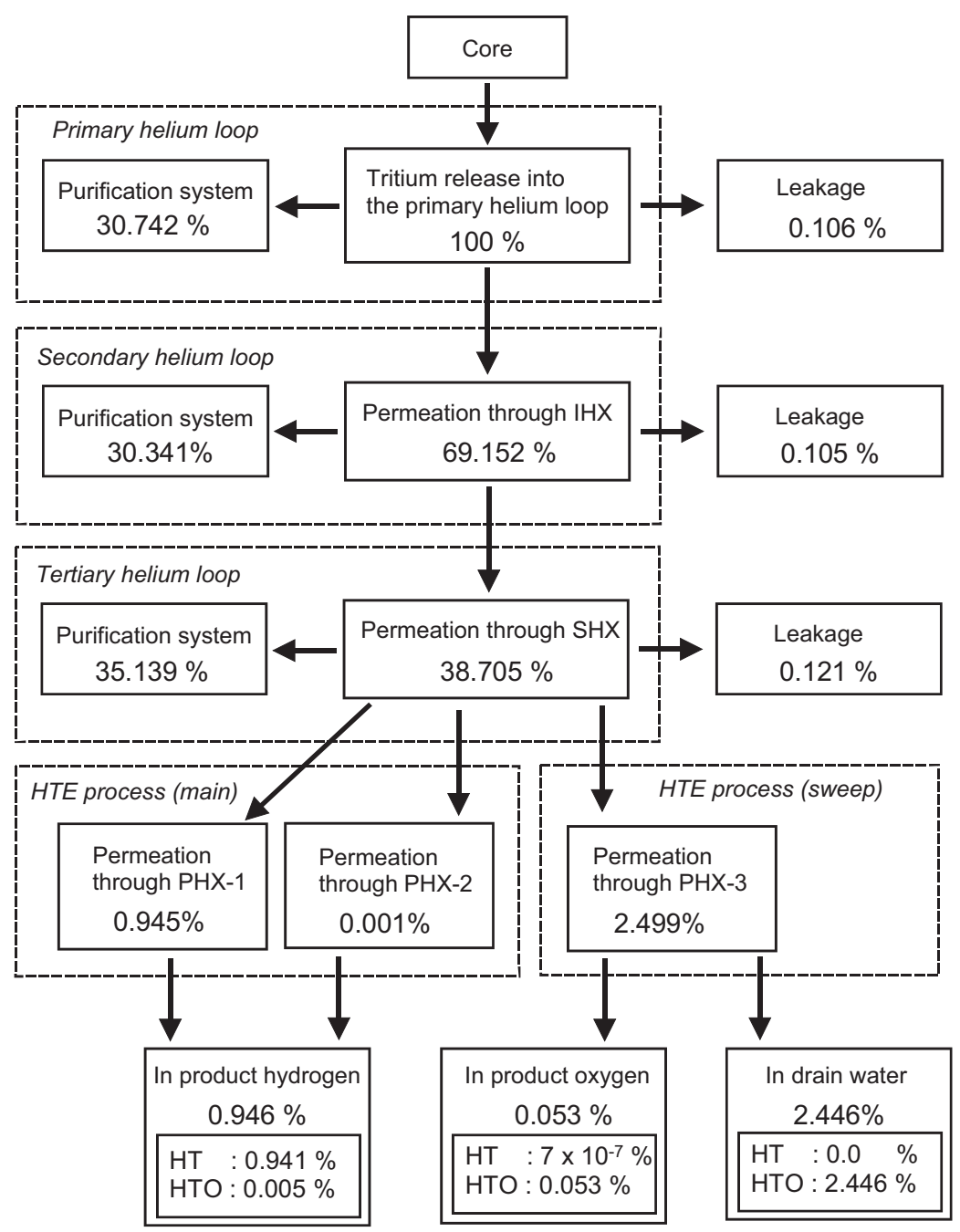

Figure 2-2. Tritium distribution in the VHTR system (Ohashi and Sherman (2007)). 


\section{THEORY}

This section summarizes the theory implemented in the TPAC code. The TPAC code is capable of modeling tritium behaviors in the simplified representations of the VHTR, the HTSE process, and the SI process. The following phenomena are taken into consideration:

- $\quad$ Mass balance of the species $\left(\mathrm{H}_{2}, \mathrm{HT}, \mathrm{HTO}, \mathrm{HTSO}_{4}\right.$ and TI)

- Tritium and hydrogen permeation through the heat transfer surface

- Tritium and hydrogen permeation to the outside through the pipe wall

- Tritium and hydrogen removal by the purification system

- Tritium and hydrogen leakage by helium leakage

- Isotope exchange between tritium-containing and hydrogen-containing chemicals

- Species movement in the electrolyzer.

\subsection{Mass Balance}

The TPAC code basically solves the mass balance of tritium-containing chemicals and hydrogen in each component block. The mass balance of tritium-containing chemicals and hydrogen is as follows:

$$
\begin{aligned}
& V_{j} \frac{d C_{i, j}}{d t}=\sum\left(F_{\text {total }, j-1} \cdot C_{i, j-1}\right)-F_{\text {total }, j} \cdot C_{i, j}-S_{i, j} \\
& S_{i, j}=-R_{\text {core }, i, j}+R_{H X, i, j}+R_{\text {copipe }, i, j}+R_{\text {comp }, i, j}+R_{\text {leak }, i, j}+R_{P F, i, j}+R_{\text {reaction }, i, j}
\end{aligned}
$$

where

$V_{j} \quad=\quad$ the volume of block $j\left[\mathrm{~m}^{3}(\mathrm{STP})\right]$

$C_{i, j}=$ the volume fraction of chemical $i$ in block $j\left[\mathrm{~m}^{3}(\mathrm{STP}) / \mathrm{m}^{3}(\mathrm{STP})\right]$

$t \quad=$ time $[\mathrm{s}]$

$F_{\text {total }, j}=$ the volumetric flow rate of all chemicals in block $j\left[\mathrm{~m}^{3}(\mathrm{STP}) / \mathrm{s}\right]$

$S_{i, j} \quad=\quad$ the total amount of volume change rate of chemical $i$ in block $j$ by considering generation, release, permeation, removal, leakage, and isotope exchange reactions $\left[\mathrm{m}^{3}(\mathrm{STP}) / \mathrm{s}\right]$

$R_{\text {core }, i, j}=$ volumetric release rate from the core to the primary coolant $\left[\mathrm{m}^{3}(\mathrm{STP}) / \mathrm{s}\right]$

$R_{H X, i, j}=$ volumetric permeation rate at heat exchanger $\left(\mathrm{i}=\mathrm{H}_{2}\right.$ and $\left.\mathrm{HT}\right)\left[\mathrm{m}^{3}(\mathrm{STP}) / \mathrm{s}\right]$

$R_{\text {copipe }, i, j}=$ volumetric permeation rate at co-axial pipe $\left(\mathrm{i}=\mathrm{H}_{2}\right.$ and $\left.\mathrm{HT}\right)\left[\mathrm{m}^{3}(\mathrm{STP}) / \mathrm{s}\right]$

$R_{\text {comp }, i, j}=$ volumetric permeation rate to the outside $\left(\mathrm{i}=\mathrm{H}_{2}\right.$ and $\left.\mathrm{HT}\right)\left[\mathrm{m}^{3}(\mathrm{STP}) / \mathrm{s}\right]$

$R_{\text {leak }, i, j}=$ volumetric leak rate with helium leakage $\left(i=\mathrm{H}_{2}, \mathrm{HT}\right.$ and HTO) $\left[\mathrm{m}^{3}(\mathrm{STP}) / \mathrm{s}\right]$

$R_{P F, i, j}=$ volumetric removal rate by purification system $\left(i=\mathrm{H}_{2}\right.$, HT and HTO) $\left[\mathrm{m}^{3}(\mathrm{STP}) / \mathrm{s}\right]$

$R_{\text {reaction }, i, j}=$ volumetric reaction rate by isotope exchange reactions $\left(i=\mathrm{H}_{2}, \mathrm{HT}, \mathrm{HTO}, \mathrm{HTSO}_{4}\right.$ and TI) $\left[\mathrm{m}^{3}(\mathrm{STP}) / \mathrm{s}\right]$. 


\subsection{Tritium Source}

There are five main sources of tritium generation in the reactor core: ternary fission, and birth from ${ }^{6} \mathrm{Li},{ }^{7} \mathrm{Li},{ }^{3} \mathrm{He}$, and ${ }^{10} \mathrm{~B}$. Table $3-1$ summarizes the tritium production sources and general contributions. Detailed equations for each source are described in the following sections.

Table 3-1. Sources of tritium production in VHTRs.

\begin{tabular}{|l|c|c|}
\hline \multicolumn{1}{|c|}{ Tritium Source } & \% total & Release Potential \\
\hline Ternary Fission & 62 & Time at temperature \\
\hline From ${ }^{3} \mathrm{He}$ & 18 & Produced in Helium coolant \\
\hline From ${ }^{6} \mathrm{Li}$ & 2 & Partly retained in graphite; \\
$\quad$ Core Graphite & 10 & \\
Core Matrix & $<1$ & \\
Reflector (replaceable) & $<1$ & Apparently retained at source \\
Reflector (permanent) & & \\
\hline From ${ }^{10} \mathrm{~B}$ & 7 & \\
Control Rod & 1 & \\
Burnable Poisson & $<1$ & \\
Reflector & \multicolumn{2}{|c|}{} \\
\hline
\end{tabular}

\subsubsection{Ternary Fission}

Tritium formed by ternary fission with yields depends on the uranium isotope undergoing fission and the neutron flux.

$$
\frac{d\left(N_{T(T e r)}\right)}{d t}=K \cdot P \cdot Y-\lambda \cdot N_{T(T e r)}
$$

where

$N_{T(T e r)}=$ number of tritium atoms from ternary fission

$K=$ fission rate per thermal megawatt [fission/MW/s]

$P \quad=$ reactor power [MW]

$Y \quad=$ average yield per fission [1/fission]

$\lambda=$ tritium decay constant $[1 / \mathrm{s}]$.

Table 3-2 summarizes the necessary information for calculating tritium production by ternary fission. Table 3-2. Basic data for THYTAN evaluation of ternary fission.

\begin{tabular}{|l|l|l|}
\hline & Unit & Values \\
\hline Reactor Power (P) & MWt & 600 \\
\hline Fission Rate (K) & Fissions/MW sec & $3.12 \mathrm{e} 16$ \\
\hline Average Yield Per Fission (Y) & $1 /$ fission & $1.0 \mathrm{e}-4$ \\
\hline
\end{tabular}

\subsubsection{Birth from ${ }^{6} \mathrm{Li}$}

As described, tritium is produced in the VHTR by various sources such as ternary fission and activation reactions with impurities and boron in the materials. Table 3-3 summarizes the tritium production reactions and cross sections (Wichner 1979). 
Table 3-3. Tritium production reaction and cross section (Wichner 1979).

\begin{tabular}{|c|c|c|}
\hline Production Reaction & Cross section (barns) & Energy range (eV) \\
\hline${ }^{3} \mathrm{He}(\mathrm{n}, \mathrm{p}) \mathrm{T}$ & 2,280 & $0-2.38$ \\
\hline${ }^{6} \mathrm{Li}(\mathrm{n}, \mathrm{a}) \mathrm{T}$ & 408 & $0-2.38$ \\
\hline${ }^{10} \mathrm{~B}(\mathrm{n}, 2 \mathrm{a}) \mathrm{T}$ & 0.050 & $>0.18 \times 10^{6}$ \\
\hline${ }^{10} \mathrm{~B}(\mathrm{n}, \mathrm{a}){ }^{7} \mathrm{Li}$ & 1,630 & $0-2.38$ \\
\hline${ }^{7} \mathrm{Li}(\mathrm{n}, \mathrm{n}$ 'a) $\mathrm{T}$ & 0.153 & $>0.18 \times 10^{6}$ \\
\hline
\end{tabular}

The birth of tritium from ${ }^{6} \mathrm{Li}$, which is impurity in the core and reflector graphite materials, is estimated by the following equations:

$$
\begin{aligned}
& \frac{d\left(N_{L i 6}\right)}{d t}=-\phi_{t h} \cdot \sigma_{L i 6 T} \cdot N_{L i 6} \\
& \frac{d\left(N_{T(L i 6)}\right)}{d t}=\phi_{t h} \cdot \sigma_{L i 6 T} \cdot N_{L i 6}-\lambda \cdot N_{T(L i 6)}
\end{aligned}
$$

where

$$
\begin{aligned}
& N_{L i 6}=\text { number of }{ }^{6} \mathrm{Li} \text { atoms } \\
& N_{T(L i 6)}=\text { number of tritium atoms from }{ }^{6} \mathrm{Li} \\
& \left.\phi_{t h}=\text { thermal neutron flux [neutrons } / \mathrm{cm}^{2} / \mathrm{s}\right] \\
& \sigma_{L i 6 T}=\text { effective cross section for }{ }^{6} \mathrm{Li}(\mathrm{n}, \alpha)^{3} \mathrm{H}\left[\mathrm{cm}^{2}\right] .
\end{aligned}
$$

\subsubsection{Birth from ${ }^{7} \mathrm{Li}$}

The birth of tritium from ${ }^{7} \mathrm{Li}$ is estimated by the following equations:

$$
\begin{aligned}
& \frac{d\left(N_{L i 7}\right)}{d t}=-\phi_{f} \cdot \sigma_{L i 7 H 3} \cdot N_{L i 7} \\
& \frac{d\left(N_{T(L i 7)}\right)}{d t}=\phi_{f} \cdot \sigma_{L i 7 T} \cdot N_{L i 7}-\lambda \cdot N_{T(L i 7)}
\end{aligned}
$$

where

$$
\begin{aligned}
& N_{L i 7}=\text { number of }{ }^{7} \mathrm{Li} \text { atoms, excluding }{ }^{10} \mathrm{~B} \text { source } \\
& N_{T(L i 7)}=\text { number of tritium atoms from }{ }^{7} \mathrm{Li} \text {, excluding birth from }{ }^{10} \mathrm{~B} \\
& \left.\phi_{f}=\text { fast neutron flux [neutrons } / \mathrm{cm}^{2} / \mathrm{s}\right] \\
& \sigma_{L i 7 T}=\text { effective cross section for }{ }^{7} \mathrm{Li}(\mathrm{n}, \mathrm{n} \alpha){ }^{3} \mathrm{H}\left[\mathrm{cm}^{2}\right] .
\end{aligned}
$$

\subsubsection{Birth from ${ }^{3} \mathrm{He}$}

Tritium is produced from ${ }^{3} \mathrm{He}$ via $\mathrm{n}(\mathrm{n}, \mathrm{p})$ reaction with thermal neutrons in the primary coolant. The natural abundance of ${ }^{3} \mathrm{He}$ in helium ranges from $1.3 \times 10^{-6}$ to $2 \times 10^{-7}$. The ${ }^{3} \mathrm{He}$ reaction has a relatively high thermal neutron cross section. The following equations express tritium birth from ${ }^{3} \mathrm{He}$.

$$
\frac{d\left(N_{H e 3}\right)}{d t}=f \cdot N_{H e 3}^{\circ}-f \cdot N_{H e 3}-\phi_{H e} \cdot \sigma_{H e 3 T} \cdot N_{H e 3}
$$




$$
\begin{aligned}
& \frac{d\left(N_{T(H e 3)}\right)}{d t}=\phi_{H e} \cdot \sigma_{H e 3 T} \cdot N_{H e 3}-\lambda \cdot N_{T(H e 3)} \\
& \phi_{H e}=\frac{W_{\text {core }}}{W_{\text {total }}} \cdot \phi_{t h}
\end{aligned}
$$

where

$$
\begin{aligned}
& N_{H e 3}=\text { number of }{ }^{3} \mathrm{He} \text { atoms } \\
& N_{T(H e 3)}=\text { number of tritium atoms from }{ }^{3} \mathrm{He} \\
& f \quad=\text { fractional supply rate of helium coolant }[1 / \mathrm{s}] \\
& N_{H e 3}^{\circ}=\text { number of }{ }^{3} \mathrm{He} \text { atoms in the supply helium } \\
& \sigma_{H e 3 T}=\text { effective cross section for }{ }^{3} \mathrm{He}(\mathrm{n}, \mathrm{p}) \mathrm{T}\left[\mathrm{cm}^{2}\right] \\
& \phi_{H e}=\text { average thermal neutron flux experienced by the total primary helium inventory }\left[\mathrm{n} / \mathrm{cm}^{2} / \mathrm{s}\right] \\
& W_{\text {core }}=\text { helium inventory in core }[\mathrm{kg}] \\
& W_{\text {total }}=\text { total primary helium inventory }[\mathrm{kg}] .
\end{aligned}
$$

\subsubsection{Birth from ${ }^{10} \mathrm{~B}$}

Tritium birth from ${ }^{10} \mathrm{~B}$ can be expressed by the following equations.

$\frac{d\left(N_{B 10}\right)}{d t}=-\left(\phi_{t h} \cdot \sigma_{B 10 L i 7}+\phi_{f} \cdot \sigma_{B 10 T}\right) \cdot N_{B 10}$

$\frac{d\left(N_{L i 7(B 10)}\right)}{d t}=\phi_{t h} \cdot \sigma_{B 10 L i 7} \cdot N_{B 10}-\phi_{f} \cdot \sigma_{L i 7 T} \cdot N_{L i 7(B 10)}$

$\frac{d\left(N_{T(B 10)}\right)}{d t}=\phi_{f} \cdot \sigma_{L i 7 T} \cdot N_{L i 7(B 10)}+\phi_{f} \cdot \sigma_{B 10 T} \cdot N_{B 10}-\lambda \cdot N_{T(B 10)}$

where

$$
\begin{array}{ll}
N_{B 10} & =\text { number of }{ }^{10} \mathrm{~B} \text { atoms } \\
N_{L i 7(B 10)} & =\text { number of }{ }^{7} \mathrm{Li} \text { atoms from }{ }^{10} \mathrm{~B} \\
N_{T(B 10)} & =\text { number of tritium from }{ }^{10} \mathrm{~B} \\
\sigma_{B 10 L i 7} & =\text { effective cross section for }{ }^{10} \mathrm{~B}(\mathrm{n}, \alpha){ }^{7} \mathrm{Li}\left[\mathrm{cm}^{2}\right] \\
\sigma_{B 10 T} & =\text { effective cross section for }{ }^{10} \mathrm{~B}(\mathrm{n}, 2 \alpha){ }^{3} \mathrm{H}\left[\mathrm{cm}^{2}\right] .
\end{array}
$$

\subsubsection{Tritium Release Rate}

After formation, tritium can rest in solids or circulate in the coolant. Retention of tritium in solids is well summarized in the General Atomics (GA) report published in 2006 (GA-911081). The following description is the guideline for determining tritium retention fraction proposed by GA:

A steady-state retention fraction is assigned for each reaction chain. In the fuel, it is assumed that tritium formed in cracked particles or from contaminants on particles escapes readily while that formed within intact tri-structural isotropic (TRISO) particles is strongly retained. Some release from intact particle may occur via diffusion.

The chains that involve reactions of nuclides in the solid phase to produce tritium depend on the content and location of possible boron and lithium impurities in graphite, which are poorly understood. 
The release rate of tritium, which is bound interstitially in graphite, is expected to be quite slow since a temperature of at least $1200^{\circ} \mathrm{C}$ is required for tritium desorption from graphite. A retention fraction of 0.99 is recommended for these reaction chains.

Each region solid is assumed to have uniform properties. This is not necessarily a good assumption for reflector blocks containing localized boron pins. Treating these regions as if boron were uniformly dispersed throughout the graphite may cause the average reaction rate for this boron to be too high. In the case of control rods, the major lithium content is in the metal. The retention of tritium formed from this source may be over-predicted because tritium escapes more readily from metal than from graphite.

The control rods will not be fully inserted. An insertion fraction of about $11 \%$ is frequently cited. The relationship between extra gas space under rods, degree of rod insertion, etc., was not treated as a variable.

Tritium from the ${ }^{3} \mathrm{He}(\mathrm{n}, \mathrm{p}) \mathrm{T}$ reaction in the primary coolant will come to rest in solids in fractions which vary from region to region depending on the space associated with channels and fabricated holes, clearance annuli, and pores. The following paragraphs summarize the method to calculate the average fraction of tritium that recoils into solids.

The recoil energy of a triton is about $0.2 \mathrm{MeV}$, leading to an estimated range of $0.05 \mathrm{~cm}$ in helium at $47.6 \mathrm{~atm}$ and $1,000^{\circ} \mathrm{C}$. In the case of pores, because they are generally smaller than $0.05 \mathrm{~cm}$, the fraction bound is taken as unity. A planar approximation is used for the clearance annuli (tolerances between graphite blocks or between the fuel rods and the graphite blocks containing them). If the width of the gap exceeds the recoil range,

Fraction Bound $=$ range $/(2 \cdot$ width $)$, range $<$ width

If the width of the gap is less than the recoil range,

Fraction Bound $=($ range - width $/ 2) /$ range, range $>$ width

For large cylindrical channels or holes,

Fraction Bound $=$ range / channel diameter

Based on above guidelines, the tritium release rate from the core to the primary coolant, $R_{\text {core }, H T, j}$ $\left[\mathrm{m}^{3}(\mathrm{STP}) / \mathrm{s}\right]$, is calculated by using the following equations:

$$
\begin{aligned}
\frac{d N_{T(\text { total })}}{d t} & =\sum\left\{\alpha_{T e r} \frac{d\left(N_{T(\text { Ter })}\right)}{d t}\right\}+\sum\left[\alpha_{L i}\left\{\frac{d\left(N_{T(\text { Li6) }}\right)}{d t}+\frac{d\left(N_{T(\text { Li7) }}\right)}{d t}\right\}\right] \\
& +\sum\left\{\alpha_{H e 3} \frac{d\left(N_{T(H e 3)}\right)}{d t}\right\}+\sum\left\{\alpha_{B 10} \frac{d\left(N_{T(B 10)}\right)}{d t}\right\}
\end{aligned}
$$

$R_{\text {core }, H T, j}=\frac{N_{T(\text { total })}}{d t} \times \frac{1}{N_{A}} \times \frac{R \cdot T_{0}}{P_{0}}$

where

$$
\begin{aligned}
& N_{T(\text { release })}=\text { number of tritium atoms released to the primary coolant } \\
& \alpha_{T e r}=\text { fractional release ratio of tritium produced from ternary fission } \\
& \alpha_{L i}=\text { fractional release ratio of tritium produced from }{ }^{6} \mathrm{Li} \text { and }{ }^{7} \mathrm{Li} \\
& \alpha_{H e 3}=\text { fractional release ratio of tritium produced from }{ }^{3} \mathrm{He} \\
& \alpha_{B 10}=\text { fractional release ratio of tritium produced from }{ }^{10} \mathrm{~B}
\end{aligned}
$$




$$
\begin{array}{ll}
N_{A} & =\text { Avogadro constant } \\
R & =\text { gas constant }(8.314) \\
T_{0} & =\text { standard temperature }(273.15 \mathrm{~K}) \\
P_{0} & =\text { standard pressure }\left(1.01325 \times 10^{5} \mathrm{~Pa}\right)
\end{array}
$$

\subsection{Permeation}

In the VHTR system, HXs are the main route of tritium permeation. Therefore, when we estimate the tritium distributions and contamination levels in hydrogen from the hydrogen production plant, it is very important to predict accurate tritium penetration rates. The permeation rate of $\mathrm{H}_{2}$ at the $\mathrm{HX}, R_{H X, H 2}\left[\mathrm{~m}^{3}\right.$ $(\mathrm{STP}) / \mathrm{s}]$, and at the co-axial pipe, $R_{\text {copipe }, H 2}\left[\mathrm{~m}^{3}(\mathrm{STP}) / \mathrm{s}\right]$, is generally estimated using the following equation:

$$
R_{H X, H 2, j}\left(\text { or } \quad R_{\text {copipe }, H 2, j}\right)=\frac{A}{l} \cdot k_{p, H} \cdot\left(\sqrt{P_{H 2, h}}-\sqrt{P_{H 2, l}}\right)
$$

where

$A=$ heat transfer area or surface area $\left[\mathrm{m}^{2}\right]$

$l=$ thickness of heat transfer tube or component casing $[\mathrm{m}]$

$k_{p, H}=$ permeability of hydrogen $\left[\mathrm{m}^{3}(\mathrm{STP}) / \mathrm{m} / \mathrm{s} / \mathrm{Pa}^{0.5}\right]$

$P_{H 2, h}=$ partial pressure of $\mathrm{H}_{2}$ at high pressure side $[\mathrm{Pa}]$

$P_{H 2, l}=$ partial pressure of $\mathrm{H}_{2}$ at low pressure side $[\mathrm{Pa}]$

$l$ is calculated by the following equation:

$l=r_{o} \cdot \ln \left(\frac{r_{o}}{r_{i}}\right)$

where

$r_{o}=$ outer radius of heat transfer tube $[\mathrm{m}]$

$r_{i}=$ inner radius of heat transfer tube [m].

Permeability is calculated by using the Arrhenius equation:

$k_{p}=f \cdot \exp \left(\frac{-E}{R T}\right)$

where

$$
\begin{aligned}
f & =\text { pre-exponential factor of permeability }\left[\mathrm{m}^{3}(\mathrm{STP}) / \mathrm{m} / \mathrm{s} / \mathrm{Pa}^{0.5}\right] \\
E & =\text { activation energy }[\mathrm{J} / \mathrm{mol}] \\
R & =\text { ideal gas constant }[\mathrm{J} / \mathrm{mol}-\mathrm{K}] \\
T & =\text { temperature }[\mathrm{K}] .
\end{aligned}
$$

The permeation rate of $\mathrm{H}_{2}$ though the outer wall of the component and piping, $R_{c o m p, H 2}$, is calculated by excluding the $\mathrm{H}_{2}$ partial pressure at the low pressure side as follows:

$$
R_{\text {comp }, H 2, j}=\frac{A}{l} \cdot k_{p, H} \cdot \sqrt{P_{H 2, h}} \text {. }
$$


The permeation rate of HT at the HX, $R_{H X, H 2}\left[\mathrm{~m}^{3}(\mathrm{STP}) / \mathrm{s}\right]$, and at the co-axial pipe, $R_{\text {copipe, }{ }_{2}}\left[\mathrm{~m}^{3}\right.$ (STP)/s], is estimated by considering the effect of the existence of hydrogen on the adsorption-dissociation and recombination-desorption step as follows:

$$
R_{H X, H T, j}\left(\text { or } \quad R_{\text {copipe }, H T, j}\right)=\frac{A}{l} \cdot k_{p, T} \cdot\left(1-\frac{P_{H 2, l}}{P_{\text {Total }, l}}\right)\left(\frac{P_{H T, h}}{\sqrt{P_{H 2, h}+P_{H T, h}}}-\frac{P_{H T, l}}{\sqrt{P_{H 2, l}+P_{H T, l}}}\right)
$$

where

$$
\begin{aligned}
& k_{p, T}=\text { permeability of tritium }\left[\mathrm{m}^{3}(\mathrm{STP}) / \mathrm{m} / \mathrm{s} / \mathrm{Pa}^{0.5}\right] \\
& P_{H T, h}=\text { partial pressure of } \mathrm{HT} \text { at high pressure side }[\mathrm{Pa}] \\
& P_{H T, l}=\text { partial pressure of } \mathrm{HT} \text { at low pressure side }[\mathrm{Pa}] \\
& P_{\text {Total }, l}=\text { total pressure at low pressure side }[\mathrm{Pa}] .
\end{aligned}
$$

The permeation rate of HT through the outer wall of the component and piping, $R_{\text {comp }, H T}$, is calculated by using the following equation:

$$
R_{\text {comp }, H T, j}=\frac{A}{l} \cdot k_{p, T} \cdot \frac{P_{H T, h}}{\sqrt{P_{H 2, h}+P_{H T, h}}} .
$$

As shown in Eq. (3-16), (3-17), (3-20), and (3-21), a tube's thickness is a sensitive factor for the tritium permeation. The tritium permeation rate is inversely proportional to the tube thickness. In the typical tubular type HXs, determination of the tube thickness is simple and straightforward. However, the determination is not simple in the printed circuit heat exchanger (PCHE), which is one of the strong candidates for VHTR HXs. Figure 3-1 shows the cross-sectional configurations of a PCHE. A PCHE is a category of the compact HX manufactured by Heatric ${ }^{\mathrm{TM}}$ (2003). It is manufactured by chemical etching and diffusion bonding process. So, it provides very large heat transfer surface area density as high as $2,500 \mathrm{~m}^{2} / \mathrm{m}^{3}$. It also allows operation at high temperatures and pressures up to $900^{\circ} \mathrm{C}$ and $50 \mathrm{MPa}$, since the tritium permeation path in the PCHEs is two dimensional, and the thickness is varying along the channel surface.

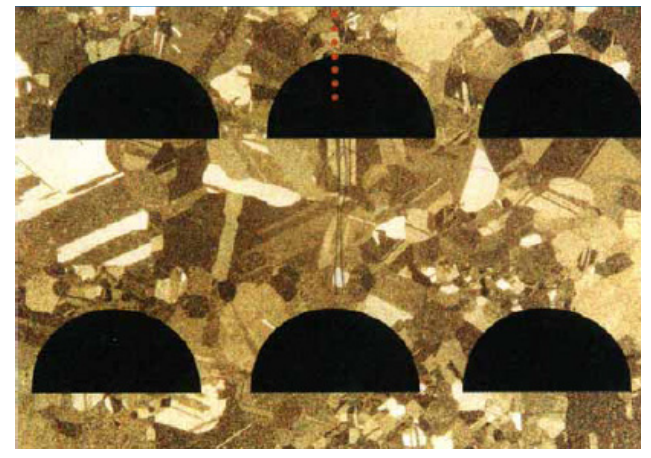

Figure 3-1. Cross-sectional picture of a PCHE (Dewson and Grady, 2003).

Oh and Kim (2008) proposed the following correlations to determine the effective thickness $\left(t_{\text {eff }}\right)$ of the PCHE channels. Two different configurations are listed below: standard configuration and offset configuration (See Figure 3-2).

(1) Standard Configuration 


$$
\begin{aligned}
& \frac{t_{\text {eff. }}}{d}=0.8 \cdot\left(\frac{t_{p}}{d}\right)^{2.92} \cdot\left(\frac{p}{d}\right)^{-0.19} \quad\left(\frac{t_{p}}{d}<0.8\right) \\
& \frac{t_{\text {eff }} \cdot}{d}=0.67 \cdot\left(\frac{t_{p}}{d}\right)^{1.51} \cdot\left(\frac{p}{d}\right)^{-0.61} \quad\left(\frac{t_{p}}{d}>0.8\right)
\end{aligned}
$$

(2) Offset Configuration

$$
\begin{array}{ll}
\frac{t_{\text {eff }} \cdot}{d}=0.48 \cdot\left(\frac{t_{p}}{d}\right)^{1.94} \cdot\left(\frac{p}{d}\right)^{-0.85} & \left(\frac{t_{p}}{d}<0.8\right) \\
\frac{t_{\text {eff }} \cdot}{d}=0.65 \cdot\left(\frac{t_{p}}{d}\right)^{1.35} \cdot\left(\frac{p}{d}\right)^{-0.26} & \left(\frac{t_{p}}{d}>0.8\right)
\end{array}
$$

where

$$
\begin{array}{ll}
d & =\text { channel diameter }[\mathrm{m}] \\
t_{p} & =\text { plate thickness }[\mathrm{m}] \\
p & =\text { horizontal pitch }[\mathrm{m}]
\end{array}
$$
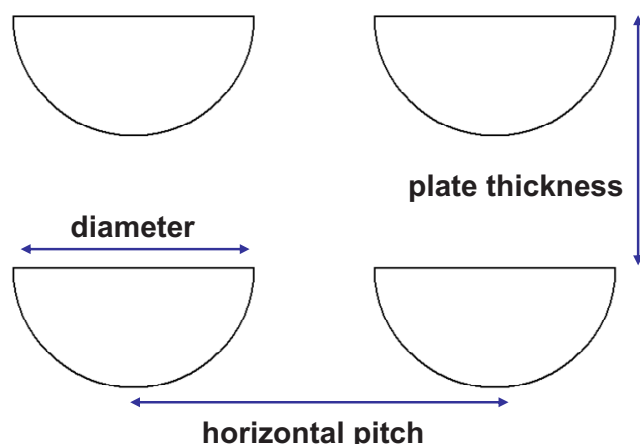

(a) Standard in-line configuration

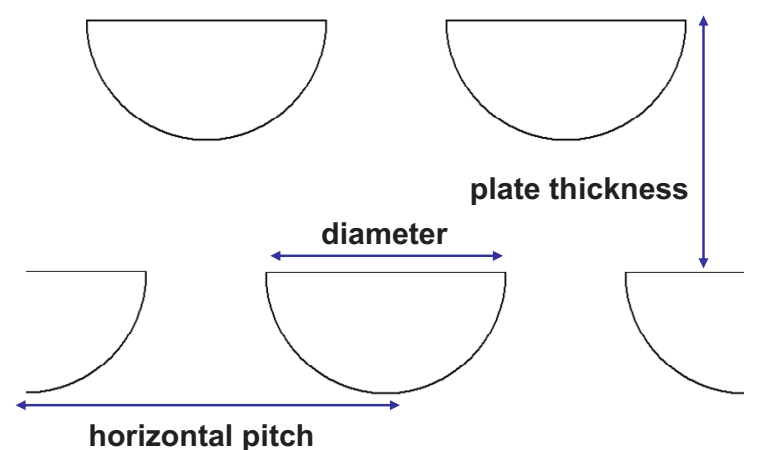

(b) Off-set configuration

Figure 3-2. PCHE channel configurations.

\subsection{Leakage}

The leak rate of helium from the loop, $R_{\text {leak }, H e}\left[\mathrm{~m}^{3}(\mathrm{STP}) / \mathrm{s}\right]$, can be expressed by the following equation:

$R_{\text {leak }, H e}=V_{\text {total }} \cdot L_{R}$

where

$V_{\text {total }}=$ total inventory in loop $\left[\mathrm{m}^{3}(\mathrm{STP})\right]$

$L_{R}=$ helium leak rate $[1 / \mathrm{s}]$.

The leak rate of $\mathrm{H}_{2}, \mathrm{HT}$, and $\mathrm{HTO}$ with helium leakage in node $\mathrm{j}, R_{\text {leak }, i, j}$, is calculated by using the following equation: 
$R_{\text {leak }, i, j}=V_{\text {total }} \cdot L_{R} \cdot \bar{C}_{i} \cdot \frac{V_{j}}{V_{\text {leak }}}\left(i=\mathrm{H}_{2}, \mathrm{HT}\right.$ and HTO $)$

where

$\bar{C}_{i}=$ average concentration of chemical $\mathrm{i}$ in nodes with helium leak

$V_{\text {leak }}=$ sum of the inventory of nodes with helium leak.

\subsection{Purification}

The removal rate, $R_{P F}$, of hydrogen and tritium-containing chemicals in the primary and intermediate loop by the purification system is expressed by the following equation:

$R_{P F, i, j}=F_{P F, H e} \cdot \eta_{i} \cdot C_{i, j}\left(i=\mathrm{H}_{2}, \mathrm{HT}\right.$, and $\left.\mathrm{HTO}\right)$

where

$$
\begin{aligned}
& F_{P F, H e}=\text { helium flow rate at purification system }\left[\mathrm{m}^{3}(\mathrm{STP}) / \mathrm{s}\right] \\
& \eta_{i}=\text { fractional efficiency of purification system for removing component } \mathrm{i} .
\end{aligned}
$$

\subsection{Electrolyzer}

In the TPAC code, a simple electrolyzer model was implemented in order to match the species conservation in the following chemical reaction.

$\mathrm{H}_{2} \mathrm{O}=\mathrm{H}_{2}+0.5 \mathrm{O}_{2}$

In this model, a complicated electrochemistry model was not applied. Decomposition of $\mathrm{H}_{2} \mathrm{O}$ into $\mathrm{H}_{2}$ and $\mathrm{O}_{2}$ was simply considered by conversion ratios. HTO was considered to be chemically identical to $\mathrm{H}_{2} \mathrm{O}$. So, the same conversion correlation was applied to HTO decomposition. Produced $\mathrm{O}_{2}$ in the cathode was considered to be transferred to anode directly.

\subsection{Isotope Exchange}

The SI process contains $\mathrm{H}_{2}, \mathrm{H}_{2} \mathrm{O}, \mathrm{H}_{2} \mathrm{SO}_{4}$, and $\mathrm{HI}$, and the HTSE process contains $\mathrm{H}_{2}$ and $\mathrm{H}_{2} \mathrm{O}$ as hydrogen-containing chemicals. The primary and intermediate coolants also contain $\mathrm{H}_{2}$ and $\mathrm{H}_{2} \mathrm{O}$ as impurities. To analyze the tritium behaviors in the VHTR/Hydrogen production system, analysts need some additional models that can handle isotope exchange reactions between some chemicals. The following isotope exchange reactions between tritium-containing chemicals and hydrogen-containing chemicals are taken into account in the TPAC code:

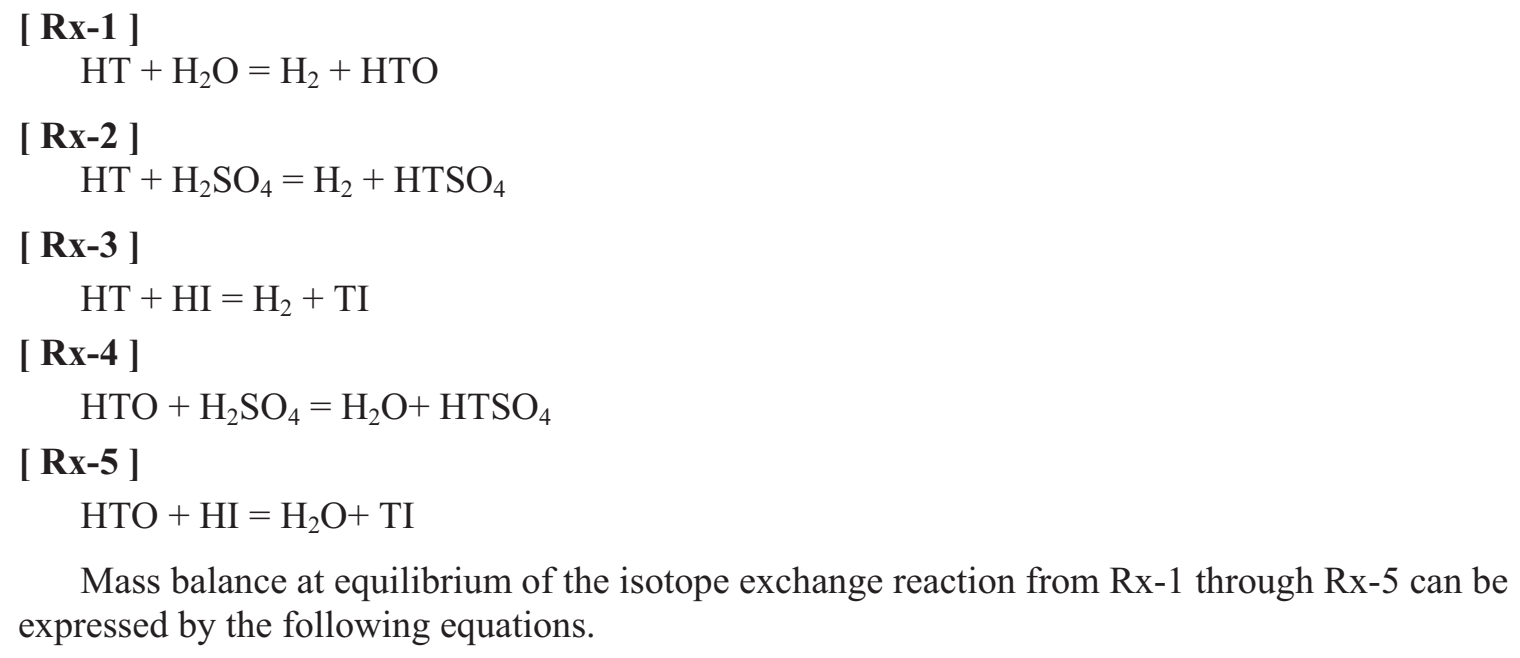




$$
\begin{aligned}
& K_{1}=\frac{F_{H 2, e q} \cdot F_{H T O, e q}}{F_{H T, e q} \cdot F_{H 2 O, e q}} \\
& K_{2}=\frac{F_{H 2, e q} \cdot F_{H T S O 4, e q}}{F_{H T, e q} \cdot F_{H 2 S O 4, e q}} \\
& K_{3}=\frac{F_{H 2, e q} \cdot F_{T I, e q}}{F_{H T, e q} \cdot F_{H I, e q}} \\
& K_{4}=\frac{K_{2}}{K_{1}}=\frac{F_{H 2 O, e q} \cdot F_{H T S O 4, e q}}{F_{H T O, e q} \cdot F_{H 2 S O 4, e q}} \\
& K_{5}=\frac{K_{3}}{K_{1}}=\frac{F_{H 2 O, e q} \cdot F_{T I, e q}}{F_{H T O, e q} \cdot F_{H I, e q}}
\end{aligned}
$$

where

$K=$ equilibrium constant of each isotope exchange reaction

$$
F_{i, e q}=\text { volumetric flow rate of each chemical at equilibrium }\left[\mathrm{m}^{3}(\mathrm{STP}) / \mathrm{s}\right]
$$

In the above equations, the Rx-4 and Rx-5 can be expressed by combinations of Rx-1 through Rx-3 . Therefore, solving Equations (3-33) and (3-34) is not necessary. To solve Equations (3-30), (3-31) and (3-32), the equilibrium, the values of $\mathrm{F}_{\mathrm{i}, \mathrm{eq}} \mathrm{S}$, were expressed as follows.

$$
\begin{aligned}
& F_{H T, e q}=F_{H T, I N}-\Delta_{1}-\Delta_{2}-\Delta_{3} \\
& F_{H 2, e q}=F_{H 2, I N}+\Delta_{1}+\Delta_{2}+\Delta_{3} \\
& F_{H 2 O, e q}=F_{H 2 O, I N}-\Delta_{1} \\
& F_{H T O, e q}=F_{H T O, I N}+\Delta_{1} \\
& F_{H 2 S O 4, e q}=F_{H 2 S O 4, I N}-\Delta_{2} \\
& F_{H T S O 4, e q}=F_{H T S O 4, I N}+\Delta_{2} \\
& F_{H I, e q}=F_{H I, I N}-\Delta_{3} \\
& F_{T I, e q}=F_{T I, I N}+\Delta_{3}
\end{aligned}
$$

where

$F_{i, I N}=$ inlet volumetric flow rate of each chemical species $\left[\mathrm{m}^{3}(\mathrm{STP}) / \mathrm{s}\right]$

$\Delta_{n} \quad=$ amount of HT conversion rate by $\mathrm{Rx}-\mathrm{n}\left[\mathrm{m}^{3}(\mathrm{STP}) / \mathrm{s}\right]$

From the above set-up, we can solve three unknowns $\left(\Delta_{1}, \Delta_{2}, \Delta_{3}\right)$ from three equations (Eq. [3-30], [3-31] and [3-32]). 
The equilibrium constants of the $\mathrm{Rx}-1$ through $\mathrm{Rx}-3$ can be expressed in the following equation (Atomic Energy Society of Japan 1982):

$\log K_{1}=0.292 \log T+(336.5 / T)-1.055$

$\log K_{2}:$ unknown

$\ln K_{3}=-1.13+1.07 \times 10^{-2} T-2.26 \times 10^{-5} T^{2}+2.10 \times 10^{-8} T^{3}-7.25 \times 10^{-12} T^{4}$ 


\section{TRITIUM PERMEATION ANALYSES CODE (TPAC)}

The TPAC is a computer code developed for the purpose of analyzing tritium permeation and distribution in the VHTR systems (Oh and Kim, 2009). The TPAC code is based on the mass conservation equations of various tritium-containing species (i.e., $\mathrm{HT}, \mathrm{HTO}, \mathrm{HTSO}_{4}, \mathrm{TI}$ ) and hydrogen $\left(\mathrm{H}_{2}\right)$ coupled with a variety of tritium source and sink models. The models include tritium source from ternary fission and neuron reactions, leakage, permeation through solid walls, purification, ion exchange reactions, and electrolysis as described in Section 3. The TPAC code provides very convenient graphical user interface (GUI) with large flexibility for system configurations. Any system configurations (not only VHTR, but also general components) can be easily made by simple drag-and-drops on the screen.

All the component models in the TPAC were developed using MATLAB SIMULINK and ware embedded in the SIMULINK library. The MATLAB SIMULINK package (Mathworks, 2009) is a world-famous numerical computing environment and language with more than one million users in the world. The MATLAB code is a high-level technical computing program language created by Mathworks. It provides easy matrix manipulation, algorithms implementation, user interface creation, and numerous built-in numerical libraries. The SIMULINK code is a built-in package integrated in the MATLAB, which specializes in modeling, simulating, and analyzing multi-domain dynamic systems. Its primary interface is a graphical block diagramming tool and a customizable set of block libraries. It offers tight integration with the rest of the MATLAB environment. It supports linear and nonlinear systems modeled in continuous time, sampled time, or hybrid of both.

The TPAC was developed based on the SIMULINK user interface. All the TPAC component libraries were built in the SIMULINK model library so that the TPAC component blocks can be easily integrated with pre-existing SIMULINK model blocks. It provides enormous flexibility and extensibility to the code. Figure 4-1 shows the basic TPAC workspace and GUI. The HX model, shown as HX in Figure 4-1, shows two parallel inlets to the HX simulating a co-current flow between the hot side and the cold side of the HX. However, two inlets were actually modeled as in the counter-current flow even though it shows as a co-current flow configuration and the temperature profile results from the TPAC calculation show the counter-current flow configuration.

\section{TPAC Sample Modeling}

\section{System Configuration}

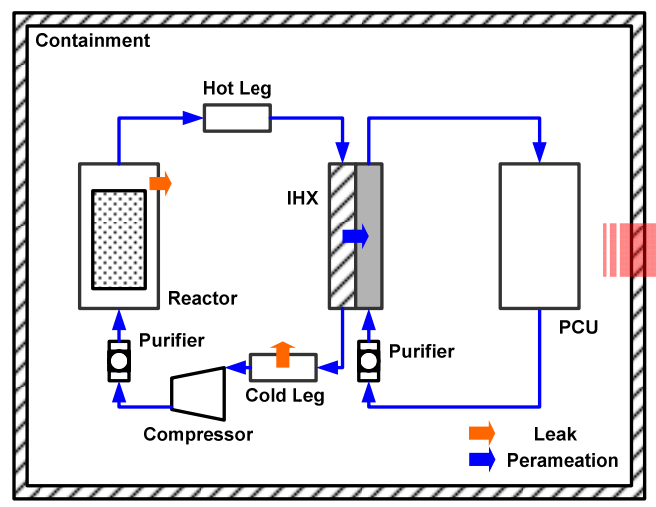

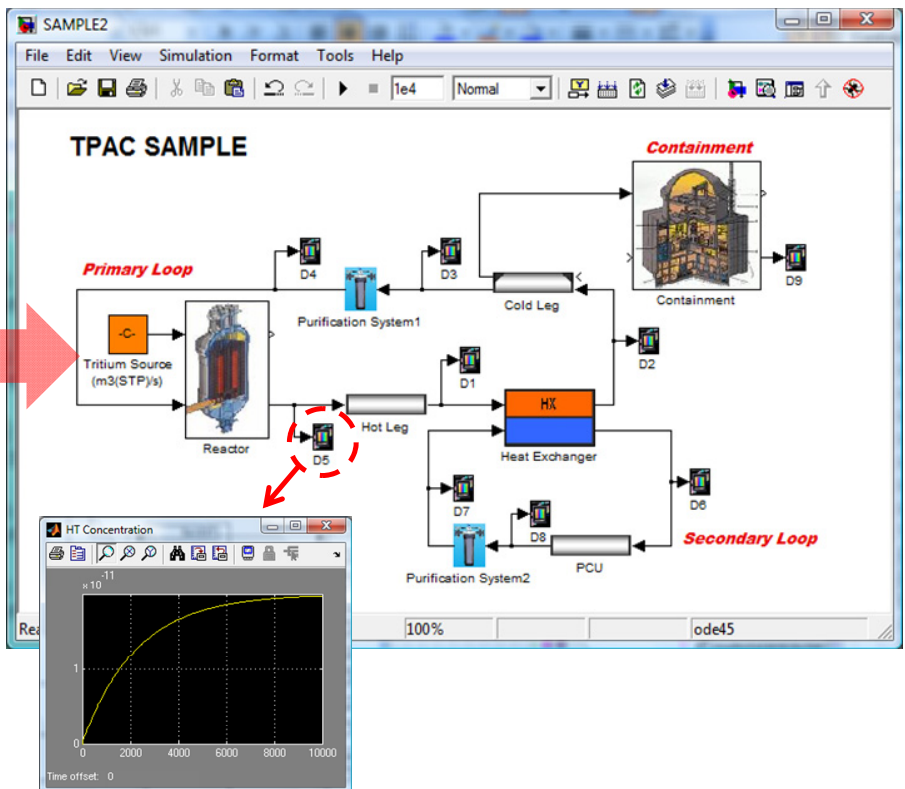

Figure 4-1. General TPAC modeling sample and GUI. 
The TPAC code has a variety of library categories. Each category has different sets of component block models. Figure 4-2 shows the structure of the TPAC code component libraries. The current version of the TPAC code is $1.5 \mathrm{~b}$, and it consists of twelve different categories (shown in the figure):

1. The VHTR system component contains the component blocks related to the VHTR systems, such as core and vessel.

2. The pipe component contains various types of pipe component blocks including VHTR, HTSE, and SI systems.

3. The heat exchanger component contains two different HX component blocks.

4. The vessel component contains various vessel components related to VHTR, HTSE, and SI systems.

5. The containment component contains the reactor containment block.

6. The purification system component contains a tritium purification system block.

7. The electrolyzer component contains an electrolyzer block.

8. The flow distributions component contains flow distributor and mixer blocks.

9. The boundary flow component contains a bound flow block that can be used for open-flow or fixed flows.

10. The detector component contains a detector block that can display the flow conditions during or after simulation.

11. The data save component contains data save blocks that export calculated results to MATLAB Workspace or external files. T

12. The sample simulation component contains some sample simulation cases including those used for code verification works.

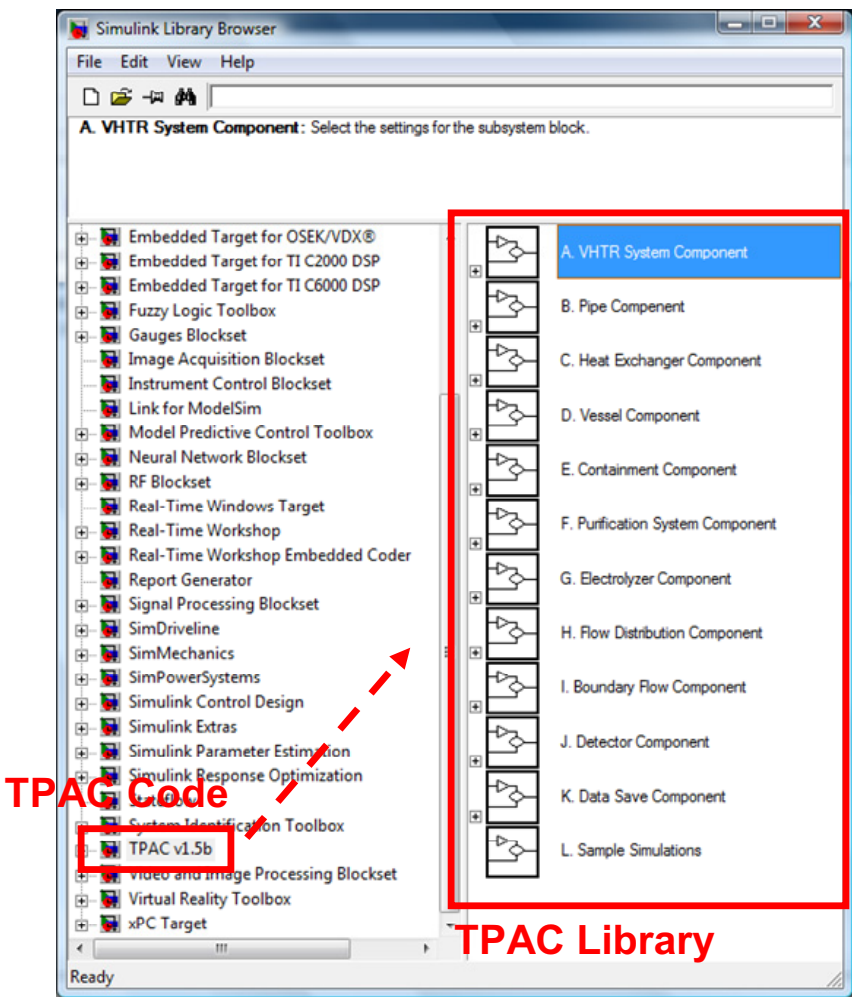

Figure 4-2. TPAC library browser. 
Table 4-1 compares the TPAC with some previous tritium analyses codes. They include THYTAN code (developed by JAEA), TRITGO code (General Atomics, 2006) developed by Oak Ridge National Laboratory [ORNL], TBEC code (developed by KAIST), and TMAP 7 (developed by INL). The TPAC code has many advantages compared to the other codes. First, this code is the only code that adopted GUI. Consequently, it is easy to use and model many kinds of VHTR systems with less time and efforts. The TPAC also adopted most of the tritium-related physical models currently available in this field. In addtion, this code incorporated 12 ordinary differential equation solvers so that the users can flexibly select solver types and settings based on the problem stiffness, accuracy, and calculation time., which makes this code easier, faster, and even more accurate than any other codes developed previously. The TPAC is considered the most advanced tritium-analysis code along with process optimization capability for the VHTR systems.

Table 4-1 Comparisons of TPAC code with other tritium analyses codes.

\begin{tabular}{|c|c|c|c|c|c|c|}
\hline & Phenomena & TPAC (INL) & THYTAN (JAEA) & TRITGO (ORNL) & TBEC (KAIST) & TMAP 7 (INL) \\
\hline $\begin{array}{l}\text { Language (User } \\
\text { interface) }\end{array}$ & - & $\begin{array}{l}\text { MATLAB } \\
\text { (GUI) }\end{array}$ & $\begin{array}{l}\text { FORTRAN } 90 \\
\text { (Text) }\end{array}$ & $\begin{array}{c}\text { FORTRAN } 77 \\
\text { (Text) }\end{array}$ & $\begin{array}{c}\mathbf{C} \\
(\text { Text })\end{array}$ & $\begin{array}{l}\text { FORTRAN } 77 \\
\text { (Text) }\end{array}$ \\
\hline $\begin{array}{l}\text { Normal Core } \\
\text { Condition }\end{array}$ & $\begin{array}{l}\text { Core Temperature } \\
\text { and flux }\end{array}$ & $\begin{array}{l}\text { User input (from } \\
\text { other code) }\end{array}$ & $\begin{array}{l}\text { User input (from } \\
\text { other code) }\end{array}$ & $\begin{array}{l}\text { User input (from } \\
\text { other code) }\end{array}$ & $\begin{array}{l}\text { User input (from } \\
\text { other code) }\end{array}$ & $\begin{array}{l}\text { User input (from } \\
\text { other code) }\end{array}$ \\
\hline \multirow{4}{*}{ Generation } & Ternary Fission & 0 & 0 & 0 & O & $x$ \\
\hline & ${ }^{6} \mathrm{Li},{ }^{7} \mathrm{Li}$ impurities & $\mathrm{O}$ & $\mathrm{O}$ & 0 & 0 & $x$ \\
\hline & ${ }^{3} \mathrm{He}$ in primary & 0 & $\mathrm{O}$ & O & 0 & $x$ \\
\hline & ${ }^{10} \mathrm{Bin}$ control rod & $\mathrm{O}$ & $\mathrm{O}$ & $\mathrm{O}$ & $\mathrm{O}$ & $x$ \\
\hline \multirow{2}{*}{$\begin{array}{l}\text { Release and } \\
\text { Transport }\end{array}$} & Release & Release fraction & Release fraction & Release fraction & Diffusion Eqn. & Diffusion Eqn. \\
\hline & Recoil & $x$ & $x$ & $x$ & $x$ & $x$ \\
\hline \multirow{2}{*}{$\begin{array}{l}\text { Leakage, } \\
\text { Purification }\end{array}$} & Leakage & $\mathrm{O}$ & $\mathrm{O}$ & O & $x$ & $x$ \\
\hline & Purification & $\mathrm{O}$ & $\mathrm{O}$ & $\mathrm{O}$ & $x$ & $x$ \\
\hline Permeation & Permeation & Sievert's law & Sievert's Law & Sievert's Law & Sievert's law & Sievert's law \\
\hline $\begin{array}{l}\text { Process } \\
\text { Optimization }\end{array}$ & $\begin{array}{l}\text { Process. } \\
\text { Optimization }\end{array}$ & $\mathrm{O}$ & $x$ & $x$ & $x$ & $x$ \\
\hline Separate Loop & \# of loops & Infinite & Infinite & $\begin{array}{l}\text { Design Fixed } \\
\text { (only } 1^{\text {st }}, 2^{\text {nd }} \text { ) }\end{array}$ & Infinite & Infinite \\
\hline Solver & type of solvers & $\begin{array}{c}\text { Fixed or Variable } \\
\text { handle stiffness } \\
\text { (Yes) }\end{array}$ & $\begin{array}{l}\text { Fixed timestep } \\
\text { handle stiffness } \\
(\text { No) }\end{array}$ & $\begin{array}{l}\text { Fixed timestep } \\
\text { handle stiffness } \\
\text { (No) }\end{array}$ & $\begin{array}{l}\text { Fixed timestep } \\
\text { handle stiffness } \\
\text { (No) }\end{array}$ & $\begin{array}{l}\text { Variable timestep } \\
\text { handle stiffness } \\
\text { (No) }\end{array}$ \\
\hline
\end{tabular}




\section{ANALYSIS OF TRITIUM BEHAVIORS IN VHTR INTEGRATED INDUSTRIAL SYSTEMS}

\subsection{Introduction}

In this fiscal year (FY-10), more extensive studies were conducted for the tritium behaviors in various VHTR integrated systems. This section presents the results of the analyses focusing on following three things:

- Tritium concentration in the industrial products and system coupled with VHTRs

- Tritium distribution in the VHTR-integrated systems

- Identification of important parameters affecting tritium behaviors in the VHTR system

First, this study focuses on how much tritium will be contained in the industrial products in the reference VHTR-coupled systems and conditions. This result also tells us whether the tritium concentration in the industrial products is less than the tritium regulatory limits (See Table 1-2). Second, the tritium distributions in the systems will be presented. This information showed how tritium sources, sinks, retention, and release are balanced in the whole system. Finally, this study presents the relative importance of various parameters affecting tritium behaviors in the systems. The parameter importance was estimated using the global sensitivity analysis method. This information provides very good insight into the tritium behaviors in the VHTR system as a guideline to reduce modeling uncertainties or to mitigate tritium contamination of the industrial products.

\subsection{Analyses on the VHTR/HTSE System}

The first system considered in this study was a hydrogen production system coupled with a VHTR $\left(900^{\circ} \mathrm{C}\right.$ core outlet temperature). The hydrogen production system was based on the high temperature steam electrolysis (HTSE) method. The following describes detailed system and models.

\subsubsection{Reference System Description}

Figure 5-1 illustrates a schematic of the reference VHTR/HTSE system investigated here. This system is based on an indirect parallel configuration of a VHTR and a HTSE system, which was proposed by Oh et al. (2007). In this configuration, the flow in the secondary coolant system is divided into two flow paths, with most of the flow going towards the power conversion unit (PCU) and the remainder going through a SHX that directs heat towards the HTSE plant through flow streams 1, 2, 3, and 4 in Figure 5-1. The flow through the hot side of the SHX is then mixed with the flow from the PCU to feed the cold side of the IHX. However, some of the flow is diverted away from the PCU, which acts to decrease the efficiency of the cycle. There are three coolant loops. The primary coolant system contains the nuclear reactor, the hot side of the IHX, and a compressor. The secondary coolant system contains the cold side of the IHX, the hot side of the SHX, the PCU, and connecting piping, which is assumed to be short. The intermediate heat transport loop connects the secondary coolant system to the HTSE plant through several PHXs. 


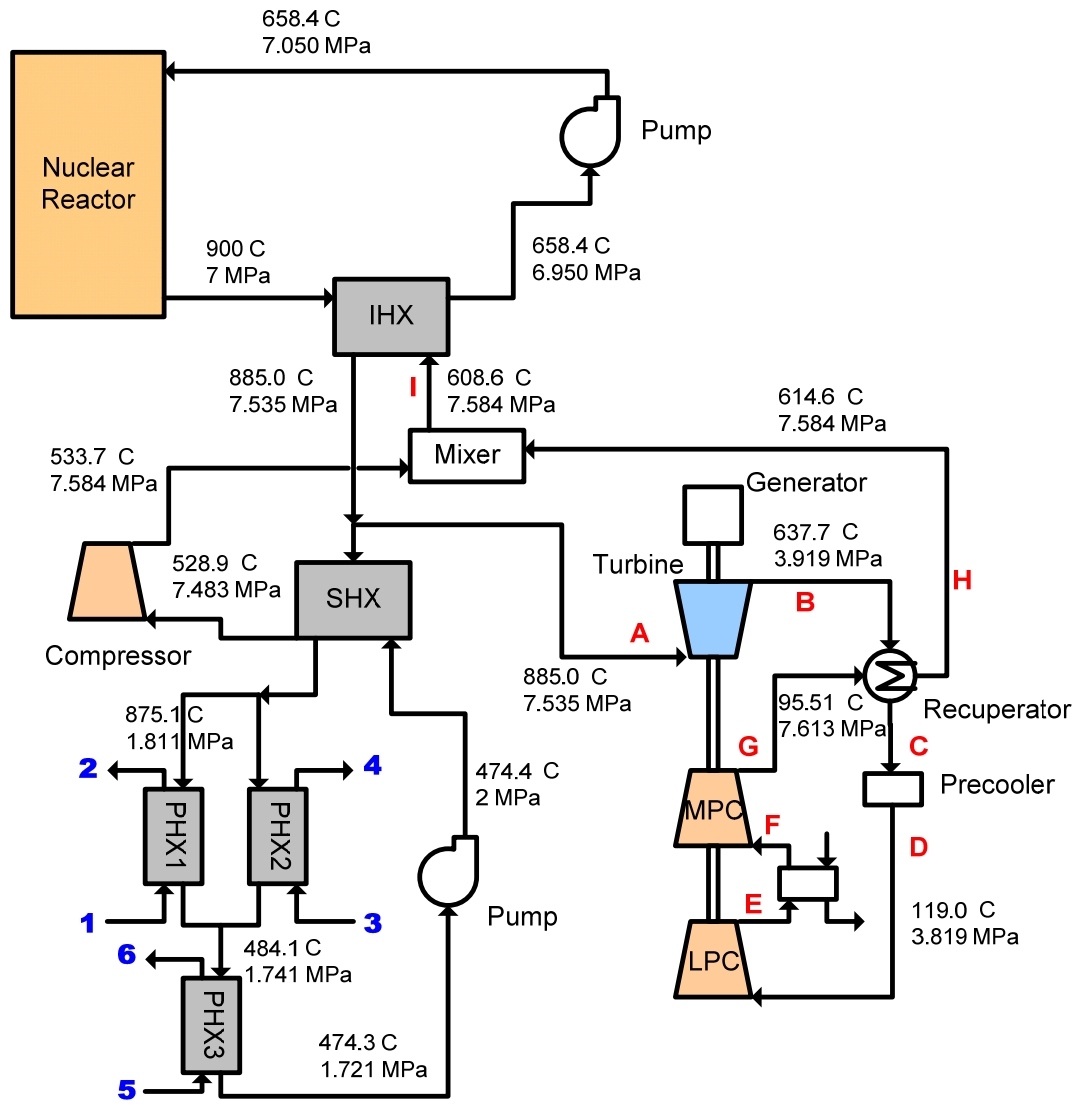

Figure 5-1. Indirect parallel configuration of VHTR/HTSE system (VHTR part).

For electrolysis, the steam is heated above $800^{\circ} \mathrm{C}$ through the SHX. The heated steam is then converted into hydrogen and oxygen in the electrolyzer and discharged through the fuel (steam $/ \mathrm{H}_{2}$ outlet in the electrolyzer) and the oxidizer outlet (sweep gas outlet in the electrolyzer), respectively, as shown in Figure 5-2. The heat of the discharged gases is recovered through three recuperators. Finally, the product gas in the fuel side contains hydrogen and steam, and the oxidizer outlet gas contains oxygen and steam. As shown in Figure 5-2 coupled with Figure 5-1, through flow streams 1, 2, 3, and 4, the discharged fuel steam is recycled to the inlet fuel stream, and the hydrogen gas is separated and collected in the separator. In the oxidizer outlet, stream heat is first recuperated and then allowed to run through an expander to recover work. The oxygen and water components of the stream are then separated. 


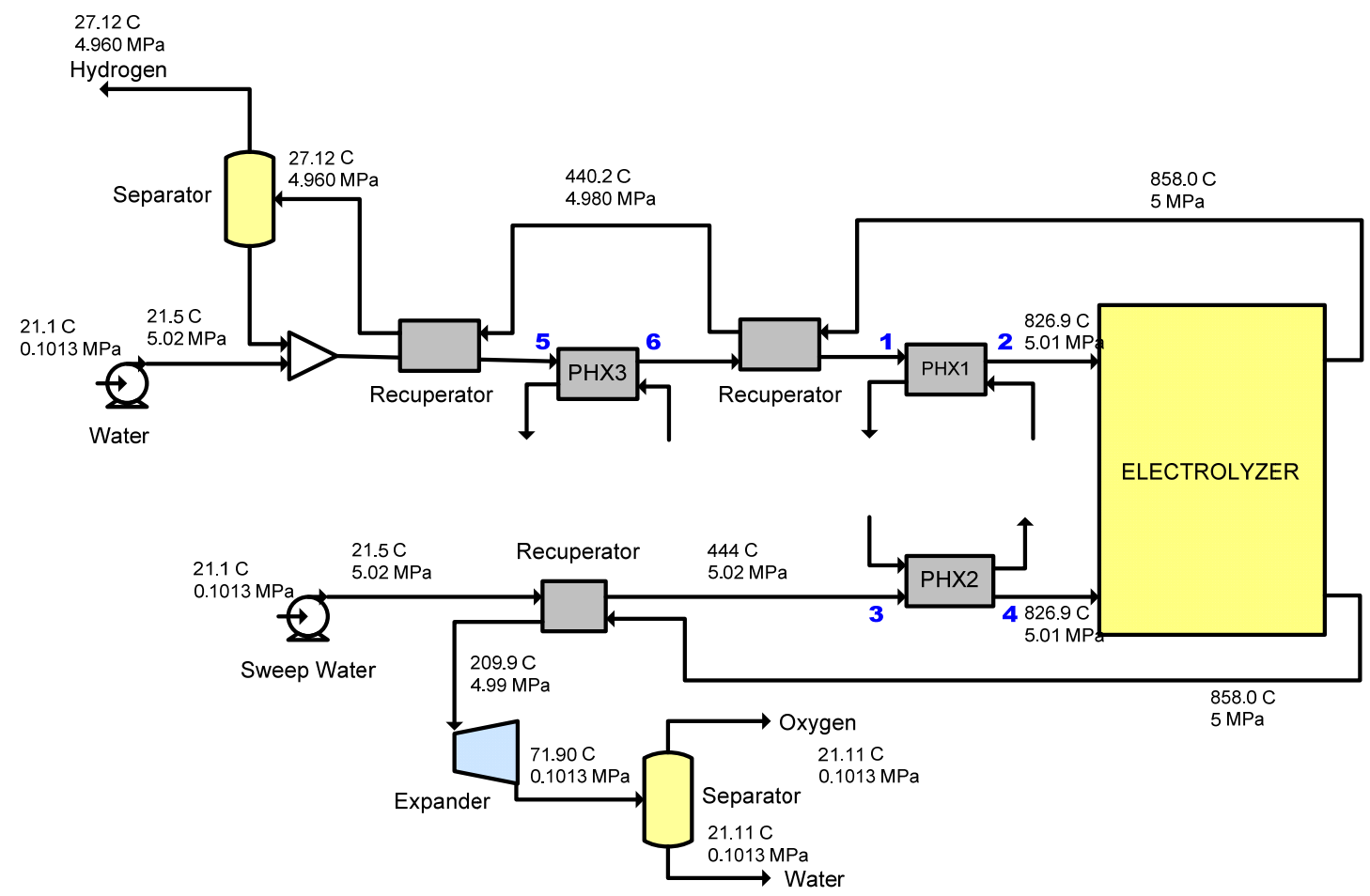

Figure 5-2. Indirect parallel configuration of VHTR/HTSE system (HTSE part).

\subsubsection{TPAC Modeling}

Figure 5-3 shows the TPAC model configured for the reference VHTR/HTSE system. In this model, the system was divided into five separate flow loops: (1) the primary side, (2) the secondary side (PCU), (3) the intermediate heat transfer loop (IHTL), (4) the HTSE (water supplier), and (5) the HTSE (purge flow). Table 5-1 summarizes the model components in the VHTR side (i.e., primary side, secondary side, and IHTL). The first column lists the names of the modeling components, and the second column lists the types of component blocks categorized in the TPAC code. 


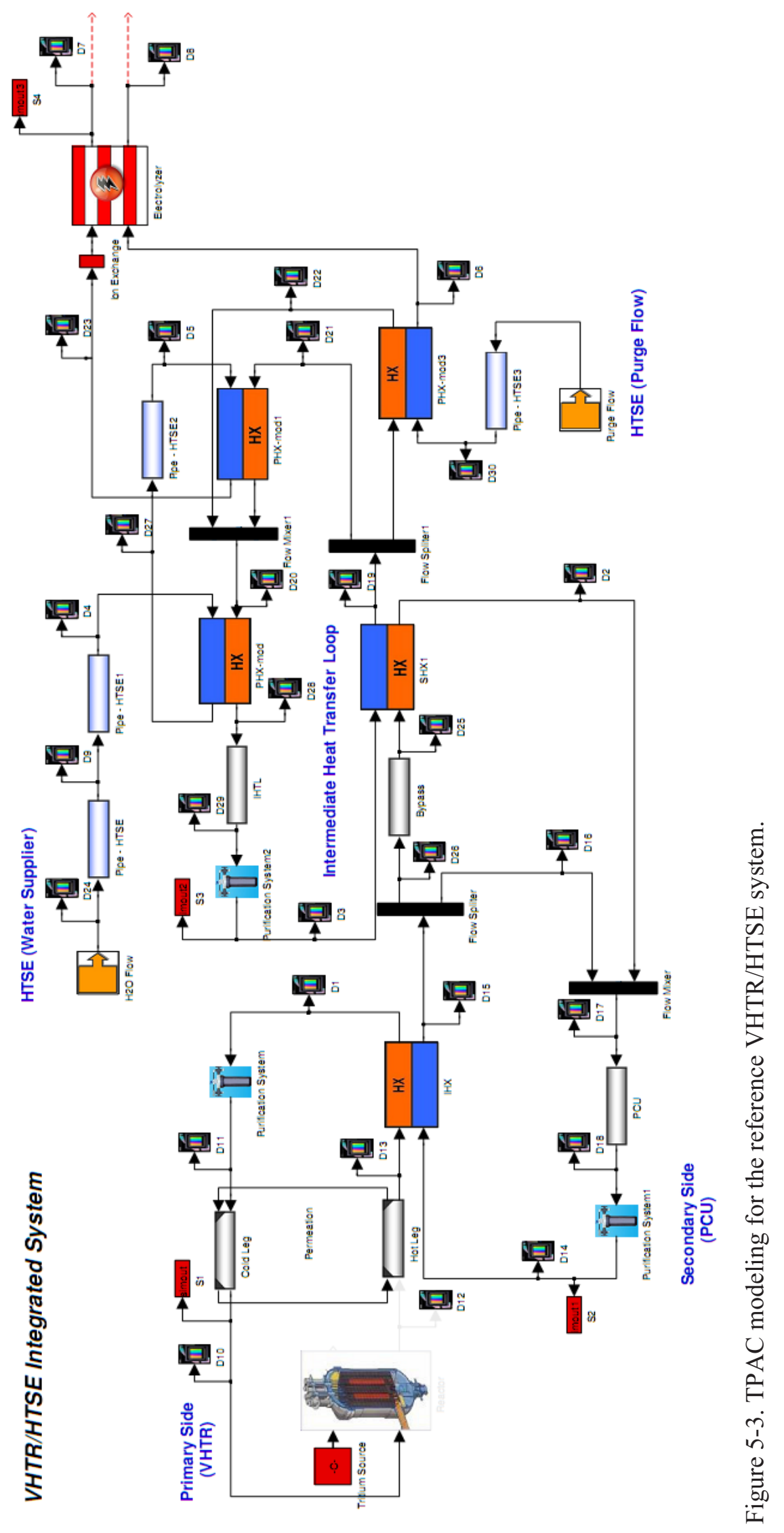


Table 5-1. Summary of modeling component blocks in the VHTR loops.

\begin{tabular}{|c|c|}
\hline Component Name in Modeling & Type of TPAC Component Block \\
\hline \multicolumn{2}{|l|}{ Primary Loop } \\
\hline Reactor & Reactor Component \\
\hline Hot-leg & VHTR Pipe Component \\
\hline Cold-leg & VHTR Pipe Component \\
\hline IHX & Heat Exchanger Component \\
\hline Purification System & Purification System Component \\
\hline \multicolumn{2}{|l|}{ Secondary Loop } \\
\hline PCU & VHTR Pipe Component \\
\hline Bypass & VHTR Pipe Component \\
\hline IHX & HX Component \\
\hline SHX & HX Component \\
\hline Flow Splitter & Flow Splitter Component \\
\hline Flow Mixer & Flow Mixer Component \\
\hline Purification System1 & Purification System Component \\
\hline \multicolumn{2}{|l|}{ Intermediate Heat Transfer Loop } \\
\hline IHTL & VHTR Pipe Component \\
\hline SHX1 & HX Component \\
\hline PHX-mod & HX Component \\
\hline PHX-mod1 & HX Component \\
\hline PHX-mod3 & HX Component \\
\hline Flow Splitter1 & Flow Splitter Component \\
\hline Flow Mixer1 & Flow Mixer Component \\
\hline Purification System2 & Purification System Component \\
\hline
\end{tabular}

Table 5-2 summarizes the TPAC model components used in the HTSE side. In this modeling, recycling and recuperating cycles were eliminated from the HTSE system for simplification. This simplification does not change any main flow configurations and is considered to provide more conservative results by estimating higher HT permeation out of the PHXs. This simplified HTSE model was made of the seven component blocks in the cathode side and four component blocks in the anode side.

Table 5-2. Summary of modeling component blocks in the HTSE loops.

\begin{tabular}{|c|l|}
\hline Component Name in Modeling & \multicolumn{1}{l|}{ Type of TPAC Component Block } \\
\hline Cathode (Product Hydrogen) & Boundary Component \\
\hline H2O Flow & HTSE Pipe Component \\
\hline Pipe-HTSE & HTSE Pipe Component \\
\hline Pipe-HTSE1 & HTSE Pipe Component \\
\hline Pipe-HTSE2 & HX Component \\
\hline PHX-mod & HX Component \\
\hline PHX-mod1 & Ion Exchange Component \\
\hline Ion Exchange & Electrolyzer Component \\
\hline Electrolyzer & \\
\hline Anode (Sweep Gas) & Boundary Component \\
\hline Purge Flow & HTSE Pipe Component \\
\hline Pipe-HTSE3 & Electrolyzer \\
\hline Electrolyzer & HX Component \\
\hline PHX-mod3 &
\end{tabular}




\subsubsection{Uncertainty and Sensitivity Analyses}

This section describes the methods of uncertainty and sensitivity analyses used for the VHTR/HTSE system. These methods were based on those introduced in Section 5.2. Figure 5-4 shows the uncertainty/sensitivity analysis procedure and methods (or software) utilized in each step. First, the fourteen sets of input parameters were selected. Then, approximately 15,000 random samples were generated as input datasets using the SIMLAB code. The inputs were then implemented into the TPAC for evaluating models. Based on the calculated results, uncertainty/sensitivity analyses were conducted using SIMLAB and MATLAB codes. In the final step, the sensitivity indices were estimated by the SOBOL method, which can cope with uncertainties for both nonlinearity and non-monotonic models.

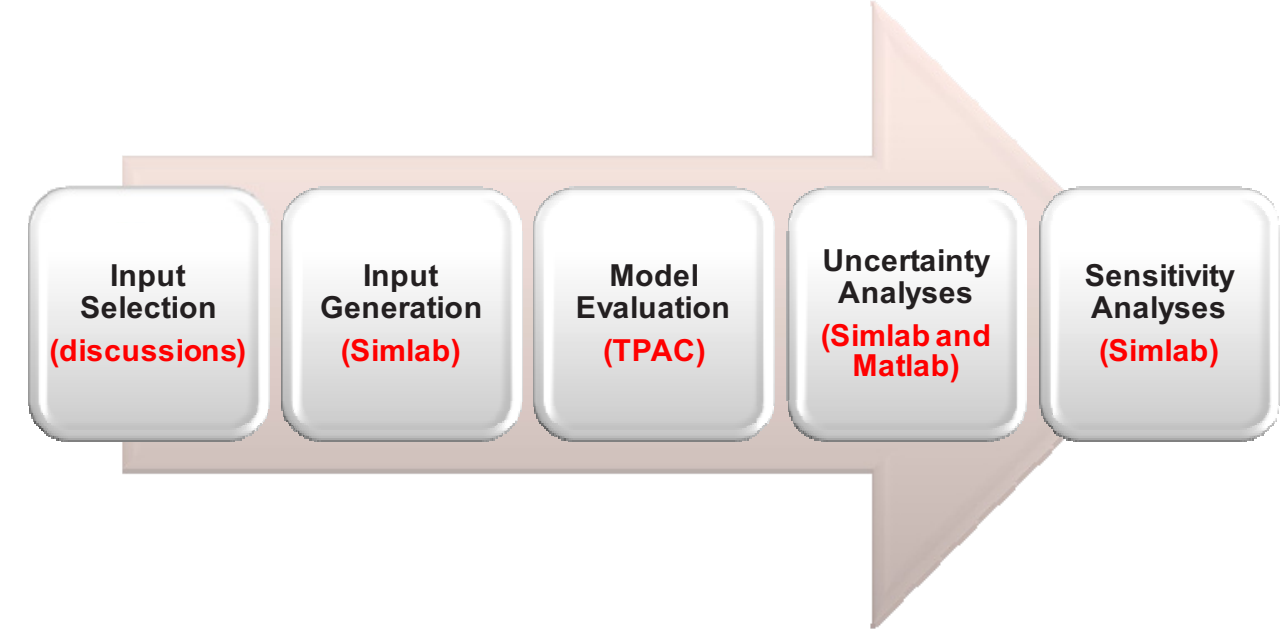

Figure 5-4. Uncertainty/sensitivity analysis procedure and methods (or software) utilized.

\subsubsection{Input Selection}

A number of parameters are associated with the reference VHTR/HTSE system for configuration in the TPAC code. Among them, 14 major input parameters were selected, which are considered as important for the tritium behaviors in this system. Table 5-3 summarizes selected input parameters and their physical representations.

Table 5-3. List of input parameters for uncertainty and sensitivity analysis.

\begin{tabular}{|l|l|}
\hline Input Parameters & Representations \\
\hline TS & Tritium release rate in the reactor core \\
\hline PMF1 & Fraction of mass flow rates to the purification system in the primary side \\
\hline PMF2 & Fraction of mass flow rates to the purification system in the secondary side \\
\hline PMF3 & Fraction of mass flow rates to the purification system in the IHTL side \\
\hline C1 & Tritium permeation coefficient (pre-exponential factor) at the IHX \\
\hline C2 3 & Tritium permeation coefficient (pre-exponential factor) at the SHX \\
\hline TH1 & Tritium permeation coefficient (pre-exponential factor) at the PHX \\
\hline TH2 & Thickness of the heat transfer surface wall (IHX) \\
\hline TH3 & Thickness of the heat transfer surface wall (SHX) \\
\hline CTL & Thickness of the heat transfer surface wall (PHX) \\
\hline EA1 & Fraction of operational temperature to the design condition \\
\hline EA2 & Activation energy for permeation (IHX) \\
\hline EA3 & Activation energy for permeation (SHX) \\
\hline
\end{tabular}




\subsubsection{Input Generation}

The TPAC input datasets were randomly generated using SIMLAB software based on the 14 input parameters listed in Table 5-3. Table 5-4 summarizes the input parameters and their ranges. This study assumed that the input parameters were uniformly distributed within the ranges because of no information available. This assumption can be considered conservative since the uniform distribution generally estimates uncertainties larger than other distributions such as a Gaussian distribution.

Table 5-4. List of input parameters and ranges for uncertainty and sensitivity analyses.

\begin{tabular}{|l|c|c|c|c|c|}
\hline \multicolumn{1}{|c|}{ Parameters } & Para N. & Min & Max & Unit & Distribution \\
\hline Tritium Source & TS & $1.13 \mathrm{E}-11$ & $5.35 \mathrm{E}-11$ & $\mathrm{~m}^{3}(\mathrm{STP}) / \mathrm{s}$ & Uniform \\
\hline $\begin{array}{l}\text { Fraction of Mass Flow to } \\
\text { Purification System (P-1st) }\end{array}$ & PMF1 & $7.38 \mathrm{E}-05$ & $1.23 \mathrm{E}-4$ & $\#$ & Uniform \\
\hline $\begin{array}{l}\text { Fraction of Mass Flow to } \\
\text { Purification System (P-2nd) }\end{array}$ & PMF2 & $7.31 \mathrm{E}-05$ & $1.22 \mathrm{E}-4$ & $\#$ & Uniform \\
\hline $\begin{array}{l}\text { Fraction of Mass Flow to } \\
\text { Purification System (P-3rd) }\end{array}$ & PMF3 & $1.06 \mathrm{E}-04$ & $1.76 \mathrm{E}-04$ & $\#$ & Uniform \\
\hline Permeation Coefficient (IHX) & C1 & $5.33 \mathrm{E}-11$ & $1.26 \mathrm{E}-8$ & $\#$ & Uniform \\
\hline Permeation Coefficient (SHX) & C2 & $5.33 \mathrm{E}-11$ & $1.26 \mathrm{E}-8$ & $\#$ & Uniform \\
\hline Permeation Coefficient (PHX) & C3 & $5.33 \mathrm{E}-11$ & $1.26 \mathrm{E}-8$ & $\#$ & Uniform \\
\hline HX Thickness (IHX) & TH1 & 0.001 & 0.003 & $\mathrm{~m}$ & Uniform \\
\hline HX Thickness (SHX) & Th2 & 0.001 & 0.003 & $\mathrm{~m}$ & Uniform \\
\hline HX Thickness (PHX) & TH3 & 0.001 & 0.003 & $\mathrm{~m}$ & Uniform \\
\hline HX Temperature (IHX) & T1 & 1060 & 1060 & $\mathrm{~K}$ & Constant \\
\hline HX Temperature (SHX) & T2 & 999 & 999 & $\mathrm{~K}$ & Constant \\
\hline HX Temperature (PHX) & T3 & 981 & 981 & $\mathrm{~K}$ & Constant \\
\hline Temperature Level & CTL & 0.95 & 1.05 & $\#$ & Uniform \\
\hline HX activation energy (IHX) & EA1 & $5.19 \mathrm{E}+04$ & $6.4 \mathrm{E}+04$ & $\mathrm{~J} / \mathrm{mol}$ & Uniform \\
\hline HX activation energy (SHX) & EA2 & $5.19 \mathrm{E}+04$ & $6.4 \mathrm{E}+04$ & $\mathrm{~J} / \mathrm{mol}$ & Uniform \\
\hline HX activation energy (PHX) & EA3 & $5.19 \mathrm{E}+04$ & $6.4 \mathrm{E}+04$ & $\mathrm{~J} / \mathrm{mol}$ & Uniform \\
\hline
\end{tabular}

\section{Tritium source}

Tritium sources in the reactor system are the most important; however, they are quantitatively very uncertain parameters in the tritium modeling. The tritium sources are significantly affected by impurities $\left({ }^{6} \mathrm{Li},{ }^{7} \mathrm{Li}{ }^{10} \mathrm{~B},{ }^{3} \mathrm{He} \ldots\right)$, neutron flux, reactor power, adsorption, etc. In our modeling, these parameters were determined based on the previous HTGR experience. Previous calculation results and data on the tritium birth rate are well summarized by Ohashi and Sherman (2007) including the following reactors: Peach Bottom (USA), Fort St. Vrain (USA), PNP-500 MWt (Germany), and England's 1500-MWt HTGR (UK). All those data are listed in Tables 5-5 and 5-6, and shows that the tritium birth rate per unit of power (MWt) ranges from $2.14 \times 10^{11}$ to $4.28 \times 10^{11} \mathrm{~Bq} / \mathrm{y} / \mathrm{MWt}$. The following are the reported and estimated tritium birth rates:

- $2.84 \times 10^{-11} \mathrm{~Bq} / \mathrm{y} / \mathrm{MWt}$ for 3,000 MWt HTGR (Gainey, 1976)

- $2.90 \times 10^{-11} \mathrm{~Bq} / \mathrm{y} / \mathrm{MWt}$ for Peach Bottom (Wichner and Dyer, 1979)

- $3.10 \times 10^{-11} \mathrm{~Bq} / \mathrm{y} / \mathrm{MWt}$ for Fort St. Vrain (Compere et al., 1974) 
- $3.83 \times 10^{-11} \mathrm{~Bq} / \mathrm{y} / \mathrm{MWt}$ for PNP-500 MWt (Steinwartz et al., 1984)

- $4.28 \times 10^{-11} \mathrm{~Bq} / \mathrm{y} / \mathrm{MWt}$ for England's 1,500-MWt HTGR (Forsyth, 1974).

The tritium release ratio was determined from the three reference values previously reported: (1) the Peach Bottom reactor, (2) Fort St. Vrain, and (3) the TRITGO code. The reported tritium release ratios are 0.32 for the Peach Bottom reactor, 0.2 for Fort St. Vrain reactor, and 0.1 for the TRITGO code. The TRITGO code was originally developed at ORNL to access tritium production and distribution in HTGRs (Compare 1974).

\section{Mass flow into the purification system}

The mass flow into the purification system was determined to be $12 \sim 20 \% / \mathrm{h}$ of the total helium inventory in each loop. The numbers 12 and 20\%/h are based on the Peach Bottom reactor (Wichner and Dyer, 1979) and the Fort St. Vrain reactor (Compere et al., 1974), respectively. According to those values, the fractions of mass flow into the purification systems are $7.38 \times 10^{-5}, 7.31 \times 10^{-5}$, and $1.11 \times 10^{-4}$ in the primary, the secondary, and the IHTL sides, respectively. 


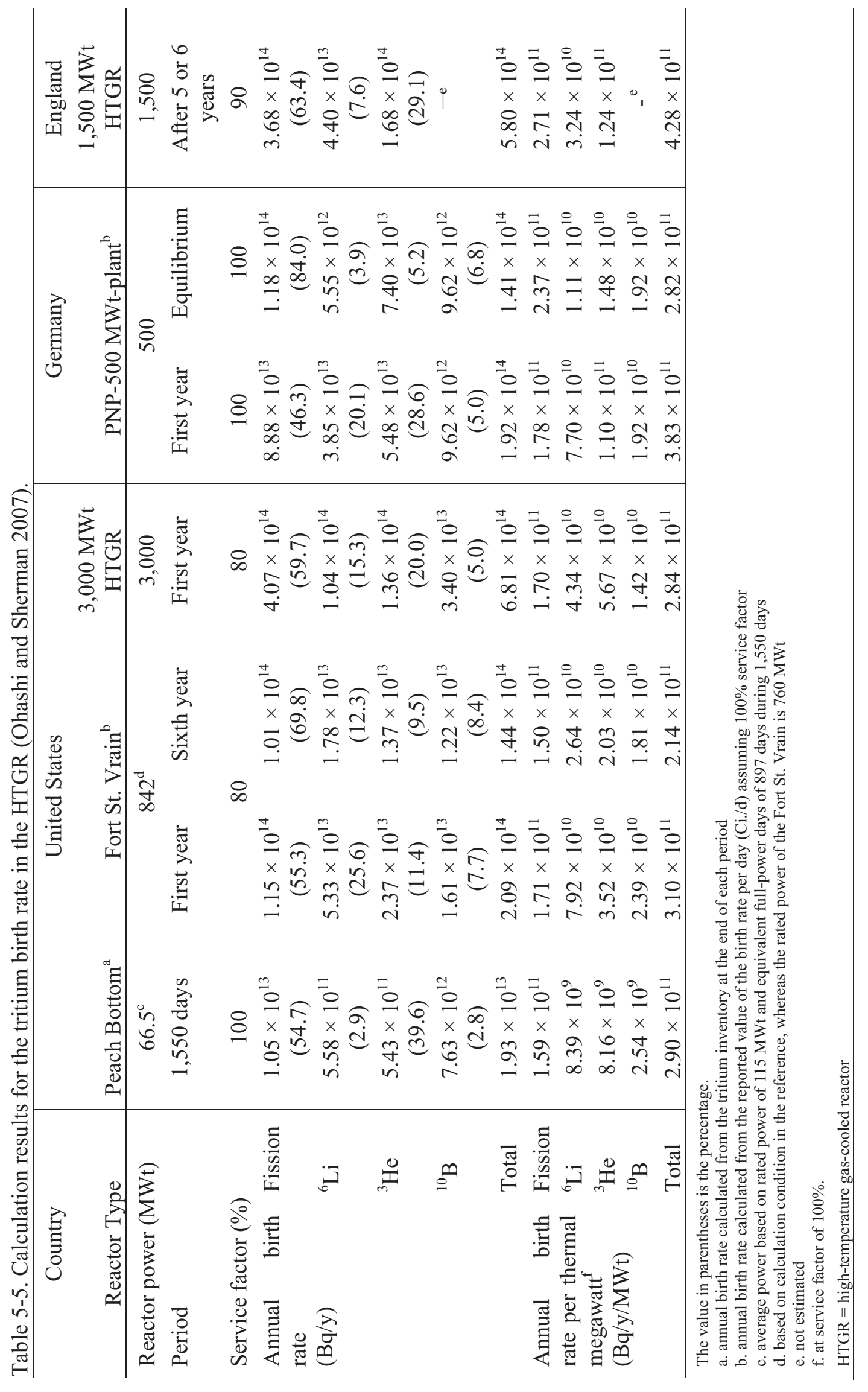




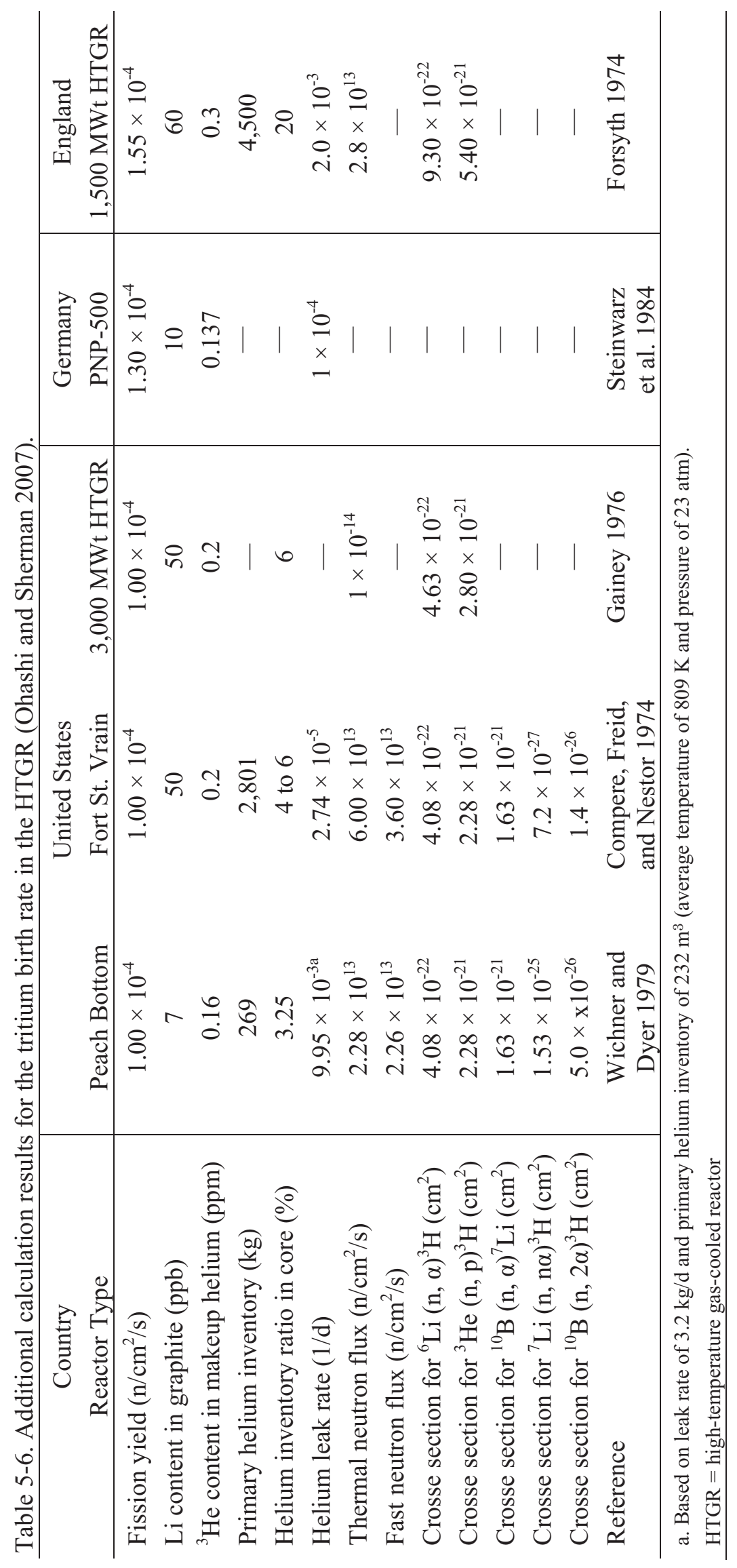




\section{Tritium Permeation Parameters}

The tritium permeation coefficients and activation energies for permeation through the HX materials were determined based on the reported Alloy 800/800H material data.

Figure 5-5 shows the permeation rates of hydrogen and tritium as a function of the inverse temperature of the heat exchanger surface. The top three lines are "laboratory experimental data" from Buckkremer et al. (1978), Rohirig et al. (1975), and INL by Calderoni \& Ebner (2010), respectively. The bottom two lines are "Peach Bottom data" from Yang, Baugh, and Baldwin (1977), and Richards et al. (2006), respectively. The heat exchanger material for Buchkremer data in Figure 5-5 was Alloy 800H. Calderoni \& Ebner (2010) also collected hydrogen permeation using Alloy $800 \mathrm{H}$ and Inconel 617. The permeation rate of the Inconel 617 lies between the top line (Buchkremer et al. (1978)) and the third line (Calderoni \& Ebner (2010).

Yang, Baugh, and Baldwin (1977) reported tritium permeation data for the superheater, evaporater, and economizer of the Peach Bottom reactor. They measured tritium permeation rate after removing surface films formed during reactor operation. Tritium permeation data was also reported by Richards et al. (2006) based on the Peach Bottom steam generator materials. Permeability reported by Richards et al. (2006) includes the effect of surface film formed by steam. Besides the Peach Bottom material test data, many laboratory experiments were also conducted using pure Alloy $800 \mathrm{H}$ material under well controlled environment (Rohirig et al. (1975), Buchkremer et al. (1978), and Calderoni \& Ebner (2010)). This study considered both Peach Bottom experimental data and Lab experimental data for conservative analyses. As shown in this figure, the hydrogen isotope permeation data are widely spread by $2 \sim 3$ order of magnitude between Peach Bottom data and Lab experimental data. In the real VHTR operations, oxide films are formed on the surface of the heat exchangers decreasing tritium permeation rates. Generally, oxide film is known to reduce tritium permeation rates, significantly, by 1 3 orders of magnitudes (Sherman and Adams, 2008). However, oxide films can spall during thermal cycling exposing bare metal. Nevertheless, it should be noted that using the laboratory experimental data (without oxide film) is very conservative approach for analysis of tritium in the VHTR integrated system. The hydrogen concentration in the coolant was assumed to be 10 ppm based on the Peach Bottom reactor (Burnette and Baldwin et al.; 1980).

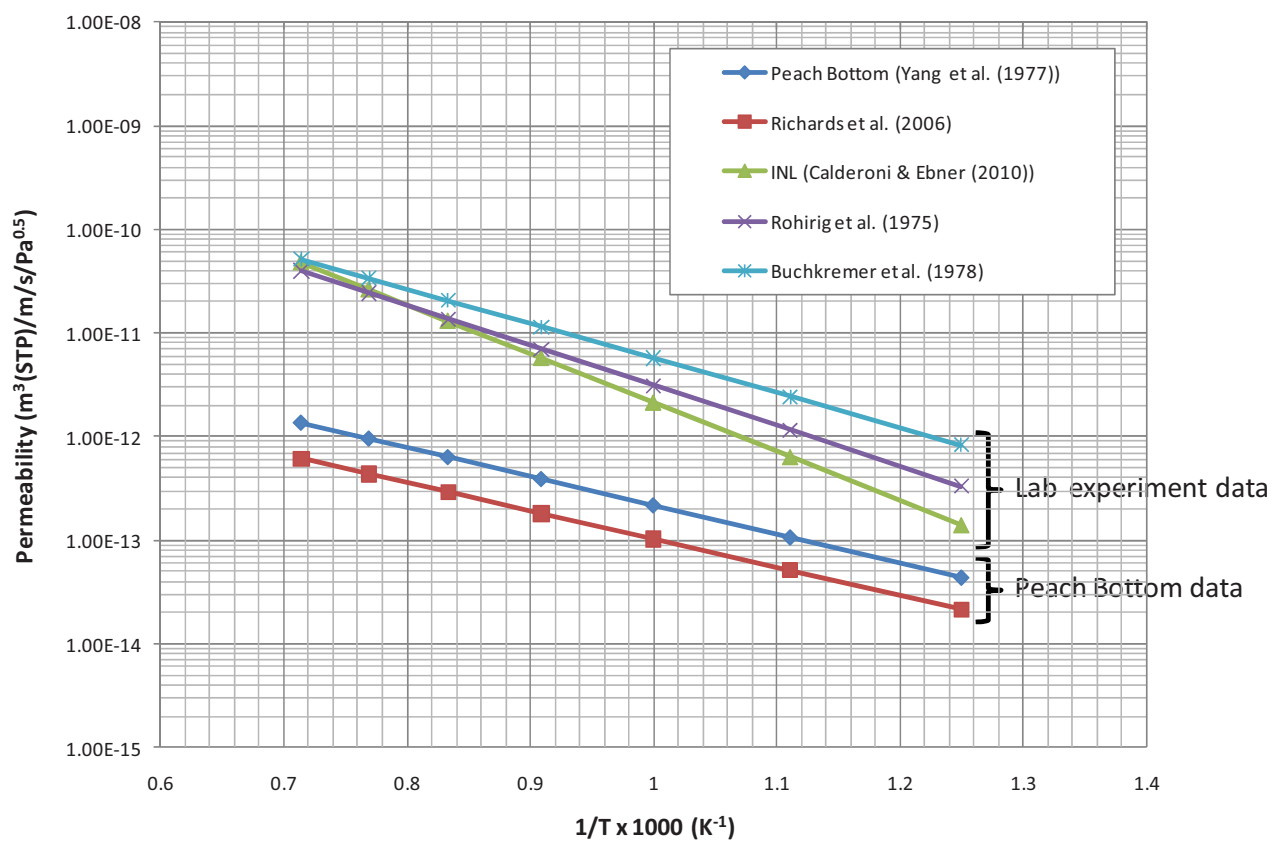

Figure 5-5. Permeability of hydrogen isotopes through Incoloy $800 / 800 \mathrm{H}$. 


\section{Heat Exchanger Temperature Level}

In this analysis, the system component temperatures were set to be constant during the operation. However, the HX surface temperatures were determined between 95 and $105 \%$ of the operating temperatures by using the multiplication factors (CTL, defined in Table 5-3).

\section{Number of Sample Cases}

In this study, the following six different sampling numbers were taken into considerations for solution convergence check. Sampling method for the SOBOL algorithm is explained, in detail, by Saltelli et al. (2004).

- $\quad$ Case 1: 490 samples

- $\quad$ Case 2: 960 samples

- $\quad$ Case 3: 1,920 samples

- $\quad$ Case 4: 3,840 samples

- Case 5: 7,680 samples

- $\quad$ Case 6: 15,360 samples.

\subsubsection{Model Evaluation}

For evaluations of the model, generated input datasets were implemented into the TPAC code. Since the number of datasets was too large - more than 15,000 - it was almost impossible to evaluate all the datasets one by one, manually. For this reason, a MATLAB script was developed, which coupled the MATLAB workspace parameters with the TPAC code parameters in the SIMULINK Model Explorer. The MATLAB script can be seen in Appendix B at the end of this report with the source code. Finally, four output results were evaluated here including tritium concentrations in the primary, secondary, and intermediate heat transfer loops and in the hydrogen product.

\subsubsection{Results and Discussions}

The evaluation and the analysis results on the tritium concentrations in the hydrogen product are discussed in this section. The results include means, standard deviations, percentiles (5\% and 95\%), convergence of the results, probability distribution, and cumulative distributions. The following are mainly discussed here:

- Tritium concentration in the hydrogen product

- Tritium distribution in the VHTR/HTSE system

- Identification of important parameters affecting tritium behaviors in the system.

\section{Tritium concentration in the hydrogen product}

Table 5-7 summarizes the means, standard deviations, and percentiles for different sample numbers. Figure 5-6 plots the data. The error bars at the points represent the 5\% and $95 \%$ percentiles. This means that $90 \%$ of the calculation results are located within this error bar. As shown in Figure 5-6, the means and the standard deviations are well converged after 3,840 samples (i.e., Case 4). According to the final results, the concentration in the product hydrogen is estimated to be $5.63 \times 10^{-2}\left(\mathrm{~Bq} / \mathrm{cm}^{3}\right)$ with $2.69 \times 10^{-2}$ $(\sim 54 \%)$ in standard deviation. In this case, $90 \%$ of the estimated tritium concentration ranges between $1.76 \times 10^{-12}$ and $1.03 \times 10^{-1}$ 
Table 5-7. Means, standard deviations, and percentiles of the tritium concentrations $\left(\mathrm{Bq} / \mathrm{cm}^{3}\right)$ in the product hydrogen.

\begin{tabular}{|ccccc|}
\hline & Mean & Std & $\mathbf{5 \%}$ & $\mathbf{9 5 \%}$ \\
\hline 490 & $5.73 \mathrm{E}-02$ & $2.57 \mathrm{E}-02$ & $2.06 \mathrm{E}-02$ & $9.76 \mathrm{E}-02$ \\
\hline 960 & $5.69 \mathrm{E}-02$ & $2.58 \mathrm{E}-02$ & $1.71 \mathrm{E}-02$ & $9.98 \mathrm{E}-02$ \\
\hline 1920 & $5.55 \mathrm{E}-02$ & $2.63 \mathrm{E}-02$ & $1.73 \mathrm{E}-02$ & $1.05 \mathrm{E}-01$ \\
\hline 3840 & $5.61 \mathrm{E}-02$ & $2.64 \mathrm{E}-02$ & $1.79 \mathrm{E}-02$ & $1.03 \mathrm{E}-01$ \\
\hline 7680 & $5.63 \mathrm{E}-02$ & $2.68 \mathrm{E}-02$ & $1.76 \mathrm{E}-02$ & $1.03 \mathrm{E}-01$ \\
\hline 15360 & $5.63 \mathrm{E}-02$ & $2.69 \mathrm{E}-02$ & $1.76 \mathrm{E}-02$ & $1.03 \mathrm{E}-01$ \\
\hline
\end{tabular}

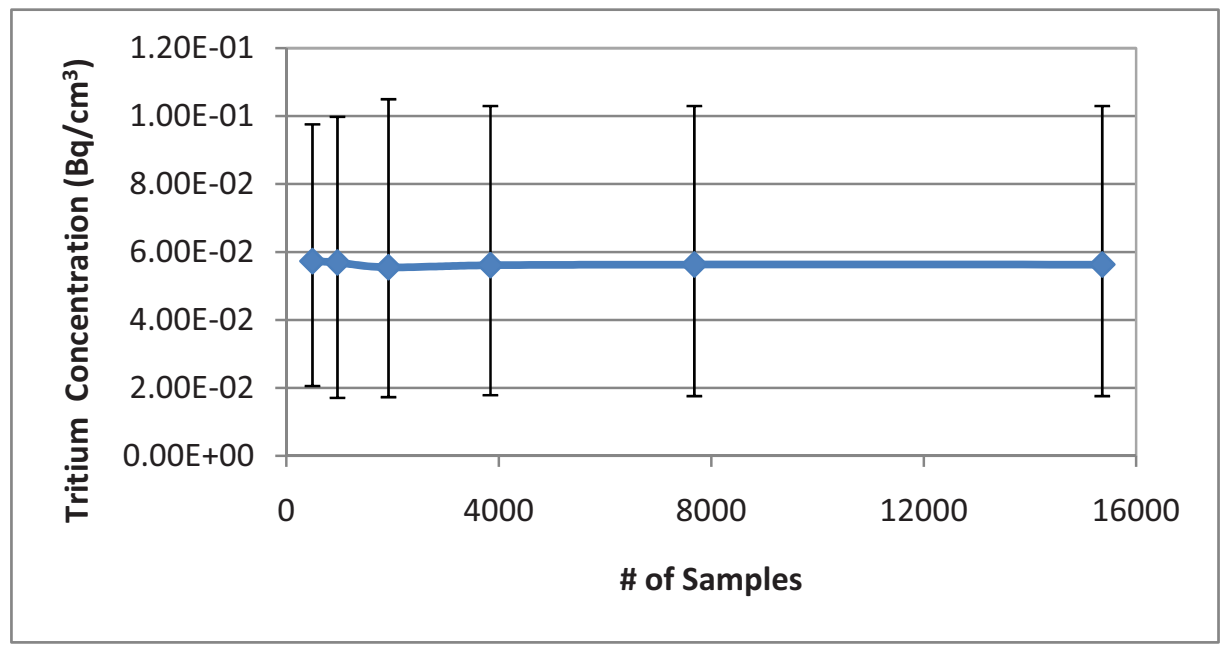

Figure 5-6. Tritium concentration in the product hydrogen.

Figures 5-7 and 5-8 show the probability and cumulative distributions of the tritium in the product hydrogen. These graphs are based on the data of the Case 6 (15,360 samples). According to the results (See Figure 5-7 (a)), the tritium concentration in the product hydrogen is widely distributed based on the selected input parameters. About $1 \%$ of the samples are within the effluent limit $\left(3.7 \times 10^{-3}\right.$ $\left.\mathrm{Bq} / \mathrm{cm}^{3}[\mathrm{STP}]\right)$, and the remaining $99 \%$ exceeds the effluent limit. It indicates that the system requires very high capacity for the purification system or excellent tritium barriers on the heat transfer surfaces. Recent extensive reviews on the tritium barrier studies (Sherman and Adams, 2008) describes that oxide layers produced in-situ or ceramic coating layers can significantly reduce tritium permeation through the HX surface by a factor of 10 to over 10,000. Therefore, effects of tritium barriers and purification system need to be investigated later in the future studies. For comparisons, the results based on only Peach Bottom material data are plotted in the Figure 5-7 (b). According to this analysis, about $25 \%$ of the samples are within the effluent limit. 


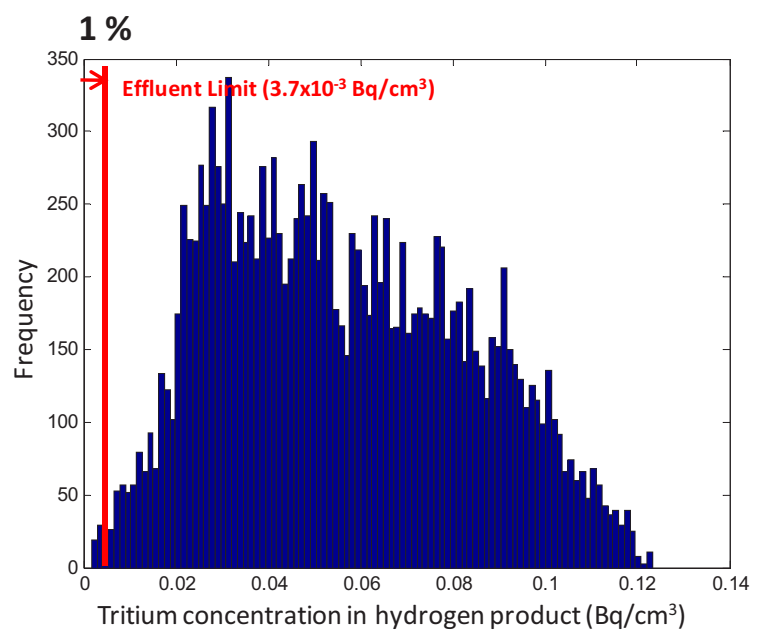

(a) Using Peach Bottom Data and Lab Experiment Data

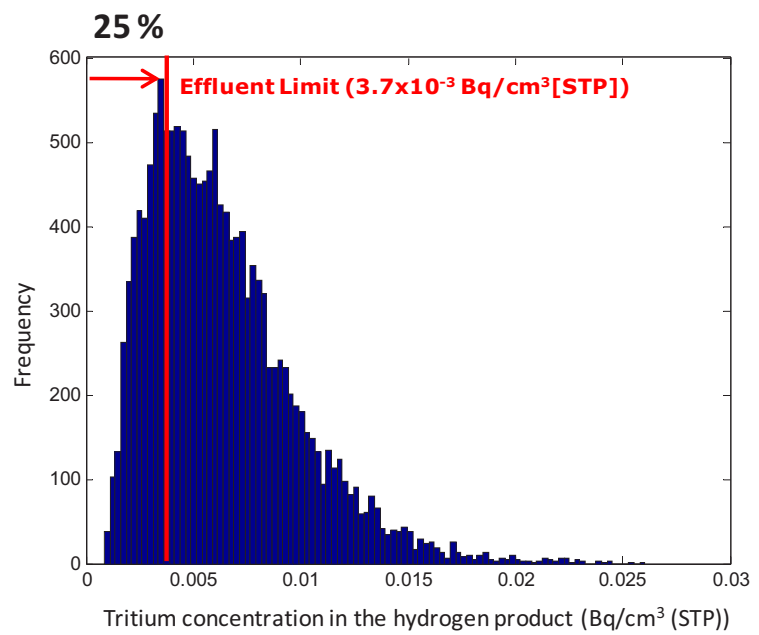

(b) Using Peach Bottom Data

Figure 5-7. Frequency distribution of the tritium concentrations in the hydrogen product (15,360 samples) without tritium barriers applied.

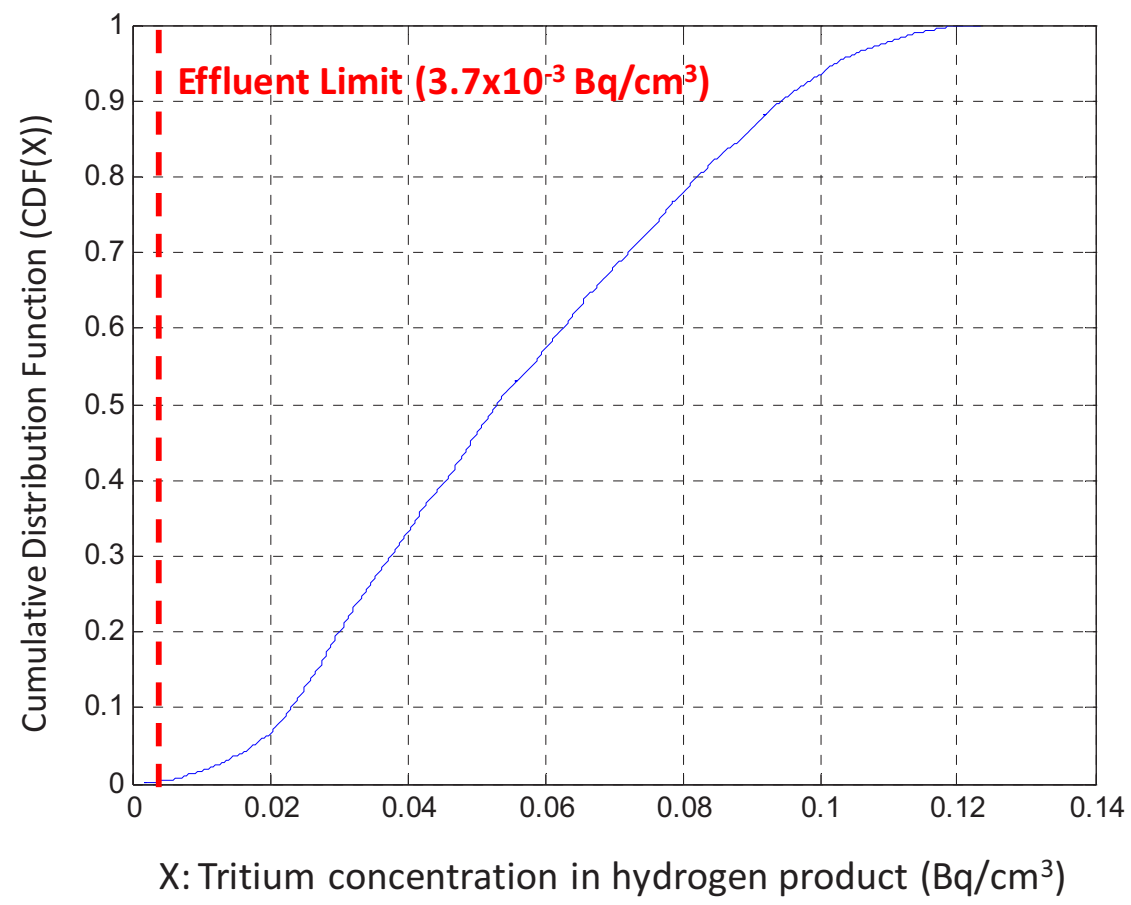

Figure 5-8. Cumulative distribution function (CDF) of tritium concentrations in the hydrogen product.

\section{Tritium distribution in the VHTR/HTSE system}

Figure 5-9 illustrates the estimated tritium distributions in the VHTR/HTSE system for the reference conditions based on the averaged values (mean values in Table 5-7). Tritium release from the core in Figure 5-9 is assumed to be $21 \%$ in the tritium birth. The rest of $79 \%$ was assumed to be retained in the core. 
As shown in Figure 5-9, about $2 \%$ of the released tritium from the core (based on the assumption of a $100 \%$ tritium release from the core) is removed by the purification system installed in the primary side. About $19 \%$ of the tritium is transferred to the secondary side through the HX wall. Only $0.1 \%$ of tritium is released to the containment (or confinement) by helium leakage. In the secondary side, the majority of the tritium (17\%) is transferred to IHTL. Of the tritium released from the core, $16 \%$ is transferred to the IHTL through the HX. In the intermediate loop, $0.1 \%$ of the tritium released from the core is removed by the purification system. About $6 \%$ of the tritium released from the core is transferred to the product hydrogen. According to the calculation results, the purification systems in the primary and secondary system looks the most important for tritium transfer removal and distribution in the system. The effect of leakage out of the system looks negligible, which is less than $0.2 \%$ in total. However, the tritium distribution and behaviors are significantly affected by system conditions and designs such as temperature, HX size, purification system capacity, system configuration, etc. Therefore, the current results should be carefully interpreted for other system conditions and options.

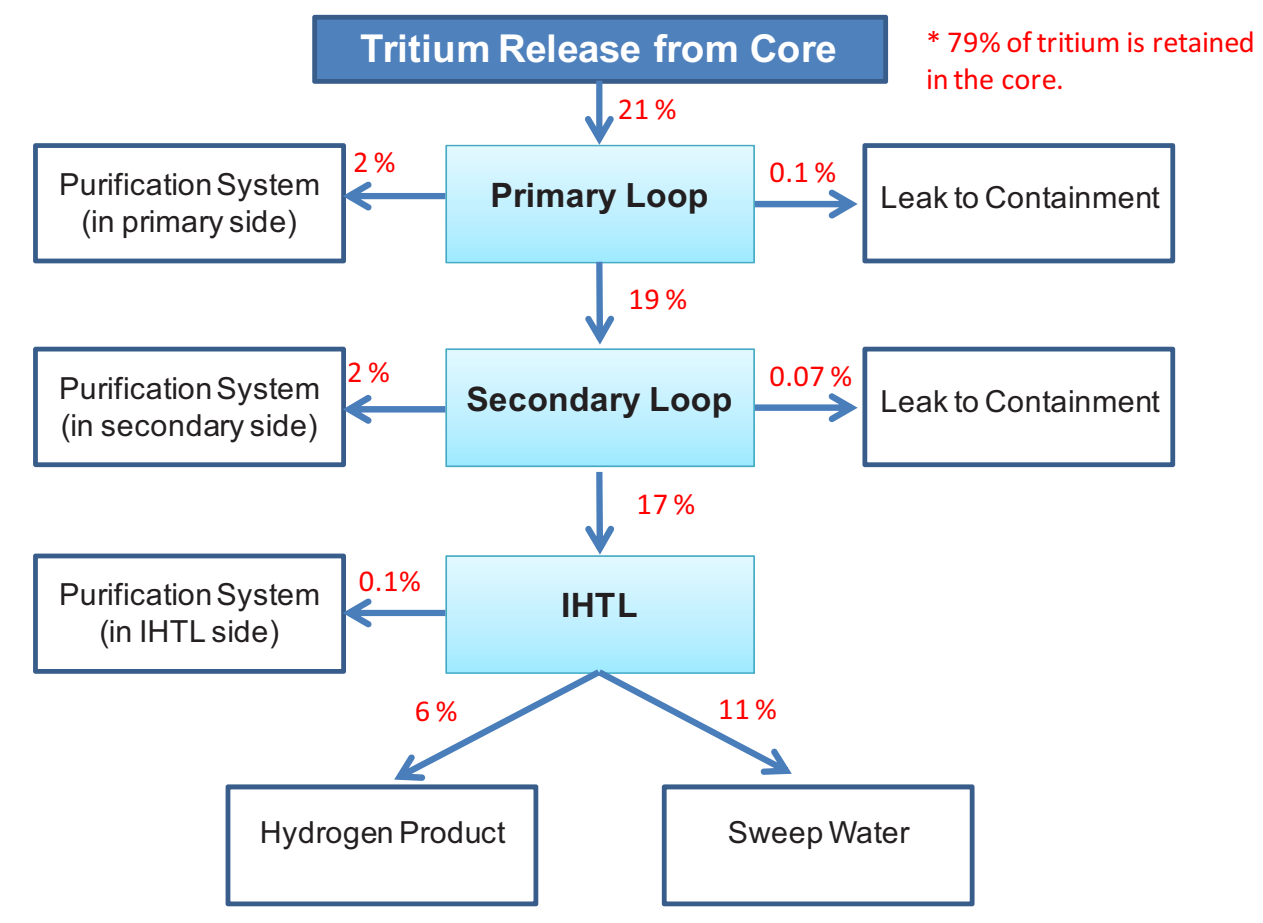

Figure 5-9. Tritium distribution in the VHTR/HTSE system.

\section{Important Parameters Affecting Tritium Behaviors in the VHTR/HTSE system}

This section summarizes the sensitivity analysis results. There are two sensitivity indices used here for measuring importance: (1) the first-order index and (2) the total index.

\section{A. Main Effect (First-order Sensitivity Index)}

The first-order index represents the main effect of the parameter. This index includes no interaction effects with other parameters. Table 5-8 summarizes the first-order indices of the 14 input parameters. Figure 5-10 plots the data and clearly shows that the sensitivity indices are getting converged to certain values as the number of samples increases. According to the definition and the physical meaning, the sensitivity indices should be always positive values. Therefore, the cases for 490 and 960 samples results in unreliable estimations, which originated from insufficient sample numbers to capture the sensitivity. 
Table 5-8. First-order sensitivity index (for the tritium concentration in the product hydrogen).

\begin{tabular}{|l|c|c|c|c|c|c|}
\multicolumn{1}{|c}{ Parameter } & $\mathbf{9 9 0}$ & $\mathbf{9 6 0}$ & $\mathbf{1 9 2 0}$ & $\mathbf{3 8 4 0}$ & $\mathbf{7 6 8 0}$ & $\mathbf{1 5 3 6 0}$ \\
\hline Tritium Source & 0.80 & 0.79 & 0.69 & 0.65 & 0.63 & 0.62 \\
\hline $\begin{array}{l}\text { Fraction of Mass Flow to } \\
\text { Purification System (P-1st) }\end{array}$ & 0.01 & 0.01 & 0.01 & 0.01 & 0.00 & 0.00 \\
\hline $\begin{array}{l}\text { Fraction of Mass Flow to } \\
\text { Purification System (P-2nd) }\end{array}$ & 0.00 & 0.00 & 0.00 & 0.00 & 0.00 & 0.00 \\
\hline $\begin{array}{l}\text { Fraction of Mass Flow to } \\
\text { Purification System (P-3rd) }\end{array}$ & 0.00 & 0.00 & 0.00 & 0.00 & 0.00 & 0.00 \\
\hline Reaction Coefficient (IHX) & 0.00 & 0.00 & 0.01 & 0.01 & 0.00 & 0.01 \\
\hline Reaction Coefficient (SHX) & -0.01 & 0.15 & 0.14 & 0.12 & 0.11 & 0.10 \\
\hline Reaction Coefficient (PHX) & 0.16 & 0.11 & 0.21 & 0.22 & 0.18 & 0.17 \\
\hline HX Thickness (IHX) & 0.00 & 0.00 & 0.00 & 0.00 & 0.00 & 0.00 \\
\hline HX Thickness (SHX) & 0.01 & 0.03 & 0.02 & 0.02 & 0.01 & 0.01 \\
\hline HX Thickness (PHX) & -0.01 & 0.02 & -0.01 & 0.00 & 0.01 & 0.01 \\
\hline Temperature Level & 0.00 & 0.01 & 0.01 & 0.00 & 0.00 & 0.00 \\
\hline HX activation energy (IHX) & 0.00 & 0.00 & 0.00 & 0.00 & 0.00 & 0.00 \\
\hline HX activation energy (SHX) & 0.04 & 0.05 & 0.01 & 0.02 & 0.01 & 0.01 \\
\hline HX activation energy (PHX) & 0.05 & 0.03 & 0.02 & 0.04 & 0.02 & 0.02 \\
\hline
\end{tabular}

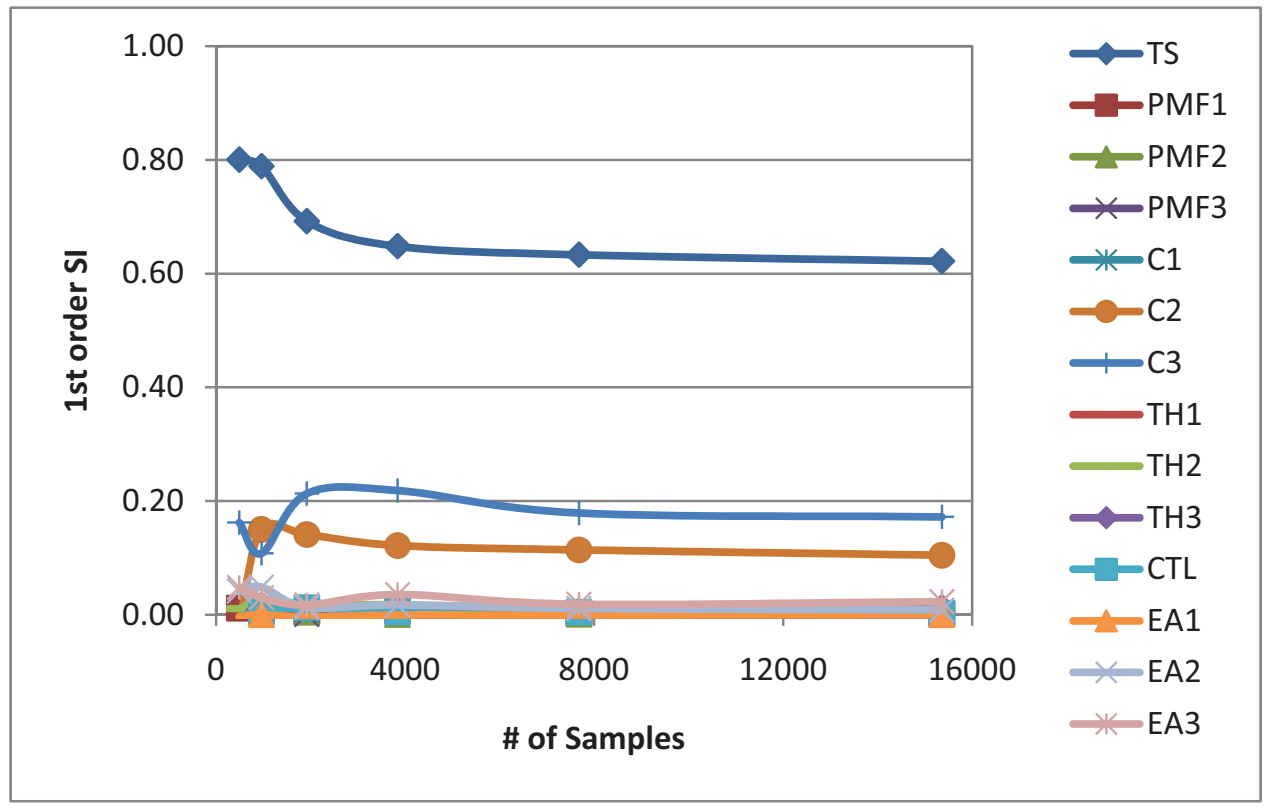

Figure 5-10. First-order index with sample numbers.

\section{B. Total Effect (Total Index)}

The total index represents the total effect including the main effect and the interactions. Table 5-9 summarizes the total indices of the 14 sensitivity parameters for six different numbers of samples. Figure 5-11 plots these data and clearly shows that the sensitivity indices are well converged to certain values as the number of samples increases. According to the data, the cases for 490 and 960 samples shows negative indices, which are unreliable estimations that originated from insufficient sample numbers. 
Table 5-9. Total index (for the tritium concentration in the product hydrogen).

\begin{tabular}{|l|c|c|c|c|c|c|}
\multicolumn{1}{r}{ Parameter } & \multicolumn{7}{c}{ Sample Numbers } \\
& $\mathbf{4 9 0}$ & $\mathbf{9 6 0}$ & $\mathbf{1 9 2 0}$ & $\mathbf{3 8 4 0}$ & $\mathbf{7 6 8 0}$ & $\mathbf{1 5 3 6 0}$ \\
\hline Tritium Source & 0.86 & 0.79 & 0.72 & 0.70 & 0.67 & 0.67 \\
\hline $\begin{array}{l}\text { Fraction of Mass Flow to } \\
\text { Purification System (P-1st) }\end{array}$ & 0.02 & 0.01 & 0.01 & 0.01 & 0.00 & 0.00 \\
\hline $\begin{array}{l}\text { Fraction of Mass Flow to } \\
\text { Purification System (P-2nd) }\end{array}$ & 0.00 & 0.01 & 0.01 & 0.00 & 0.00 & 0.00 \\
\hline $\begin{array}{l}\text { Fraction of Mass Flow to } \\
\text { Purification System (P-3rd) }\end{array}$ & 0.00 & 0.00 & 0.00 & 0.00 & 0.00 & 0.00 \\
\hline Reaction Coefficient (IHX) & 0.00 & 0.00 & 0.01 & 0.01 & 0.00 & 0.00 \\
\hline Reaction Coefficient (SHX) & -0.05 & 0.11 & 0.15 & 0.13 & 0.12 & 0.13 \\
\hline Reaction Coefficient (PHX) & 0.25 & 0.18 & 0.25 & 0.27 & 0.21 & 0.21 \\
\hline HX Thickness (IHX) & 0.00 & 0.00 & 0.00 & 0.00 & 0.00 & 0.00 \\
\hline HX Thickness (SHX) & 0.01 & 0.01 & 0.03 & 0.02 & 0.01 & 0.01 \\
\hline HX Thickness (PHX) & -0.09 & -0.01 & -0.02 & 0.00 & 0.01 & 0.01 \\
\hline Temperature Level & 0.01 & 0.02 & 0.01 & 0.01 & 0.01 & 0.00 \\
\hline HX activation energy (IHX) & 0.00 & 0.00 & 0.00 & 0.00 & 0.00 & 0.00 \\
\hline HX activation energy (SHX) & 0.04 & 0.05 & 0.02 & 0.01 & 0.01 & 0.02 \\
\hline HX activation energy (PHX) & 0.00 & 0.01 & 0.00 & 0.03 & 0.03 & 0.03 \\
\hline
\end{tabular}

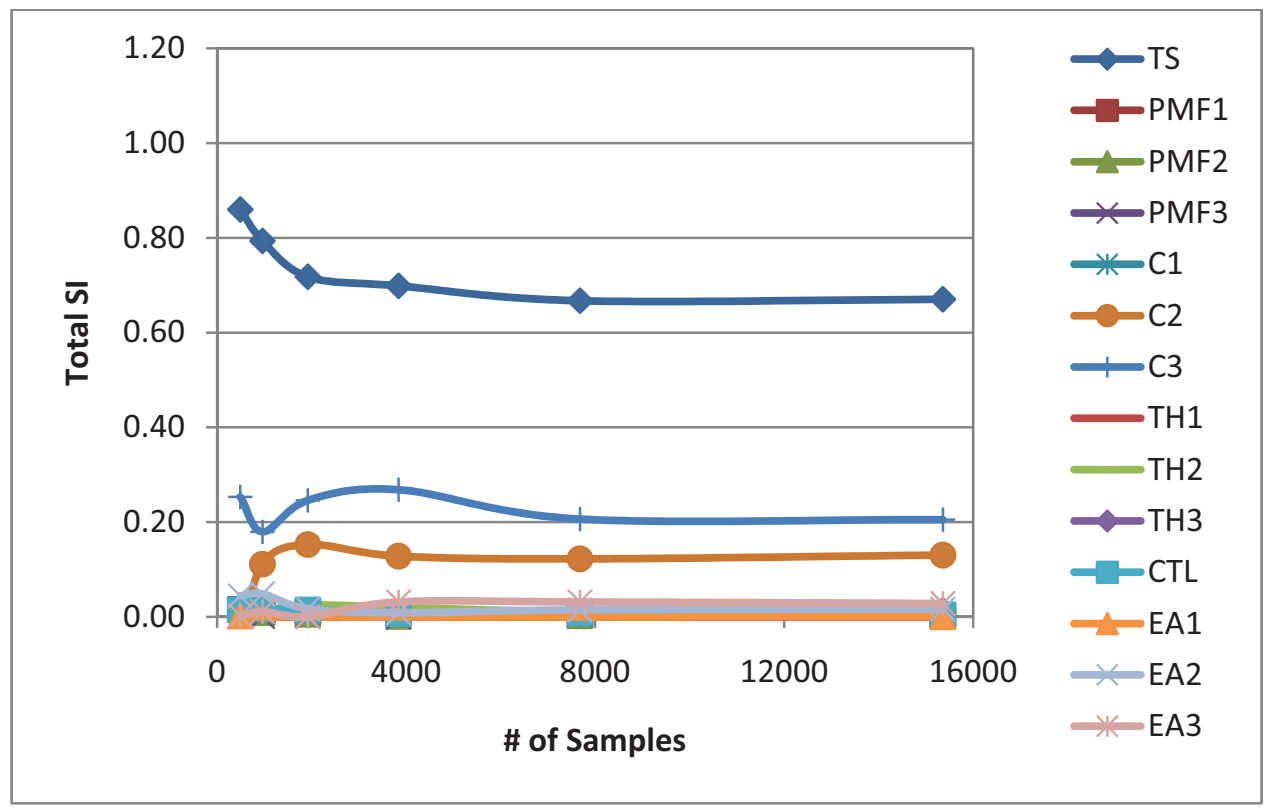

Figure 5-11. Total index with sample numbers.

\section{Interpretation of the Results}

Valuable information can be obtained from the sensitivity indices. This study interpreted the results from two different perspectives. One is associated with uncertainty reduction in the model, while the other is associated with the lowering of the tritium level in the hydrogen product. Regarding the uncertainty reduction, we will consider what the most effective way is for reducing modeling uncertainties, which will eventually lead us to more design and safety margins. Moreover, we will also 
realize what should be investigated to reduce uncertainties for the future, which is the main interest of the modelers. Finally, we will provide some useful ideas for effectively reducing the tritium level in the hydrogen product, which is the main interest of the system designer and end users.

Figures 5-12 and 5-13 illustrate the relative importance of various input parameters on the tritium concentrations in the hydrogen product. According to these figures, the tritium source (TS) looks the most important parameter. The first-order index and the total index of this parameter are 0.62 and 0.67 , respectively. It indicates that $62 \%$ of the total uncertainty is contributed from the uncertainty of the tritium source, while $5 \%$ of the uncertainty is associated with interactions with this parameter.

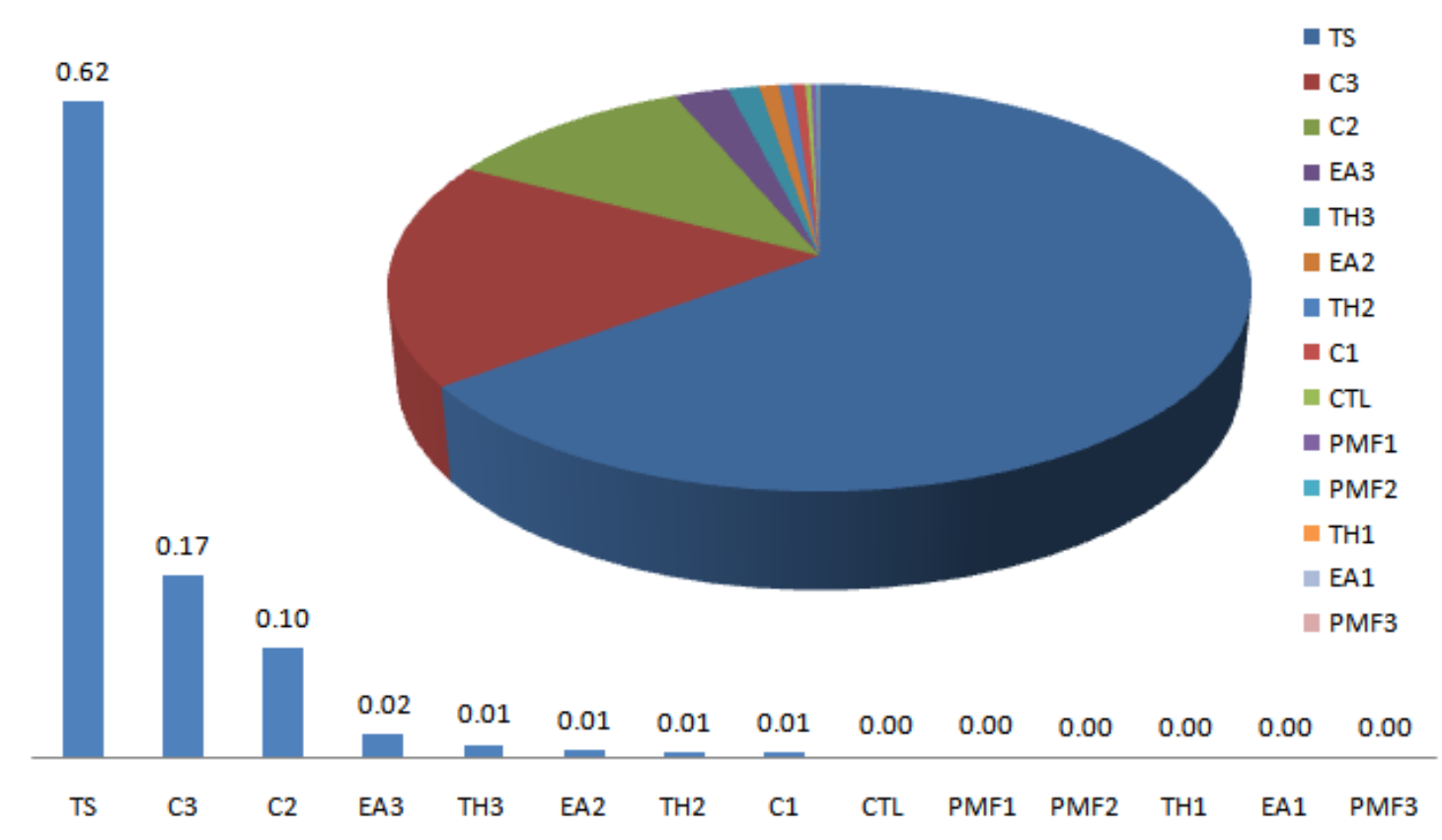

Figure 5-12. First-order index (tritium concentration in the product hydrogen). 


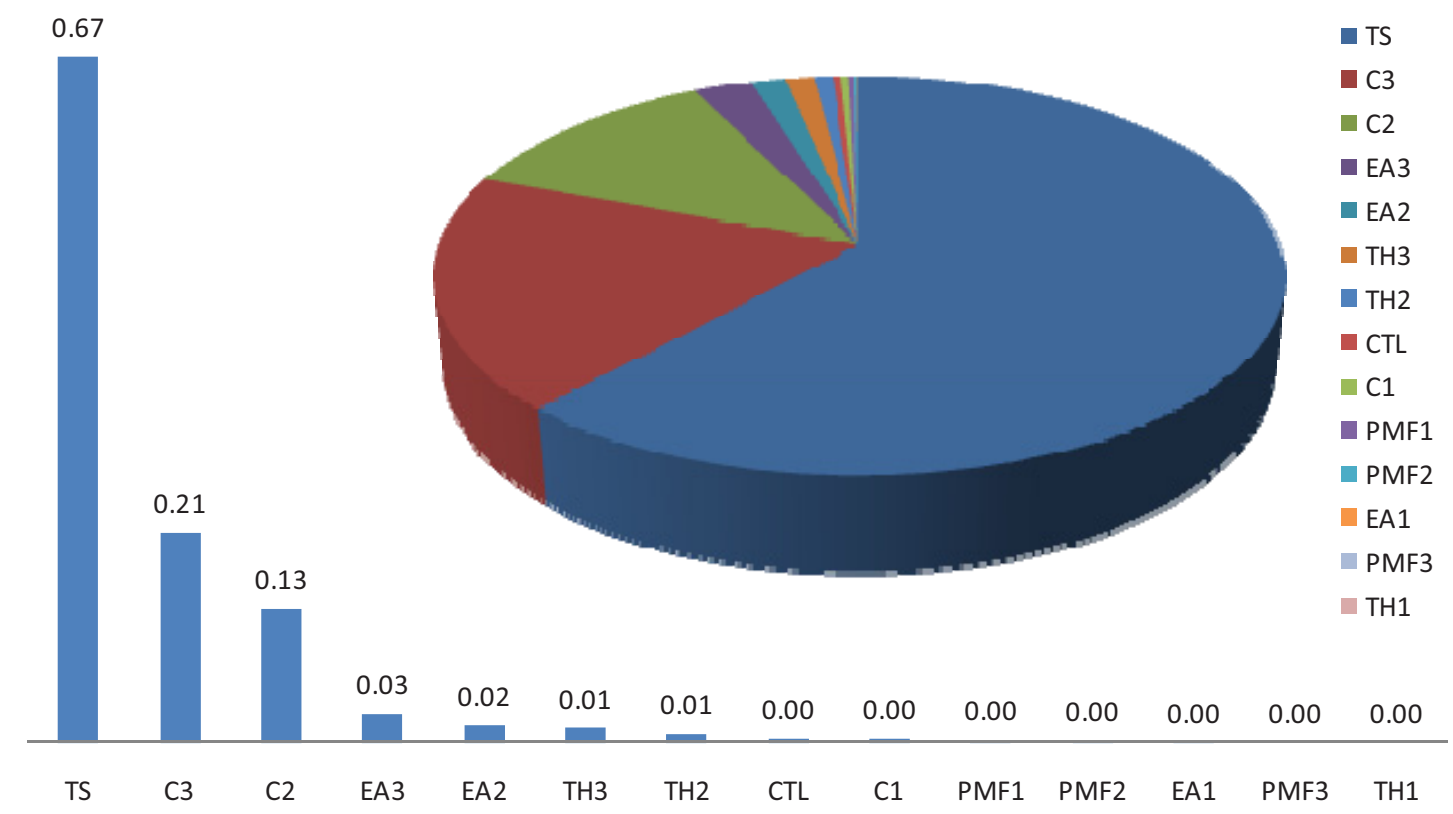

Figure 5-13. Total index (tritium concentration in the product hydrogen).

The largest first order TS index shows that if the TS uncertainty is reduced, the total modeling uncertainty can be dramatically reduced. Therefore, further researches and efforts are strongly recommended to be focused on reducing the uncertainties of tritium birth and release from the core to improve the modeling accuracies.

The large total TS index indicates that controlling this parameter is very effective to reduce the tritium concentration in the product hydrogen. According to Wichner and Dyer (1979) and Ohashi and Sherman (2007), the most important source of the TSs are ternary fission in the core and ${ }^{3} \mathrm{He}$ neutron reactions in the coolant. There are also two factors associated with the TS: tritium birth and tritium release. Technically, controlling tritium birth is almost impossible for the given reactor design, but it seems to be possible to control the release rate. Figure 5-15 shows that the first-order indices and the total indices are not very different from each other for this analysis. It indicates that the main effects are dominant and the interaction effects are relatively very small. 


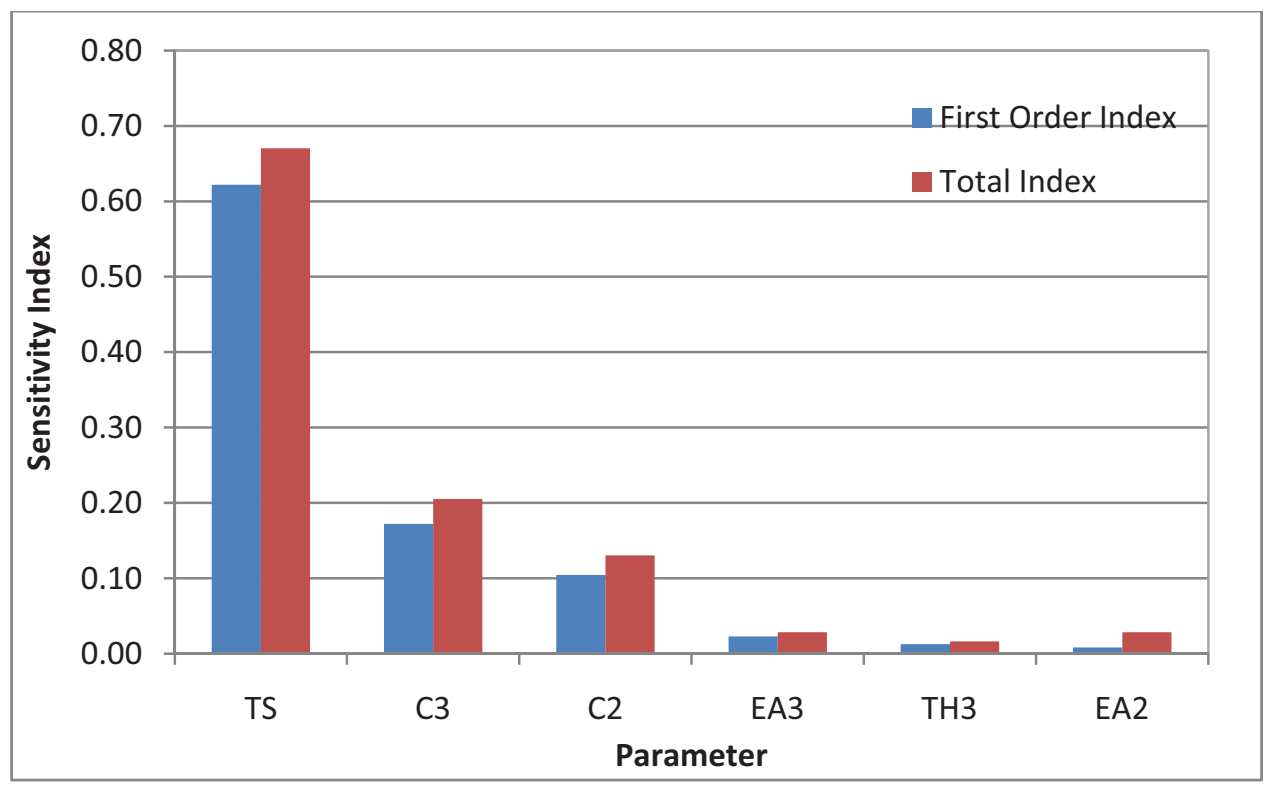

Figure 5-14. First-order indices and total indices for six major parameters.

Tritium permeation coefficients of the PHX and the SHX are the second and third most important parameters, respectively. The first-order indices are 0.17 and 0.10 , respectively. According to the results, the uncertainties (permeation coefficient, activation energy, and wall thickness) in the PHX provide about $20 \%$ of the total uncertainty. Compared to parameters in the PHX, the IHX and the SHX show relatively less importance. These results show that the HX closer to the HTSE system becomes more important. In case of the IHX, the parameters show almost negligible effect on the tritium concentration in the hydrogen product. This fact strongly recommends that our research should be more focused on the PHX characterization and improvement. According to the total indices $(0.21$ for the permeation coefficient in the PHX and 0.03 for the activation energy), improvement of tritium resistance in the PHX materials looks effective for reducing tritium concentration in the product hydrogen. The change of material or passive coating on the channel in the PHX can be effective way to improve resistance to tritium permeation. Especially since the tritium permeation is highly active at high temperatures, splitting the PHXs into two parts (a high-temperature unit and a low-temperature unit) and improving the design and material to the only high-temperature unit can be a good approach from an economical and technical point of view.

The purification system is an important component in the VHTR/HTSE system since most of the tritium is removed from this component. However, in this study, the purification system parameters (i.e., PMF1, PMF2, and PMF3) were not estimated to be sensitive to the output uncertainties under the given input ranges. This is primarily because of its very small purification capacities. In our modeling, the flow to the purification system was only about $1 \mathrm{e}-4 \sim 1 \mathrm{e}-5$ in the main flow, which are $12 \sim 20 \% / \mathrm{hr}$ of the total helium inventory. This number is determined by the previous coolant chemical control systems used in Peach Bottom reactor and Fort St. Vrain reactor. However, our results show that this helium purification system capacity is not sufficient to remove tritium in the coolant, effectively. It strongly recommends increasing purification system capacity to much higher level. However, increase of purification system capacity leads to the decrease of the system efficiency and the increase of cost. Therefore, optimization studies are also required in the future studies.

\subsubsection{Summary}

In the VHTR, tritium permeation from the core into the product hydrogen or process steam is a serious concern because the tritium can be easily permeated through high-temperature heat exchanger 
tubes contaminating coolant or product gases. In this paper, sensitivity analyses on the tritium behaviors in the VHTR/HTSE system were carried out by the TPAC code in order to study the impact of parameters on the tritium behaviors in the system. This study used SOBOL (Satelli et. al., 2004) sensitivity indices based on the Monte Carlo analysis performing multiple evaluations with randomly selected model input. Two sensitivity indices are used here: first-order index and total index. The estimations on the sensitivity indices were realized by SIMLAB software. The number of samples was selected between 490 and 15,360 for convergence study. The following summarizes the notable results and discussions of this study.

The analyses results showed that the tritium concentration in the product hydrogen is widely distributed based on the selected input parameters. About $1 \%$ of the samples are within the effluent limit $\left(3.7 \times 10^{-3} \mathrm{~Bq} / \mathrm{cm}^{3}[\mathrm{STP}]\right)$, and the remaining $99 \%$ exceeds the effluent limit. It indicates that the system requires higher purification system capacity or tritium barriers on the heat transfer surfaces. Recent extensive reviews on the tritium barrier studies (Sherman and Adams, 2008) describes how oxide layers produced in-situ or ceramic coating layers can significantly reduce tritium permeation through the HX surface by a factor of 10 to over 10,000. Therefore, it should be investigated in the future studies.

The tritium source was estimated to be the most important parameter among the 14 input parameters. The uncertainty of the tritium source contributes about $62 \%$ of the total uncertainty. Therefore, reducing the uncertainty in the tritium source is essential and the most effective way to reduce the modeling uncertainties. Reducing tritium release from the core is also considered to be the most effective way to lower the tritium level in the hydrogen product. Further studies are strongly recommended for this area.

The parameters related to the PHX were also estimated to be second in importance. About $20 \%$ of output uncertainties were contributed by these. Therefore, improvement of PHX tritium resistance is considered to be an effective way to reduce the tritium level in the hydrogen product.

The purification system was not sensitive to the output results under the given input ranges based on previous reactor designs. However, increasing purification capacity will obviously reduce the tritium level in the whole system since the most of the tritium in the system is removed by this component. However, it might lead to reduced system efficiency and increased cost. Therefore, the design on the purification system should be made from the economic perspective. Some optimization studies are recommended for the future researches. 


\subsection{Analyses on the HTGR/HTSE System}

This section discusses the tritium analyses results for the HTGR/HTSE system. This system is also a hydrogen system coupled with nuclear reactors, but it differs from the VHTR/HTSE system in detail. This system is designed to be operated at the core outlet temperature of $750^{\circ} \mathrm{C}$ with a steam Rankin cycle for power conversion. The following section describes the details.

\subsubsection{Reference System Description}

The reference system of the current study is based on the HTSE system integrated with the HTGR using the Rankin steam cycle with a $750^{\circ} \mathrm{C}$ core outlet temperature. Figures 5-15 and 5-16 show the flowsheet that INL developed (Mckellar et al. 2009). In this system, the heat and electrical power from the reactor can be used to split water using solid oxide electrolysis cells to create hydrogen and oxygen. The process heat from the reactor reduces the amount of electricity needed to split water, thus increasing the efficiency of the process when compared to low-temperature electrolysis. HYSYS process modeling software was used to model the HTGR/HTSE system. HYSYS allowed for accurate mass and energy balances and contains components like compressors, turbines, pumps, valves, and heat exchangers to simulate components in the process.

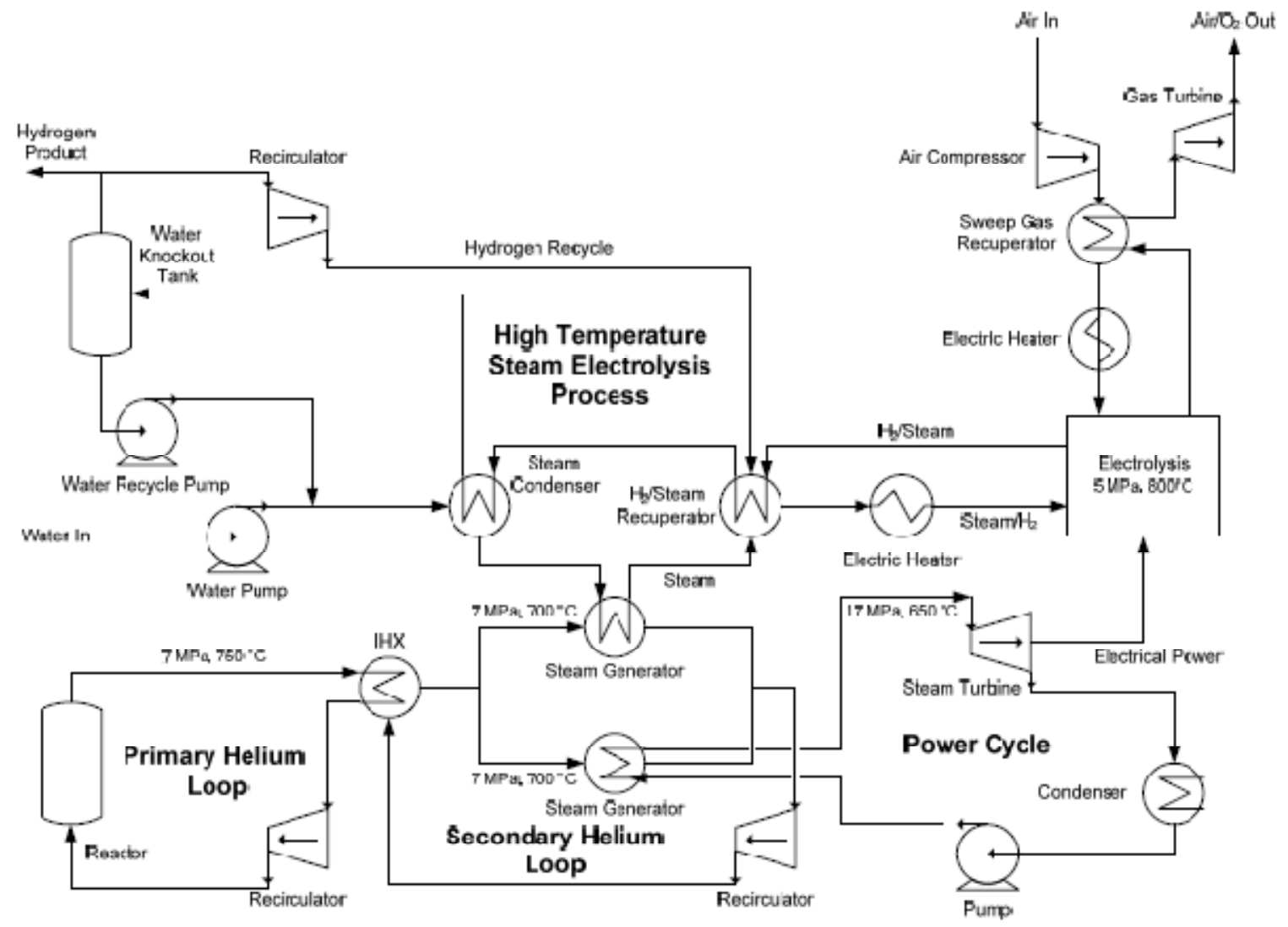

Figure 5-15. Process flow diagram of HTSE (Mckellar et al. 2009). 


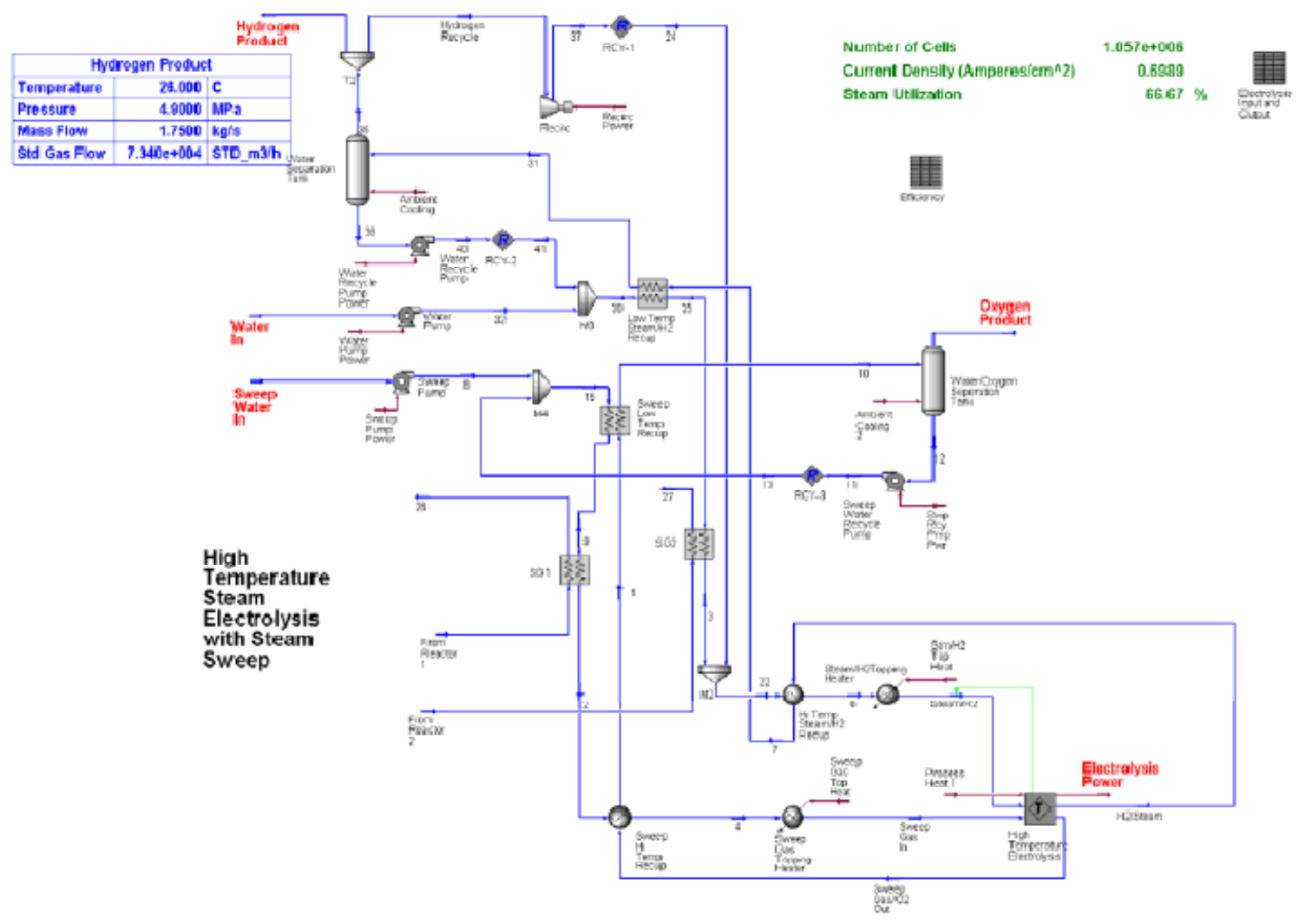

Figure 5-16. HYSYS modeling for HTSE system (Mckellar et al. 2009).

\subsubsection{TPAC Modeling}

Figure 5-17 shows the TPAC model for the reference HTGR/HTSE system. The system configuration, operating temperature, pressure, and flow rates were obtained from McKellar et al. (2009). The component volumes were assumed based on the pre-conceptual design of various VHTR systems. The IHX sizing and rating were carried out based on the helical-coil tubular heat exchanger and PCHE designs. The model consists of four different loops: (1) the primary helium loop, (2) the secondary helium loop, (3) the power cycle, and (4) the HTSE process. 


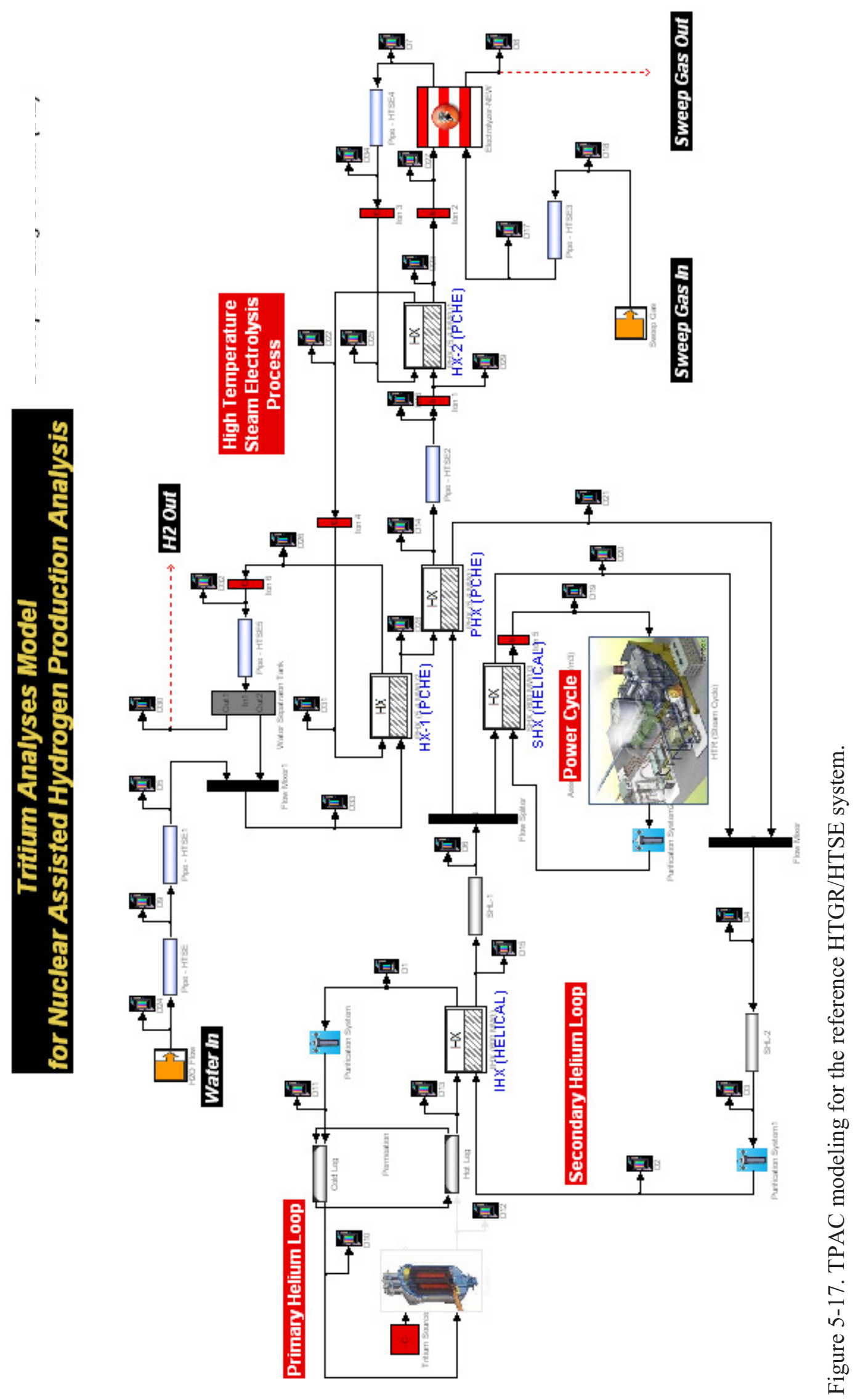




\subsubsection{Uncertainty and Sensitivity Analyses}

This section describes the uncertainty and sensitivity analyses for the HTGR/HTSE system. The analysis method is basically the same as that used in Section 5.3. First, the inputs were selected by discussion. Then, we used SIMLAB software for generating inputs. About 15,000 randomly generated input datasets were used in this analysis. The generated inputs were implemented into the TPAC code for evaluation. Based on the evaluated outputs, uncertainty results and SOBOL sensitivity indices were estimated using the SIMLAB and MATLAB codes.

\subsubsection{Input Selection}

We also selected 14 major parameters in this analysis. Table 5-10 summarizes the input parameters and their physical representations.

Table 5-10. List of input parameters for uncertainty and sensitivity analysis.

\begin{tabular}{|l|l|}
\hline Input Parameters & Representations \\
\hline TS & $\begin{array}{l}\text { Tritium release rate in the reactor core } \\
\text { side }\end{array}$ \\
\hline PMF1 & $\begin{array}{l}\text { Fraction of mass flow rates to the purification system in the } \\
\text { secondary side }\end{array}$ \\
\hline PMF2 & $\begin{array}{l}\text { Fraction of mass flow rates to the purification system in the IHTL } \\
\text { side }\end{array}$ \\
\hline PMF3 & Tritium permeation coefficient (pre-exponential factor) at the IHX \\
\hline C1 & Tritium permeation coefficient (pre-exponential factor) at the SHX \\
\hline C3 & Tritium permeation coefficient (pre-exponential factor) at the PHX \\
\hline TH1 & Thickness of the heat transfer surface wall (IHX) \\
\hline TH2 & Thickness of the heat transfer surface wall (SHX) \\
\hline TH3 & Thickness of the heat transfer surface wall (PHX) \\
\hline CTL & Fraction of operational temperature to the design condition \\
\hline EA1 & Activation energy for permeation (IHX) \\
\hline EA2 & Activation energy for permeation (SHX) \\
\hline EA3 & Activation energy for permeation (PHX) \\
\hline
\end{tabular}

\subsubsection{Input Generation}

Table 5-11 summarizes the input parameters and ranges with sample distributions. This study assumed that all the sample distribution is uniform throughout the input ranges, since the detailed information was not available. As described in the previous section, the uniform distribution generally provides more conservative results than the other distributions. 
Table 5-11. List of input parameters and ranges for sensitivity analyses.

\begin{tabular}{|l|c|c|c|c|c|}
\hline \multicolumn{1}{|c|}{ Parameters } & Para N. & Min & Max & Unit & Distribution \\
\hline Tritium Source & TS & $1.13 \mathrm{E}-11$ & $5.35 \mathrm{E}-11$ & $\mathrm{~m} 3(\mathrm{STP}) / \mathrm{s}$ & Uniform \\
\hline $\begin{array}{l}\text { Fraction of Mass Flow to } \\
\text { Purification System (P-1st) }\end{array}$ & PMF1 & 0.00013 & 0.00022 & $\#$ & Uniform \\
\hline $\begin{array}{l}\text { Fraction of Mass Flow to } \\
\text { Purification System (P-2nd) }\end{array}$ & PMF2 & $3.75 \mathrm{E}-5$ & $6.26 \mathrm{E}-5$ & $\#$ & Uniform \\
\hline $\begin{array}{l}\text { Fraction of Mass Flow to } \\
\text { Purification System (P-3rd) }\end{array}$ & PMF3 & $1.1 \mathrm{E}-4$ & $2.0 \mathrm{E}-4$ & $\#$ & Uniform \\
\hline Permeation Coefficient (IHX) & C1 & $5.33 \mathrm{E}-11$ & $1.26 \mathrm{E}-8$ & $\#$ & Uniform \\
\hline Permeation Coefficient (SHX) & C2 & $5.33 \mathrm{E}-11$ & $1.26 \mathrm{E}-8$ & $\#$ & Uniform \\
\hline Permeation Coefficient (PHX) & C3 & $5.33 \mathrm{E}-11$ & $1.26 \mathrm{E}-8$ & $\#$ & Uniform \\
\hline Hx Thickness (IHX) & TH1 & 0.001 & 0.003 & $\mathrm{M}$ & Uniform \\
\hline Hx Thickness (SHX) & Th2 & 0.001 & 0.003 & $\mathrm{M}$ & Uniform \\
\hline Hx Thickness (PHX) & TH3 & 0.001 & 0.003 & $\mathrm{M}$ & Uniform \\
\hline HX Temperature (IHX) & T1 & 833 & 833 & $\mathrm{~K}$ & Constant \\
\hline HX Temperature (SHX) & T2 & 761 & 761 & $\mathrm{~K}$ & Constant \\
\hline HX Temperature (PHX) & T3 & 800 & 800 & $\mathrm{~K}$ & Constant \\
\hline Temperature Level & CTL & 0.95 & 1.05 & $\#$ & Uniform \\
\hline HX activation energy (IHX) & EA1 & $5.19 \mathrm{E}+04$ & $6.4 \mathrm{E}+04$ & $\mathrm{~J} / \mathrm{mol}$ & Uniform \\
\hline HX activation energy (SHX) & EA2 & $5.19 \mathrm{E}+04$ & $6.4 \mathrm{E}+04$ & $\mathrm{~J} / \mathrm{mol}$ & Uniform \\
\hline HX activation energy (PHX) & EA3 & $5.19 \mathrm{E}+04$ & $6.4 \mathrm{E}+04$ & $\mathrm{~J} / \mathrm{mol}$ & Uniform \\
\hline
\end{tabular}

The tritium source ranges between $1.13 \times 10^{-11}$ and $5.35 \times 10^{-11} \mathrm{~m}^{3}(\mathrm{STP}) / \mathrm{s}$. This condition was obtained from the reported tritium birth rates and the tritium release ratios. The tritium birth rates for the various reactors range from $2.84 \times 10^{-11} \mathrm{~Bq} / \mathrm{y} / \mathrm{MWt}$ (for 3,000-MWt HTGR) to $4.28 \times 10^{-11} \mathrm{~Bq} / \mathrm{y} / \mathrm{MWt}$ (for England's 1,500-MWt HTGR). The tritium release ratios are reported to be 0.32 for the Peach Bottom reactor and 0.2 for the Fort St. Vrain reactor. In the TRITGO code, the release ratio is recommended to be 0.1 . By combining the tritium birth rates and the release ratios, the tritium release rate (TS) was estimated to be between $1.13 \times 10^{-11}$ and $5.35 \times 10^{-11} \mathrm{~m}^{3}(\mathrm{STP}) / \mathrm{s}$. The distribution was assumed to be uniform.

The mass flow into the purification system was determined to be $12 \sim 20 \% / \mathrm{h}$ of the total helium inventory in each loop. The numbers 12 and 20\%/h are based on the Peach Bottom and Fort St. Vrain reactors, respectively.

The same tritium permeation coefficients and activation energies for permeation through the HX materials were used as previous analyses.

In this analysis, the reference temperature was set to be constant during the analyses. However, the HX temperatures were determined between to be 95 and $105 \%$ of the reference temperature. The IHX, SHX, and PHX temperatures were adjusted simultaneously by applying the same multiplication factors, CTL, which represent the temperature level.

In this study, the following six different sampling numbers were taken into consideration for checking convergence and accepting reliability of the results. The minimum number of samples is 490 for Case 1 , and the maximum number of samples is 15,360 for Case 6; the following shows all cases:

- $\quad$ Case 1: 490 samples

- $\quad$ Case 2: 960 samples 
- Case 3: 3,840 samples

- $\quad$ Case 4: 1,920 samples

- Case 5: 7,680 samples

- Case 6: 15,360 samples.

\subsubsection{Model Evaluation}

The TPAC model was evaluated by adding the input data into the code. Since there are too many samples - more than 15,000 - it is almost impossible to manually evaluate the models one by one for all the sample cases. For this reason, we developed a MATLAB script for evaluating all the input dataset automatically. In this process, the parameters in the MATLAB workspace were coupled with the TPAC code parameters in the SIMULINK Model Explorer. The MATLAB script is seen in Appendix B of this report with the source code. Finally, four output results were evaluated. They include tritium concentrations in the primary and secondary loops, steam Rankin cycle, and hydrogen product.

\subsubsection{Results and Discussions}

This section summarizes the evaluation and uncertainty analysis results on the tritium concentrations in the hydrogen product. The following three results are discussed:

- Tritium concentration in the hydrogen product

- Tritium distribution in the HTGR/HTSE system

- Identification of important parameters affecting tritium behaviors in the system.

\section{Tritium concentration in the hydrogen product}

Table 5-12 summarizes the means, standard deviations, and percentiles for the evaluated tritium concentrations in the hydrogen products. Figure 5-18 plots the data for different numbers of random samples. As shown in Figure 5-18, the means and the standard deviations are well converged after 8,000 samples. According to the final results, the average concentration in the product hydrogen is $1.50 \times 10^{-2}$ $\mathrm{Bq} / \mathrm{cm}^{3}$. In this case, $90 \%$ of the estimated tritium concentration ranges between $9.32 \times 10^{-4} \mathrm{~Bq} / \mathrm{cm}^{3}$ and $4.62 \times 10^{-2} \mathrm{~Bq} / \mathrm{cm}^{3}$.

Table 5-12. Tritium concentrations in the hydrogen product $\left(\mathrm{Bq} / \mathrm{cm}^{3}\right)$.

\begin{tabular}{|c|c|c|c|c|}
\hline \# of Samples & Mean & Std & $\mathbf{5 \%}$ & $\mathbf{9 5} \%$ \\
\hline 490 & $1.49 \mathrm{E}-02$ & $1.50 \mathrm{E}-02$ & $1.10 \mathrm{E}-03$ & $4.30 \mathrm{E}-02$ \\
\hline 960 & $1.49 \mathrm{E}-02$ & $1.50 \mathrm{E}-02$ & $1.10 \mathrm{E}-03$ & $4.30 \mathrm{E}-02$ \\
\hline 1920 & $1.50 \mathrm{E}-02$ & $1.52 \mathrm{E}-02$ & $1.12 \mathrm{E}-03$ & $4.51 \mathrm{E}-02$ \\
\hline 3840 & $1.53 \mathrm{E}-02$ & $1.58 \mathrm{E}-02$ & $1.07 \mathrm{E}-03$ & $4.97 \mathrm{E}-02$ \\
\hline 7680 & $1.49 \mathrm{E}-02$ & $1.50 \mathrm{E}-02$ & $1.04 \mathrm{E}-03$ & $4.66 \mathrm{E}-02$ \\
\hline 15360 & $1.50 \mathrm{E}-02$ & $1.47 \mathrm{E}-02$ & $9.32 \mathrm{E}-04$ & $4.62 \mathrm{E}-02$ \\
\hline
\end{tabular}




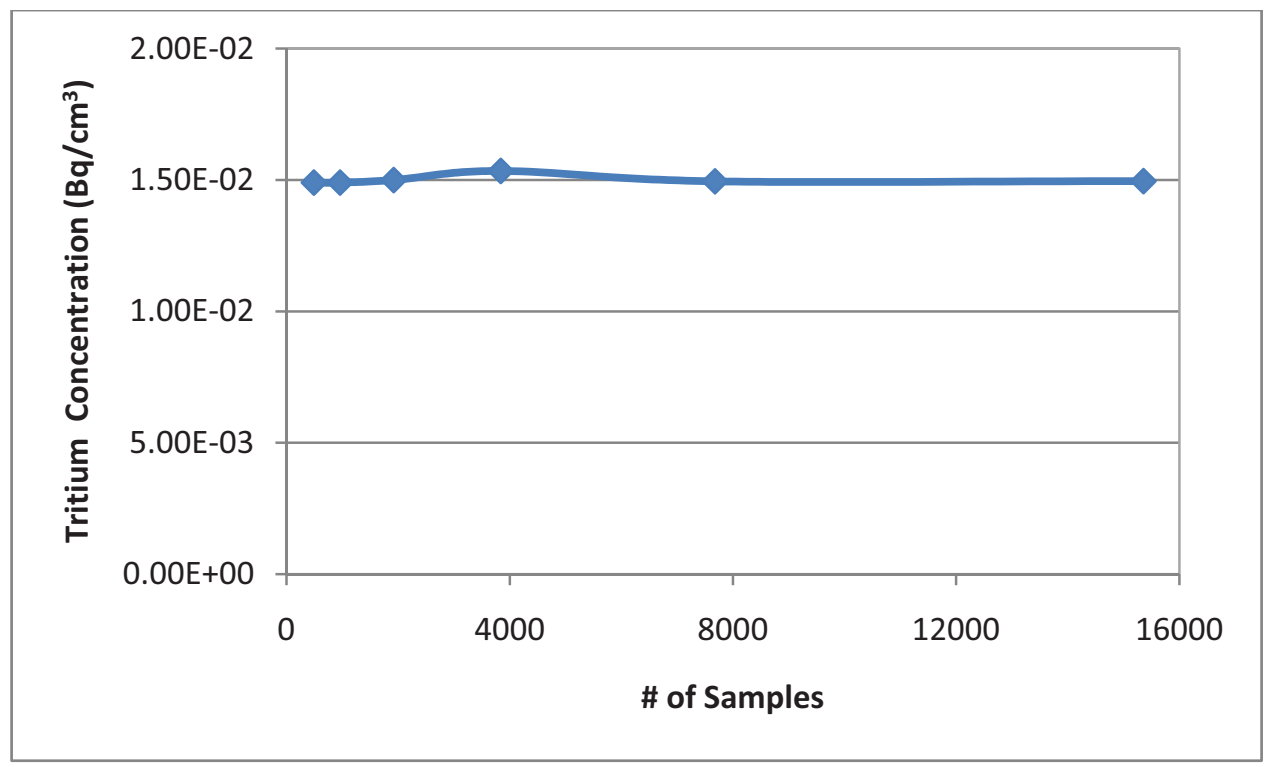

Figure 5-18. Convergence of TPAC results (tritium concentration in the product hydrogen).

Figures 5-19 and 5-20 show the probability and cumulative distributions, respectively, of the tritium concentrations in the product hydrogen obtained from Case 6 results (15,360 samples). According to the results (Figure 5-19(a) and Figure 5-20), the tritium concentration in the product hydrogen is widely distributed for the selected input parameters. About $30 \%$ of the cases are within the effluent limit $\left(3.7 \times 10^{-3} \mathrm{~Bq} / \mathrm{cm}^{3}[\mathrm{STP}]\right)$, and $70 \%$ exceed the effluent limit. The maximum tritium concentration in the system reached up to $0.1 \mathrm{~Bq} / \mathrm{cm}^{3}[\mathrm{STP}]$, which is two order higher than the effluent limit. It indicates that the system should be designed carefully and the novel tritium permeation barrier methods should be implemented into the actual heat exchanger design and fabrication to achieve sufficiently low tritium concentration. For comparisons, Figure 5-19(b) plots the tritium estimation results based on only Peach Bottom material tritium permeation data (See Figure 5-5). In this case, about $97 \%$ of data are within the effluent limit.

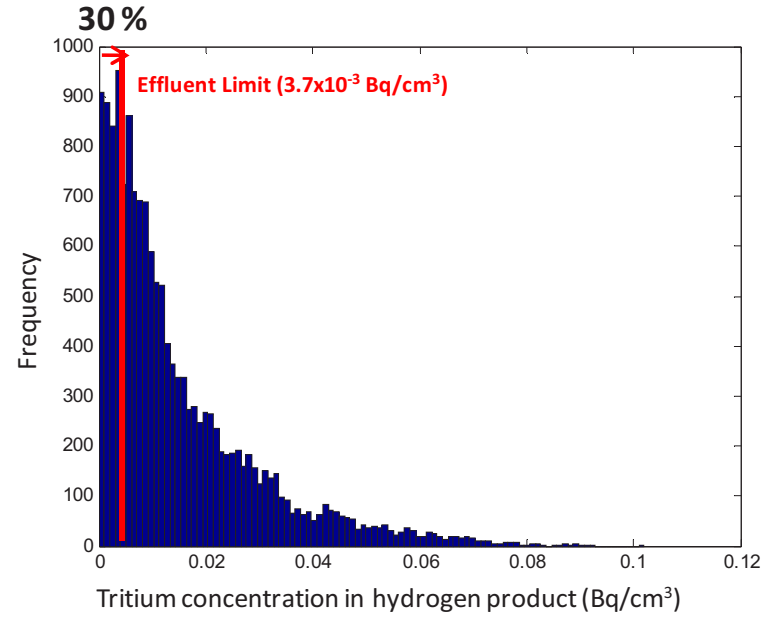

(a) Using Peach Bottom Data and Lab Experiment Data

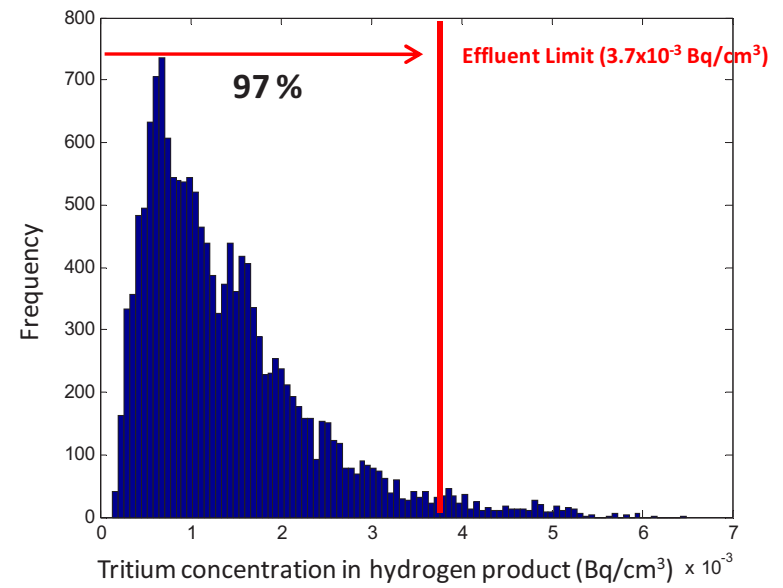

(b) Using Peach Bottom Data

Figure 5-19. Frequency distribution of the tritium concentrations in the hydrogen product $(15,360$ samples $)$ without tritium barriers applied. 


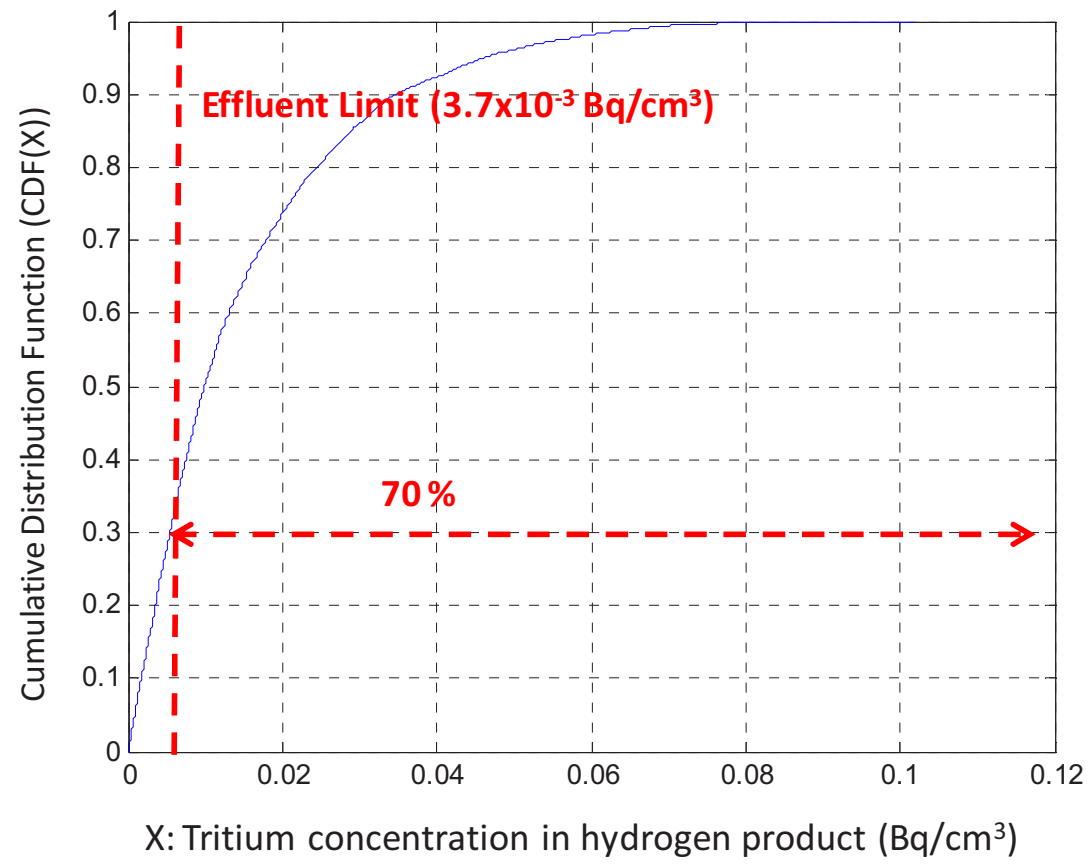

Figure 5-20. CDF of tritium concentrations in the hydrogen product.

\section{Tritium distribution in the HTGR/HTSE system}

Figure 5-21 shows the tritium distributions estimated by the TPAC code in the HTGR/HTSE system. In this study, it was assumed that $21 \%$ of tritium is released from the core, and therefore $79 \%$ of tritium was retained in the core. According to this result, about $2 \%$ of the tritium generated is removed by the purification system installed in the primary side. About $18 \%$ of the tritium is permeated to the secondary side through the IHX walls. Only $0.1 \%$ of the tritium is released to the containment (or confinement) by helium leakage. In the secondary side, $1 \%$ of the tritium is removed by the purification system, and $15 \%$ of the tritium is permeated to the steam Rankin cycle from the secondary helium loop (the SHX hot side). About $3 \%$ of the tritium transfers to the hydrogen production system. According to the calculation results, tritium removal by purification systems is ineffective in the given design ranges. Therefore, high capacity tritium purification systems need to be installed. However, increase of tritium purification capacity decreases system efficiency and requires much more cost. The effect of leakage out of the system is negligible-less than $0.2 \%$ in total. However, the detail numbers can be changed for different system conditions and designs including configuration, temperature, heat exchanger size, and purification system capacity. Therefore, this result should be carefully interpreted for other system designs and conditions. 


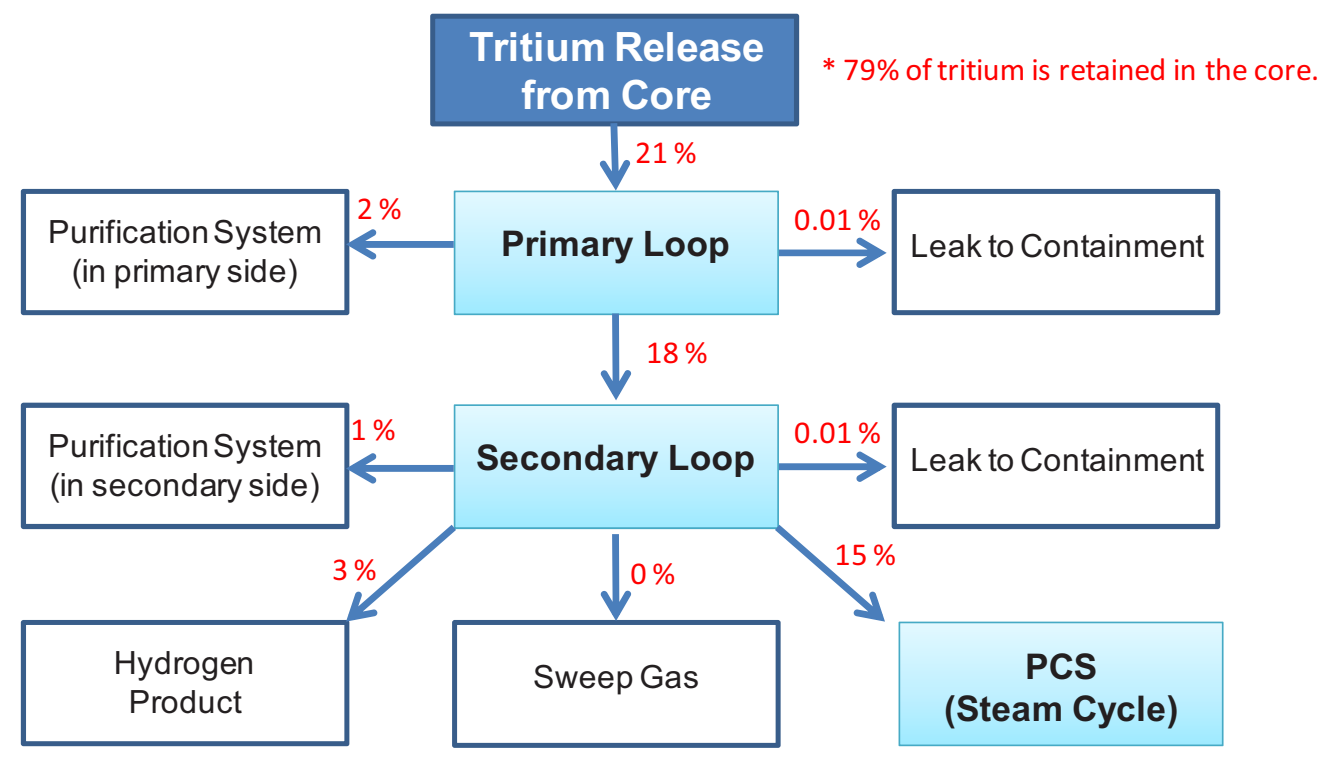

Figure 5-21. Tritium distribution in the system.

\section{Important Parameters Affecting Tritium Behaviors in the VHTR/HTSE system}

This section summarizes the sensitivity analysis results. Two sensitivity indices were used here for measuring parameter importance: (1) the first-order index and (2) the total index.

\section{A. Main Effect (First-order Index)}

The first-order index, which represents the main effect of an input parameter, is closely related to the contribution of the parameter on the total output uncertainties. Table 5-13 summarizes the results from different numbers of samples. The numbers listed in the table represent the effects of the input parameters on the tritium concentrations in the hydrogen product. Physically, the number means the contributions of a certain parameter uncertainty to the total uncertainty. For example, the first-order index of the TS is listed in the table as 0.17 . It means that $17 \%$ of the total uncertainty came from the uncertainty of the TS parameter. Therefore, as this number gets larger, the parameter becomes more important.

This sensitivity study is based on the Monte-Carlo-based random sampling method. Therefore, convergence of the results should be validated for various sample numbers. As described, six cases were investigated in this study by changing sample numbers from 1,920 to 15,360. Figure 5-22 shows the variations of sensitivity indices with various sample numbers. As shown in this figure, all the sensitivity indices are well converged after 8,000 samples. Therefore, it can be deduced that Case 6, based on 15,360 samples, will present well-converged solutions. 
Table 5-13. First-order sensitivity indices for tritium concentration of the hydrogen product.

\begin{tabular}{|c|c|c|c|c|}
\hline \multirow{2}{*}{ Parameter } & $\mathbf{5 2 0}$ & $\mathbf{3 8 4 0}$ & $\mathbf{7 6 8 0}$ & $\mathbf{1 5 3 6 0}$ \\
\hline TS & 0.17 & 0.13 & 0.14 & 0.17 \\
\hline PMF1 & 0.00 & 0.00 & 0.00 & 0.00 \\
\hline PMF2 & 0.00 & 0.00 & 0.00 & 0.00 \\
\hline PMF3 & 0.00 & 0.00 & 0.00 & 0.00 \\
\hline C1 & 0.02 & 0.02 & 0.01 & 0.01 \\
\hline C2 & 0.10 & 0.10 & 0.12 & 0.13 \\
\hline C3 & 0.16 & 0.17 & 0.19 & 0.22 \\
\hline TH1 & 0.01 & 0.00 & 0.00 & 0.00 \\
\hline TH2 & -0.01 & 0.00 & 0.01 & 0.02 \\
\hline TH3 & 0.04 & 0.05 & 0.03 & 0.04 \\
\hline EA1 & 0.00 & 0.00 & 0.00 & 0.00 \\
\hline EA2 & 0.09 & 0.06 & 0.06 & 0.07 \\
\hline EA3 & 0.15 & 0.12 & 0.12 & 0.13 \\
\hline CTL & 0.02 & 0.00 & 0.00 & 0.00 \\
\hline
\end{tabular}

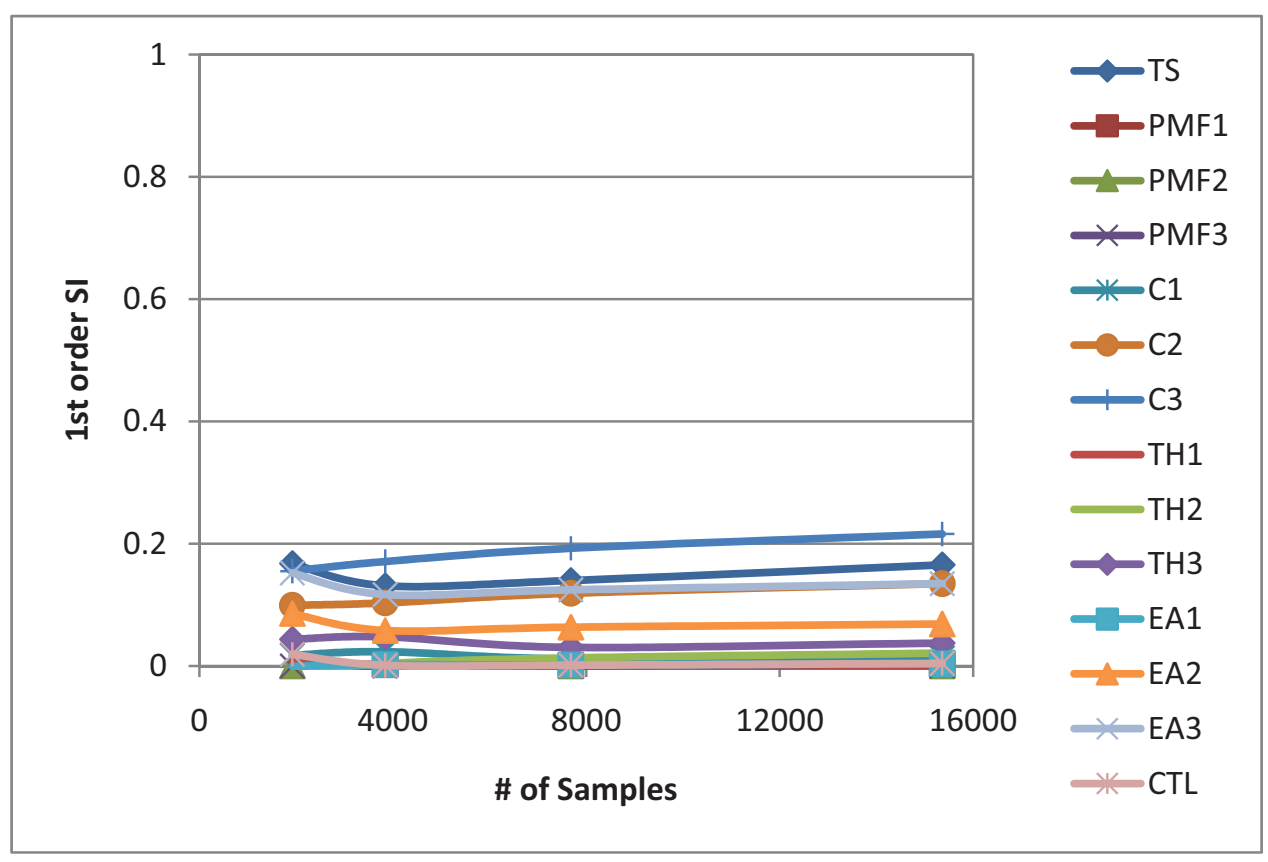

Figure 5-22. First-order index of tritium concentrations in the product hydrogen with sample numbers (convergence check).

Figure 5-23 shows the input parameters and their first-order sensitivity indices. In this comparison, the following four parameters were identified as important among the 14 input parameters:

- PHX permeation coefficient (C3)

- $\quad$ Tritium Source (TS)

- SHX permeation coefficient (C2)

- $\mathrm{PHX}$ activation energy (EA3). 
According to the results, about $65 \%$ of output uncertainties are contributed from these four parameters. The other 10 parameters are estimated to be negligible. The modeling uncertainties can be significantly reduced by decreasing uncertainties of these four parameters: C3, TS, C2, and EA3. On the other hand, the PMF3, PMF2, TH1, PMF1, EA1, CTL, and C1 parameters do not improve modeling uncertainties. The major contributor in the first-order index is dependent on configuration (Figure 1 for the VHTR outlet temperature of $900^{\circ} \mathrm{C}$ vs. Figure 15 for the VHTR outlet temperature of $750{ }^{\circ} \mathrm{C}$ ). The VHTR/HTSE system shown in Figure 1 integrates the PCS and the HTSE in serial while the HTGR/HTSE system shown in Figure 15 integrates the PCS and the HTSE in parallel.

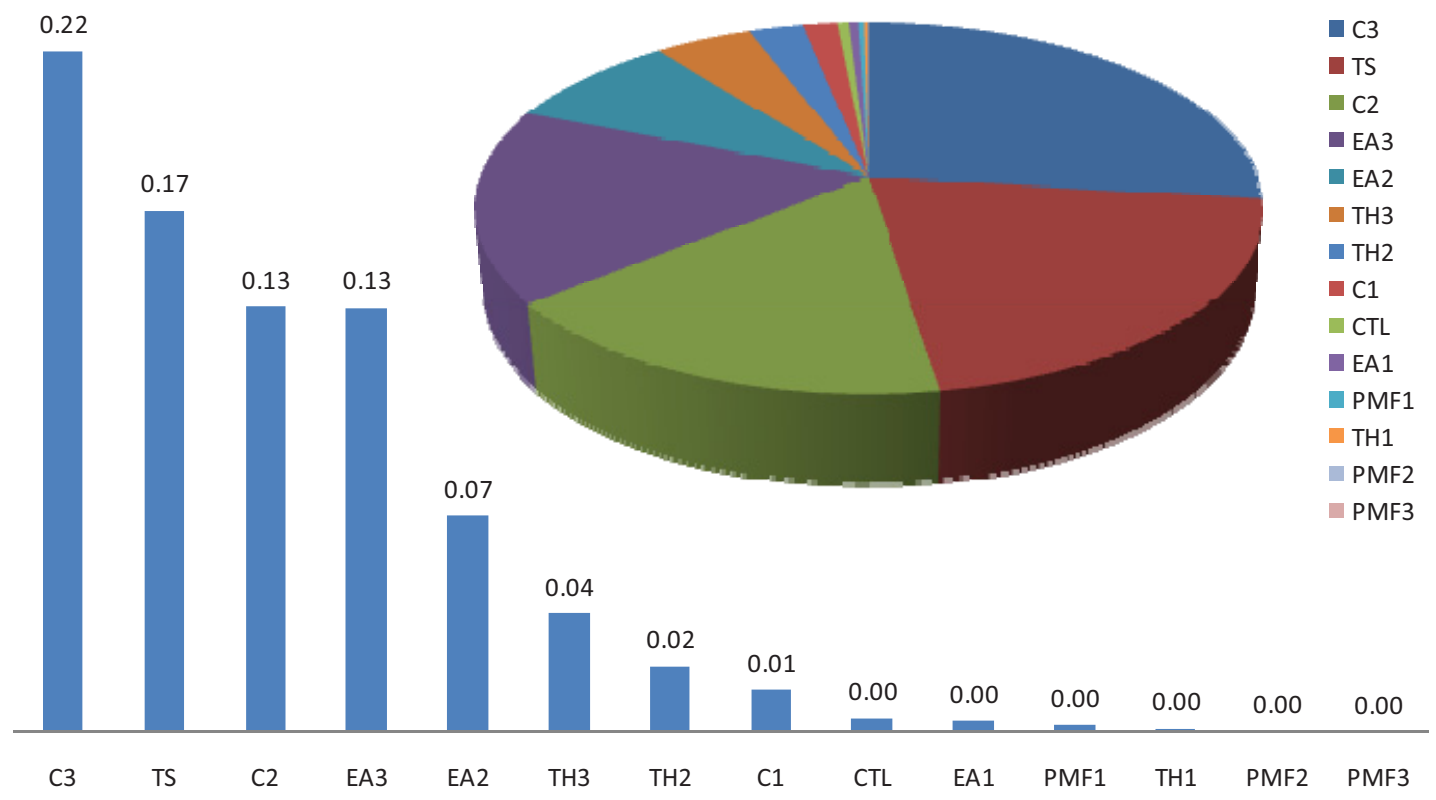

Figure 5-23. First-order index (tritium concentration in the product hydrogen).

\section{B. Total Effect (Total Index)}

Total uncertainty, which represents the total effect of a certain input parameter, is closely related to the contribution of the parameter on the output value. Table 5-14 summarizes the estimated total sensitivity indices for different numbers of samples, and Figure 5-24 illustrates the results. In this figure, the $\mathrm{x}$-axis represents the sample number and the y-axis, the total sensitivity indices. As shown in this figure, the results are well converged after 8,000 samples, which indicates that the solutions are well converged in this study. 
Table 5-14. Total indices for tritium concentration of the hydrogen product.

\begin{tabular}{|c|c|c|c|c|}
\hline \multirow{2}{*}{ Parameters } & \multicolumn{5}{c|}{ Sample Numbers } \\
\hline TS & 0.27 & 0.22 & 0.25 & 0.27 \\
\hline PMF1 & 0.00 & 0.00 & 0.00 & 0.01 \\
\hline PMF2 & 0.00 & 0.00 & 0.00 & 0.00 \\
\hline PMF3 & 0.00 & 0.00 & 0.00 & 0.00 \\
\hline C1 & 0.02 & 0.03 & 0.02 & 0.01 \\
\hline C2 & 0.16 & 0.19 & 0.18 & 0.19 \\
\hline C3 & 0.27 & 0.31 & 0.31 & 0.31 \\
\hline TH1 & 0.00 & 0.00 & 0.00 & 0.00 \\
\hline TH2 & 0.00 & 0.03 & 0.04 & 0.03 \\
\hline TH3 & 0.04 & 0.07 & 0.05 & 0.05 \\
\hline EA1 & 0.01 & 0.01 & 0.00 & 0.00 \\
\hline EA2 & 0.23 & 0.13 & 0.12 & 0.11 \\
\hline EA3 & 0.30 & 0.21 & 0.23 & 0.21 \\
\hline CTL & 0.02 & 0.02 & 0.02 & 0.02 \\
\hline
\end{tabular}

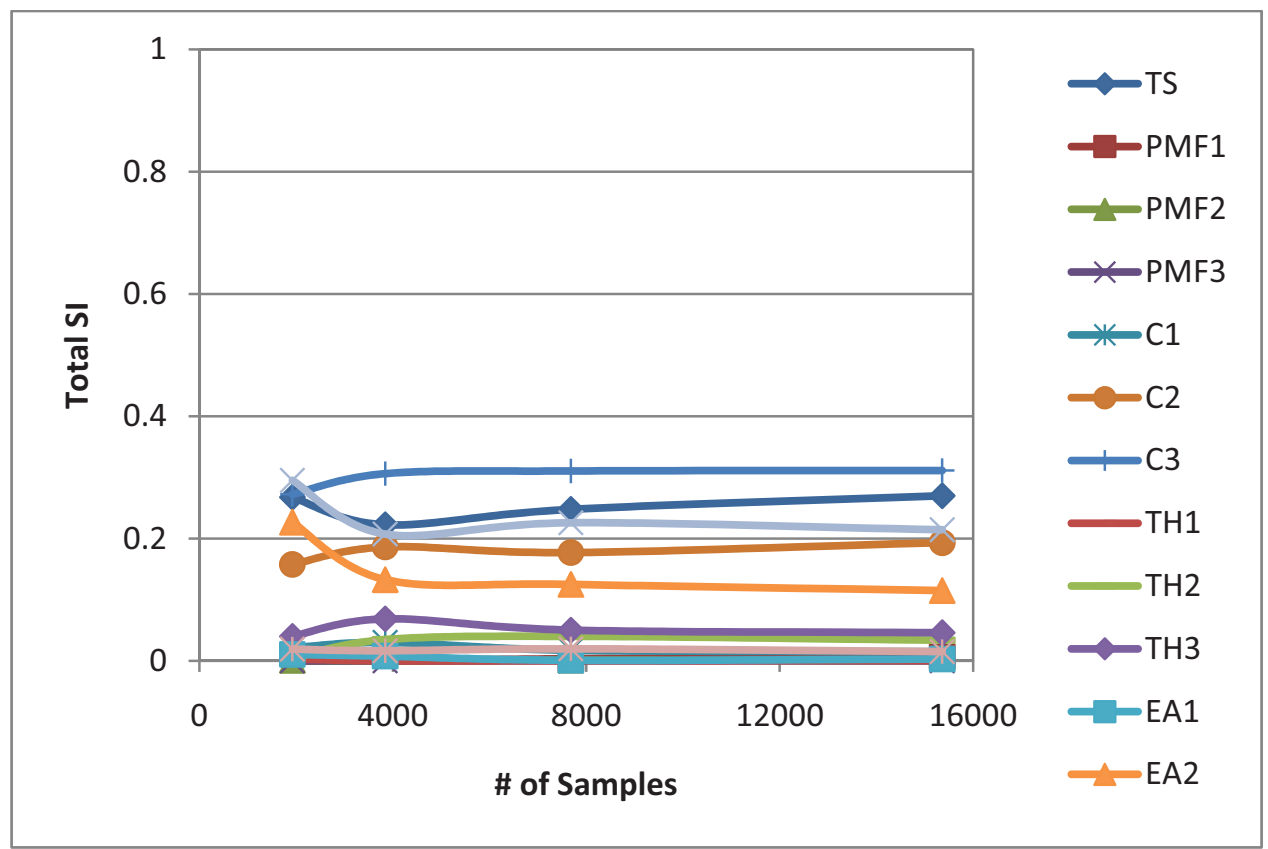

Figure 5-24. Total index of tritium concentrations in the product hydrogen with sample numbers (convergence check).

Figure 5-25 compares the total sensitivity indices for all the input parameters. The total indices can be interpreted as follows: if the total index of a certain parameter is larger, the output value is more affected by the change of that parameter. Therefore, the physical meaning of the total indices is different from that of the first-order indices. The first-order indices focus on the uncertainty while the total indices, on the output values. In this comparison, the following four parameters were identified as important:

- $\quad$ PHX permeation coefficient (C3)

- $\quad$ Tritium Source (TS) 
- $\quad$ SHX permeation coefficient (C2)

- $\quad$ PHX activation energy (EA3).

Therefore, if we control the above parameters, we can effectively reduce the tritium concentration level in the hydrogen product. On the other hand, the following parameters were identified as ineffective for reducing tritium in the hydrogen product:

- Flow rate to purification system-2 and 3 (PMF2, PMF3)

- IHX wall thickness and activation energy (TH1, EA1)

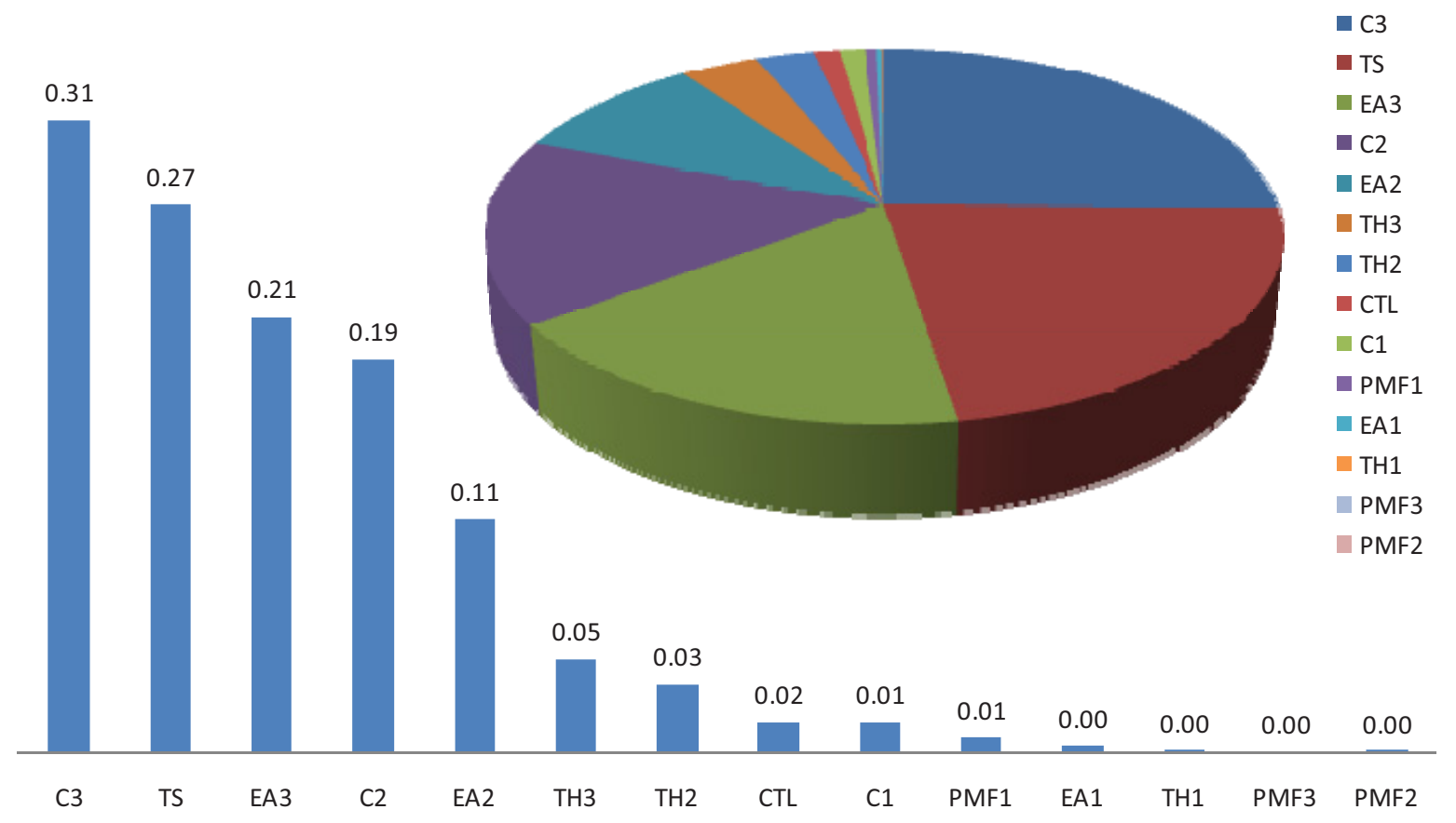

Figure 5-25. Total index (tritium concentration in the product hydrogen).

Figure 5-26 shows the first-order indices and the total indices in the same plot. As shown in this figure, the total indices are larger than the first-order indices by about $30 \%$. The differences between the first-order indices and the total indices represent a sum of the higher order terms, which means parameter interactions. It indicates that the interactions between each parameter are not negligible. 


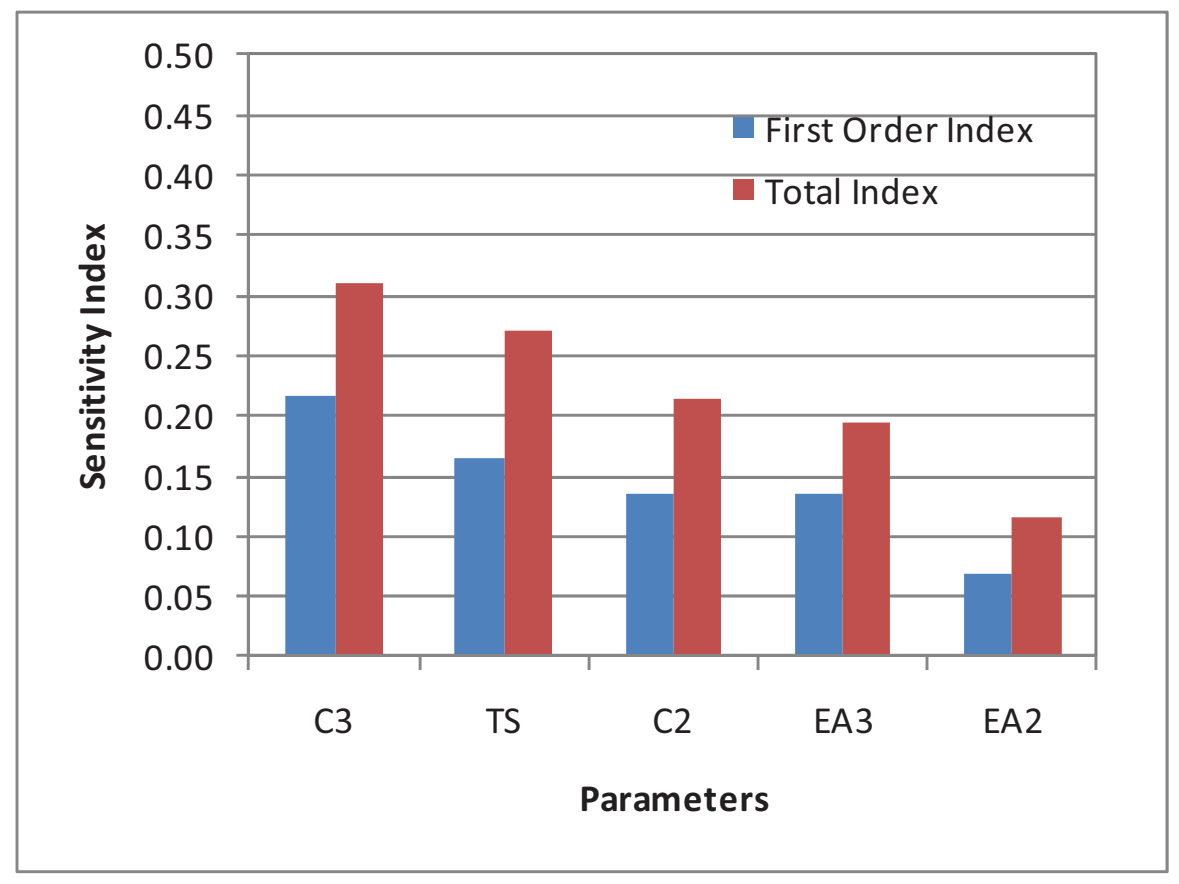

Figure 5-26. First-order indices and total indices for five major parameters.

\subsubsection{Summary}

In this section, we analyzed tritium behaviors in the HTGR/HTSE system. The HTGR system was designed based on $600-\mathrm{MWt}$ power and $750^{\circ} \mathrm{C}$ core outlet temperature. This system consists of the following four separate loops:

- Reactor primary side

- Reactor secondary side

- Power conversion system (PCS)

- HTSE system

The primary heat was transferred to the secondary side through an IHX. In secondary side, the heat was transferred to the PCS and HTSE system through an SHX and a PHX. The PCS was based on the steam Rankin cycle. In the HTSE system, since the PHX outlet steam temperature is insufficient for electrolysis, the steam was heated up to $800^{\circ} \mathrm{C}$ by an electric heater.

The HTGR/HTSE system was modeled by the TPAC code. Most of the information for modeling was obtained or determined from previous literatures, HYSYS flowsheet analyses, and some assumptions. For sensitivity analyses, we agreed on 14 input parameters by discussion, and randomly generated 15,360 inputs using the SIMLAB software. For automatic evaluations of a large number of samples, we developed a MATLAB script that links MATLAB workspace parameters and the TPAC input variables. In this study, the following three things were taken into account in detail:

- Tritium concentration in the hydrogen product

- Tritium distribution in the HTGR/HTSE system

- Important factors affecting tritium behaviors.

First, we estimated tritium concentration in the hydrogen product. According to the results, the average concentration in the product hydrogen is $1.50 \times 10^{-2} \mathrm{~Bq} / \mathrm{cm}^{3}$. In this case, $90 \%$ of the estimated tritium concentration ranges between $9.32 \times 10^{-4} \mathrm{~Bq} / \mathrm{cm}^{3}$ and $4.62 \times 10^{-2} \mathrm{~Bq} / \mathrm{cm}^{3}$. 
In this study, it was assumed that $21 \%$ of tritium is released from the core and $79 \%$ of tritium is retained in the core. According to the result, about $2 \%$ of the tritium is removed by the purification system installed in the primary side. About $18 \%$ of the tritium is permeated to the secondary side through the IHX walls. Only $0.1 \%$ of the tritium is released to the containment (or confinement) by helium leakage. In the secondary side, $1 \%$ of the tritium is removed by the purification system, and $15 \%$ of the tritium is permeated to the steam Rankin cycle from the secondary helium loop (the SHX hot side). About $3 \%$ of the tritium transfers to the hydrogen production system.

Finally, we conducted global sensitivity analyses in order to identify important factors that affect tritium behaviors in the HTGR/HTSE system. These analyses were based on the method proposed by Sobol, and two importance measures were estimated by the SIMLAB software. In these analyses, the following four parameters were identified as important for both reducing modeling uncertainties and reducing tritium concentration in the hydrogen product.

- $\quad$ PHX permeation coefficient (C3)

- $\quad$ Tritium Source (TS)

- SHX permeation coefficient (C2)

- PHX activation energy (EA3).

The above parameters were estimated to contribute about $65 \%$ of the total uncertainties. It strongly recommended that future research concentrate on improving those 4 parameters and model accuracies. Also, effective methods to control those parameters should be developed for mitigating tritium in the system. 


\subsection{Analyses on the HTGR/MTG System (I)}

This study analyzed tritium behaviors in the two different MTG system designs integrated with HTGRs. These systems generate gasoline from natural gas using nuclear heat. This section discusses the first HTGR/MTG system design based on the steam Rankin PCS with the core outlet temperature of $750^{\circ} \mathrm{C}$. The following section describes the system details.

\subsubsection{Reference System Description}

Figure 5-28 shows a schematic of the nuclear-assisted MTG system (Wood et al. 2009). The proposed system includes operation units for air separation (ASU), natural gas purification and reforming (NG-RFMR), methanol synthesis (MEOH-SYN), methanol conversion to gasoline (MTG), power production (heat recovery steam generator- steam turbine (HTSG-ST)), cooling tower, and water treatment. Nuclear heat is used to preheat all streams entering the primary reformer. In addition, nuclear heat is used rather than firing fuel gas for product upgrading in the MTG plant. Each unit operation is briefly described below (Wood et al. 2009).

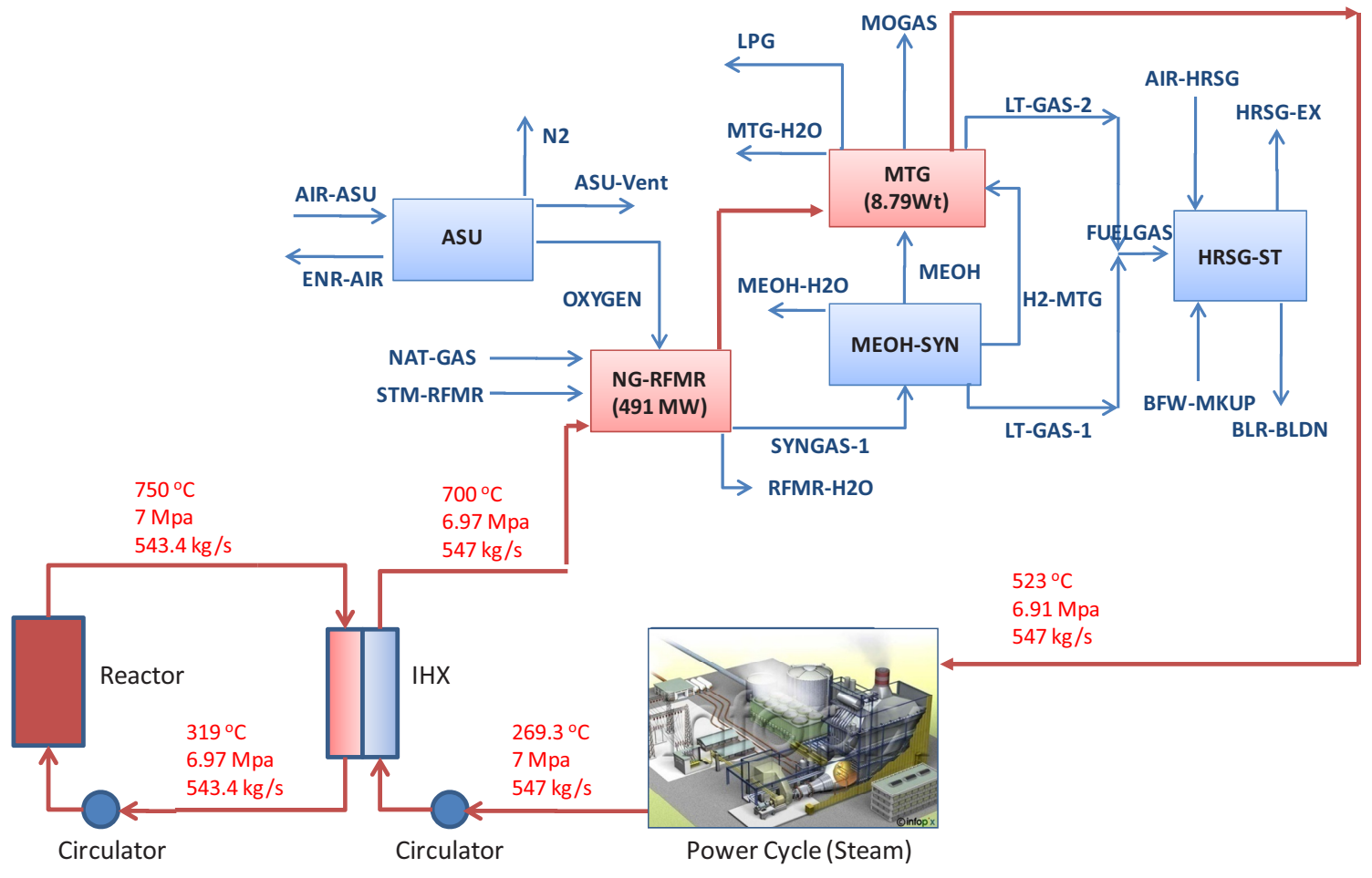

Figure 5-28. Nuclear-assisted MTG system.

\section{Air Separation Unit (ASU)}

Oxygen is produced by a standard cryogenic Linde-type ASU. The oxygen product is used for natural gas reforming. In order to reduce the inert content in the synthesis gas, an $\mathrm{O}_{2}$ purity of $99.5 \%$ is specified. High-purity oxygen is desired to minimize diluent nitrogen in the fuel synthesis loops.

\section{Natural Gas Purification and Reforming (NG-RFMR)}

Syngas for methanol production is produced in this unit. The reforming process in this study was based on the two steps: (1) primary steam reforming, and (2) secondary autothermal reforming. The process is as follows.

Natural gas is first compressed to 363 psi and then passes through a sulfur-removal bed. After sulfur removal, hot water is added to the natural gas stream to saturate it. The gas is then heated further and 
mixed with steam to achieve the desired stream-to-carbon molar ratio of 1.8 . The hot natural gas stream is then fed to a performer that irreversibly converts $\mathrm{C}_{2}+$ hydrocarbons to $\mathrm{CH} 3, \mathrm{CO}, \mathrm{H}_{2}$, and $\mathrm{CO}_{2}$. The preforming step is required because further heating of the natural gas and steam could result in steam cracking of the $\mathrm{C}_{2}+$ components to olefins, which tend to form carbon in the primary reformer. Carbon formation is detrimental to long-term operation as it deactivates the reforming catalyst.

After preforming, the natural gas/steam mixture is fed to the primary reformer where methane is converted over a catalyst to $\mathrm{CO}, \mathrm{H}_{2}$, and $\mathrm{CO}_{2}$. Methane conversion in this reactor is approximately $37 \%$. Hot offgas from the reformer is further exchanged with inlet syngas, water, and steam to provide preheats for these streams.

The effluent from the primary reformer is mixed with oxygen and fed to an autothermal reformer where conversion of the remaining methane to syngas is accomplished. The resulting syngas has a $\mathrm{H} 2 / \mathrm{CO}$ ratio of 2.98 and contains $6.6 \mathrm{~mol}^{\%} \mathrm{CO}_{2}$.

The heat for the reformer is supplied via exchange with hot helium in the nuclear reactor.

\section{Methanol Synthesis (MEOH-SYN)}

The syngas from the NG-RFMR is converted to methanol in this unit. Incoming feed gas is compressed to $1,090 \mathrm{psi}$, followed by heating via recuperation to $433^{\circ} \mathrm{F}$ prior to introduction into the methanol conversion reactor. Methanol and unreacted syngas exiting the reactor are cooled by recuperation with the incoming feed gas, followed by condensation and separation of the liquid methanol product. Unreacted gas is recompressed, mixed with fresh incoming syngas, and fed back to the methanol synthesis reactor. A purge on the unreacted gas stream is set to limit buildup of inert gas within the synthesis loop; the molar recycle ratio is currently set at 4.0:1. These conditions result in a reactor inlet $\mathrm{CO}_{2}$ concentration of $1 \mathrm{~mol} \%$ and a methanol concentration in the reactor exit stream of $7.6 \mathrm{~mol} \%$. Condensed methanol product is purified in a distillation column to remove light gases prior to storage in the methanol intermediate product tank. A portion of the methanol synthesis loop purge gas is routed through a pressure swing absorption (PSA) system to recover unreacted $\mathrm{H}_{2}$ for use in the sulfur reduction and gasoline refining portions of the plant.

\section{Methanol to Gasoline Process (MTG)}

Methanol is converted to gasoline using ExxonMobil's presented process. Methanol is first pumped to $345 \mathrm{psia}$ and heated using recuperation to $590^{\circ} \mathrm{F}$ prior to introduction to the dimethyl ether (DME) reactor. In this reactor, methanol is exothermically converted to an equilibrium concentration of DME, water, and methanol. The product of this reactor is mixed with recycle gas to cool the stream to $357^{\circ} \mathrm{F}$ before it is introduced to the ZSM-5 catalytic MTG reactor. In this reactor, methanol and DME are converted to hydrocarbons ranging from $\mathrm{C}_{1}$ (methane) to $\mathrm{C}_{11}$ (1-naphtha). The overall reaction from $\mathrm{DME}$ and methanol to gasoline is exothermic, resulting in an exit temperature of around $750^{\circ} \mathrm{F}$. The crude gasoline product is cooled via recuperation. Additional heat is removed by raising steam, followed by condensation. Liquid product is separated for further refining, while light gas is recompressed and recycled to the ZSM-5 catalytic MTG reactor. A portion of the gas is purged to limit inert gas building within the gasoline synthesis loop. Crude liquid gasoline is purified using three distillation columns: de-ethanizer, de-propanizer, and de-waxing. Light gas exiting the de-ethanizer is used as fuel gas for coal drying and power production. Light gas exiting the de-propanizer is sold as a liquefied petroleum gas (LPG) product. Gasoline product exits the top of the de-waxing column, while a durene-rich heavy stream is taken off as the bottom product from this column. The durene-rich stream is treated in a hydrodealkylation unit to convert it to lighter hydrocarbons more suitable for gasoline. Light gases produced in the hydrodealkylation unit are removed as LPG product in a second de-propanizer, while the bottom product from this column is mixed with the final gasoline product. The heat for the de-propanizer reboiler and the hydrodealkylation unit are supplied via exchange with hot helium from the nuclear.

\section{Power Production (HRSG-ST)}


The high- (700 psia), medium- (381 psia), and low-pressure (60 psia) steams generated throughout the plant are sent to the power production block where they are passed through three steam turbines to generate power. The efficiencies of the turbines are approximately $81 \%$. The condensed steams from the turbine outlets are mixed with condensate return from the plant and makeup water is added to provide the necessary flow to the boiler feedwater pumps. Low-pressure steam is added to the deaerator. Purge gas produced in the plant is fired in the heat recovery steam generator (HRSG) to (1) superheat and reheat steam feeds to the turbines, (2) raise additional steam to bolster power production, and (3) preheat boiler feed water prior to deaeration.

\section{Nuclear Reactor}

Two reactor modules with $600 \mathrm{MWt}$ were combined with the MTG system and the steam power cycle. So, total reactor power supplied to the system is 1,200 MWt. It is an indirect cycle. The primary and secondary coolants are helium. The maximum core outlet temperature is $750^{\circ} \mathrm{C}$, and the inlet temperature is $322^{\circ} \mathrm{C}$. The primary and secondary sides are connected via an IHX. In the secondary side, the hot helium exiting the IHX first enters into the reformer and the MTG system. The MTG exit temperature of the helium coolant is $523^{\circ} \mathrm{C}$. The exit of the MTG helium coolant is connected to the steam power cycle via a steam generator and a reheater. The steam cycle is based on the Rankin cycle and the efficiency is about $38 \%$. About half of the reactor power is consumed in the power cycle. The helium coolant temperature in the secondary side is cooled down to $264^{\circ} \mathrm{C}$ passing through the steam generator.

\subsubsection{TPAC Modeling}

Figure 5-29 shows the TPAC model for the HTGR/MTG system. This study determined the system configuration, operating temperature, pressure, and flow rates from McKellar et al.'s (2009) flowsheet. For determination of the component size and volumes, we used pre-conceptual designs of various VHTR systems for modeling. The TPAC model used five heat exchangers for integrating systems including a nuclear reactor, a steam power cycle, and a MTG plant: (1) IHX, (2) steam generator, (3) reheater, (4) PHX-1, and (5) PHX-2. The model assumed the IHX as a PCHE and the others as tubular types. The HX sizes and rates were based on typical heat exchanger design methodologies.

\section{Basic Assumptions on the TPAC Model for the MTG System}

The MTG plant had to be highly simplified because of its complexity and lack of information. This study used the following assumptions for configuring the MTG system in the TPAC code.

- Tritium containing species (HT, HTO) will be conserved between inlet and outlet of the components.

- The amount of tritium-containing species (HT and HTO) is negligibly small compared to the main flow rate. (Generation or absorption of the tritium does not affect the main stream conditions and properties.)

- $\quad \mathrm{HT}$ is chemically identical to $\mathrm{H}_{2}$.

- $\mathrm{HTO}$ is chemically identical to $\mathrm{H}_{2} \mathrm{O}$.

- All species are homogeneously mixed.

- The isotope exchange between $\mathrm{HT}$ and $\mathrm{H}_{2} \mathrm{O}$ will be considered in modeling the steam Rankin cycle. $\left(\mathrm{HT}+\mathrm{H}_{2} \mathrm{O}=\mathrm{H}_{2}+\mathrm{HTO}\right)$

- Isotope exchanges for other species will not be considered because of the lack of information. 


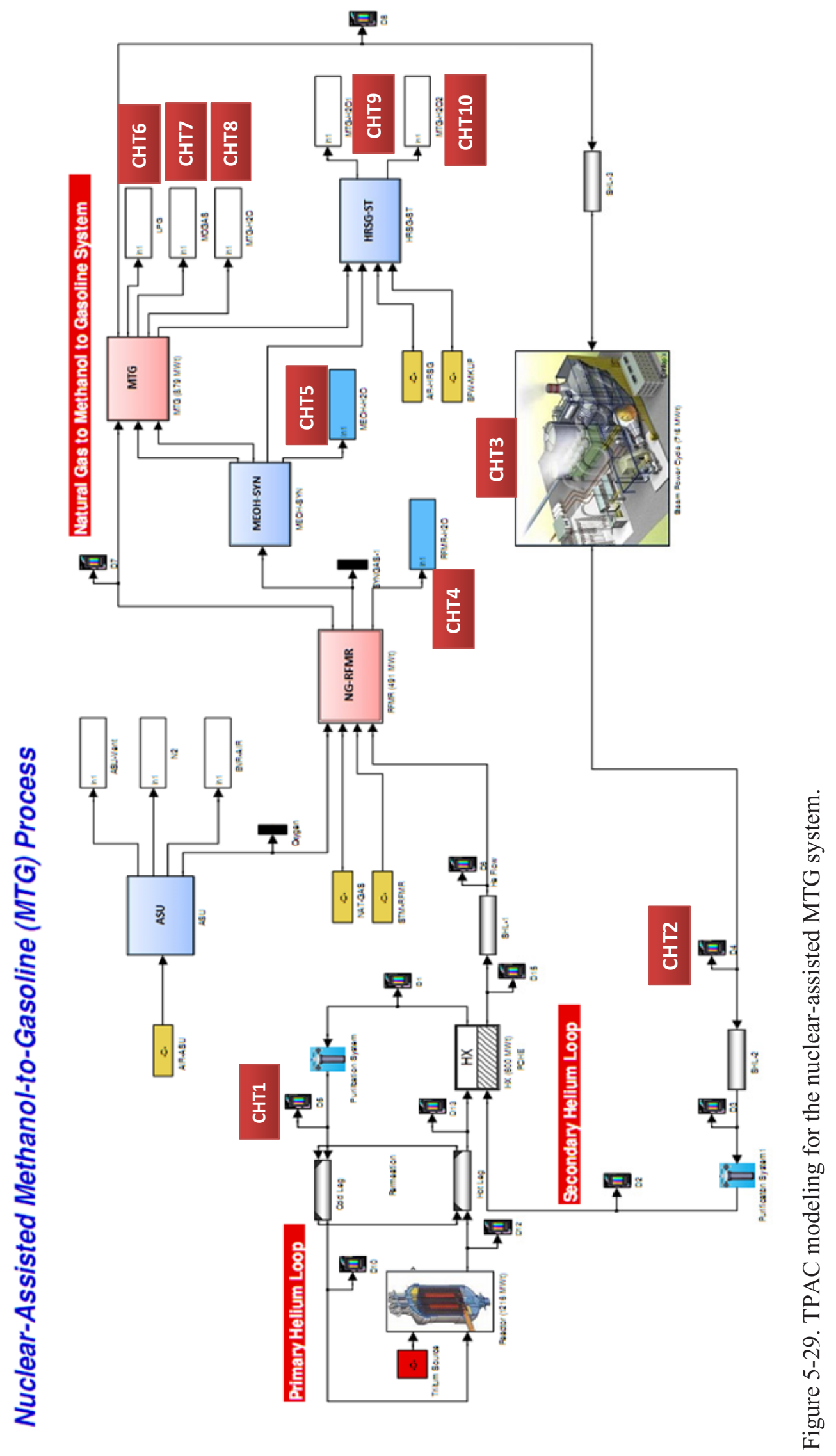




\subsubsection{Uncertainty and Sensitivity Analyses}

This section describes the uncertainty and sensitivity analyses for the HTGR/MTG system. The analysis method is basically the same as that used in the Section 5.3. First, the inputs were selected by discussion. Then, we used SIMLAB software for generating inputs. In these analyses, about 20,000 randomly generated input datasets were used. The generated inputs were implemented into the TPAC code for evaluation. Based on the evaluated outputs, uncertainty results and SOBOL sensitivity indices were estimated using SIMLAB and MATLAB code.

\subsubsection{Input Selection}

We also selected 19 major parameters in this analysis. Table 5-17 summarizes the input parameters and their physical representations.

Table 5-17. List of input parameters for uncertainty and sensitivity analysis.

\begin{tabular}{|c|l|}
\hline Input Parameters & \multicolumn{1}{|c|}{ Representations } \\
\hline TS & Tritium Source \\
\hline PMF1 & Fraction of Mass Flow to Purification System (P-1st) \\
\hline PMF2 & Fraction of Mass Flow to Purification System (P-2nd) \\
\hline C1 & Reaction Coefficient (IHX) \\
\hline C2 & Reaction Coefficient (S/G) \\
\hline C3 & Reaction Coefficient (Reheater) \\
\hline C4 & Reaction Coefficient (PHX-1) \\
\hline C5 & Reaction Coefficient (PHX-2) \\
\hline TH1 & HX Thickness (IHX) \\
\hline TH2 & HX Thickness (S/G) \\
\hline TH3 & HX Thickness (Reheater) \\
\hline TH4 & HX Thickness (PHX-1) \\
\hline TH5 & HX Thickness (PHX-2) \\
\hline EA1 & HX activation energy (IHX) \\
\hline EA2 & HX activation energy (S/G) \\
\hline EA3 & HX activation energy (Reheater) \\
\hline EA4 & HX activation energy (PHX-1) \\
\hline EA5 & HX activation energy (PHX-2) \\
\hline CTL & Temperature Level \\
\hline & \\
\hline &
\end{tabular}

\subsubsection{Input Generation}

Table 5-18 summarizes 19 model input parameters and their ranges. This study assumed uniform distribution for all the input parameters because information was lacking. Uniform distribution generally provides higher uncertainties than any other distributions such as Gaussian or Lognormal distributions. It indicates that the results estimated by uniform distribution can be considered conservative. 
Table 5-18. List of input parameters and ranges for sensitivity analyses.

\begin{tabular}{|l|c|c|c|c|c|}
\hline \multicolumn{1}{|c|}{ Parameters } & Para N. & Min & Max & Unit & Distribution \\
\hline Tritium Source & TS & $2.29 \mathrm{E}-11$ & $1.08 \mathrm{E}-10$ & $\mathrm{~m} 3(\mathrm{STP}) / \mathrm{s}$ & Uniform \\
\hline $\begin{array}{l}\text { Fraction of Mass Flow to } \\
\text { Purification System (P-1st) }\end{array}$ & PMF1 & $1.20 \mathrm{E}-4$ & $2.03 \mathrm{E}-4$ & $\#$ & Uniform \\
\hline $\begin{array}{l}\text { Fraction of Mass Flow to } \\
\text { Purification System (P-2nd) }\end{array}$ & PMF2 & $3.48 \mathrm{E}-5$ & $5.80 \mathrm{E}-5$ & $\#$ & Uniform \\
\hline Reaction Coefficient (IHX) & C1 & $5.33 \mathrm{E}-11$ & $1.26 \mathrm{E}-8$ & $\#$ & Uniform \\
\hline Reaction Coefficient (S/G) & C2 & $5.33 \mathrm{E}-11$ & $1.26 \mathrm{E}-8$ & $\#$ & Uniform \\
\hline Reaction Coefficient (Reheater) & C3 & $5.33 \mathrm{E}-11$ & $1.26 \mathrm{E}-8$ & $\#$ & Uniform \\
\hline Reaction Coefficient (PHX-1) & C4 & $5.33 \mathrm{E}-11$ & $1.26 \mathrm{E}-8$ & $\#$ & Uniform \\
\hline Reaction Coefficient (PHX-2) & C5 & $5.33 \mathrm{E}-11$ & $1.26 \mathrm{E}-8$ & $\#$ & Uniform \\
\hline HX Thickness (IHX) & TH1 & 0.001 & 0.003 & $\mathrm{~m}$ & Uniform \\
\hline HX Thickness (S/G) & TH2 & 0.001 & 0.003 & $\mathrm{~m}$ & Uniform \\
\hline HX Thickness (Reheater) & TH3 & 0.001 & 0.003 & $\mathrm{~m}$ & Uniform \\
\hline HX Thickness (PHX-1) & TH4 & 0.001 & 0.003 & $\mathrm{~m}$ & Uniform \\
\hline HX Thickness (PHX-2) & TH5 & 0.001 & 0.003 & $\mathrm{~m}$ & Uniform \\
\hline HX activation energy (IHX) & EA1 & $5.19 \mathrm{E}+04$ & $6.4 \mathrm{E}+04$ & $\mathrm{~J} / \mathrm{mol}$ & Uniform \\
\hline HX activation energy (S/G) & EA2 & $5.19 \mathrm{E}+04$ & $6.4 \mathrm{E}+04$ & $\mathrm{~J} / \mathrm{mol}$ & Uniform \\
\hline HX activation energy (Reheater) & EA3 & $5.19 \mathrm{E}+04$ & $6.4 \mathrm{E}+04$ & $\mathrm{~J} / \mathrm{mol}$ & Uniform \\
\hline HX activation energy (PHX-1) & EA4 & $5.19 \mathrm{E}+04$ & $6.4 \mathrm{E}+04$ & $\mathrm{~J} / \mathrm{mol}$ & Uniform \\
\hline HX activation energy (PHX-2) & EA5 & $5.19 \mathrm{E}+04$ & $6.4 \mathrm{E}+04$ & $\mathrm{~J} / \mathrm{mol}$ & Uniform \\
\hline Temperature Level & CTL & 0.95 & 1.05 & $\#$ & Uniform \\
\hline
\end{tabular}

The tritium source ranges between $2.29 \times 10^{-11}$ and $1.08 \times 10^{-10} \mathrm{~m}^{3}(\mathrm{STP}) / \mathrm{s}$. This condition was obtained from the reported tritium birth rates and the tritium release ratio previously. The tritium birth rates for the various reactors range from $2.84 \times 10^{-11} \mathrm{~Bq} / \mathrm{y} / \mathrm{MWt}$ (for 3,000-MWt HTGR) to $4.28 \times 10^{-11} \mathrm{~Bq} / \mathrm{y} / \mathrm{MWt}$ (for England's 1,500-MWt HTGR). The tritium release ratios are reported to be 0.32 for the Peach Bottom reactor and 0.2 for the Fort St. Vrain reactor. In the TRITGO code, the release ratio is recommended to be 0.1 . By combining the tritium birth rates and the release ratios, the tritium release rate (tritium source) was estimated to range between $2.29 \times 10^{-11}$ and $1.08 \times 10^{-10} \mathrm{~m}^{3}(\mathrm{STP}) / \mathrm{s}$. The distribution was assumed to be uniform.

The mass flow into the purification system was determined to be $12 \sim 20 \% / \mathrm{h}$ of the total helium inventory in each loop. The numbers, 12 and 20\%/h are based on the Peach Bottom reactor and the Fort St. Vrain reactor, respectively.

The same tritium permeation coefficients and activation energies for permeation through the HX materials were used as the previous analyses.

In this analysis, the reference temperature was set to be constant during the analyses. However, the HX temperatures were determined to be between 95 and 105\% of the reference temperature. The IHX, SHX, and PHX temperatures were adjusted simultaneously by applying the same multiplication factors, CTL, which represent the temperature level.

In this study, the following six different sampling numbers were taken into consideration for checking convergence and accepting reliability of the results. The minimum number of samples is 640 for Case 1 , and the maximum number of samples is 20,480 for Case 6 .

- $\quad$ Case 1: 640 samples

- Case 2: 1,280 samples 
- Case 3: 2,560 samples

- $\quad$ Case 4: 5,120 samples

- Case 5: 10,240 samples

- Case 6: 20,480 samples.

\subsubsection{Model Evaluation}

The TPAC model was evaluated by adding the input data into the code. Because of too many samples - more than 20,000 - it is almost impossible to manually evaluate the models one by one for each sample case. For this reason, this study developed a MATLAB script for evaluating all the input dataset automatically. The MATLAB script and source code can be seen in Appendix B.

\subsubsection{Results and Discussions}

This section summarizes the evaluation and the uncertainty analysis results on the tritium concentrations in the gasoline, natural gas, and waste water. The following three results are mainly discussed here.

- Tritium concentrations in the gasoline, LPG, and waste water

- Tritium distribution in the HTGR/MTG system

- Identification of important parameters affecting tritium behaviors in the system.

Tritium concentrations in the gasoline, LPG, and waste water

The first results are tritium concentrations in the various system locations. Table 5-19 summarizes means, standard deviations, and percentiles (5\% and 95\%). Figure 5-29 shows the locations from CHT1 to CHT10. The locations in Table 5-19 are as follows:

- CHT1: Tritium concentration in the HTGR primary helium coolant

- CHT2: Tritium concentration in the secondary helium coolant

- CHT3: Tritium concentration in the PCS water

- CHT4: Tritium concentration in the waste water in the NG-RFMR

- CHT5: Tritium concentration in the waste water in the MEOH-SYN

- CHT6: Tritium concentration in the LPG product

- CHT7: Tritium concentration in the Gasoline product

- CHT8: Tritium concentration in the waste water in the MTG

- CHT9: Tritium concentration in the heat recovery steam generator-exhaust (HRSG-EX)

- CHT10: Tritium concentration in the boiler-blowdown (BLR-BLDN).

Among the following locations, this study focused on CHT6, CHT7, and CHT8, which are the main industrial products, and waste water. Table 5-19 shows that all the tritium concentrations are well converged for sample numbers higher than Case 5 (10,240 samples). 
Table 5-19. Results summary (statistics).

a. Mean

\begin{tabular}{|c|c|c|c|c|c|c|c|c|c|c|}
\hline \multicolumn{10}{|c|}{ Mean $(\mathrm{Bq} / \mathrm{cm} 3)$} \\
\hline & CHT1 & CHT2 & CHT3 & CHT4 & CHT5 & CHT6 & CHT7 & CHT8 & CHT9 & CHT10 \\
\hline Case1 & $1.15 \mathrm{E}+00$ & $5.82 \mathrm{E}-01$ & $1.05 \mathrm{E}-11$ & $4.70 \mathrm{E}-03$ & $4.70 \mathrm{E}-03$ & $2.17 \mathrm{E}-02$ & $2.90 \mathrm{E}-02$ & $4.95 \mathrm{E}-03$ & $5.25 \mathrm{E}-04$ & $4.22 \mathrm{E}-03$ \\
\hline Case2 & $1.26 \mathrm{E}+00$ & $6.28 \mathrm{E}-01$ & $1.09 \mathrm{E}-11$ & $4.54 \mathrm{E}-03$ & $4.54 \mathrm{E}-03$ & $2.09 \mathrm{E}-02$ & $2.80 \mathrm{E}-02$ & $4.78 \mathrm{E}-03$ & $5.07 \mathrm{E}-04$ & $4.07 \mathrm{E}-03$ \\
\hline Case3 & $1.26 \mathrm{E}+00$ & $6.15 \mathrm{E}-01$ & $1.08 \mathrm{E}-11$ & $4.49 \mathrm{E}-03$ & $4.49 \mathrm{E}-03$ & $2.07 \mathrm{E}-02$ & $2.78 \mathrm{E}-02$ & $4.73 \mathrm{E}-03$ & $5.02 \mathrm{E}-04$ & $4.03 \mathrm{E}-03$ \\
\hline Case4 & $1.29 \mathrm{E}+00$ & $6.13 \mathrm{E}-01$ & $1.09 \mathrm{E}-11$ & $4.47 \mathrm{E}-03$ & $4.47 \mathrm{E}-03$ & $2.06 \mathrm{E}-02$ & $2.76 \mathrm{E}-02$ & $4.71 \mathrm{E}-03$ & $4.99 \mathrm{E}-04$ & $4.01 \mathrm{E}-03$ \\
\hline Case5 & $1.31 \mathrm{E}+00$ & $6.29 \mathrm{E}-01$ & $1.08 \mathrm{E}-11$ & $4.50 \mathrm{E}-03$ & $4.50 \mathrm{E}-03$ & $2.08 \mathrm{E}-02$ & $2.78 \mathrm{E}-02$ & $4.74 \mathrm{E}-03$ & $5.03 \mathrm{E}-04$ & $4.04 \mathrm{E}-03$ \\
\hline Case6 & $1.32 \mathrm{E}+00$ & $6.35 \mathrm{E}-01$ & $1.10 \mathrm{E}-11$ & $4.46 \mathrm{E}-03$ & $4.46 \mathrm{E}-03$ & $2.06 \mathrm{E}-02$ & $2.76 \mathrm{E}-02$ & $4.69 \mathrm{E}-03$ & $4.98 \mathrm{E}-04$ & $4.00 \mathrm{E}-03$ \\
\hline
\end{tabular}

\section{b. Standard Deviation}

\begin{tabular}{|c|c|c|c|c|c|c|c|c|c|c|}
\hline \multicolumn{10}{|c|}{ Std (Bq/cm3) } \\
\hline & CHT1 & CHT2 & CHT3 & CHT4 & CHT5 & CHT6 & CHT7 & CHT8 & CHT9 & CHT10 \\
\hline Case1 & $6.52 \mathrm{E}-01$ & $3.26 \mathrm{E}-01$ & $6.60 \mathrm{E}-12$ & $3.21 \mathrm{E}-03$ & $3.21 \mathrm{E}-03$ & $1.48 \mathrm{E}-02$ & $1.98 \mathrm{E}-02$ & $3.37 \mathrm{E}-03$ & $3.59 \mathrm{E}-04$ & $2.88 \mathrm{E}-03$ \\
\hline Case2 & $8.72 \mathrm{E}-01$ & $4.90 \mathrm{E}-01$ & $7.87 \mathrm{E}-12$ & $2.95 \mathrm{E}-03$ & $2.95 \mathrm{E}-03$ & $1.36 \mathrm{E}-02$ & $1.82 \mathrm{E}-02$ & $3.09 \mathrm{E}-03$ & $3.29 \mathrm{E}-04$ & $2.64 \mathrm{E}-03$ \\
\hline Case3 & $8.83 \mathrm{E}-01$ & $4.43 \mathrm{E}-01$ & $7.88 \mathrm{E}-12$ & $2.93 \mathrm{E}-03$ & $2.93 \mathrm{E}-03$ & $1.35 \mathrm{E}-02$ & $1.81 \mathrm{E}-02$ & $3.07 \mathrm{E}-03$ & $3.27 \mathrm{E}-04$ & $2.63 \mathrm{E}-03$ \\
\hline Case4 & $1.01 \mathrm{E}+00$ & $4.51 \mathrm{E}-01$ & $8.04 \mathrm{E}-12$ & $2.91 \mathrm{E}-03$ & $2.91 \mathrm{E}-03$ & $1.34 \mathrm{E}-02$ & $1.79 \mathrm{E}-02$ & $3.05 \mathrm{E}-03$ & $3.25 \mathrm{E}-04$ & $2.61 \mathrm{E}-03$ \\
\hline Case5 & $1.05 \mathrm{E}+00$ & $4.89 \mathrm{E}-01$ & $8.17 \mathrm{E}-12$ & $2.95 \mathrm{E}-03$ & $2.95 \mathrm{E}-03$ & $1.36 \mathrm{E}-02$ & $1.82 \mathrm{E}-02$ & $3.09 \mathrm{E}-03$ & $3.29 \mathrm{E}-04$ & $2.64 \mathrm{E}-03$ \\
\hline Case6 & $1.05 \mathrm{E}+00$ & $5.06 \mathrm{E}-01$ & $8.21 \mathrm{E}-12$ & $2.89 \mathrm{E}-03$ & $2.89 \mathrm{E}-03$ & $1.33 \mathrm{E}-02$ & $1.78 \mathrm{E}-02$ & $3.04 \mathrm{E}-03$ & $3.23 \mathrm{E}-04$ & $2.59 \mathrm{E}-03$ \\
\hline
\end{tabular}

\section{c. $5 \%$ Percentile}

\begin{tabular}{|c|c|c|c|c|c|c|c|c|c|c|}
\hline \multicolumn{10}{|c|}{$5 \%$ Percentile (Bq/cm3) } \\
\hline & CHT1 & CHT2 & CHT3 & CHT4 & CHT5 & CHT6 & CHT7 & CHT8 & CHT9 & CHT10 \\
\hline Case1 & $3.44 \mathrm{E}-01$ & $1.68 \mathrm{E}-01$ & $2.35 \mathrm{E}-12$ & $9.36 \mathrm{E}-04$ & $9.36 \mathrm{E}-04$ & $4.36 \mathrm{E}-03$ & $5.84 \mathrm{E}-03$ & $9.94 \mathrm{E}-04$ & $1.05 \mathrm{E}-04$ & $8.43 \mathrm{E}-04$ \\
\hline Case2 & $3.15 \mathrm{E}-01$ & $1.21 \mathrm{E}-01$ & $1.80 \mathrm{E}-12$ & $5.77 \mathrm{E}-04$ & $5.77 \mathrm{E}-04$ & $2.75 \mathrm{E}-03$ & $3.68 \mathrm{E}-03$ & $6.27 \mathrm{E}-04$ & $6.50 \mathrm{E}-05$ & $5.22 \mathrm{E}-04$ \\
\hline Case3 & $2.91 \mathrm{E}-01$ & $1.07 \mathrm{E}-01$ & $1.68 \mathrm{E}-12$ & $6.07 \mathrm{E}-04$ & $6.07 \mathrm{E}-04$ & $2.81 \mathrm{E}-03$ & $3.76 \mathrm{E}-03$ & $6.41 \mathrm{E}-04$ & $6.78 \mathrm{E}-05$ & $5.44 \mathrm{E}-04$ \\
\hline Case4 & $2.96 \mathrm{E}-01$ & $1.23 \mathrm{E}-01$ & $1.67 \mathrm{E}-12$ & $5.73 \mathrm{E}-04$ & $5.73 \mathrm{E}-04$ & $2.70 \mathrm{E}-03$ & $3.61 \mathrm{E}-03$ & $6.15 \mathrm{E}-04$ & $6.44 \mathrm{E}-05$ & $5.17 \mathrm{E}-04$ \\
\hline Case5 & $3.04 \mathrm{E}-01$ & $1.31 \mathrm{E}-01$ & $1.63 \mathrm{E}-12$ & $5.81 \mathrm{E}-04$ & $5.81 \mathrm{E}-04$ & $2.75 \mathrm{E}-03$ & $3.68 \mathrm{E}-03$ & $6.27 \mathrm{E}-04$ & $6.53 \mathrm{E}-05$ & $5.24 \mathrm{E}-04$ \\
\hline Case6 & $3.13 \mathrm{E}-01$ & $1.32 \mathrm{E}-01$ & $1.63 \mathrm{E}-12$ & $6.04 \mathrm{E}-04$ & $6.04 \mathrm{E}-04$ & $2.84 \mathrm{E}-03$ & $3.80 \mathrm{E}-03$ & $6.47 \mathrm{E}-04$ & $6.78 \mathrm{E}-05$ & $5.45 \mathrm{E}-04$ \\
\hline
\end{tabular}

d. $95 \%$ Percentile

\begin{tabular}{|c|c|c|c|c|c|c|c|c|c|c|}
\hline \multicolumn{11}{|c|}{$95 \%$ Percentile $(\mathrm{Bq} / \mathrm{cm} 3)$} \\
\hline & CHT1 & CHT2 & CHT3 & CHT4 & CHT5 & CHT6 & CHT7 & CHT8 & CHT9 & CHT10 \\
\hline Case1 & $2.48 \mathrm{E}+00$ & $1.19 \mathrm{E}+00$ & $2.28 \mathrm{E}-11$ & $1.13 \mathrm{E}-02$ & $1.13 \mathrm{E}-02$ & $5.22 \mathrm{E}-02$ & $7.00 \mathrm{E}-02$ & $1.19 \mathrm{E}-02$ & $1.27 \mathrm{E}-03$ & $1.02 \mathrm{E}-02$ \\
\hline Case2 & $3.33 \mathrm{E}+00$ & $1.60 \mathrm{E}+00$ & $2.77 \mathrm{E}-11$ & $1.08 \mathrm{E}-02$ & $1.08 \mathrm{E}-02$ & $4.99 \mathrm{E}-02$ & $6.68 \mathrm{E}-02$ & $1.14 \mathrm{E}-02$ & $1.21 \mathrm{E}-03$ & $9.71 \mathrm{E}-03$ \\
\hline Case3 & $3.35 \mathrm{E}+00$ & $1.49 \mathrm{E}+00$ & $2.80 \mathrm{E}-11$ & $1.01 \mathrm{E}-02$ & $1.01 \mathrm{E}-02$ & $4.65 \mathrm{E}-02$ & $6.23 \mathrm{E}-02$ & $1.06 \mathrm{E}-02$ & $1.13 \mathrm{E}-03$ & $9.05 \mathrm{E}-03$ \\
\hline Case 4 & $3.38 \mathrm{E}+00$ & $1.49 \mathrm{E}+00$ & $2.77 \mathrm{E}-11$ & $9.99 \mathrm{E}-03$ & $9.99 \mathrm{E}-03$ & $4.60 \mathrm{E}-02$ & $6.16 \mathrm{E}-02$ & $1.05 \mathrm{E}-02$ & $1.12 \mathrm{E}-03$ & $8.96 \mathrm{E}-03$ \\
\hline Case 5 & $3.31 \mathrm{E}+00$ & $1.60 \mathrm{E}+00$ & $2.77 \mathrm{E}-11$ & $1.03 \mathrm{E}-02$ & $1.03 \mathrm{E}-02$ & $4.74 \mathrm{E}-02$ & $6.35 \mathrm{E}-02$ & $1.08 \mathrm{E}-02$ & $1.15 \mathrm{E}-03$ & $9.21 \mathrm{E}-03$ \\
\hline Case6 & $3.25 \mathrm{E}+00$ & $1.65 \mathrm{E}+00$ & $2.80 \mathrm{E}-11$ & $1.01 \mathrm{E}-02$ & $1.01 \mathrm{E}-02$ & $4.63 \mathrm{E}-02$ & $6.21 \mathrm{E}-02$ & $1.06 \mathrm{E}-02$ & $1.12 \mathrm{E}-03$ & $9.01 \mathrm{E}-03$ \\
\hline
\end{tabular}


Figures 5-30, 5-31, and 5-32 show all the estimated tritium concentrations and their frequencies for CHT6 (LPG), CHT7 (gasoline), and CHT8 (waste water), respectively. The average tritium concentration in the LPG (Figure 5-30 (a)) was estimated to be $2.06 \times 10^{-2} \mathrm{~Bq} / \mathrm{cm}^{3}$. About $7 \%$ of the cases were within the tritium effluent limit $\left(3.7 \times 10^{-3} \mathrm{~Bq} / \mathrm{cm}^{3}\right)$. The average tritium concentration in the gasoline (Figure 531 (a)) was estimated to be $2.76 \times 10^{-2} \mathrm{~Bq} / \mathrm{cm}^{3}$. About $5 \%$ of the cases were within tritium effluent limit $\left(3.7 \times 10^{-3} \mathrm{~Bq} / \mathrm{cm}^{3}\right)$. These tritium levels are considered to be very large even in low operating temperatures. Two main reasons for this high tritium concentration in the gasoline and LPG products are (1) large reactor power (1,200 MWt), and (2) large hydrogen atom numbers for each molecule. Large reactor power provides more tritium birth and release in the reactor core, and large hydrogen atom numbers make a molecule have several tritium atoms in itself, resulting in large tritium concentrations in a unit volume. For comparisons, Figures 5-30(b), 5-31(b), and 5-32(b) plot the tritium estimation results based on only Peach Bottom tritium permeation data in Figure 5-5. In this case, about $60 \%$ of the cases were within the tritium effluent limit $\left(3.7 \times 10^{-3} \mathrm{~Bq} / \mathrm{cm}^{3}\right)$. The average tritium concentration in the gasoline was estimated to be $4.00 \times 10^{-3} \mathrm{~Bq} / \mathrm{cm}^{3}$. About $50 \%$ of the cases were within tritium effluent limit $\left(3.7 \times 10^{-3} \mathrm{~Bq} / \mathrm{cm}^{3}\right)$.

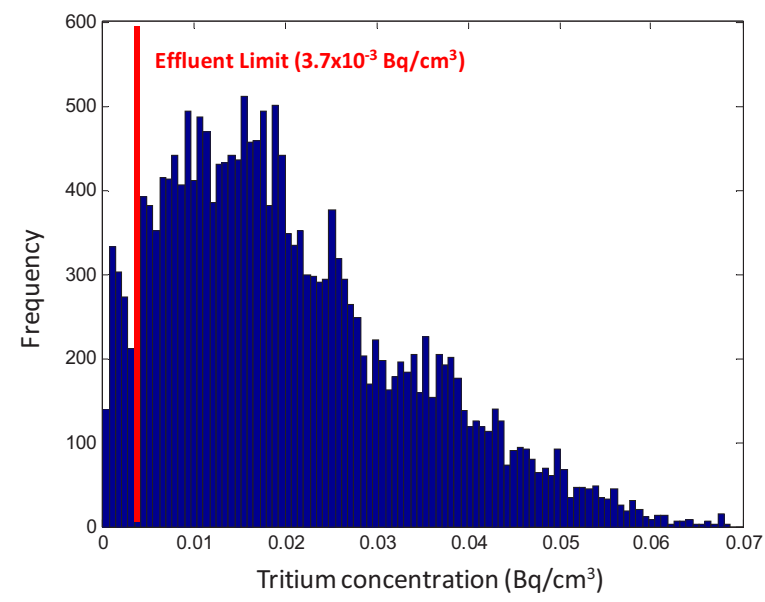

(a) Using Peach Bottom Data and Lab Experiment Data

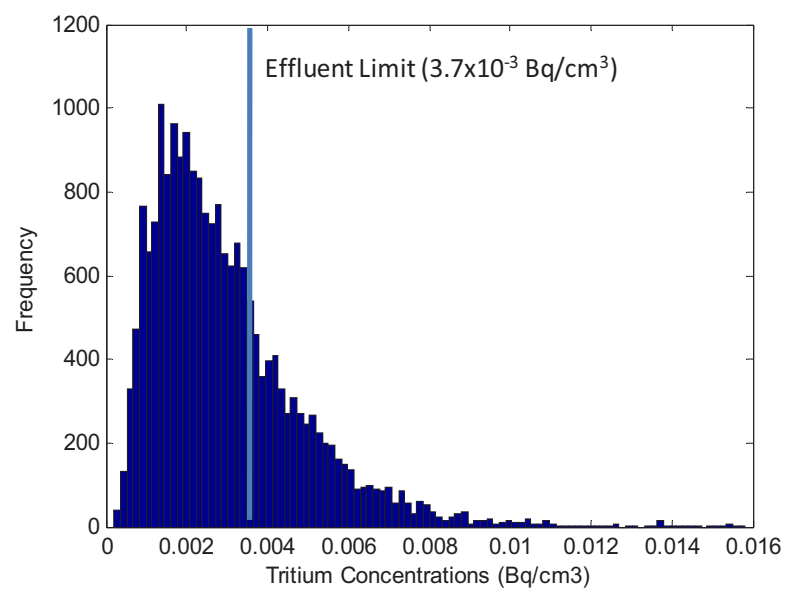

(b) Using Peach Bottom Data

Figure 5-30. Frequency distribution of the tritium concentration (LPG) without tritium barriers applied. 


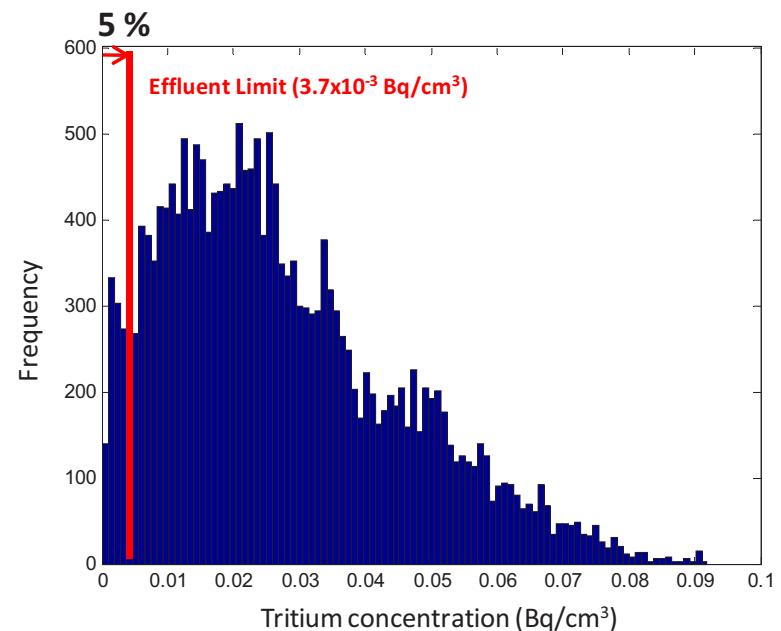

(a) Using Peach Bottom Data and Lab Experiment Data

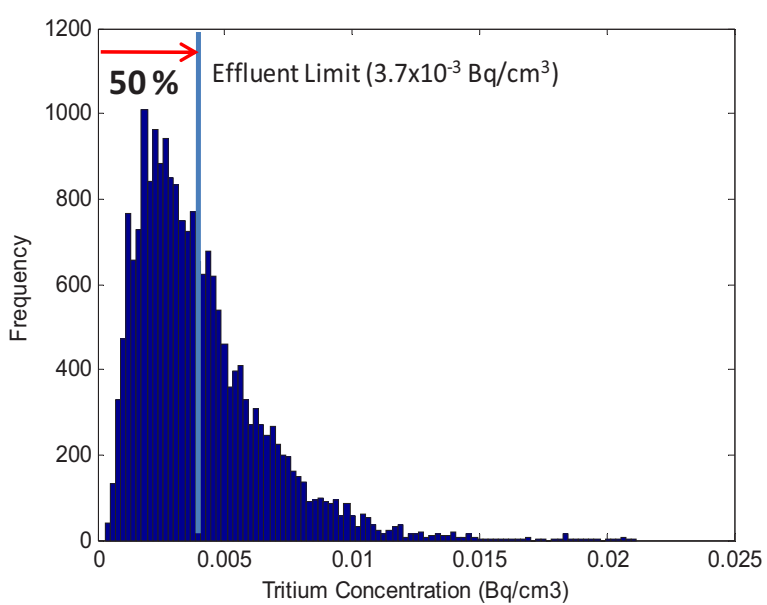

(b) Using Peach Bottom Data

Figure 5-31. Frequency distribution of the tritium concentration (gasoline) without tritium barriers applied.

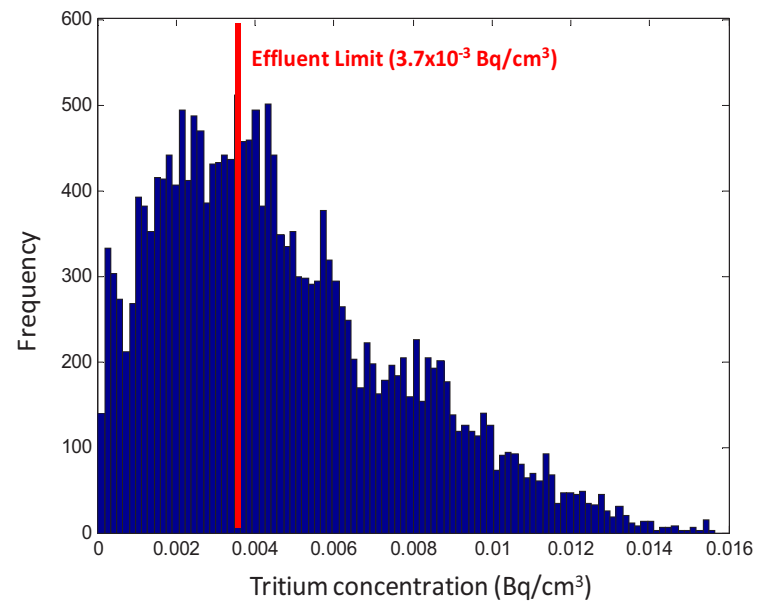

(a) Using Peach Bottom Data and Lab Experiment Data

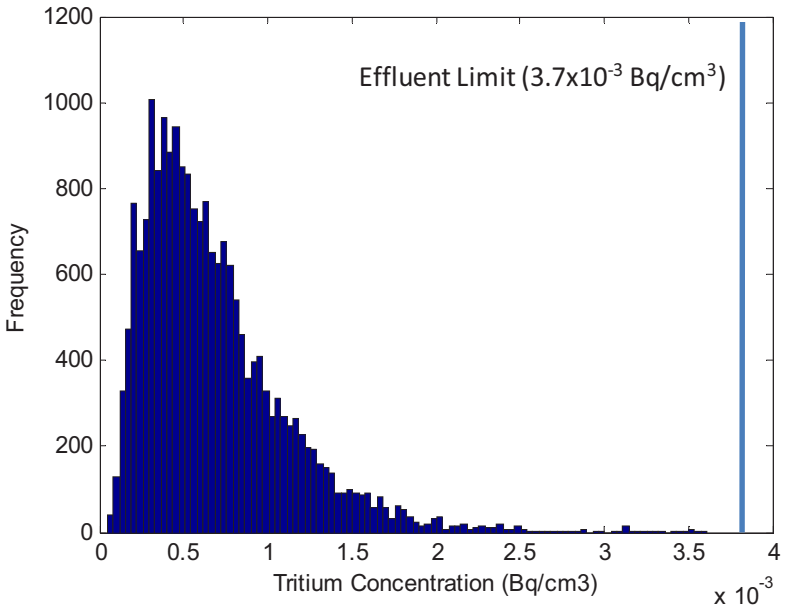

(b) Using Peach Bottom Data

Figure 5-32. Frequency distribution of tritium concentration $\left(\mathrm{MTG}-\mathrm{H}_{2} \mathrm{O}\right)$ without tritium barrier applied.

\section{Tritium distribution in the HTGR/MTG system}

Figure 5-33 shows tritium distribution in the HTGR/MTG system. The following summarizes the results:

- Initially, the tritium generated in the reactor core and $21 \%$ of the tritium is released to the primary loop.

- In the primary loop, about $3.38 \%$ of the tritium is purified in the purification system, and $17.6 \%$ is permeated to the secondary side through the IHX walls. Only $0.02 \%$ of the tritium is leaked to the outside of the primary loop.

- In the secondary loop, $2.6 \%$ of the tritium is purified and $5 \%$ is permeated to the PCS through the SHX and repeater. About $10 \%$ of the tritium transports to the MTG system through two PHXs. 
- In the MTG system, the tritium can go everywhere in the system components. Finally, $2.14 \%$ of the tritium release goes to the gasoline and $0.36 \%$, to the LPG. The rest, $7.5 \%$, goes to the other parts of the system components and waste products.

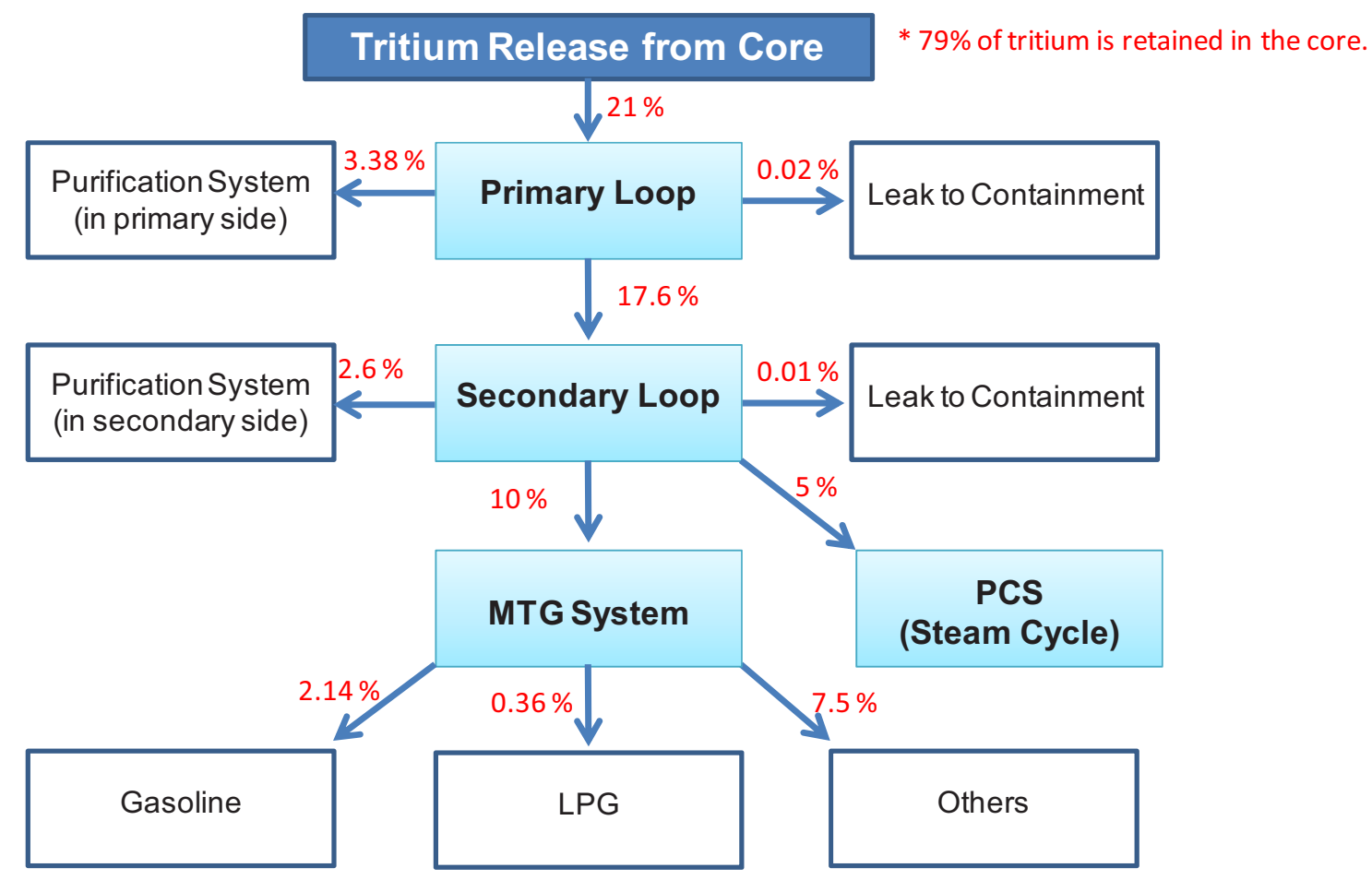

Figure 5-33. Tritium distribution in the nuclear-assisted MTG system.

\section{Important Parameters Affecting Tritium Behaviors in the HTGR/MTG system}

This section summarizes the results of the sensitivity study for the HTGR/MTG system. This study used two sensitivity indices used for measuring importance: (1) first-order index and (2) total index. The following describes the details.

\section{A. Main Effect (First-order Index)}

The main effect of a certain parameter can be quantified by the first-order index. The first-order index is highly related to the modeling uncertainties. If the first-order index of a certain parameter is large, it indicates that that parameter provides large contributions to the output uncertainties. Table 5-20 summarizes the first-order indices of the 19 input parameters estimated for the tritium concentrations. The locations of the CHT1 through CHT10 are already explained in Section 5.5.3.4. As shown in this table, the tritium concentration sensitivities in the MTG system are preserved throughout the whole system. Figure 5-34 shows the variations of the first-order indices for different sample numbers. As shown in this figure, the first-order indices are well converged for higher than 10,000 samples. The data summarized in Table 5-20 are obtained from Case 6, which is based on 20,480 sample numbers. 
Table 5-20. First-order indices.

\begin{tabular}{|c|c|c|c|c|c|c|c|c|c|c|}
\hline & CHT1 & CHT2 & CHT3 & CHT4 & CHT5 & CHT6 & CHT7 & CHT8 & CHT9 & CHT10 \\
\hline TS & 0.20 & 0.22 & 0.26 & 0.35 & 0.35 & 0.35 & 0.35 & 0.35 & 0.35 & 0.35 \\
\hline PMF1 & 0.00 & 0.00 & 0.00 & 0.00 & 0.00 & 0.00 & 0.00 & 0.00 & 0.00 & 0.00 \\
\hline PMF2 & 0.00 & 0.00 & 0.00 & 0.00 & 0.00 & 0.00 & 0.00 & 0.00 & 0.00 & 0.00 \\
\hline C1 & 0.45 & 0.03 & 0.03 & 0.05 & 0.05 & 0.05 & 0.05 & 0.05 & 0.05 & 0.05 \\
\hline C2 & 0.01 & 0.04 & 0.11 & 0.02 & 0.02 & 0.02 & 0.02 & 0.02 & 0.02 & 0.02 \\
\hline C3 & 0.00 & 0.01 & 0.02 & 0.01 & 0.01 & 0.01 & 0.01 & 0.01 & 0.01 & 0.01 \\
\hline C4 & 0.03 & 0.22 & 0.17 & 0.28 & 0.28 & 0.27 & 0.27 & 0.27 & 0.28 & 0.28 \\
\hline C5 & 0.00 & 0.00 & 0.00 & 0.00 & 0.00 & 0.00 & 0.00 & 0.00 & 0.00 & 0.00 \\
\hline TH1 & 0.02 & 0.00 & 0.00 & 0.00 & 0.00 & 0.00 & 0.00 & 0.00 & 0.00 & 0.00 \\
\hline TH2 & 0.01 & 0.01 & 0.02 & 0.01 & 0.01 & 0.01 & 0.01 & 0.01 & 0.01 & 0.01 \\
\hline TH3 & 0.00 & -0.01 & 0.01 & 0.01 & 0.01 & 0.01 & 0.01 & 0.01 & 0.01 & 0.01 \\
\hline TH4 & 0.00 & 0.02 & 0.02 & 0.03 & 0.03 & 0.03 & 0.03 & 0.03 & 0.03 & 0.03 \\
\hline TH5 & 0.00 & 0.00 & 0.00 & 0.00 & 0.00 & 0.00 & 0.00 & 0.00 & 0.00 & 0.00 \\
\hline EA1 & 0.04 & 0.00 & 0.00 & 0.00 & 0.00 & 0.00 & 0.00 & 0.00 & 0.00 & 0.00 \\
\hline EA2 & 0.00 & 0.02 & 0.09 & 0.03 & 0.03 & 0.04 & 0.04 & 0.04 & 0.03 & 0.03 \\
\hline EA3 & 0.00 & 0.02 & 0.01 & 0.01 & 0.01 & 0.01 & 0.01 & 0.01 & 0.01 & 0.01 \\
\hline EA4 & 0.02 & 0.08 & 0.07 & 0.11 & 0.11 & 0.11 & 0.11 & 0.11 & 0.11 & 0.11 \\
\hline EA5 & 0.00 & 0.00 & 0.00 & 0.00 & 0.00 & 0.00 & 0.00 & 0.00 & 0.00 & 0.00 \\
\hline CTL & 0.05 & 0.07 & 0.02 & 0.00 & 0.00 & 0.00 & 0.00 & 0.00 & 0.00 & 0.00 \\
\hline
\end{tabular}

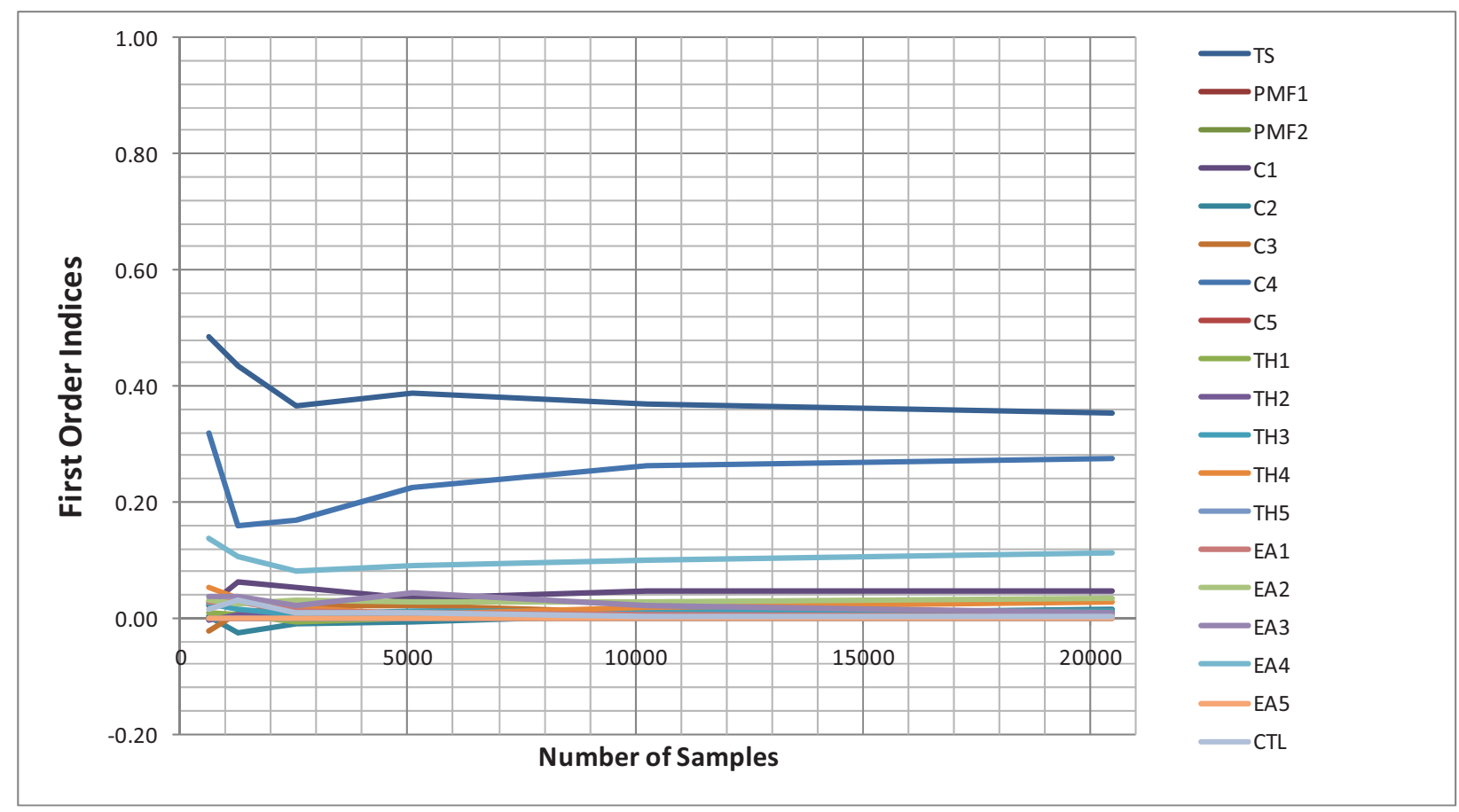

Figure 5-34. First-order indices for different sample numbers (tritium concentration in the MTG products).

Figure 5-35 compares the first-order indices for various parameters in the MTG system. As shown in this figure, the TS has the largest first-order index, which is 0.35 . It means that $35 \%$ of the output uncertainties come from the TS model and parameter uncertainties. The second important parameter is the PHX-1 permeation coefficient (C4). In this case, the sensitivity index is 0.27 , which means that $27 \%$ of 
the output uncertainties are contributed by this parameter. The third and fourth important parameters are activation energy of the PHX-1 and permeation coefficient of the IHX. These four parameters (TS, C4, EA4, and C1) contribute about $78 \%$ of output uncertainties. On the other hand, the effects of the other 14 parameters are negligible. This result gives us some ideas to reduce modeling uncertainties, which will eventually provide more design margins. The model uncertainties can be effectively reduced by:

- Improving accuracy of the input parameters on the tritium birth and release models

- Improving accuracy of the tritium permeation models and parameters

- Obtaining accurate information of the PHX-1detailed design.

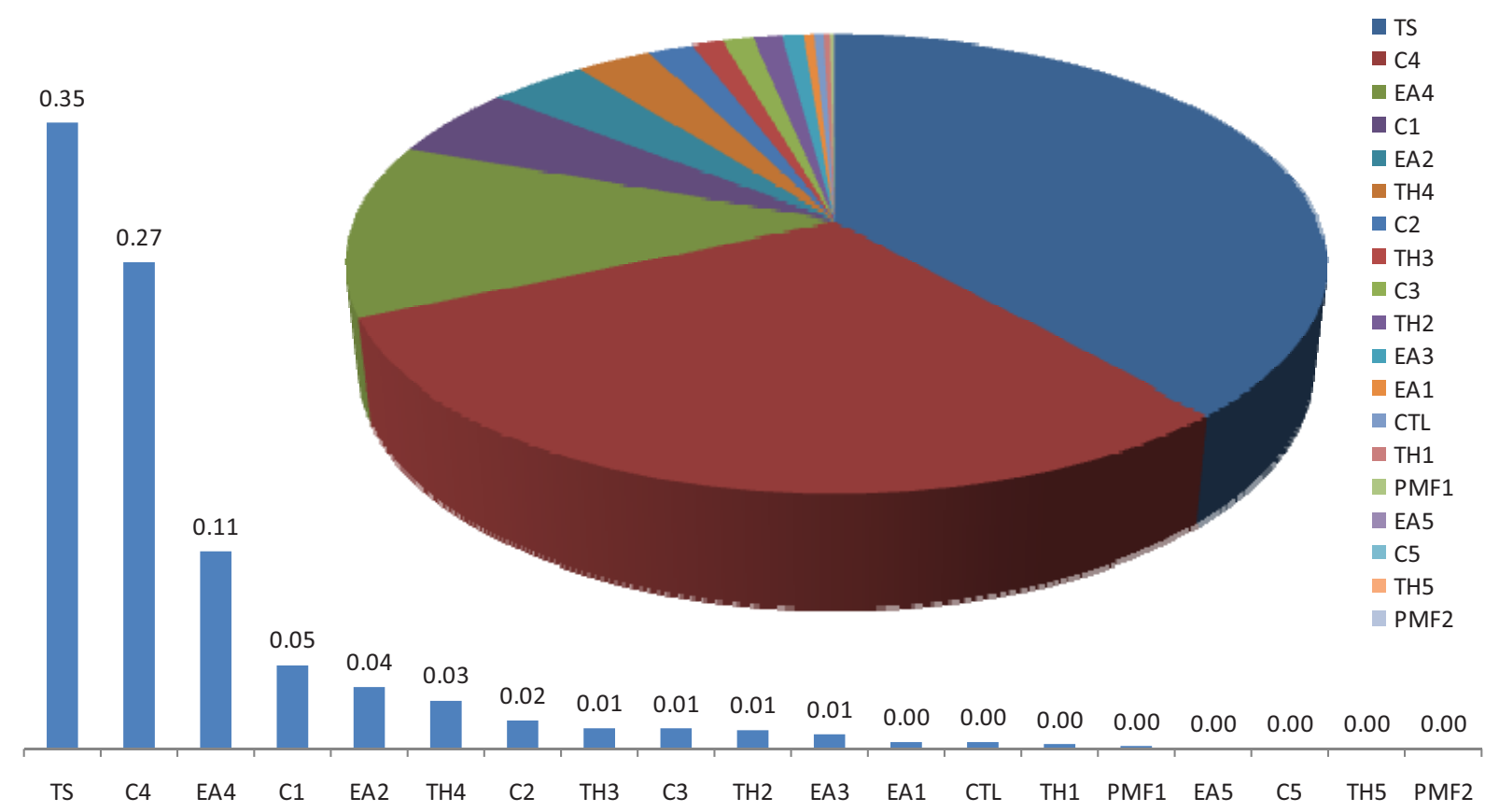

Figure 5-35. First-order indices (tritium concentration in the MTG system).

\section{B. Total Effect (Total Index)}

The total effect of a certain parameter can be quantified by the total index, which is a summation of the first-order index and all its interactions. The total index is highly related to the output value itself. If the total index is large for a certain parameter, it indicates that the output is very sensitive to the change of that parameter. Table 5-21 summarizes the estimated total indices of the 19 input parameters for tritium concentrations. In this table, the locations from CHT4 to CHT10 represent the MTG system. The detailed locations can be seen in Figure 5-29. As shown in this table, the tritium sensitivities in the MTG system are uniform throughout the whole system. Figure 5-36 shows the variations of the first-order indices for different sample numbers. As shown in this figure, the first-order indices are well converged for higher than 10,000 samples. The data summarized in Table 5-21 are based on the 20,480 sample numbers. 
Table 5-21. Total indices.

\begin{tabular}{|c|c|c|c|c|c|c|c|c|c|c|}
\hline & CHT1 & CHT2 & CHT3 & CHT4 & CHT5 & CHT6 & CHT7 & CHT8 & CHT9 & CHT10 \\
\hline TS & 0.29 & 0.30 & 0.35 & 0.43 & 0.43 & 0.43 & 0.43 & 0.43 & 0.43 & 0.43 \\
\hline PMF1 & 0.02 & 0.00 & 0.01 & 0.00 & 0.00 & 0.00 & 0.00 & 0.00 & 0.00 & 0.00 \\
\hline PMF2 & 0.00 & 0.00 & 0.00 & 0.00 & 0.00 & 0.00 & 0.00 & 0.00 & 0.00 & 0.00 \\
\hline C1 & 0.55 & 0.05 & 0.06 & 0.07 & 0.07 & 0.07 & 0.07 & 0.07 & 0.07 & 0.07 \\
\hline C2 & 0.02 & 0.11 & 0.15 & 0.02 & 0.02 & 0.02 & 0.02 & 0.02 & 0.02 & 0.02 \\
\hline C3 & 0.01 & 0.03 & 0.04 & 0.02 & 0.02 & 0.02 & 0.02 & 0.02 & 0.02 & 0.02 \\
\hline C4 & 0.06 & 0.32 & 0.23 & 0.34 & 0.34 & 0.33 & 0.33 & 0.33 & 0.34 & 0.34 \\
\hline C5 & 0.00 & 0.00 & 0.00 & 0.00 & 0.00 & 0.00 & 0.00 & 0.00 & 0.00 & 0.00 \\
\hline TH1 & 0.04 & 0.00 & 0.00 & 0.00 & 0.00 & 0.00 & 0.00 & 0.00 & 0.00 & 0.00 \\
\hline TH2 & 0.00 & 0.00 & 0.03 & 0.01 & 0.01 & 0.01 & 0.01 & 0.01 & 0.01 & 0.01 \\
\hline TH3 & 0.00 & 0.00 & 0.01 & 0.01 & 0.01 & 0.01 & 0.01 & 0.01 & 0.01 & 0.01 \\
\hline TH4 & 0.01 & 0.04 & 0.03 & 0.03 & 0.03 & 0.03 & 0.03 & 0.03 & 0.03 & 0.03 \\
\hline TH5 & 0.00 & 0.00 & 0.00 & 0.00 & 0.00 & 0.00 & 0.00 & 0.00 & 0.00 & 0.00 \\
\hline EA1 & 0.07 & 0.00 & 0.01 & 0.01 & 0.01 & 0.01 & 0.01 & 0.01 & 0.01 & 0.01 \\
\hline EA2 & 0.02 & 0.08 & 0.12 & 0.05 & 0.05 & 0.05 & 0.05 & 0.05 & 0.05 & 0.05 \\
\hline EA3 & 0.02 & 0.07 & 0.03 & 0.01 & 0.01 & 0.01 & 0.01 & 0.01 & 0.01 & 0.01 \\
\hline EA4 & 0.03 & 0.14 & 0.09 & 0.14 & 0.14 & 0.14 & 0.14 & 0.14 & 0.14 & 0.14 \\
\hline EA5 & 0.00 & 0.00 & 0.00 & 0.00 & 0.00 & 0.00 & 0.00 & 0.00 & 0.00 & 0.00 \\
\hline CTL & 0.06 & 0.09 & 0.03 & 0.00 & 0.00 & 0.00 & 0.00 & 0.00 & 0.00 & 0.00 \\
\hline
\end{tabular}

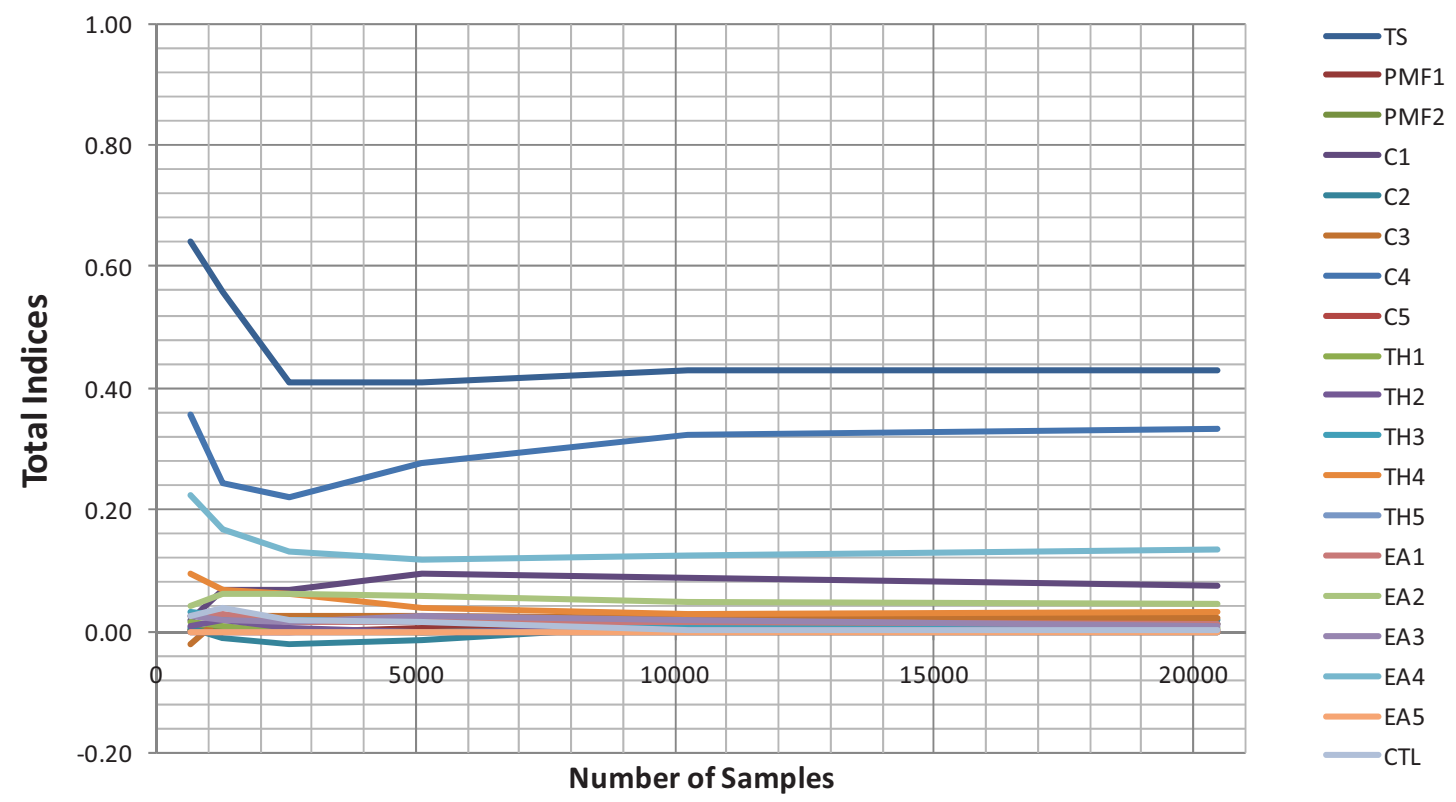

Figure 5-36. Total indices for different sample numbers (tritium concentration in the MTG products). 
Figure 5-37 compares the total indices for various parameters in the MTG system. As shown in this figure, the TS has the total index, which is 0.43 . It means that the change of this parameter affects tritium concentration in the MTG system the most significantly. The second important parameter is the permeation coefficient of the PHX-1 (C4), and the third and the fourth important parameters are the activation energy of the PHX-1 (EA4) and the permeation coefficient of the IHX (C1). Compared to these four parameters, the effects of the other 14 parameters are very small. This result gives us some ideas to reduce tritium concentration in the MTG system, which will eventually mitigate tritium in the system. The tritium level in the MTG system can be effectively reduced by:

- Improving fuel quality in the core (reducing tritium release)

- Reducing impurities in the core structures (reducing tritium birth)

- Changing or improving heat exchanger wall materials

- Coating heat exchanger walls with tritium barriers

- $\quad$ Reducing operating temperatures.

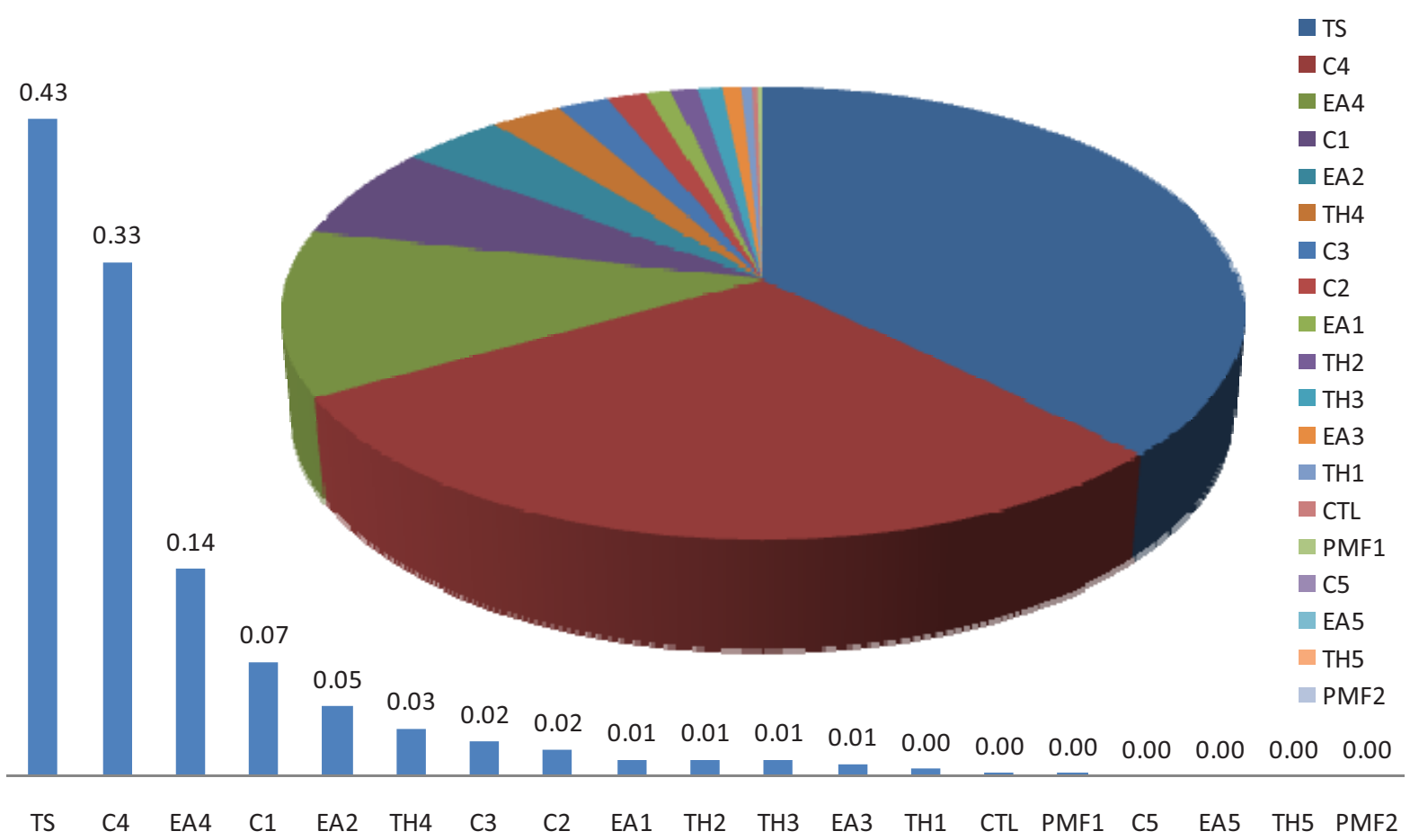

Figure 5-37. Total indices (tritium concentration in the MTG system).

Figure 5-38 shows the first-order indices and the total indices in the same plot. As shown in this figure, the total indices are not much different from the first-order indices. It indicates that the main parameter effect is dominant compared to the interaction effects. The differences between the first-order indices and the total indices represent a sum of the higher order terms, which means parameter interactions. 


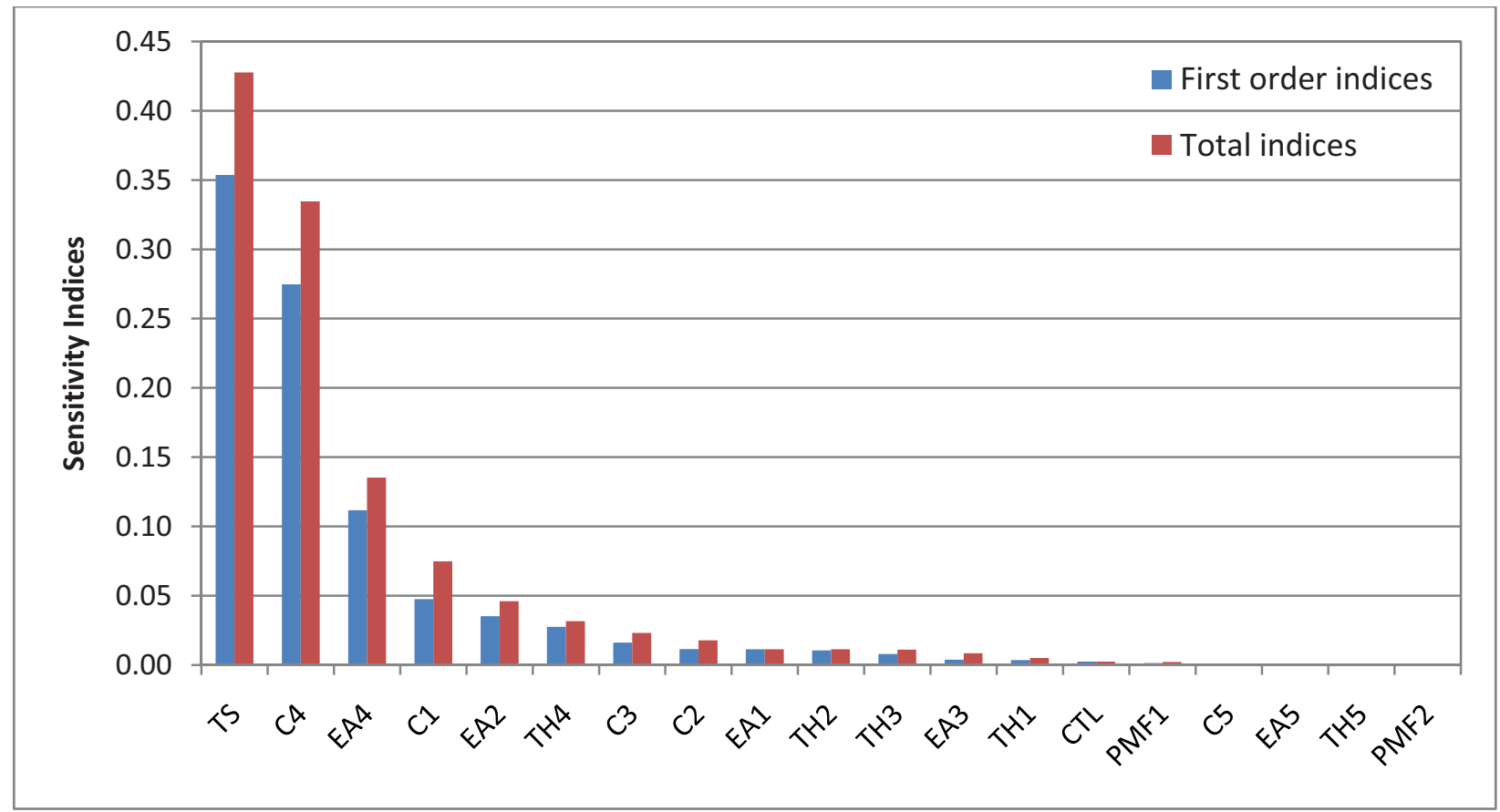

Figure 5-38. First-order indices and total indices (tritium concentration in the MTG system).

\subsubsection{Summary}

In this section, we analyzed tritium behaviors in the HTGR/MTG system. The HTGR system was designed based on 1,200-MWt power (two 600-MWt modules) and a $750^{\circ} \mathrm{C}$ core outlet temperature. This system consists of the following four separate loops:

- Reactor primary side

- Reactor secondary side

- $\quad$ PCS

- $\quad$ MTG system

The primary heat was transferred to the secondary side through an IHX. In secondary side, the heat was transferred to the PCS and HTSE system through an SHX and a PHX. The PCS was based on the steam Rankin cycle. The proposed MTG system includes operation units for air separation (ASU), natural gas purification and reforming (NG-RFMR), methanol synthesis (MEOH-SYN), methanol conversion to gasoline (MTG), power production (HTSG-ST), cooling tower, and water treatment. Nuclear heat is used to preheat all streams entering the primary reformer.

The HTGR/MTG system was modeled by the TPAC code. Most of the information for modeling was obtained or determined from previous literature, HYSYS flowsheet analyses, and some assumptions. For sensitivity analyses, we agreed on 19 input parameters by discussion and randomly generated 20,450 inputs using the SIMLAB software. For automatic evaluations of a large number of samples, we developed a MATLAB script that links MATLAB workspace parameters and the TPAC input variables. In this study, the following three things were taken into account in detail:

- Tritium concentration in the hydrogen product

- Tritium distribution in the HTGR/HTSE system

- Important factors affecting tritium behaviors. 
First, we estimated tritium concentration in the three locations: (1) gasoline, (2) LPG, and (3) waste water. According to the estimations, the average tritium concentration in the LPG was estimated to be $2.06 \times 10^{-2} \mathrm{~Bq} / \mathrm{cm}^{3}$. About $7 \%$ of the cases were within tritium effluent limit $\left(3.7 \times 10^{-3} \mathrm{~Bq} / \mathrm{cm}^{3}\right)$. The average tritium concentration in the gasoline was estimated to be $2.76 \times 10^{-2} \mathrm{~Bq} / \mathrm{cm}^{3}$. About $5 \%$ of the cases were within tritium effluent limit $\left(3.7 \times 10^{-3} \mathrm{~Bq} / \mathrm{cm}^{3}\right)$. These tritium levels are considered to be very large even in the low operating temperatures. This is because of many hydrogen atoms in gasoline and LPG molecules. One molecule can have several tritium atoms that are replaced with hydrogen. This leads to large tritium concentrations in a unit volume.

Second, we estimated tritium distribution in the HTGR/MTG system. According to the analyses, initially, the tritium generated in the reactor core and $21 \%$ of the tritium is released to the primary loop. In the primary loop, about $3.38 \%$ of the tritium is purified in the purification system, and $17.6 \%$ is permeated to the secondary side through the IHX walls. Only $0.02 \%$ of the tritium is leaked to the outside of the primary loop. In the secondary loop, $2.6 \%$ of the tritium release is purified and $5.0 \%$ is permeated to the PCS through the SHX and repeater. About $10 \%$ of the tritium transports to the MTG system through two PHXs. In the MTG system, the tritium can go everywhere in the system components. Finally, $2.14 \%$ of the tritium release goes to the gasoline and $0.36 \%$, to the LPG. The rest, $7.5 \%$, goes to the other parts of the system components and waste products.

Finally, we conducted global sensitivity analyses in order to identify important factors that affect tritium behaviors in the HTGR/MTG system. These analyses were based on the method proposed by Sobol, and two importance measures were estimated by the SIMLAB software. In these analyses, the following four parameters were identified as important for both reducing modeling uncertainties and reducing tritium concentration in the hydrogen product.

- TSs

- Permeation coefficient for PHX-1 (C4)

- Activation energy for PHX-1 (EA4)

- Permeation coefficient for IHX (C1)

The above parameters were estimated to contribute about $78 \%$ of the total uncertainties. It is strongly recommended that future research concentrate on improving those parameters and model accuracies. Also, it is recommended that the methods to effectively control those parameters are developed in the future for mitigating tritium in the system. 


\subsection{Analyses on the HTGR/MTG System (II) - Improved Flowsheet}

This section discusses the tritium analyses results for another HTGR/MTG system, which was improved from the flowsheet estimated in Section 5.5 (Wood et al. 2010). This system also generates gasoline from natural gas using nuclear heat. In this system, the core outlet temperature is $750^{\circ} \mathrm{C}$, and the PCS is designed based on the steam Rankin cycle. The proposed system includes operation units for air separation (ASU), natural gas purification and reforming (NG-RFMR), methanol synthesis (MEOHSYN), methanol conversion to gasoline (MTG), power production (HTSG-ST), the cooling tower, and water treatment. Nuclear heat is used to preheat all streams entering the primary reformer. In addition, nuclear heat is used rather than firing fuel gas for product upgrading in the MTG plant. Each unit operation is the same as explained in Section 5.5 except for the nuclear reactor specifications.

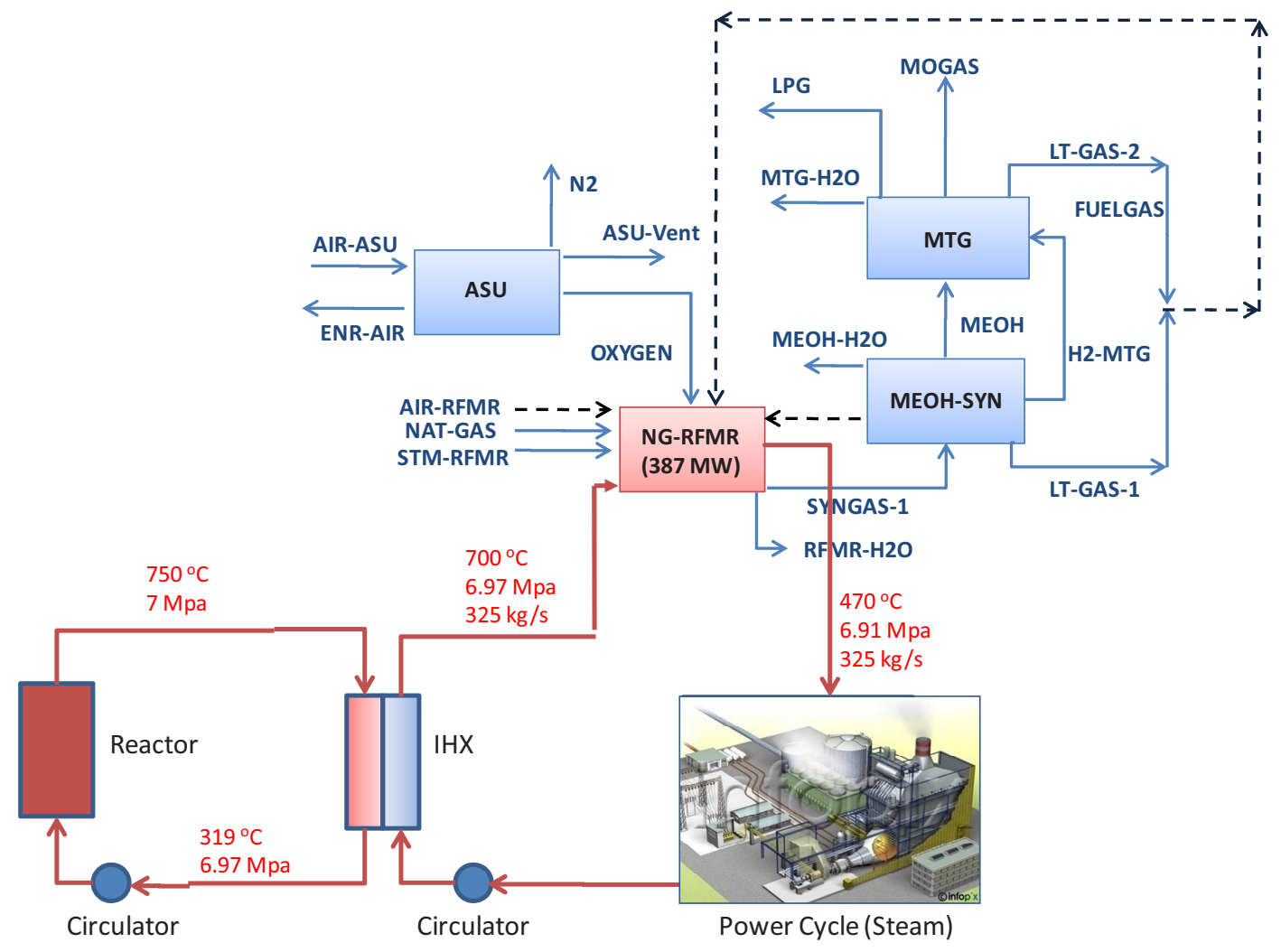

Figure 5-39. Nuclear-assisted methanol-to-gasoline (MTG) system (II).

The improved MTG system is much simpler than the previous one. Figure 5-39 shows a schematic of the new system. In this system, a single reactor module with $721 \mathrm{MWt}$ was combined with the MTG system and the steam Rankin cycle for generation of gasoline and electricity. Helium was selected as the primary and secondary coolants. The maximum core outlet temperature is $750^{\circ} \mathrm{C}$ and the inlet temperature, $322^{\circ} \mathrm{C}$. The primary side and the secondary side are connected via an IHX. In the secondary side, the hot helium exiting the IHX is first entered to the reformer for transferring heat to the MTG system. The reformer exit temperature of the helium coolant is $470^{\circ} \mathrm{C}$. The helium coolant at the exit of the reformer is connected to the steam power cycle via a steam generator and a reheater. The steam cycle is based on the Rankin cycle, and the power generation efficiency is about $31.55 \%$, which is $6 \%$ lower than the original MTG system. The lower reformer exit temperature decreases Rankin cycle maximum temperature, finally resulting in lower efficiency. However, in the new system, the overall gasoline generation efficiency and heat requirement were improved. Table 5-22 compares the new MTG system with the original one. 
Table 5-22. Comparisons of the new MTG system with the original one.

\begin{tabular}{|l|c|c|}
\hline & Original System (Section 5.5) & Improved System (Section 5.6) \\
\hline Reactor Power (MWt) & 1,200 & 721 \\
\hline $\begin{array}{l}\text { Total Electrical Demand } \\
\text { (MW) }\end{array}$ & 79.6 & 79.7 \\
\hline Total Heat Demand (MW) & 500 & 387 \\
\hline Gasoline Product (Ton/day) & 4,267 & 4,267 \\
\hline LPG Product (Ton/day) & 508 & 508 \\
\hline $\mathrm{CO}_{2}$ Emission (Ton/day) & 706 & 884 \\
\hline
\end{tabular}

\subsubsection{TPAC Modeling}

Figure 5-40 shows the TPAC model for the improved nuclear-assisted MTG system (II). The TPAC model used four heat exchangers for integration of a nuclear reactor, a steam power cycle, and a MTG plant: (1) an IHX, (2) a steam generator, (3) a reheater, and (4) a PHX. The model assumed the IHX as a PCHE and the others as tubular types. The HX sizes and rates were based on typical heat exchanger design methodologies (Kakac and Liu, 2002). 


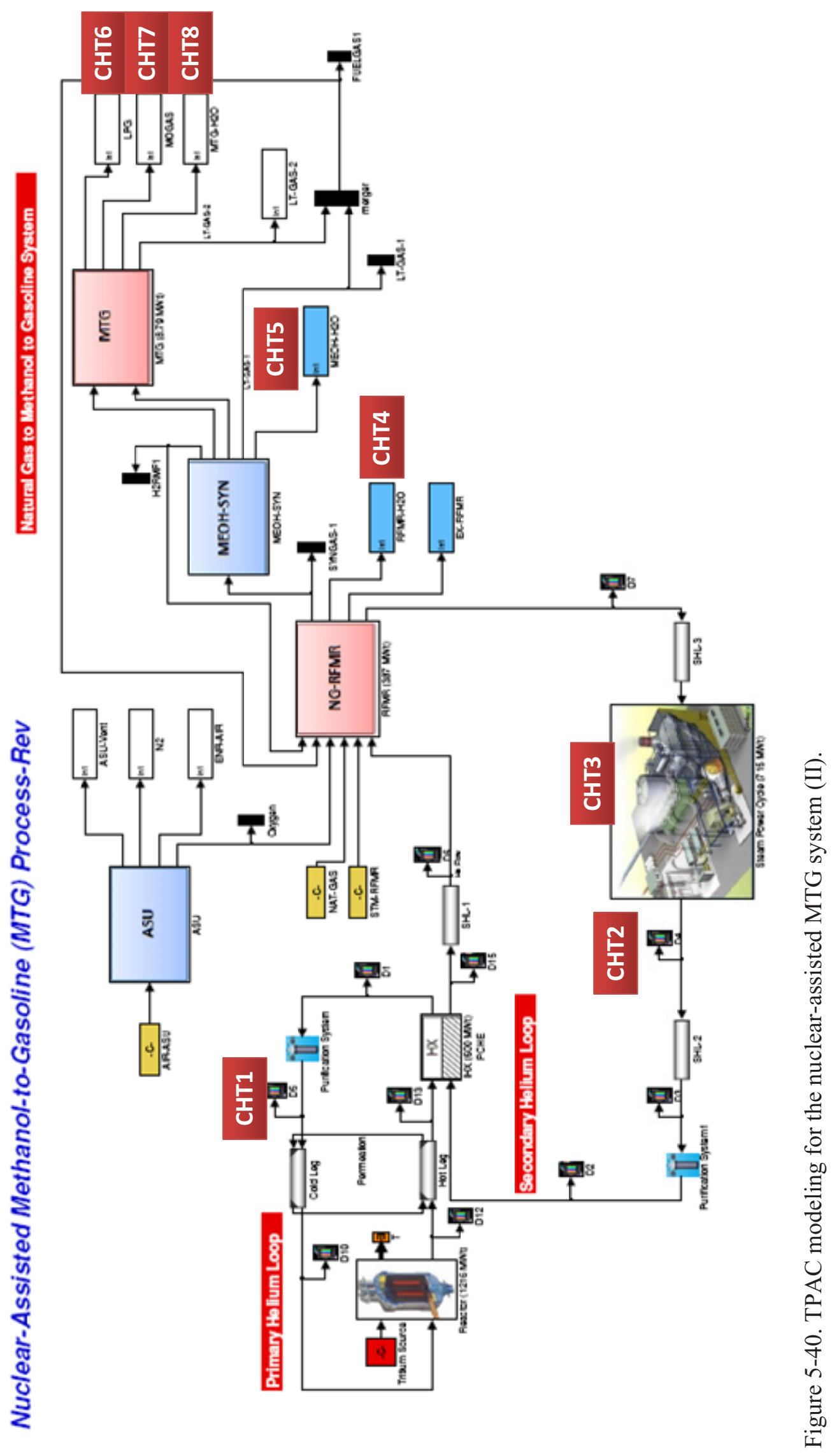




\section{Basic Assumptions on the TPAC Model for the MTG System}

The MTG plant had to be simplified because of its complexity and lack of information. The following assumptions were used for configuring the MTG system in the TPAC code.

- Tritium-containing species (HT, HTO) will be conserved between inlet and outlet of the components.

- The amount of tritium-containing species (HT and HTO) is negligibly small compared to the main flow rate. (Generation or absorption of the tritium does not affect the main stream conditions and properties.)

- $\quad$ HT is chemically identical to $\mathrm{H}_{2}$.

- $\quad \mathrm{HTO}$ is chemically identical to $\mathrm{H}_{2} \mathrm{O}$.

- All the species are homogeneously mixed.

- The isotope exchange between $\mathrm{HT}$ and $\mathrm{H}_{2} \mathrm{O}$ will be considered in the modeling of the steam Rankin cycle. $\left(\mathrm{HT}+\mathrm{H}_{2} \mathrm{O}=\mathrm{H}_{2}+\mathrm{HTO}\right)$

- Isotope exchanges for other species will not be considered because of the lack of information.

\subsubsection{Uncertainty and Sensitivity Analyses}

This section describes the uncertainty and sensitivity analyses for the HTGR/MTG system (II). The analysis method is basically the same as that described in the Section 5.3. In this study, about 18,000 samples were randomly generated and implemented into the TPAC code. The following summarizes the detailed procedures.

\subsubsection{Input Selection}

We first selected 16 major parameters in this analysis. Table 5-23 summarizes the input parameters and their physical representations.

Table 5-23. List of input parameters for uncertainty and sensitivity analysis.

\begin{tabular}{|l|l|}
\hline Input Parameters & Representations \\
\hline TS & Tritium Source \\
\hline PMF1 & Fraction of Mass Flow to Purification System (P-1st) \\
\hline PMF2 & Fraction of Mass Flow to Purification System (P-2nd) \\
\hline C1 & Reaction Coefficient (IHX) \\
\hline C2 & Reaction Coefficient (S/G) \\
\hline C3 & Reaction Coefficient (Reheater) \\
\hline C4 & Reaction Coefficient (PHX) \\
\hline TH1 & HX Thickness (IHX) \\
\hline TH2 & HX Thickness (S/G) \\
\hline TH3 & HX Thickness (Reheater) \\
\hline TH4 & HX Thickness (PHX) \\
\hline EA1 & HX activation energy (IHX) \\
\hline EA2 & HX activation energy (S/G) \\
\hline EA3 & HX activation energy (Reheater) \\
\hline EA4 & HX activation energy (PHX) \\
\hline CTL & Temperature Level \\
\hline
\end{tabular}




\subsubsection{Input Generation}

Table 5-24 summarizes sixteen model input parameters and their ranges. This study assumed uniform distribution for all the input parameters because of lacking information. The uniform distribution generally provides higher uncertainties than any other distributions such as Gaussian or Lognormal distributions. It indicates that the results estimated in this study are considered conservative.

Table 5-24. List of input parameters and ranges for sensitivity analyses.

\begin{tabular}{|l|c|c|c|c|c|}
\hline \multicolumn{1}{|c|}{ Parameters } & Para N. & Min & Max & Unit & Distribution \\
\hline Tritium Source & TS & $1.36 \mathrm{E}-11$ & $6.44 \mathrm{E}-11$ & $\mathrm{~m}^{3}(\mathrm{STP}) / \mathrm{s}$ & Uniform \\
\hline $\begin{array}{l}\text { Fraction of Mass Flow to } \\
\text { Purification System (P-1st) }\end{array}$ & PMF1 & $1.20 \mathrm{E}-4$ & $2.07 \mathrm{E}-4$ & & Uniform \\
\hline $\begin{array}{l}\text { Fraction of Mass Flow to } \\
\text { Purification System (P-2nd) }\end{array}$ & PMF2 & $5.07 \mathrm{E}-5$ & $8.44 \mathrm{E}-5$ & & Uniform \\
\hline Reaction Coefficient (IHX) & C1 & $5.33 \mathrm{E}-11$ & $1.26 \mathrm{E}-8$ & & Uniform \\
\hline Reaction Coefficient (S/G) & C2 & $5.33 \mathrm{E}-11$ & $1.26 \mathrm{E}-8$ & & Uniform \\
\hline Reaction Coefficient (Reheater) & C3 & $5.33 \mathrm{E}-11$ & $1.26 \mathrm{E}-8$ & & Uniform \\
\hline Reaction Coefficient (PHX-1) & C4 & $5.33 \mathrm{E}-11$ & $1.26 \mathrm{E}-8$ & & Uniform \\
\hline Hx Thickness (IHX) & TH1 & 0.001 & 0.003 & $\mathrm{~m}$ & Uniform \\
\hline Hx Thickness (S/G) & TH2 & 0.001 & 0.003 & $\mathrm{~m}$ & Uniform \\
\hline Hx Thickness (Reheater) & TH3 & 0.001 & 0.003 & $\mathrm{~m}$ & Uniform \\
\hline Hx Thickness (PHX-1) & TH4 & 0.001 & 0.003 & $\mathrm{~m}$ & Uniform \\
\hline HX activation energy (IHX) & EA1 & $5.19 \mathrm{E}+04$ & $6.4 \mathrm{E}+04$ & $\mathrm{~J} / \mathrm{mol}$ & Uniform \\
\hline HX activation energy (S/G) & EA2 & $5.19 \mathrm{E}+04$ & $6.4 \mathrm{E}+04$ & $\mathrm{~J} / \mathrm{mol}$ & Uniform \\
\hline HX activation energy (Reheater) & EA3 & $5.19 \mathrm{E}+04$ & $6.4 \mathrm{E}+04$ & $\mathrm{~J} / \mathrm{mol}$ & Uniform \\
\hline HX activation energy (PHX-1) & EA4 & $5.19 \mathrm{E}+04$ & $6.4 \mathrm{E}+04$ & $\mathrm{~J} / \mathrm{mol}$ & Uniform \\
\hline Temperature Level & CTL & 0.95 & 1.05 & & Uniform \\
\hline
\end{tabular}

The tritium source ranges between $1.36 \times 10^{-11}$ and $6.44 \times 10^{-11} \mathrm{~m}^{3}(\mathrm{STP}) / \mathrm{s}$. This condition was obtained from the reported tritium birth rates and the tritium release ratio previously. The tritium birth rates for the various reactors ranges from $2.84 \times 10^{-11} \mathrm{~Bq} / \mathrm{y} / \mathrm{MWt}$ (for 3,000-MWt HTGR) to $4.28 \times 10^{-11} \mathrm{~Bq} / \mathrm{y} / \mathrm{MWt}$ (for England's 1,500-MWt HTGR). The tritium release ratios are reported to be 0.32 for the Peach Bottom reactor and 0.2 for the Fort St. Vrain reactor. In the TRITGO code, the release ratio is recommended to be 0.1 . By combining the tritium birth rates and the release ratios, the tritium release rate (tritium source) was estimated to be ranged between $1.36 \times 10^{-11}$ and $6.44 \times 10^{-11} \mathrm{~m}^{3}(\mathrm{STP}) / \mathrm{s}$. The distribution was assumed to be uniform.

The mass flow into the purification system was determined to be $12 \sim 20 \% / \mathrm{h}$ of the total helium inventory in each loop. The numbers, 12 and 20\%/h are based on the Peach Bottom reactor and the Fort St. Vrain reactor, respectively.

The same tritium permeation coefficients and activation energies for permeation through the HX materials were used as the previous analyses.

In this analysis, the reference temperature was set to be constant during the analyses. However, the HX temperatures were determined to be between 95 and 105\% of the reference temperature. The IHX, SHX, and PHX temperatures were adjusted simultaneously by applying the same multiplication factors, CTL, which represent the temperature level.

In this study, the following six different sampling numbers were taken into consideration for checking convergence and accepting reliability of the results. The minimum number of samples is 544 for Case 1 , and the maximum number of samples is 17,408 for Case 6 . 
- Case 1: 544 samples

- Case 2: 1,088 samples

- Case 3: 2,176 samples

- Case 4: 4,352 samples

- Case 5: 8,704 samples

- Case 6: 17,408 samples.

\subsubsection{Model Evaluation}

For model evaluation, a MATLAB script was developed as shown in Appendix B.

\subsubsection{Results and Discussions}

This section summarizes the evaluation and the uncertainty analysis results on the tritium concentrations in the gasoline, natural gas, and waste water. The following three results are discussed here.

- Tritium concentrations in the gasoline, LPG, and waste water

- Tritium distribution in the HTGR/MTG system

- Identification of important parameters affecting tritium behaviors in the system.

\section{Tritium concentrations in the gasoline, LPG, and waste water}

The first results estimated here are tritium concentrations in the various system locations. Table 5-25 summarizes means, standard deviations, and percentiles (5\% and 95\%). Figure 5-40 shows the locations from $\mathrm{CHT} 1$ to CHT8. The locations in Table 5-25 are as follows:

- CHT1: Tritium concentration in the HTGR primary helium coolant

- CHT2: Tritium concentration in the secondary helium coolant

- CHT3: Tritium concentration in the PCS water

- CHT4: Tritium concentration in the waste water in the NG-RFMR

- CHT5: Tritium concentration in the waste water in the MEOH-SYN

- CHT6: Tritium concentration in the LPG product

- CHT7: Tritium concentration in the gasoline product

- CHT8: Tritium concentration in the waste water in the MTG.

Among the following locations, this study focused on CHT6, CHT7, and CHT8, which are the main industrial products and waste water. The table shows that all the tritium concentrations are well converged for sample numbers higher than Case 5 (8,704 samples). 
Table 5-25. Results summary (statistics).

a. Mean

\begin{tabular}{|c|c|c|c|c|c|c|c|c|}
\hline \multicolumn{10}{|c|}{ Mean (Bq/cm3) } \\
\hline & CHT1 & CHT2 & CHT3 & CHT4 & CHT5 & CHT6 & CHT7 & CHT8 \\
\hline Case1 & $3.12 \mathrm{E}+00$ & $2.42 \mathrm{E}+00$ & $4.26 \mathrm{E}-12$ & $5.27 \mathrm{E}-04$ & $5.27 \mathrm{E}-04$ & $2.43 \mathrm{E}-03$ & $3.25 \mathrm{E}-03$ & $5.53 \mathrm{E}-04$ \\
\hline Case2 & $3.05 \mathrm{E}+00$ & $2.37 \mathrm{E}+00$ & $4.38 \mathrm{E}-12$ & $4.82 \mathrm{E}-04$ & $4.82 \mathrm{E}-04$ & $2.22 \mathrm{E}-03$ & $2.97 \mathrm{E}-03$ & $5.06 \mathrm{E}-04$ \\
\hline Case3 & $3.11 \mathrm{E}+00$ & $2.41 \mathrm{E}+00$ & $4.39 \mathrm{E}-12$ & $4.96 \mathrm{E}-04$ & $4.96 \mathrm{E}-04$ & $2.28 \mathrm{E}-03$ & $3.06 \mathrm{E}-03$ & $5.21 \mathrm{E}-04$ \\
\hline Case4 & $3.13 \mathrm{E}+00$ & $2.41 \mathrm{E}+00$ & $4.44 \mathrm{E}-12$ & $4.90 \mathrm{E}-04$ & $4.90 \mathrm{E}-04$ & $2.26 \mathrm{E}-03$ & $3.02 \mathrm{E}-03$ & $5.14 \mathrm{E}-04$ \\
\hline Case5 & $3.14 \mathrm{E}+00$ & $2.41 \mathrm{E}+00$ & $4.39 \mathrm{E}-12$ & $4.93 \mathrm{E}-04$ & $4.93 \mathrm{E}-04$ & $2.27 \mathrm{E}-03$ & $3.04 \mathrm{E}-03$ & $5.17 \mathrm{E}-04$ \\
\hline Case6 & $3.13 \mathrm{E}+00$ & $2.41 \mathrm{E}+00$ & $4.39 \mathrm{E}-12$ & $4.95 \mathrm{E}-04$ & $4.95 \mathrm{E}-04$ & $2.28 \mathrm{E}-03$ & $3.05 \mathrm{E}-03$ & $5.19 \mathrm{E}-04$ \\
\hline
\end{tabular}

b. Standard Deviation

\begin{tabular}{|c|c|c|c|c|c|c|c|c|}
\hline \multicolumn{10}{|c|}{ Std (Bq/cm3) } \\
\hline & CHT1 & CHT2 & CHT3 & CHT4 & CHT5 & CHT6 & CHT7 & CHT8 \\
\hline Case1 & $1.35 \mathrm{E}+00$ & $1.15 \mathrm{E}+00$ & $2.39 \mathrm{E}-12$ & $4.64 \mathrm{E}-04$ & $4.64 \mathrm{E}-04$ & $2.13 \mathrm{E}-03$ & $2.86 \mathrm{E}-03$ & $4.87 \mathrm{E}-04$ \\
\hline Case2 & $1.37 \mathrm{E}+00$ & $1.14 \mathrm{E}+00$ & $3.36 \mathrm{E}-12$ & $4.18 \mathrm{E}-04$ & $4.18 \mathrm{E}-04$ & $1.93 \mathrm{E}-03$ & $2.58 \mathrm{E}-03$ & $4.39 \mathrm{E}-04$ \\
\hline Case3 & $1.37 \mathrm{E}+00$ & $1.11 \mathrm{E}+00$ & $3.19 \mathrm{E}-12$ & $4.06 \mathrm{E}-04$ & $4.06 \mathrm{E}-04$ & $1.87 \mathrm{E}-03$ & $2.50 \mathrm{E}-03$ & $4.27 \mathrm{E}-04$ \\
\hline Case4 & $1.37 \mathrm{E}+00$ & $1.13 \mathrm{E}+00$ & $3.26 \mathrm{E}-12$ & $3.91 \mathrm{E}-04$ & $3.91 \mathrm{E}-04$ & $1.80 \mathrm{E}-03$ & $2.41 \mathrm{E}-03$ & $4.11 \mathrm{E}-04$ \\
\hline Case5 & $1.38 \mathrm{E}+00$ & $1.12 \mathrm{E}+00$ & $3.21 \mathrm{E}-12$ & $3.92 \mathrm{E}-04$ & $3.93 \mathrm{E}-04$ & $1.81 \mathrm{E}-03$ & $2.42 \mathrm{E}-03$ & $4.12 \mathrm{E}-04$ \\
\hline Case6 & $1.37 \mathrm{E}+00$ & $1.10 \mathrm{E}+00$ & $3.23 \mathrm{E}-12$ & $3.99 \mathrm{E}-04$ & $3.99 \mathrm{E}-04$ & $1.84 \mathrm{E}-03$ & $2.46 \mathrm{E}-03$ & $4.19 \mathrm{E}-04$ \\
\hline
\end{tabular}

c. $5 \%$ Percentile

\begin{tabular}{|c|c|c|c|c|c|c|c|c|}
\hline \multicolumn{10}{|c|}{$5 \%$ Percentile (Bq/cm3) } \\
\hline & CHT1 & CHT2 & CHT3 & CHT4 & CHT5 & CHT6 & CHT7 & CHT8 \\
\hline Case1 & $1.36 \mathrm{E}+00$ & $1.14 \mathrm{E}+00$ & $6.84 \mathrm{E}-13$ & $1.12 \mathrm{E}-04$ & $1.12 \mathrm{E}-04$ & $5.16 \mathrm{E}-04$ & $6.91 \mathrm{E}-04$ & $1.18 \mathrm{E}-04$ \\
\hline Case2 & $1.25 \mathrm{E}+00$ & $1.00 \mathrm{E}+00$ & $8.52 \mathrm{E}-13$ & $8.48 \mathrm{E}-05$ & $8.48 \mathrm{E}-05$ & $3.90 \mathrm{E}-04$ & $5.22 \mathrm{E}-04$ & $8.90 \mathrm{E}-05$ \\
\hline Case3 & $1.22 \mathrm{E}+00$ & $9.62 \mathrm{E}-01$ & $8.59 \mathrm{E}-13$ & $7.16 \mathrm{E}-05$ & $7.16 \mathrm{E}-05$ & $3.29 \mathrm{E}-04$ & $4.41 \mathrm{E}-04$ & $7.51 \mathrm{E}-05$ \\
\hline Case4 & $1.21 \mathrm{E}+00$ & $9.10 \mathrm{E}-01$ & $8.39 \mathrm{E}-13$ & $6.51 \mathrm{E}-05$ & $6.51 \mathrm{E}-05$ & $3.00 \mathrm{E}-04$ & $4.01 \mathrm{E}-04$ & $6.84 \mathrm{E}-05$ \\
\hline Case5 & $1.21 \mathrm{E}+00$ & $8.67 \mathrm{E}-01$ & $8.18 \mathrm{E}-13$ & $5.69 \mathrm{E}-05$ & $5.69 \mathrm{E}-05$ & $2.62 \mathrm{E}-04$ & $3.51 \mathrm{E}-04$ & $5.97 \mathrm{E}-05$ \\
\hline Case6 & $1.20 \mathrm{E}+00$ & $8.42 \mathrm{E}-01$ & $7.24 \mathrm{E}-13$ & $5.69 \mathrm{E}-05$ & $5.69 \mathrm{E}-05$ & $2.62 \mathrm{E}-04$ & $3.51 \mathrm{E}-04$ & $5.97 \mathrm{E}-05$ \\
\hline
\end{tabular}

d. $95 \%$ Percentile

\begin{tabular}{|c|c|c|c|c|c|c|c|c|}
\hline \multicolumn{10}{|c|}{$95 \%$ Percentile (Bq/cm3) } \\
\hline & CHT1 & CHT2 & CHT3 & CHT4 & CHT5 & CHT6 & CHT7 & CHT8 \\
\hline Case1 & $5.81 \mathrm{E}+00$ & $4.87 \mathrm{E}+00$ & $8.56 \mathrm{E}-12$ & $1.48 \mathrm{E}-03$ & $1.48 \mathrm{E}-03$ & $6.81 \mathrm{E}-03$ & $9.12 \mathrm{E}-03$ & $1.55 \mathrm{E}-03$ \\
\hline Case2 & $5.84 \mathrm{E}+00$ & $4.66 \mathrm{E}+00$ & $9.73 \mathrm{E}-12$ & $1.45 \mathrm{E}-03$ & $1.45 \mathrm{E}-03$ & $6.66 \mathrm{E}-03$ & $8.92 \mathrm{E}-03$ & $1.52 \mathrm{E}-03$ \\
\hline Case3 & $5.40 \mathrm{E}+00$ & $4.46 \mathrm{E}+00$ & $1.01 \mathrm{E}-11$ & $1.38 \mathrm{E}-03$ & $1.38 \mathrm{E}-03$ & $6.37 \mathrm{E}-03$ & $8.53 \mathrm{E}-03$ & $1.45 \mathrm{E}-03$ \\
\hline Case4 & $5.47 \mathrm{E}+00$ & $4.44 \mathrm{E}+00$ & $1.08 \mathrm{E}-11$ & $1.31 \mathrm{E}-03$ & $1.31 \mathrm{E}-03$ & $6.03 \mathrm{E}-03$ & $8.08 \mathrm{E}-03$ & $1.38 \mathrm{E}-03$ \\
\hline Case5 & $5.52 \mathrm{E}+00$ & $4.39 \mathrm{E}+00$ & $1.07 \mathrm{E}-11$ & $1.30 \mathrm{E}-03$ & $1.30 \mathrm{E}-03$ & $5.96 \mathrm{E}-03$ & $7.99 \mathrm{E}-03$ & $1.36 \mathrm{E}-03$ \\
\hline Case6 & $5.54 \mathrm{E}+00$ & $4.35 \mathrm{E}+00$ & $1.07 \mathrm{E}-11$ & $1.31 \mathrm{E}-03$ & $1.31 \mathrm{E}-03$ & $6.01 \mathrm{E}-03$ & $8.05 \mathrm{E}-03$ & $1.37 \mathrm{E}-03$ \\
\hline
\end{tabular}

Figures 5-41, 5-42, and 5-43 show the estimated tritium concentrations and their frequencies for CHT6 (LPG), CHT7 (gasoline), and CHT8 (waste water), respectively. The average tritium concentration in the LPG (Figure 5-41(a)) was estimated to be $2.28 \times 10^{-3} \mathrm{~Bq} / \mathrm{cm}^{3}$. As shown in Figure 5-41(a), all the 
estimation results were a little bit less than the tritium effluent limit $\left(3.7 \times 10^{-3} \mathrm{~Bq} / \mathrm{cm}^{3}\right)$. In this case, about $75 \%$ of the cases were less than the effluent limit. Figure 5-42(a) shows the tritium concentration in the gasoline. In this case, average tritium concentration was estimated to be $3.05 \times 10^{-3} \mathrm{~Bq} / \mathrm{cm}^{3}$, and about $62 \%$ of the cases were within tritium effluent limit $\left(3.7 \times 10^{-3} \mathrm{~Bq} / \mathrm{cm}^{3}\right)$. In the waste water (Figure 543(a)), the average tritium concentration was estimated to be $5.19 \times 10^{-4} \mathrm{~Bq} / \mathrm{cm}^{3}$, which is less than the effluent limit by a factor of 8 (see Figure 5-43(a)). These tritium levels are considered very low compared to the original MTG system estimated in Section 5-5. The reasons are as follows. The improved MTG system uses much lower reactor power $(721 \mathrm{MWt})$ than the original one $(1200 \mathrm{MWt})$ for generating the same amount of gasoline. Since the tritium birth rate is proportional to the reactor power, it is anticipated that the original system will release much more tritium from the core. In addition, the higher reactor power requires a larger heat transfer surface area for the IHX, which leads to more tritium permeation to the secondary and the industrial plants. Therefore, the new system is considered better than the original from the tritium permeation perspective. For comparisons, Figures 5-41(b), 5-42(b), and 5-43(b) plot tritium estimation results based on only Peach Bottom tritium permeation data shown in Figure 5-5. In this case, average tritium concentration in the LPG was estimated to be $4.40 \times 10^{-4} \mathrm{~Bq} / \mathrm{cm}^{3}$, which is far less than the tritium effluent limit $\left(3.7 \times 10^{-3} \mathrm{~Bq} / \mathrm{cm}^{3}\right)$. In the gasoline product, average tritium concentration was estimated to be $5.90 \times 10^{-4} \mathrm{~Bq} / \mathrm{cm}^{3}$, and about $99.9 \%$ of the cases were within tritium effluent limit $\left(3.7 \times 10^{-3} \mathrm{~Bq} / \mathrm{cm}^{3}\right)$. In the waste water, the average tritium concentration was estimated to be $1.00 \times 10^{-4} \mathrm{~Bq} / \mathrm{cm}^{3}$, which is less than the effluent limit by a factor of 40 .

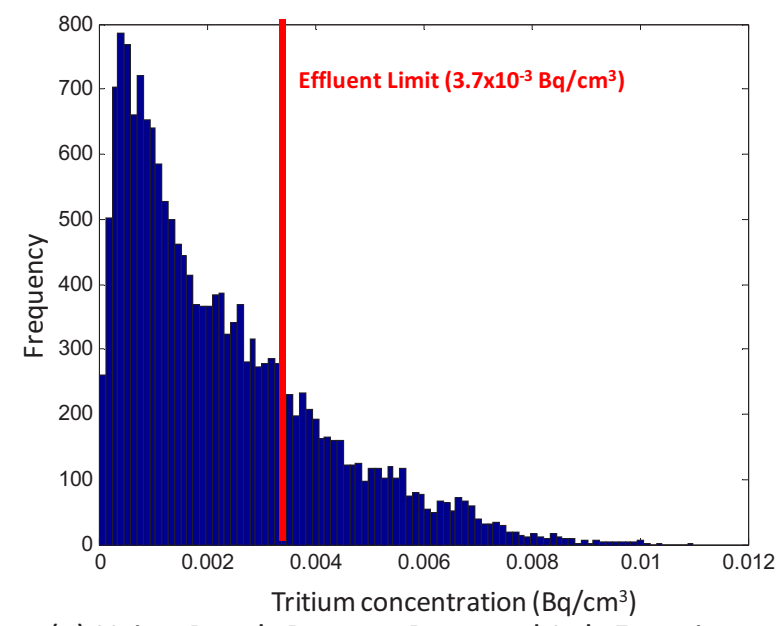

(a) Using Peach Bottom Data and Lab Experiment Data

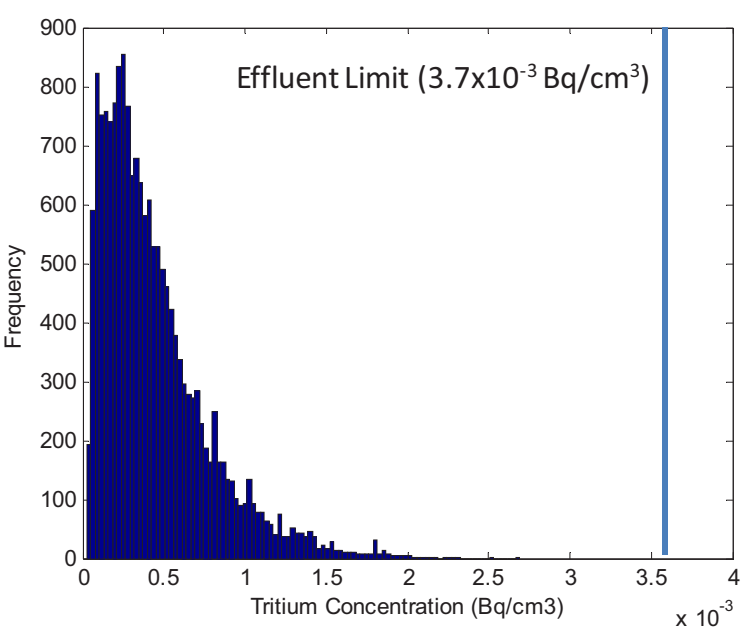

(b) Using Peach Bottom Data

Figure 5-41. Frequency distribution of the tritium concentration (LPG) without tritium barrier applied. 


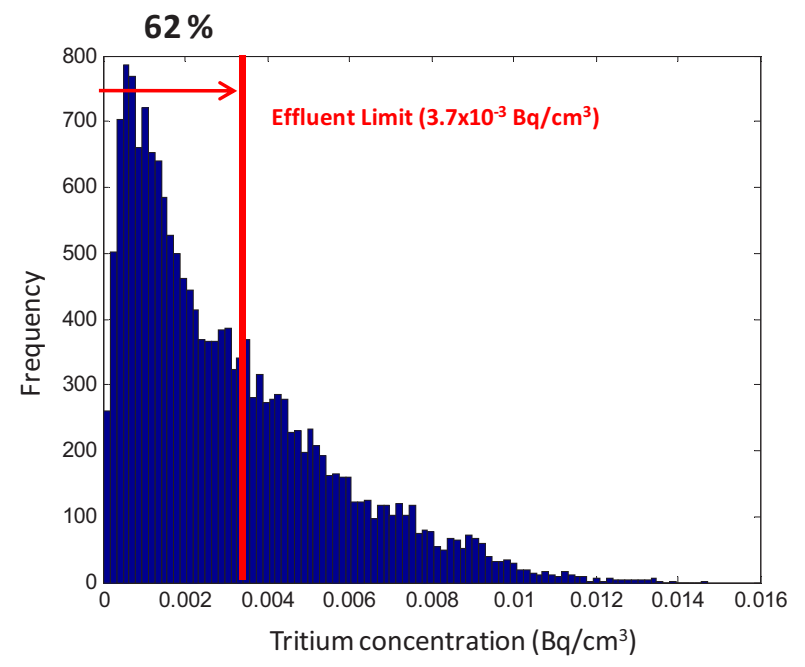

(a) Using Peach Bottom Data and Lab Experiment Data

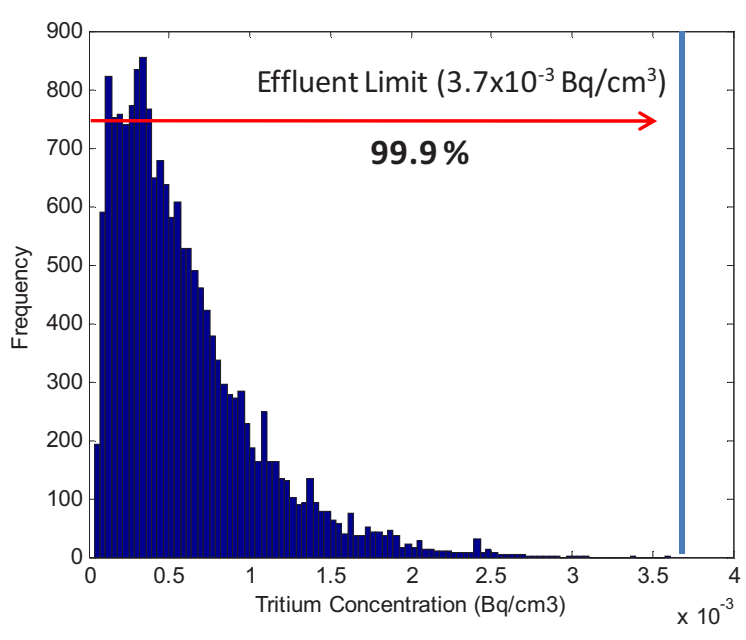

(b) Using Peach Bottom Data

Figure 5-42. Frequency distribution of the tritium concentration (gasoline) without tritium barrier applied.

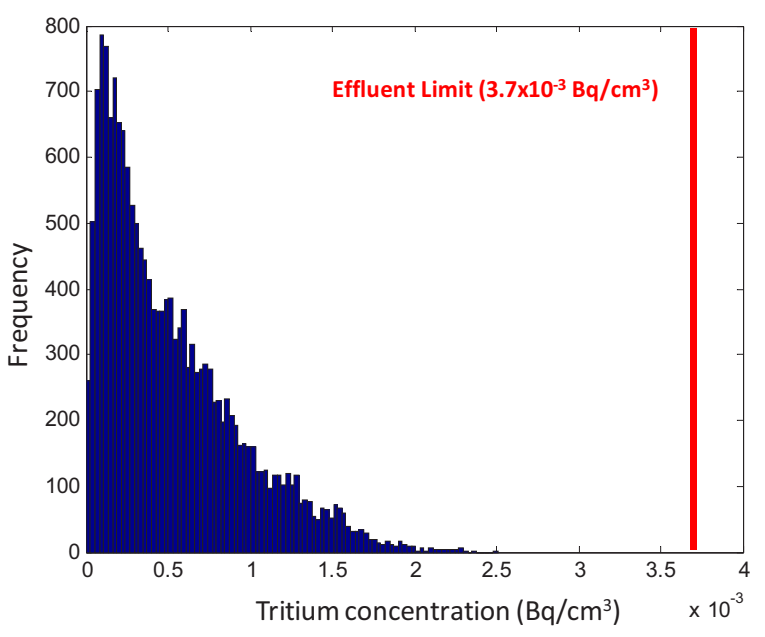

(a) Using Peach Bottom Data and Lab Experiment Data

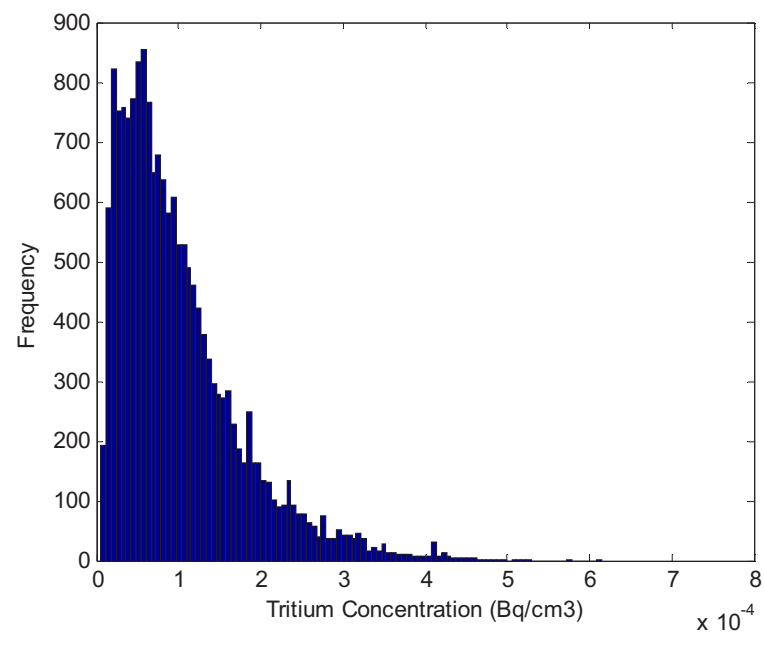

(b) Using Peach Bottom Data

Figure 5-43. Frequency distribution of tritium concentration $\left(\mathrm{MTG}-\mathrm{H}_{2} \mathrm{O}\right)$ without tritium barrier applied.

\section{Tritium distribution in the HTGR/MTG system}

Figure 5-44 shows the tritium distribution in the HTGR/MTG system. The following summarizes the results:

- Initially, the tritium generated in the reactor core and $21 \%$ of the tritium is released to the primary loop.

- In the primary loop, about $10.4 \%$ of the tritium is purified in the purification system, and $10.45 \%$ is permeated to the secondary side through the IHX walls. Only $0.15 \%$ of the tritium is leaked to the outside of the primary loop.

- In the secondary loop, $4.62 \%$ of the released tritium is purified and $4.74 \%$ is permeated to the PCS through the SHX and repeater. About $0.97 \%$ of the tritium transports to the MTG system through a PHX. 
- In the MTG system, the tritium can go everywhere in the system components. Finally, $0.19 \%$ of the released tritium goes to the gasoline and $0.03 \%$, to the LPG. The rest, $0.75 \%$, goes to the other parts of the system components and waste products.

\section{Tritium Release from Core $\quad * 79 \%$ of tritium is retained in the core.}

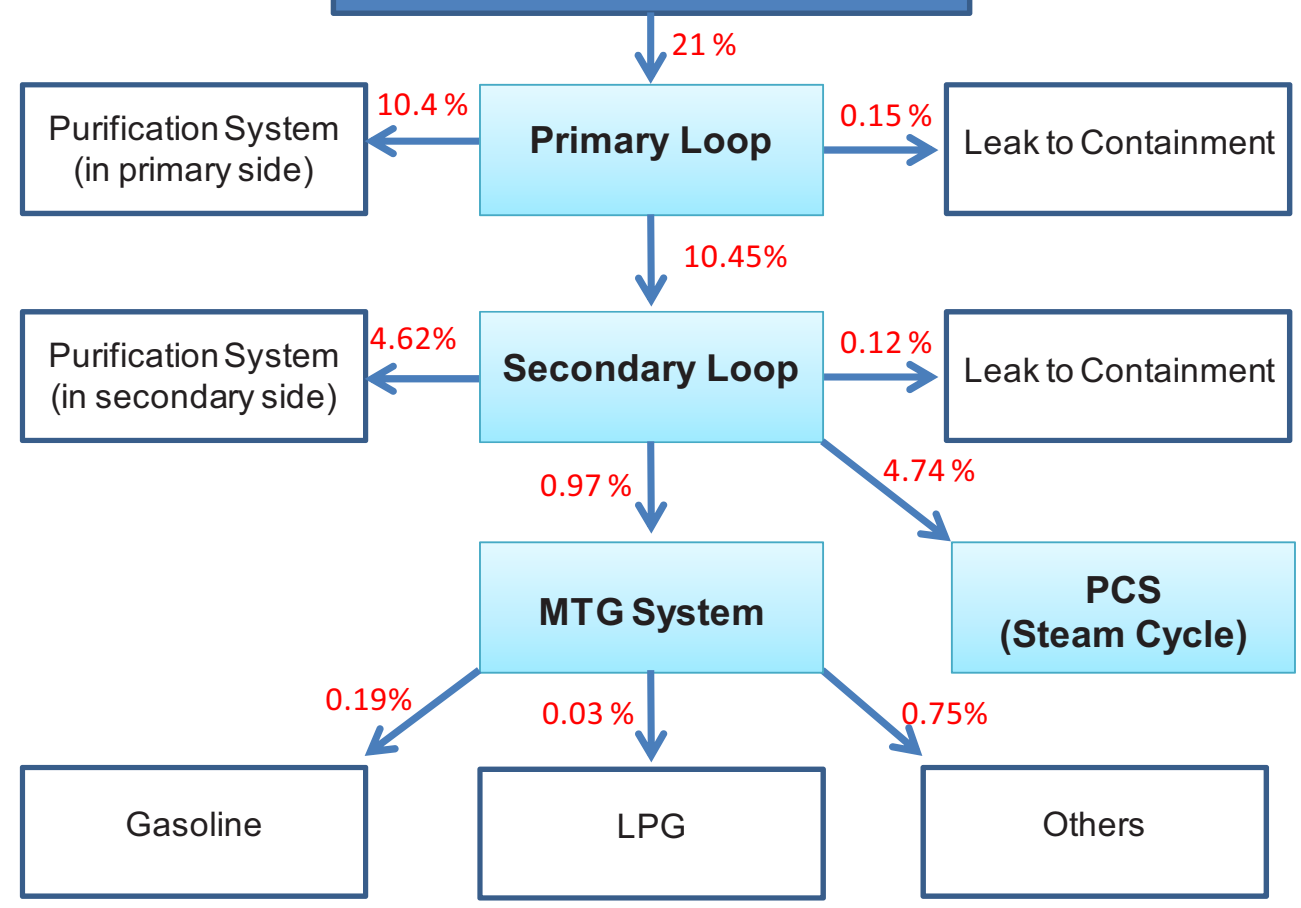

Figure 5-44. Tritium distribution in the nuclear-assisted MTG system.

\section{Important Parameters Affecting Tritium Behaviors in the HTGR/MTG system}

This section summarizes the sensitivity study results on the tritium behaviors in the HTGR/MTG system (II). This study used two sensitivity indices used for measuring importance: (1) first-order index and (2) total index. The following describes the details.

\section{A. Main Effect (First-order Index)}

The main effect of a certain parameter can be quantified by the first-order index. The first-order index is highly related to the modeling uncertainties. If the first-order index of a certain parameter is large, it indicates that that parameter provides large contributions to the output uncertainties. Table 5-26 summarizes the estimated the first-order indices of the 16 input parameters for tritium concentrations. The locations of the CHT1 through CHT8 are shown in Figure 5-40. In the sampling-based method, the solution convergence should be checked for different numbers of samples. Figure 5-45 shows the variations of the first-order indices for different sample numbers. As shown in this figure, the first-order indices are well converged for higher than 10,000 samples. The summarized data in Table 5-26 are based on the 17,408 sample numbers.

Table 5-26. First-order indices.

\begin{tabular}{|c|c|c|c|c|c|c|c|c|}
\hline & CHT1 & CHT2 & CHT3 & CHT4 & CHT5 & CHT6 & CHT7 & CHT8 \\
\hline TS & 0.68 & 0.60 & 0.24 & 0.52 & 0.52 & 0.52 & 0.52 & 0.52 \\
\hline CTL & 0.03 & 0.02 & 0.01 & 0.02 & 0.02 & 0.02 & 0.02 & 0.02 \\
\hline TH1 & 0.00 & 0.00 & 0.00 & 0.00 & 0.00 & 0.00 & 0.00 & 0.00 \\
\hline C1 & 0.11 & 0.09 & 0.03 & 0.05 & 0.05 & 0.05 & 0.05 & 0.05 \\
\hline
\end{tabular}




\begin{tabular}{|c|c|c|c|c|c|c|c|c|}
\hline TH4 & 0.01 & 0.01 & 0.05 & 0.01 & 0.01 & 0.01 & 0.01 & 0.01 \\
\hline PMF1 & 0.03 & 0.06 & 0.16 & 0.07 & 0.07 & 0.07 & 0.07 & 0.07 \\
\hline C4 & 0.00 & 0.00 & 0.00 & 0.06 & 0.06 & 0.06 & 0.06 & 0.06 \\
\hline PMF2 & 0.01 & 0.00 & 0.00 & -0.01 & -0.01 & -0.01 & -0.01 & -0.01 \\
\hline EA1 & 0.00 & 0.00 & 0.01 & 0.00 & 0.00 & 0.00 & 0.00 & 0.00 \\
\hline EA4 & 0.01 & 0.01 & 0.03 & 0.01 & 0.01 & 0.01 & 0.01 & 0.01 \\
\hline TH3 & 0.00 & 0.00 & 0.00 & 0.00 & 0.00 & 0.00 & 0.00 & 0.00 \\
\hline TH2 & 0.01 & 0.01 & 0.00 & 0.00 & 0.00 & 0.00 & 0.00 & 0.00 \\
\hline C3 & 0.01 & 0.02 & 0.05 & 0.01 & 0.01 & 0.01 & 0.01 & 0.01 \\
\hline C2 & 0.02 & 0.06 & 0.14 & 0.04 & 0.04 & 0.04 & 0.04 & 0.04 \\
\hline EA3 & 0.00 & 0.00 & 0.00 & 0.01 & 0.01 & 0.01 & 0.01 & 0.01 \\
\hline EA2 & 0.03 & 0.02 & 0.10 & 0.01 & 0.01 & 0.01 & 0.01 & 0.01 \\
\hline
\end{tabular}

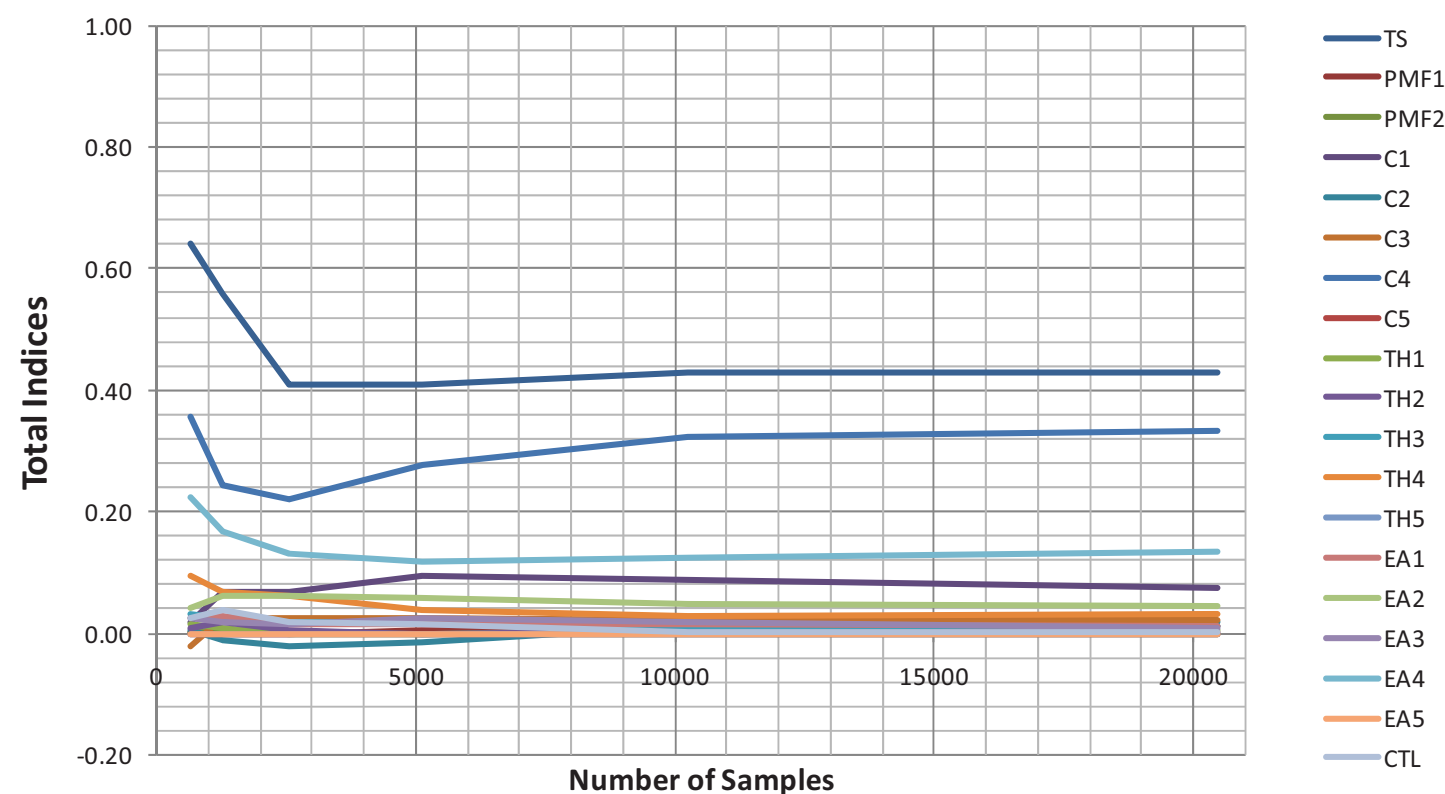

Figure 5-45. First-order indices for different sample numbers (tritium concentration in the MTG products).

Figure 5-46 compares the first-order indices for various parameters in the MTG system. As shown in this figure, the TS has the largest first-order index, which is 0.52 . It means that $52 \%$ of the output uncertainties are generated by the tritium source model and parameter uncertainties. The second important parameters are the permeation coefficients of PHX, Reheater, and IHX. In this case, the sensitivity indices are $0.07,0.06$, and 0.05 , respectively. It means that $20 \%$ of the output uncertainties are contributed by the permeation coefficients. On the other hand, effects of the following parameters are negligible: CTL, TH3, EA2, C2, EA4, TH4, EA1, PMF1, TH2, and TH1. This result gives us some ideas to reduce modeling uncertainties, which will eventually provide more design margins. The model uncertainties can be effectively reduced by:

- Improving accuracy of the tritium birth or release models

- Improving accuracy of the input parameters on the tritium birth and release models 
- Improving accuracy of the tritium permeation models and parameters

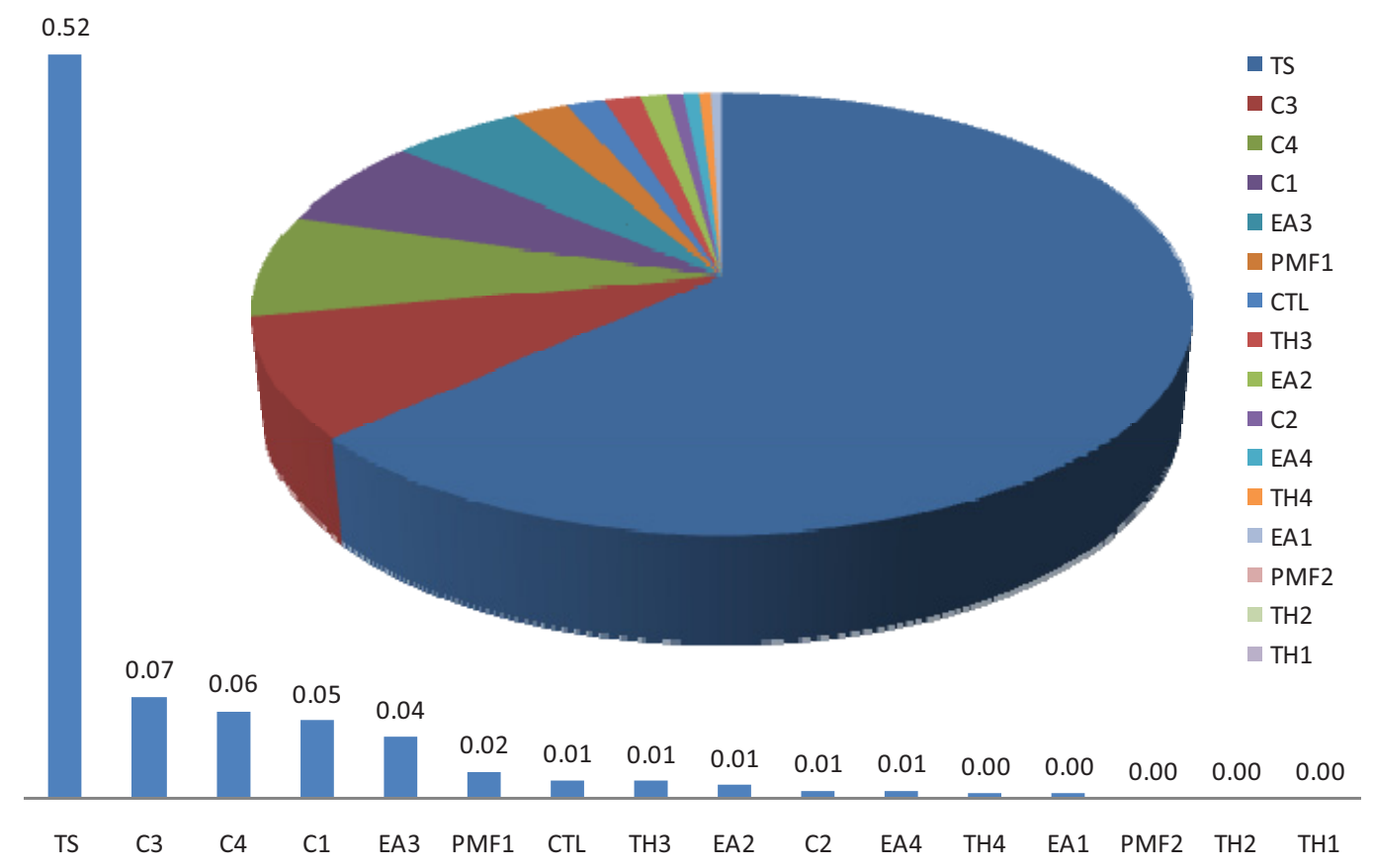

Figure 5-46. First-order indices (tritium concentration in the MTG system).

\section{B. Total Effect (Total Index)}

The total effect of a certain parameter can be quantified by the total index, which is a summation of the first-order index and all its interactions. The total index is highly related to the output value itself. If the total index is large for a certain parameter, it indicates that the output is very sensitive to the change of that parameter. Table 5-27 summarizes the estimated total indices of the 16 input parameters for tritium concentrations. As shown in this table, the tritium sensitivities in the MTG system are uniform throughout the whole system. Figure 5-47 shows the variations of the total indices for different sample numbers. As shown in this figure, the totals are well converged for higher than 10,000 samples. The data in Table 5-27 are based on the 17,408 sample numbers.

Table 5-27. Total indices.

\begin{tabular}{|c|c|c|c|c|c|c|c|c|c|c|}
\hline & CHT1 & CHT2 & CHT3 & CHT4 & CHT5 & CHT6 & CHT7 & CHT8 & CHT9 & CHT10 \\
\hline TS & 0.71 & 0.64 & 0.34 & 0.64 & 0.64 & 0.64 & 0.64 & 0.64 & 0.71 & 0.64 \\
\hline PMF1 & 0.05 & 0.03 & 0.01 & 0.04 & 0.04 & 0.04 & 0.04 & 0.04 & 0.05 & 0.03 \\
\hline PMF2 & 0.00 & 0.00 & 0.00 & 0.00 & 0.00 & 0.00 & 0.00 & 0.00 & 0.00 & 0.00 \\
\hline C1 & 0.13 & 0.12 & 0.05 & 0.09 & 0.09 & 0.09 & 0.09 & 0.09 & 0.13 & 0.12 \\
\hline C2 & 0.01 & 0.02 & 0.08 & 0.02 & 0.02 & 0.02 & 0.02 & 0.02 & 0.01 & 0.02 \\
\hline C3 & 0.05 & 0.10 & 0.24 & 0.11 & 0.11 & 0.11 & 0.11 & 0.11 & 0.05 & 0.10 \\
\hline C4 & 0.00 & 0.01 & 0.00 & 0.11 & 0.11 & 0.11 & 0.11 & 0.11 & 0.00 & 0.01 \\
\hline C5 & 0.01 & 0.01 & 0.01 & 0.01 & 0.01 & 0.01 & 0.01 & 0.01 & 0.01 & 0.01 \\
\hline TH1 & 0.00 & 0.00 & 0.01 & 0.00 & 0.00 & 0.00 & 0.00 & 0.00 & 0.00 & 0.00 \\
\hline TH2 & 0.01 & 0.02 & 0.04 & 0.02 & 0.02 & 0.02 & 0.02 & 0.02 & 0.01 & 0.02 \\
\hline TH3 & 0.00 & 0.00 & 0.00 & 0.01 & 0.01 & 0.01 & 0.01 & 0.01 & 0.00 & 0.00 \\
\hline TH4 & 0.02 & 0.02 & 0.00 & 0.02 & 0.02 & 0.02 & 0.02 & 0.02 & 0.02 & 0.02 \\
\hline
\end{tabular}




\begin{tabular}{|l|l|l|l|l|l|l|l|l|l|l|}
\hline TH5 & 0.01 & 0.02 & 0.08 & 0.02 & 0.02 & 0.02 & 0.02 & 0.02 & 0.01 & 0.02 \\
\hline EA1 & 0.04 & 0.09 & 0.20 & 0.09 & 0.09 & 0.09 & 0.09 & 0.09 & 0.04 & 0.09 \\
\hline EA2 & 0.00 & 0.00 & 0.00 & 0.02 & 0.02 & 0.02 & 0.02 & 0.02 & 0.00 & 0.00 \\
\hline EA3 & 0.03 & 0.03 & 0.14 & 0.02 & 0.02 & 0.02 & 0.02 & 0.02 & 0.03 & 0.03 \\
\hline EA4 & 0.71 & 0.64 & 0.34 & 0.64 & 0.64 & 0.64 & 0.64 & 0.64 & 0.71 & 0.64 \\
\hline EA5 & 0.05 & 0.03 & 0.01 & 0.04 & 0.04 & 0.04 & 0.04 & 0.04 & 0.05 & 0.03 \\
\hline CTL & 0.00 & 0.00 & 0.00 & 0.00 & 0.00 & 0.00 & 0.00 & 0.00 & 0.00 & 0.00 \\
\hline
\end{tabular}

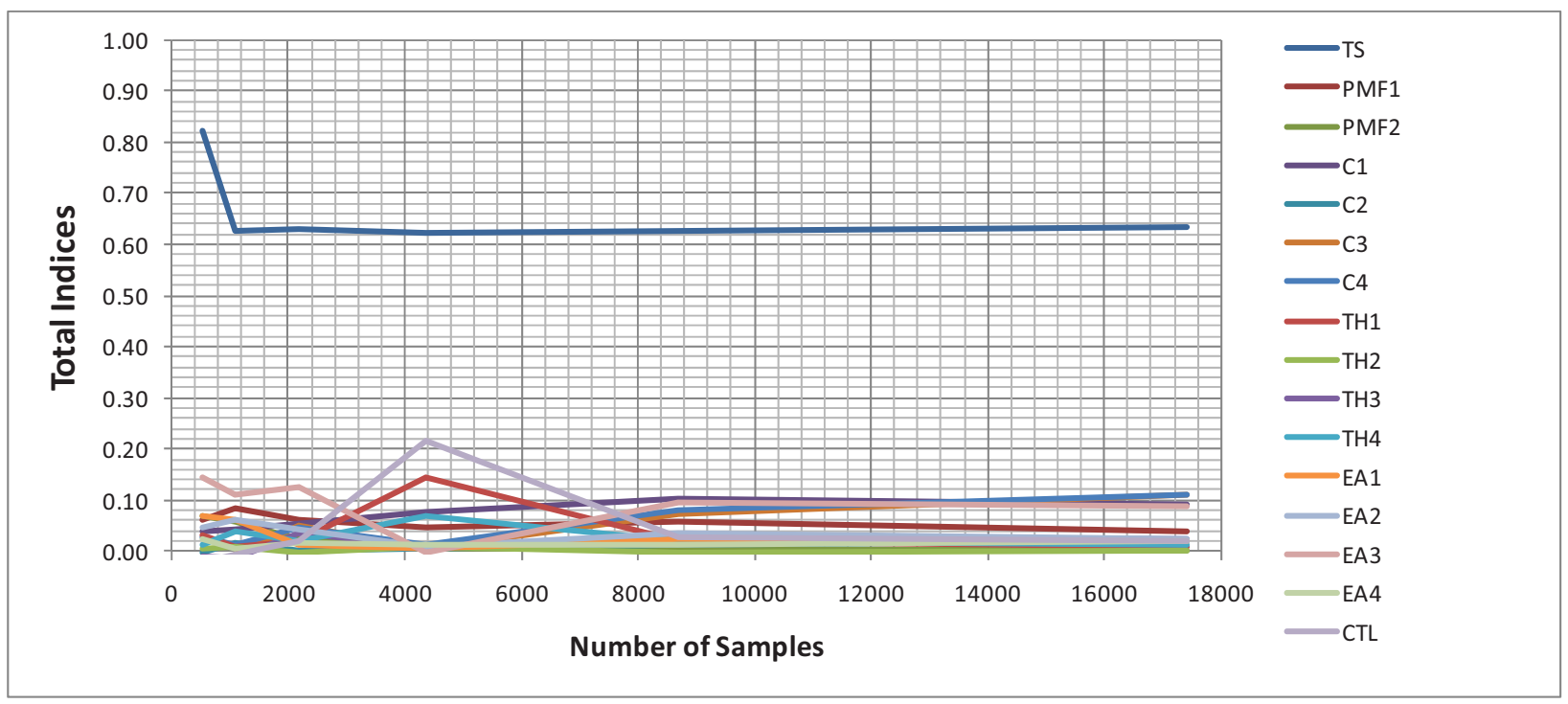

Figure 5-47. Total indices for different sample numbers (tritium concentration in the MTG products).

Figure 5-48 compares the total indices for various parameters in the MTG system. As shown in this figure, the TS has the total index, which is 0.64 . It means that the change of this parameter affects tritium concentration in the MTG system the most significantly. The second important parameter is the tritium permeation coefficient of the reheater (C4). The third and the fourth important parameters are the permeation coefficient of the PHX and the IHX, respectively. Compared to these four parameters, the effects of the other 14 parameters are very small. This result gives us some ideas to reduce tritium concentration in the MTG system, which will eventually mitigate tritium in the system. The tritium level in the MTG system can be effectively reduced by:

- Improving fuel quality in the core (reducing tritium release)

- Reducing impurities in the core structures (reducing tritium birth)

- Changing or improving heat exchanger wall materials

- Coating heat exchanger walls with tritium barriers 


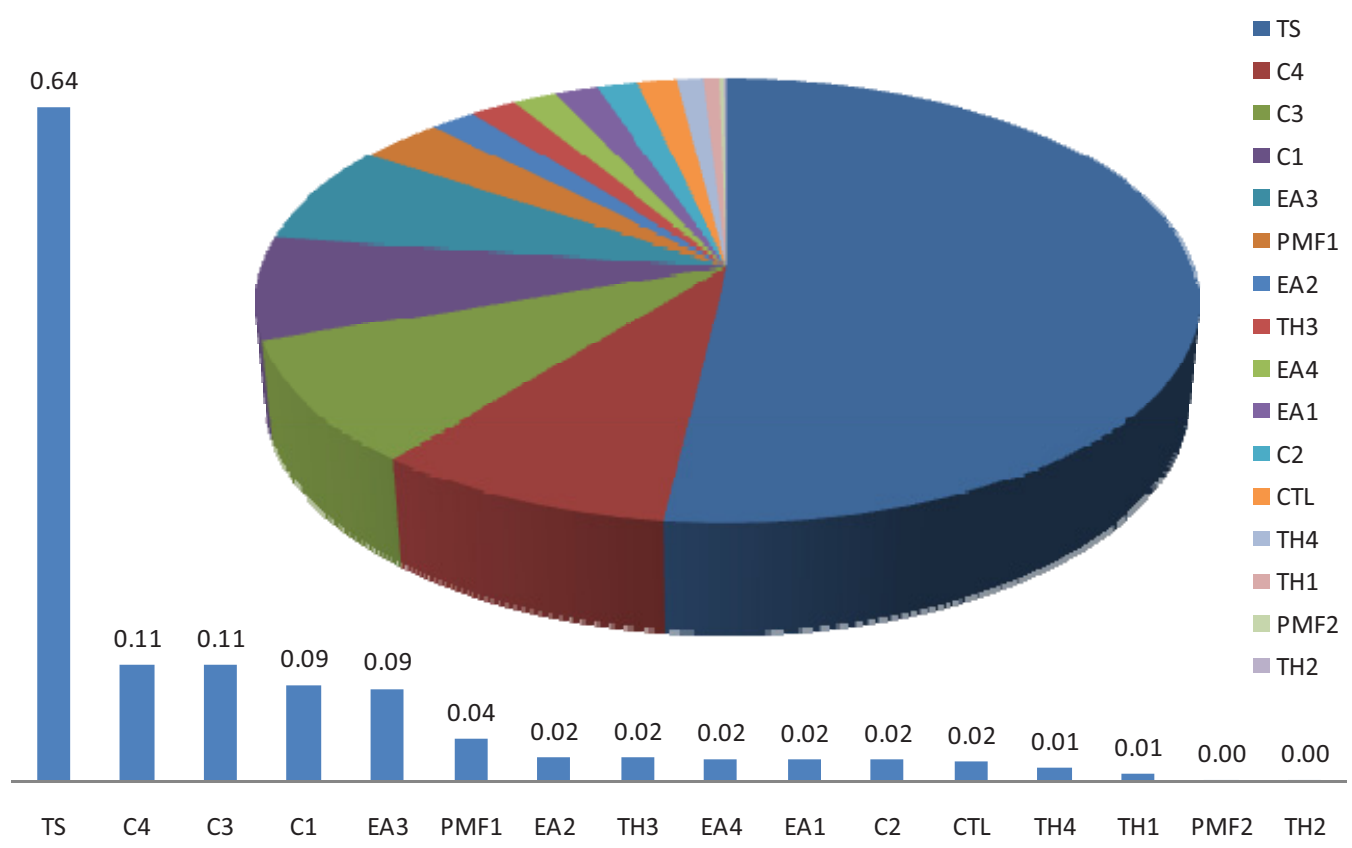

Figure 5-48. Total indices (tritium concentration in the MTG system).

Figure 5-49 shows the first-order indices and the total indices in the same plot.

As shown in this figure, the total indices are not much different from the first-order indices. It indicates that the main parameter effect is dominant compared to the interaction effects. The differences between the first-order indices and the total indices represent a sum of the higher order terms, which means parameter interactions.

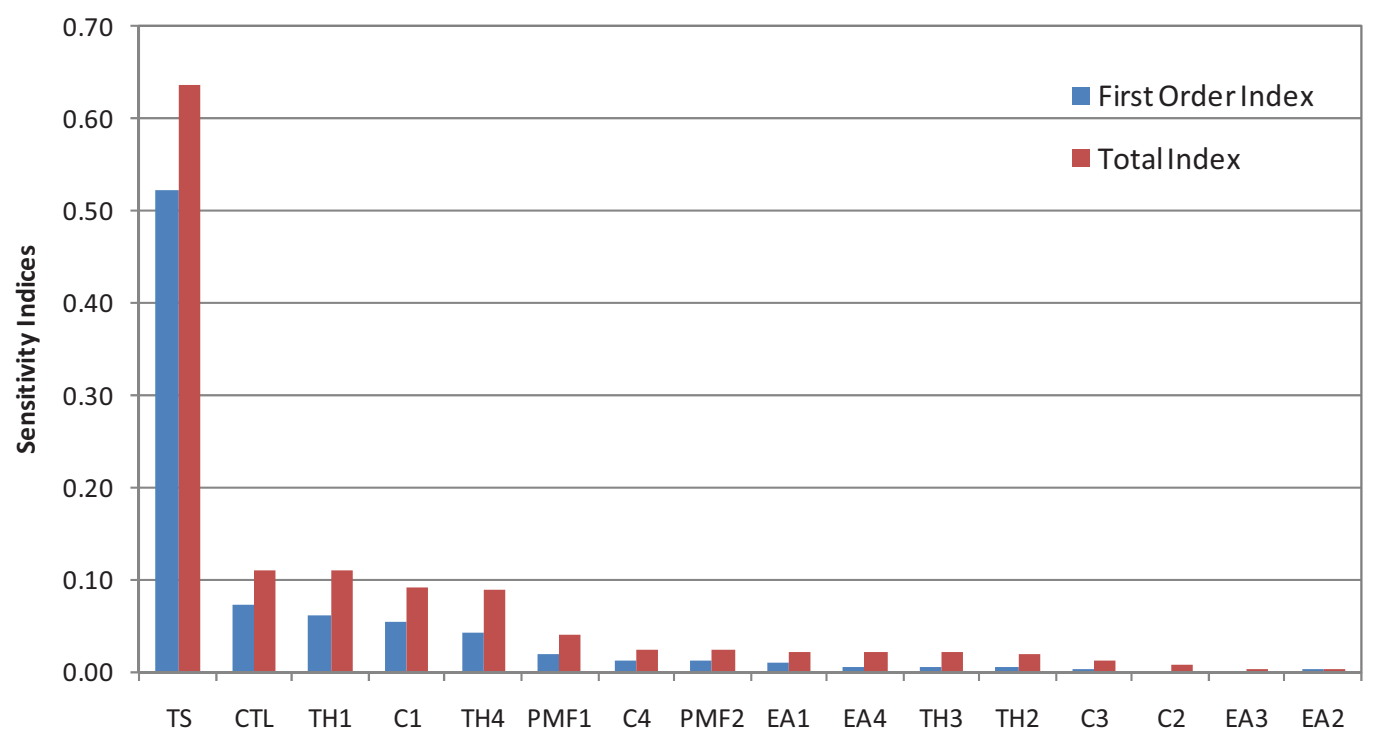

Figure 5-49. First-order indices and total indices (tritium concentration in the MTG system). 


\subsubsection{Summary}

In this section, we analyzed tritium behaviors in the improved HTGR/MTG system. The HTGR system was designed based on 721-MWt power and $750^{\circ} \mathrm{C}$ core outlet temperature. This system consists of the following four separate loops:

- Reactor primary side

- Reactor secondary side

- $\quad$ PCS

- $\quad$ MTG system

The primary heat was transferred to the secondary side through an IHX. In secondary side, the heat was transferred to the PCS and HTSE system through an SHX and a PHX. The PCS was based on the steam Rankin cycle. The proposed MTG system includes operation units for air separation (ASU), natural gas purification and reforming (NG-RFMR), methanol synthesis (MEOH-SYN), methanol conversion to gasoline (MTG), power production (HTSG-ST), the cooling tower, and water treatment. Nuclear heat is used to preheat all streams entering the primary reformer.

The HTGR/MTG system was modeled by the TPAC code. Most of the information for modeling was obtained or determined from previous literature, HYSYS flowsheet analyses, and some assumptions. For sensitivity analyses, we agreed on 16 input parameters by discussion and randomly generated 17,408 inputs using the SIMLAB software. For automatic evaluations of a large number of samples, we developed a MATLAB script that links MATLAB workspace parameters and the TPAC input variables. In this study, the following three things were taken into account in detail:

- Tritium concentration in the hydrogen product

- Tritium distribution in the HTGR/HTSE system

- Important factors affecting tritium behaviors.

First, we estimated tritium concentration in the three locations: (1) gasoline, (2) LPG, and (3) waste water. According to the estimations, the average tritium concentration in the LPG was estimated to be $2.28 \times 10^{-3} \mathrm{~Bq} / \mathrm{cm}^{3}$. In this case, about $75 \%$ of the cases were less than the effluent limit $\left(3.7 \times 10^{-3} \mathrm{~Bq} / \mathrm{cm}^{3}\right)$. The average tritium concentration in the gasoline was estimated to be $3.05 \times 10^{-3} \mathrm{~Bq} / \mathrm{cm}^{3}$. About $62 \%$ of the cases were within the tritium effluent limit $\left(3.7 \times 10^{-3} \mathrm{~Bq} / \mathrm{cm}^{3}\right)$. These tritium levels are considered to be very low compared to the original MTG system. The improved MTG system has much less reactor power $(721 \mathrm{MWt})$ than the original one $(1200 \mathrm{MWt})$. Since the tritium birth rate is proportional to the reactor power, it is anticipated that the original system releases much more tritium into the reactor primary side. In addition, the higher reactor power requires larger heat transfer surface area of the IHX, which leads to more tritium permeation to the secondary and the industrial plants. Therefore, the new system is considered better than the original from the tritium permeation perspective.

Second, we estimated tritium distribution in the HTGR/MTG system. According to the analyses, initially, the tritium generated in the reactor core and $20 \%$ of the tritium is released to the primary loop. In the primary loop, about $10.4 \%$ of the tritium is purified in the purification system, and $10.45 \%$ is permeated to the secondary side through the IHX walls. Only $0.15 \%$ of the tritium is leaked to the outside of the primary loop. In the secondary loop, $4.62 \%$ of the tritium release is purified and $4.74 \%$ is permeated to the PCS through the SHX and repeater. About $0.97 \%$ of the tritium transports to the MTG system through two PHXs. In the MTG system, the tritium can go everywhere in the system components. Finally, $0.19 \%$ of the tritium release goes to the gasoline and $0.03 \%$, to the LPG. The rest, $0.75 \%$, goes to the other parts of the system components and waste products. 
Finally, we conducted global sensitivity analyses in order to identify important factors that affect tritium behaviors in the HTGR/MTG system. These analyses were based on the method proposed by Sobol, and two importance measures were estimated by the SIMLAB software. In these analyses, the following four parameters were identified to be important for both reducing modeling uncertainties and reducing tritium concentration in the hydrogen product.

- TS

- Tritium Permeation Coefficient of Reheater (C3)

- Tritium Permeation Coefficient of PHX (C4)

- Tritium permeation coefficient of IHX (C1).

The above parameters were estimated to contribute about $80 \%$ of the total uncertainties. It is strongly recommended that future research concentrate on improving those parameters and model accuracies. Also, it is recommended that the methods to effectively control those parameters are developed in the future for mitigating tritium in the system. 


\section{SUMMARY}

This study focused on the tritium behaviors in the VHTR integrated system, which is currently an important issue for industrial applications of the VHTRs. Tritium is mostly generated in the reactor by ternary fission of the fuel and neutron reactions with lithium impurities in the graphite, boron control materials in the reflector block, and the ${ }^{3} \mathrm{He}$ reaction with neutron occurring in the helium coolant. Tritium that is diffused from the reactor core and is formed in the helium primary coolant $\left({ }^{3} \mathrm{He}(\mathrm{n}, \mathrm{p}){ }^{3} \mathrm{H}\right)$ will be circulated or permeated to the integrated industrial plants, potentially contaminating their products if the tritium transport is not mitigated.

The INL TPAC, based on the mass and species conservation laws of the tritium or hydrogen containing molecules such as $\mathrm{HT}, \mathrm{H}_{2}, \mathrm{HTO}, \mathrm{H}_{2} \mathrm{O}, \mathrm{H}_{2} \mathrm{SO}_{4}, \mathrm{HTSO}_{4}$, TI, etc., was used for this study. Various tritium birth models were implemented into the code. The models are ternary fission and neutron reactions with impurities $\left({ }^{6} \mathrm{Li},{ }^{7} \mathrm{Li},{ }^{10} \mathrm{~B},{ }^{3} \mathrm{He}\right)$ in the core structures and the coolant. A tritium permeation model using an Arrhenius-type equation form was considered in the HX walls, vessel walls, and pipe walls. The TPAC also adopted most of the tritium-related physical models currently available in this field. The TPAC has many advantages compared to the existing tritium analysis codes (i.e., THYTAN [JAEA], TRITGO [ORNL], TBAK [KAIST], TMAP7 [INL], etc.). TPAC is the only code that adopted GUI so that the users can easily use and model any configurations of VHTR systems with much less time and effort. In addition, TPAC has 12 ordinary differential equation solvers that can be selected depending on the problem type, accuracy, and problem stiffness. It makes this code faster and more accurate than any other existing tritium analysis codes.

In FY-10, tritium behaviors in the VHTR integrated systems were investigated for the following industry processes coupled with VHTR/HTGR:

- VHTR/HTSE system (600 MWt, gas Brayton cycle, $900^{\circ} \mathrm{C}$ core outlet temerature)

- HTGR/HTSE system (600 MWt, steam Rankin cycle, $750^{\circ} \mathrm{C}$ core outlet temperature)

- HTGR/MTG system (I) (1200 MWt, steam Rankin cycle, $750^{\circ} \mathrm{C}$ core outlet temperature)

- $\quad$ HTGR/MTG system (II) (721 MWt, steam Rankin cycle, $750^{\circ} \mathrm{C}$ core outlet temperature)

The following details the results:

\subsection{VHTR/HTSE System}

Tritium behaviors in the VHTR/HTSE system were analyzed using the TPAC. This system is based on the indirect parallel configuration of a VHTR and a HTSE system. The total reactor power was 600 MWt and the PCS was based on the gas Brayton cycle. The reactor core maximum temperature was designed to be $900^{\circ} \mathrm{C}$. For the sensitivity study, two SOBOL sensitivity indices were estimated using the SIMLAB software: (1) first-order index and (2) total index.

The analyses results showed that the tritium concentration in the product hydrogen is widely distributed based on the selected input parameters. About $1 \%$ of the samples are within the effluent limit $\left(3.7 \times 10^{-3} \mathrm{~Bq} / \mathrm{cm}^{3}[\mathrm{STP}]\right)$, and the remaining $99 \%$ exceeds the effluent limit. It indicates that the system requires higher purification system capacity or tritium barriers on the heat transfer surfaces. Recent extensive reviews on the tritium barrier studies (Sherman and Adams, 2008) describes how oxide layers produced in-situ or ceramic coating layers can significantly reduce tritium permeation through the HX surface by a factor of 10 to over 10,000. Therefore, it should be investigated in the future studies.

The tritium source was estimated to be the most important parameter among the 14 input parameters. The uncertainty of the tritium source contributes about $62 \%$ of the total uncertainty. Therefore, reducing the uncertainty in the tritium source is essential and the most effective way to reduce the modeling 
uncertainties. Reducing tritium release from the core is also considered to be the most effective way to lower the tritium level in the hydrogen product. Further studies are strongly recommended for this area.

The parameters related to the PHX were also estimated to be second in importance. About $20 \%$ of output uncertainties were contributed by these. Therefore, improvement of PHX tritium resistance is considered to be an effective way to reduce the tritium level in the hydrogen product.

The purification system was not sensitive to the output results under the given input ranges based on previous reactor designs. However, increasing purification capacity will obviously reduce the tritium level in the whole system since the most of the tritium in the system is removed by this component. However, it might lead to reduced system efficiency and increased cost. Therefore, the design on the purification system should be made from the economic perspective. Some optimization studies are recommended for the future researches.

\subsection{HTGR/HTSE system}

The HTGR system was designed based on 600 -MWt power and $750^{\circ} \mathrm{C}$ core outlet temperature in this study. This system consists of the four separate loops including the reactor primary side, the reactor secondary side, the PCS, and the HTSE system. Primary heat was transferred to the secondary side through an IHX. In the secondary side, the heat was transferred to the PCS and HTSE system through an SHX and a PHX. The PCS was based on the steam Rankin cycle. In the HTSE system, since the PHX outlet steam temperature is insufficient for electrolysis, the steam was heated up to $800^{\circ} \mathrm{C}$ by an electric heater.

The HTGR/HTSE system was modeled using the TPAC. Most of the information for modeling was obtained or determined from previous literature, HYSYS flowsheet analyses, and some assumptions. For sensitivity analyses, 14 input parameters were selected, which randomly generated 15,360 inputs using the SIMLAB software. A MATLAB script was developed to link MATLAB workspace parameters and the TPAC input variables for treating a large number of sampling continuously. In this study, the following three aspects were taken into account in detail:

- Tritium concentration in the hydrogen product

- Tritium distribution in the HTGR/HTSE system

- Important factors affecting tritium behaviors.

According to the results, the average concentration in the product hydrogen is $1.50 \times 10^{-2} \mathrm{~Bq} / \mathrm{cm}^{3}$. In this case, $90 \%$ of the estimated tritium concentration ranges between $9.32 \times 10^{-4} \mathrm{~Bq} / \mathrm{cm}^{3}$ and $4.62 \times 10^{-2}$ $\mathrm{Bq} / \mathrm{cm}^{3}$. About $30 \%$ of the cases are within the effluent limit $\left(3.7 \times 10^{-3} \mathrm{~Bq} / \mathrm{cm}^{3}[\mathrm{STP}]\right)$, and $70 \%$ exceed the effluent limit. In this study, it was assumed that $21 \%$ of tritium is released from the core and $79 \%$ of tritium is retained in the core. According to the result, about $3 \%$ of the tritium transfers to the hydrogen production system.

Global sensitivity analyses were performed based on the method proposed by Sobol. In these analyses, the following four parameters were identified as important for both reducing modeling uncertainties and reducing tritium concentration in the hydrogen product.

- $\quad$ PHX permeation coefficient (C3)

- Tritium Source (TS)

- SHX permeation coefficient (C2)

- $\quad$ PHX activation energy (EA3). 
The above parameters were estimated to contribute about $65 \%$ of the total uncertainties. It strongly recommended that future research concentrate on improving those 4 parameters and model accuracies. Also, effective methods to control those parameters should be developed for mitigating tritium in the system.

\subsection{HTGR/MTG system (I)}

This study investigated tritium behaviors in the HTGR/MTG system. The HTGR system was designed based on 1,200-MWt power (two 600 -MWt modules) and $750^{\circ} \mathrm{C}$ core outlet temperature. This system consists of the following four separate loops: the reactor primary side, the reactor secondary side, the PCS, and the MTG system. The primary heat was transferred to the secondary side through an IHX. In secondary side, the heat was transferred to the PCS and HTSE system through an SHX and a PHX. The PCS was based on the steam Rankin cycle. The proposed MTG system includes operation units for air separation (ASU), natural gas purification and reforming (NG-RFMR), methanol synthesis (MEOHSYN), methanol conversion to gasoline (MTG), power production (HTSG-ST), cooling tower, and water treatment. Nuclear heat is used to preheat all streams entering the primary reformer.

The HTGR/MTG system was modeled using the TPAC. Most of the information for modeling was obtained or determined from previous literature, HYSYS flowsheet analyses, and some assumptions. For sensitivity analyses, 19 input parameters were selected, which randomly generated 20,450 inputs using the SIMLAB software. A MATLAB script was developed to link MATLAB workspace parameters and the TPAC input variables for treating a large number of samples continuously. In this study, the following three aspects were taken into account in detail:

- Tritium concentration in the hydrogen product

- Tritium distribution in the HTGR/HTSE system

- Important factors affecting tritium behaviors.

First, we estimated tritium concentration in the three locations: (1) gasoline, (2) LPG, and (3) waste water. According to the estimations, the average tritium concentration in the LPG was estimated to be $2.06 \times 10^{-2} \mathrm{~Bq} / \mathrm{cm}^{3}$. About $7 \%$ of the cases were within tritium effluent limit $\left(3.7 \times 10^{-3} \mathrm{~Bq} / \mathrm{cm}^{3}\right)$. The average tritium concentration in the gasoline was estimated to be $2.76 \times 10^{-2} \mathrm{~Bq} / \mathrm{cm}^{3}$. About $5 \%$ of the cases were within tritium effluent limit $\left(3.7 \times 10^{-3} \mathrm{~Bq} / \mathrm{cm}^{3}\right)$. These tritium levels are considered to be very large even in the low operating temperatures. This is because of many hydrogen atoms in gasoline and LPG molecules. One molecule can have several tritium atoms that are replaced with hydrogen. This leads to large tritium concentrations in a unit volume. According to the analyses, initially, the tritium generated in the reactor core and $21 \%$ of the tritium is released to the primary loop. Finally, $2.14 \%$ of the tritium was migrated to the gasoline and $0.36 \%$, to the LPG.

Global sensitivity analyses were performed based on the method proposed by Sobol. In these analyses, the following four parameters were identified as important for both reducing modeling uncertainties and reducing tritium concentration in the hydrogen product.

- TSs

- Permeation coefficient for PHX-1 (C4)

- Activation energy for PHX-1 (EA4)

- Permeation coefficient for IHX (C1)

The above parameters were estimated to contribute about $78 \%$ of the total uncertainties. It is strongly recommended that future research concentrate on improving those parameters and model accuracies. Also, it is recommended that the methods to effectively control those parameters are developed in the future for mitigating tritium in the system. 


\subsection{HTGR/MTG system (II)}

This study investigated tritium behaviors in the improved HTGR/MTG system. The HTGR system was designed based on $721-\mathrm{MWt}$ power and $750^{\circ} \mathrm{C}$ core outlet temperature. The primary heat was transferred to the secondary side through an IHX. In secondary side, the heat was transferred to the PCS and HTSE system through an SHX and a PHX. The PCS was based on the steam Rankin cycle. The proposed MTG system includes operation units for air separation (ASU), natural gas purification and reforming (NG-RFMR), methanol synthesis (MEOH-SYN), methanol conversion to gasoline (MTG), power production (HTSG-ST), the cooling tower, and water treatment. Nuclear heat is used to preheat all streams entering the primary reformer. The HTGR/MTG system was modeled by the TPAC code.

First, we estimated tritium concentration in the three locations: (1) gasoline, (2) LPG, and (3) waste water. According to the estimations, the average tritium concentration in the LPG was estimated to be $2.28 \times 10^{-3} \mathrm{~Bq} / \mathrm{cm}^{3}$. In this case, about $75 \%$ of the cases were less than the effluent limit $\left(3.7 \times 10^{-3} \mathrm{~Bq} / \mathrm{cm}^{3}\right)$. The average tritium concentration in the gasoline was estimated to be $3.05 \times 10^{-3} \mathrm{~Bq} / \mathrm{cm}^{3}$. About $62 \%$ of the cases were within the tritium effluent limit $\left(3.7 \times 10^{-3} \mathrm{~Bq} / \mathrm{cm}^{3}\right)$. These tritium levels are considered to be very low compared to the original MTG system. The improved MTG system has much less reactor power $(721 \mathrm{MWt})$ than the original one (1200 MWt). Since the tritium birth rate is proportional to the reactor power, it is anticipated that the original system releases much more tritium into the reactor primary side. In addition, the higher reactor power requires larger heat transfer surface area of the IHX, which leads to more tritium permeation to the secondary and the industrial plants. Therefore, the new system is considered better than the original from the tritium permeation perspective. According to the analyses, initially, the tritium generated in the reactor core and $21 \%$ of the tritium is released to the primary loop. In the primary loop, about $10.4 \%$ of the tritium is purified in the purification system, and $10.45 \%$ is permeated to the secondary side through the IHX walls. Finally, $0.19 \%$ of the tritium release goes to the gasoline and $0.03 \%$, to the LPG.

Global sensitivity analyses were based on the method proposed by Sobol. In these analyses, the following four parameters were identified to be important for both reducing modeling uncertainties and reducing tritium concentration in the hydrogen product.

- TS

- Tritium Permeation Coefficient of Reheater (C3)

- $\quad$ Tritium Permeation Coefficient of PHX (C4)

- Tritium permeation coefficient of IHX (C1).

The above parameters were estimated to contribute about $80 \%$ of the total uncertainties. It is strongly recommended that future research concentrate on improving those parameters and model accuracies. Also, it is recommended that the methods to effectively control those parameters are developed in the future for mitigating tritium in the system. 


\section{FUTURE PLANS}

The following summarize the future plans of the tritium permeation study:

- Validation of the TPAC code will be conducted using the JAEA tritium data.

- Tritium behavior studies will be conducted on some additional nuclear-assisted industrial process applications.

- Minimum purification system capacities for limiting tritium level in the industrial products such as hydrogen will be estimated for various nuclear integrated systems. Optimization will be also performed if possible.

- Oxide layers can decrease the hydrogen/tritium permeation rate by more than two orders of magnitude and therefore permeation barrier study will be included.

- TPAC software and configuration control will be initiated and documented for the ultimate licensing opportunity. 


\section{REFERENCES}

1. ABAQUS, Inc, 2004, "Getting Started with ABAQUS."

2. Atomic Energy Society of Japan, "Tritium no Kagaku," Atomic Energy Society of Japan, Vol 31 [in Japanese], 1982.

3. Compare, E. L., Freid, S. H., and Nestor, C. W., Distribution and Release of Tritium in HighTemperature Gas-Cooled Reactors as a Function of Design, Operational, and Material Parameters, ORNL_TM-4303, Oak Ridge National Laboratory, June 1974.

4. DOE, A Technology Roadmap for Generation-IV Nuclear Energy Systems, GIF-002-00, U.S.DOE Nuclear Energy Research Advisory Committee and the Generation IV International Forum, December 2002.

5. Forsyth, N., 1974, "Tritium production and distribution in High Temperature Gas Cooled Reactors: Tritium generation, retention, distribution, and environmental release in a national 1,500 MW(th) HTR," O.E.C.D. High Temperature Reactor Project DRAGON, DP REPORT 905, October 1974.

6. Gainey, B. W., 1976, “A Review of Tritium Behavior in HTGR Systems," GA A13461, General Atomic Company, April 30, 1976.

7. General Atomic Company, 1978, "Metallurgical Examination of Primary Circuit Components from the Peach Bottom HTGR, GA A14506, General Atomic Company, February 1978.

8. General Atomics, 2006, TRITGO Code Description and User's Guide, GA Project 20128, 2006.

9. Heatric ${ }^{\mathrm{TM}}$, 2003, Workshop at MIT on October 2, 2003, Cambridge, MA.

10. Kakac, S., Liu, H., Heat Exchangers: Selection, Rating, and Thermal Design, CRC Press, ISBN 08493-0902-6, 2002.

11. Mekellar, M. G., Boardman, R. D., Patterson, M. W., "Power Cycles for the Generation of Electricity from a Next Generation Nuclear Plant," Idaho National Laboratory, TEV-674, Project Number 23843, 2009.

12. Mekellar, M. G., Boardman, R. D., Patterson, M. W., "Nuclear Assisted Hydrogen Production Analysis, Idaho National Laboratory," TEV-693, Project Number 23843, 2009.

13. Oh, C. H., Kim, E. S., Sherman, S. R., Vilim, R., Lee, Y. J. and Lee, W. J., 2007, HyPEP FY-07 Annual Report: A Hydrogen Production Plant Efficiency Calculation Program, INL/EXT-07-13078.

14. Oh, C.H., and Kim, E.S., Heat Exchanger Design Options and Tritium Transport Study for the VHTR System, INL/EXT-08-14799, 2008.

15. Oh, C. H. and Eung S. Kim, Development and Verification of Tritium Analyses Code for Very High Temperature Reactor, INL/EXT-09-16743, September, 2009.

16. Ohashi, H. and Sherman, S., 2007, Tritium Movement and Accumulation in the NGNP System Interface and Hydrogen Plant, INL/EXT-07-12746, 2007.

17. Richards, M. B., Shenoy, A. S., Brown, L. C., Buckingham, R. T., Harvego, E. A., Peddicord, K. L., Reza, S. M., and Coupey, J. P., H2-MHR Pre-conceptual Design Report: SI-Based Plant, GAA25401, General Atomics Company, April 2006.

18. Satelli, A., Tarntola, S., Campolongo, F., Ratto, M., Sensitivity Analysis in Practice, John Wiley \& Sons, ISBN 0-470-87093-1, 2004.

19. Sherman and Adams, Tritium Barrier Materials and Separation System in NGNP, WSRC-STI-200800358, Rev.0, 2008. 
20. SIMLAB, Simlab 2.2 Reference Manual, 2008.

21. Sobol, L. M., "Sensitivity analysis for non linear mathematical models," Math. Model. Comput. Exp., Vol 1, pp. 407-414, 1993.

22. Sobol, L. M., “Quasi-Monte Carlo methods,” Prog. Nucl. Energy, Vol 24, pp. 55-61, 1990.

23. Steinwarz, W., H. D. Rohrig, and R. Nieder, 1980, Tritium Behavior in an HTR System Based on AVR Experience, IWGGCR2, International Atomic Energy Agency, Vienna (Austria), pp. 153-160.

24. The Mathworks, MATLAB 7.8 User Guide, 2009.

25. Wichner, R. P. and F. F. Dyer, 1979, Distribution and Transport of Tritium in the Peach Bottom HTGR, ORNL 5497, Oak Ridge National Laboratory, August 1979.

26. Wood, R. A., Boardman, R. D., Patterson, M. W., "Nuclear Integrated Methanol to Gasoline Production Analysis," Idaho National Laboratory, TEV-667, Project Number 23843, 2009.

27. Wood, R. A., Boardman, R. D., Patterson, M. W., "Nuclear Integrated Methanol to Gasoline Production Analysis," Idaho National Laboratory, TEV-667 Rev2, Project Number 23843, 2010.

28. Yang, L., W. A. Baugh, and N. L. Baldwin, 1977, Study of Tritium Permeation Through Peach Bottom Steam Generator Tubes, GA A14376, General Atomics Company, June 1977. 
Appendix A

\section{MATLAB Script for Automatic TPAC Evaluation}




\section{Appendix A}

\section{Global Sensitivity Analyses}

This section briefly summarizes the global sensitivity analysis method used in this study. This method is based on the Monte-Carlo-based random sampling. The details are as follows.

\section{Overview of Global Sensitivity Analyses}

According to the definition by Satelli et al. (2004), sensitivity analysis (SA) is the study of how the variation in the output of a model can be contributed to different sources of variations and of how the given model depends on the information fed into it. Originally, SA was created to deal simply with uncertainties in the input variables and model parameters. Over time, the idea was expanded to incorporate model conceptual uncertainty (i.e., uncertainty in model structures, assumptions, and specifications). As a whole, SA is used to increase confidence in the model and its predictions by providing an understanding of how the model response variables respond to changes in the inputs. Therefore, SA is closely related to uncertainty analysis (UA), which aims to quantify the overall uncertainty associated with the response as a result of uncertainties in the model input.

The SA can be categorized by the following three different types of analyses:

1. Screening

2. Local sensitivity study

3. Global sensitivity study.

The screening method is useful when the model is expensive to compute and it has many input factors. The screening method is aimed at identifying a subset of input factors that will most likely have a strong effect in the model output. Therefore, this method is approximate, but with low computational effort. The local sensitivity study focuses on the local (point) impact of the factors on the model. This analysis is usually carried out by computing partial derivatives of the output functions with respect to the input factors. The local sensitivity study approach is practicable when the variation around the midpoint of the input factors is small and the trend is linear. When significant uncertainty exists in the input factors, the linear sensitivities alone are not likely to provide a reliable estimator of the output uncertainty in the model. Global sensitivity analysis focuses on apportioning the input uncertainty to the uncertainty in the input factors. Typically, global sensitivity analyses are based on the sampling-based method to quantify the influence of uncertain input parameters on the response variability of a numerical model. There are several different methods that belong to the global sensitivity analysis: standard regression coefficient (SRC), Pearson product moment coefficient (PEAR), Spearman coefficient (SPEAR), and measure of importance (i.e., SOBOL (Satelli et al., 2004), Fourier Amplitude Sensitivity Test (FAST), and etc.

\section{Variance-Based Methods}

In this study, we used variance-based methods for sensitivity analyses based on the variance decomposition. When the input variables are mutually orthogonal, independent, or non-correlated, it is possible to decompose the variance of $\boldsymbol{f}(\boldsymbol{X})$ into terms of increasing dimensionality (SOBOL, 1990, 1993):

$\mathrm{V}(\mathrm{Y})=\sum_{\mathrm{i}} \mathrm{V}_{\mathrm{i}}+\sum_{\mathrm{i}<j} \mathrm{~V}_{\mathrm{ij}}+\sum_{\mathrm{i}<j<k} \mathrm{~V}_{\mathrm{ijk}}+\mathrm{V}_{1,2, \ldots \mathrm{d}}$

The terms $V_{i}, V_{i j}, V_{i j k}, \ldots$, are called partial variance. These terms can be computed, for instance, as follows.

$\mathrm{V}_{\mathrm{i}}=\mathrm{V}\left[\mathrm{E}\left(\mathrm{Y} \mid \mathrm{X}_{\mathrm{i}}\right)\right]$ 
$\mathrm{V}_{\mathrm{ij}}=\mathrm{V}\left[\mathrm{E}\left(\mathrm{Y} \mid \mathrm{X}_{\mathrm{i}}, \mathrm{X}_{\mathrm{j}}\right)\right]-\mathrm{V}_{\mathrm{i}}-\mathrm{V}_{\mathrm{j}}$

$\mathrm{V}_{\mathrm{ijk}}=\mathrm{V}\left[\mathrm{E}\left(\mathrm{Y} \mid \mathrm{X}_{\mathrm{i}}, \mathrm{X}_{\mathrm{j}}, \mathrm{X}_{\mathrm{k}}\right)\right]-\mathrm{V}_{\mathrm{i}}-\mathrm{V}_{\mathrm{j}}-\mathrm{V}_{\mathrm{k}}$

The decomposition in Eq. (5-1) is useful in that all its terms sum to 1.

$\sum_{\mathrm{i}} \mathrm{S}_{\mathrm{i}}+\sum_{\mathrm{i}<j} \mathrm{~S}_{\mathrm{ij}}+\sum_{\mathrm{i}<j<k} \mathrm{~S}_{\mathrm{ijk}}+\mathrm{S}_{1,2, \ldots \mathrm{d}}=1$

Hence:

$$
\begin{array}{ll}
V_{i} / V(Y)=S_{i} & : \text { the first order sensitivity indices } \\
V_{i j} / V(Y)=S_{i j} & : \text { the second order sensitivity indices } \\
V_{i j k} / V(Y)=S_{i j k} & : \text { the third order sensitivity indices. }
\end{array}
$$

The sensitivity indices have a natural interpretation since they represent the fraction of the total variance of $\boldsymbol{f}(\boldsymbol{X})$ because of any individual factor or combination of factors. One limitation of SOBOL's sensitivity indices is their high computational cost.

The first order sensitivity index $\left(\mathrm{S}_{\mathrm{i}}\right)$, which is called "main effect," represents the expected amount of variance removed from total output variance, in case the uncertainty of $\mathrm{X}_{\mathrm{i}}$ is known. This measure indicates the relative importance of an individual input variable $X_{i}$ in driving the uncertainty, and can be seen as indicating where to direct effort to reduce that uncertainty. The first order indices are an essential parameter for factor prioritization (FP) setting, which focuses on indentifying the most important factor.

The total effect for the input variable $\mathrm{X}_{\mathrm{i}}$ is the sum of the first order index and all higher order effects in which the factor participates. The total index represents the expected amount of output variance that would remain if $\mathrm{X}_{\mathrm{i}}$ is left free to vary over its uncertainty range, all other variables being fixed. The total sensitivity index can be expressed by

$\mathrm{S}_{\mathrm{Ti}}=\frac{\mathrm{E}\left(\mathrm{V}\left(\mathrm{Y} \mid \mathrm{X}_{-\mathrm{i}}\right)\right]}{\mathrm{V}(\mathrm{Y})}$.

$\mathrm{X}_{-\mathrm{i}}$ represents all the input variables except $\mathrm{X}_{\mathrm{i}}$. The total sensitivity index is the essential parameter for factors fixing (FF) setting, which focuses on identifying the factor or the subset of input factors that we can fix at any given values over their ranges of uncertainty without significantly reducing the output variance. If such a factor or subset of factors is identified, the remaining ones, being varied within their own ranges, explain most of the unconditional variance.

\section{General Analysis Procedure for Global Sensitivity Analyses and SIMLAB}

This study used the SIMLAB code, a global sensitivity analysis software designed for Monte Carlo-based uncertainty and sensitivity analysis (SIMLAB, 2008). This program is based on performing multiple evaluations with probabilistically selected input factors and then using the results of these evaluations to determine the uncertainty in model predictions and the input factors that gave rise to this uncertainty (Satelli et. al., 2004). This program is financed by the Unit of Econometrics and Applied Statistics of the Joint Research Centre (European Commission). In general, Monte Carlo-based analyses consist of the following five steps (Satelli et al., 2004):

1. Input Selection: A range and distribution are selected for each input variable (input factor). Theses selections will be used in the next step in the generation of a sample from the input factors. If the analysis is primarily of an extrapolatory nature, a rough distribution assumption may be adequate.

2. Input Generation: A sample of points is generated from the distribution of the inputs specified in the first step. The result of this step is a sequence of sample elements. 
3. Model Evaluation: The model is fed with the sample elements and a set of model output is produced. In essence, these model evaluations create a mapping from the space of the input to the space of the results. This mapping is the basis for subsequent uncertainty and sensitivity analysis.

4. Uncertainty Analysis: The results of model evaluations are used as the basis for uncertainty analysis. One way to characterize the uncertainty is with a mean value and a variance. Other model output statistics are provided.

5. Sensitivity Analysis: The results of model evaluations are used as the basis for the sensitivity analysis.

\section{General Strengths and Weaknesses of Global Sensitivity Analyses}

It is useful to know the strengths and weaknesses of the Monte Carlo-based SA method before discussing the analyses. Typical strengths of the Monte Carlo simulation include:

- It provides comprehensive insight into how specified uncertainty in inputs propagate through a model

- It forces analysts to explicitly consider uncertainty and interdependencies among different inputs

- It can cope with any conceivable shape of probability distribution function (PDF) and can account for correlations

- It can be used in two-dimensional mode to separately assess variability and epistemological uncertainty.

The following are the general weaknesses of Monte Carlo simulation:

- It is limited to those uncertainties that can be quantified and expressed as probabilities.

- One may not have any reasonable basis on which to ascribe a parameterized probability distribution to parameters.

- It may take long run time for computationally intensive models. This can partly be remedied by using more efficient sampling techniques.

- The interpretation of a probability distribution of the model output by decision makers is not always straightforward. No single rule arises out of such a distribution that can guide decision makers concerning the acceptable balance between, for instance, expected return and the variance of that return. 


\section{Appendix B}

\section{MATLAB Script for Automatic TPAC Evaluation}

The following MATLAB script was developed for automatic evaluation of the TPAC model for generated inputs. Before running this script, a data file should be first made and loaded into the MATLAB workspace. The data file contains the input data generated by SIMLAB software. In the following script, the file named 'iTPAC_SEN_GL_L6.m' is loaded for evaluation. This script finally generates four output files named as CHT1, CHT2, CHT3, and CHT4, which represent the tritium concentrations in the primary side, secondary side, intermediate heat transfer loop, and product hydrogen.

\section{A. VHTR/HTSE System}

\section{MATLAB SCRIPT}

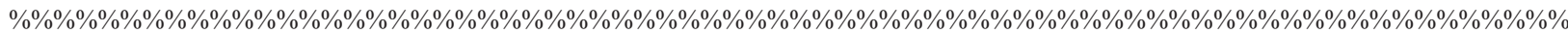
$\% \% \% \%$ Script for TPAC Running in the Matlab (S_TPAC_GS.m)

$\% \% \% \%$ BY EUNG SOO KIM (Idaho National Laboratory)

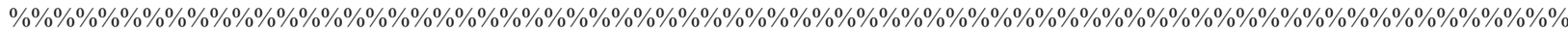

\%initialize all variables

clear;

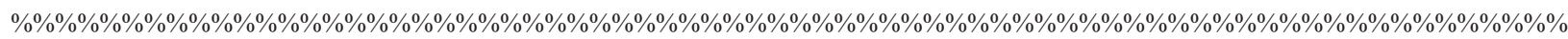
$\%$ 1. Preparation of Data (We can load MAT Data)

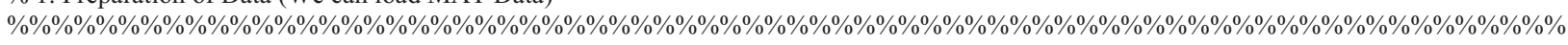
$\%$ Variables:

$\% \quad$ (1) Tritium source : TS

$\%$ (2) Fraction of mass flow to purification system (primary): PMF1

$\%$ (3) Fraction of mass flow to purification system (secondary): PMF2

$\%$ (4) Fraction of mass flow to purification system (IHTL): PMF3

$\% \quad$ (5) Reaction Coefficient (IHX): C1

$\%$ (6) Reaction Coefficient (SHX): C2

$\% \quad$ (7) Reaction Coefficient (PHX): C3

$\% \quad$ (8) HX thickness (IHX): TH1

$\% \quad$ (9) HX thickness (SHX): TH2

$\% \quad$ (10) HX thickness (PHX): TH3

$\% \quad$ (11) HX temperature (IHX): T1

$\% \quad$ (12) HX temperature (SHX): T2

$\% \quad$ (13) HX temperature (PHX): T3

$\% \quad$ (14) HX activation energy (IHX): EA1

$\% \quad$ (15) HX activation energy (SHX): EA2

$\% \quad$ (16) HX activation energy (PHX): EA3

$\% \quad$ (17) HX Temperature level (IHX/SHX/PHX):CTL

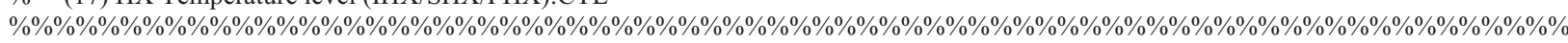
$\% \% \%$

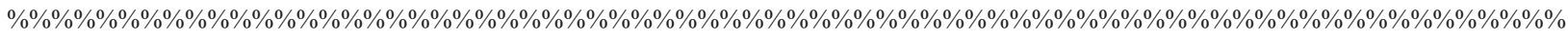
$\%$ 2. Read Input Data

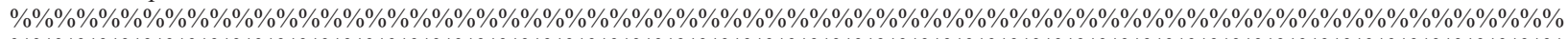

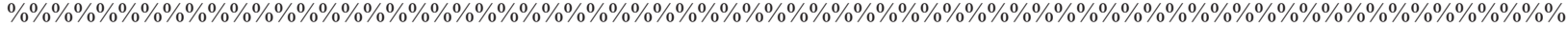

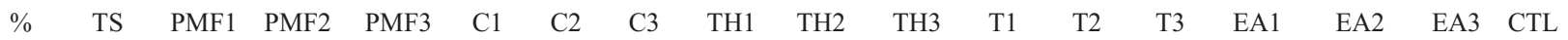

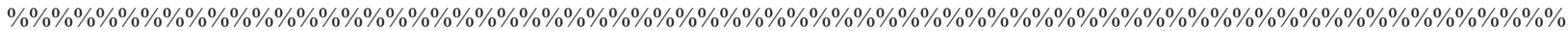
\%\%\%\%\%\%\%\%\%\%\%\%\%\%\%\%\%\%\%\%\%\%\%\%\%\%\%\%\%\%\%\%\%\%\%\%\%\%\%\%\%\%\%\%\%\%\%\%\%\%\%\%\%\%\%\%\%\%\%\%\%\%\%\%\%\%\%\%\%\% load iTPAC_SEN_GL_L6;

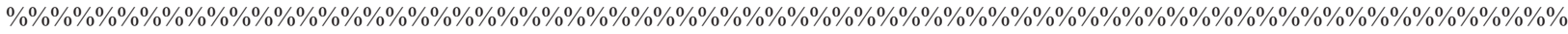
$\%$ Initialization of Output File

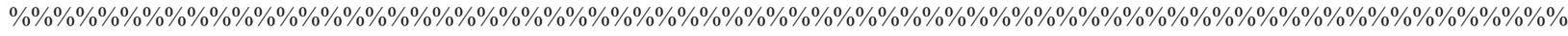




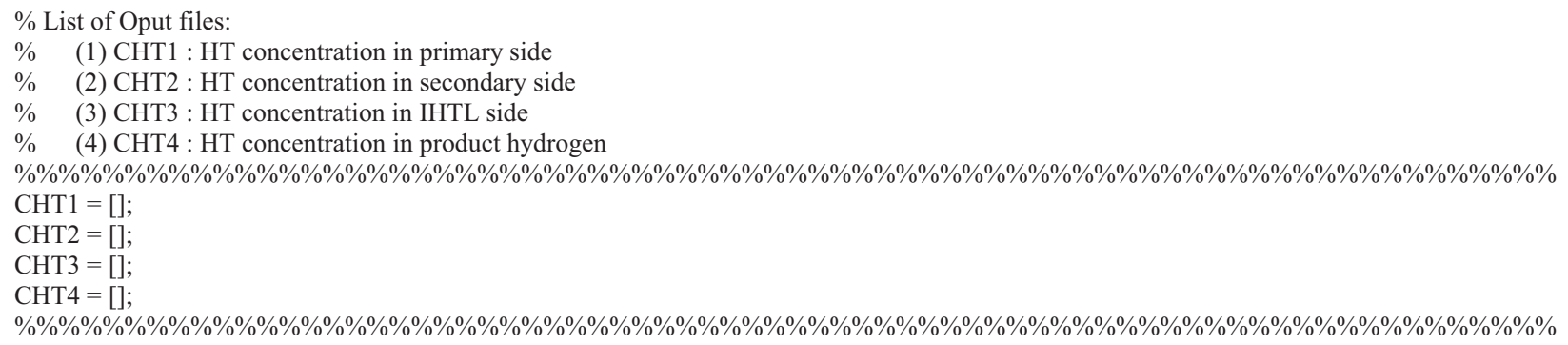


end

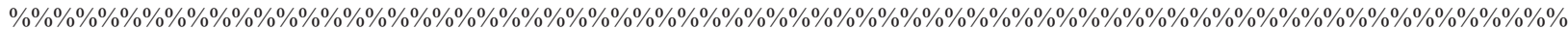
$\% \% \% \%$ END OF SCRIPT

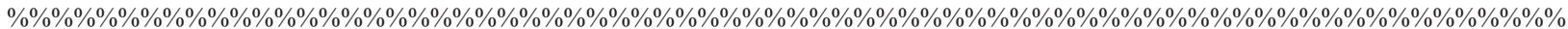




\title{
B. HTGR/HTSE System
}

\author{
MATLAB SCRIPT
}

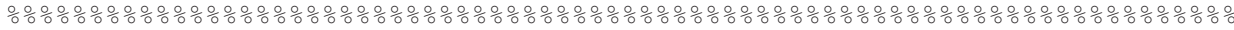

$\% \% \% \%$ Script for TPAC Running in the Matlab (S_TPAC_GS.m)

응으을 BY EUNG SOO KIM (Idaho National Laboratōry)

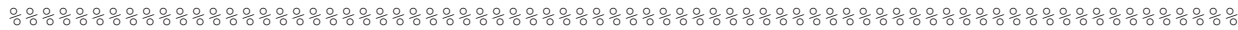

oinitialize all variables

clear;

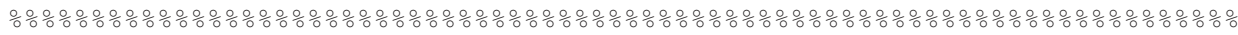

\% 1. Preparation of Data (We can load MAT Data)

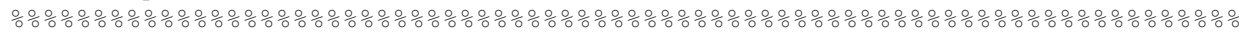

Variables:

\% (1) Tritium source : TS

\% (2) Fraction of mass flow to purification system (primary): PMF1

\% (3) Fraction of mass flow to purification system (secondary): PMF2

\% (4) Fraction of mass flow to purification system (IHTL): PMF3

(5) Reaction Coefficient (IHX) : C1

(6) Reaction Coefficient (SHX) : C2

(7) Reaction Coefficient (PHX) : C3

(8) HX thickness (IHX) : TH1

(9) HX thickness (SHX) : TH2

(10) HX thickness (PHX) : TH3

(11) HX temperature (IHX) : T1

(12) HX temperature (SHX) : T2

(13) HX temperature (PHX) : T3

\% (14) HX activation energy (IHX) : EA1

\% (15) HX activation energy (SHX) : EA2

(16) HX activation energy (PHX) : EA3

(17) HX Temperature level (IHX/SHX/PHX) : CTL

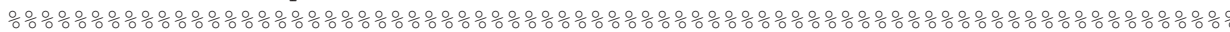

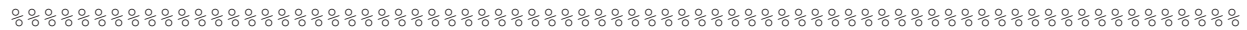

ㄴ 2. Read Input Data

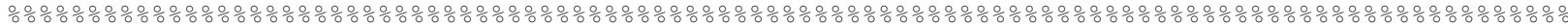

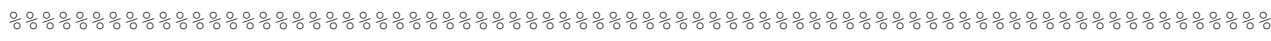

$\begin{array}{lllllllll}\circ & \text { TS } & \text { PMF1 } & \text { PMF2 } & \text { PMF3 } & \text { C1 } & \text { C2 } & \text { C3 }\end{array}$

$\begin{array}{lllllll}\text { TH3 } & \text { T1 } & \text { T2 } & \text { T3 } & \text { EA1 } & \text { EA2 } & \text { EA3 }\end{array}$

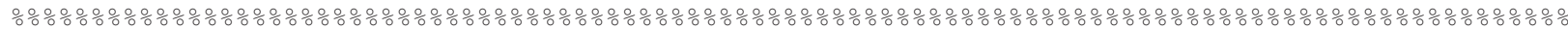
$\frac{\circ}{0} \circ \% \circ \% \circ \%$

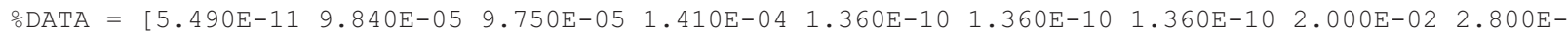
$021.000 \mathrm{E}-02 \quad 1.060 \mathrm{E}+03 \quad 9.990 \mathrm{E}+02 \quad 9.810 \mathrm{E}+02 \quad 53.50 \mathrm{E}+03 \quad 53.50 \mathrm{E}+03 \quad 53.50 \mathrm{E}+03 \quad 1.0 ;$

\% 6.490E-11 8.840E-05 9.750E-05 1.410E-04 1.360E-10 1.360E-10 1.360E-10 2.000E-02 2.800E$021.000 \mathrm{E}-02 \quad 1.060 \mathrm{E}+03 \quad 9.990 \mathrm{E}+02 \quad 9.810 \mathrm{E}+02 \quad 53.50 \mathrm{E}+03 \quad 53.50 \mathrm{E}+03 \quad 53.50 \mathrm{E}+03 \quad 1.0 ;$

ㄱ $7.490 \mathrm{E}-11 \quad 7.840 \mathrm{E}-05 \quad 9.750 \mathrm{E}-05 \quad 1.410 \mathrm{E}-04 \quad 1.360 \mathrm{E}-10 \quad 1.360 \mathrm{E}-10 \quad 1.360 \mathrm{E}-10 \quad 2.000 \mathrm{E}-02 \quad 2.800 \mathrm{E}-$ $021.000 \mathrm{E}-021.060 \mathrm{E}+03 \quad 9.990 \mathrm{E}+02 \quad 9.810 \mathrm{E}+02 \quad 53.50 \mathrm{E}+03 \quad 53.50 \mathrm{E}+03 \quad 53.50 \mathrm{E}+03 \quad 1.0] ;$

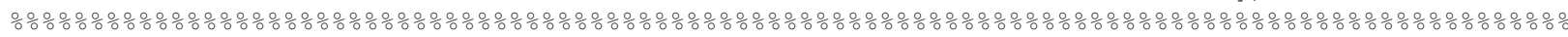

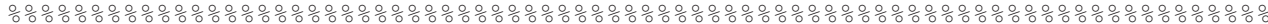

load I8000;

○load ITPAC SEN GL;

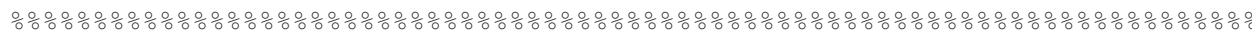

ㅇitialization of Output File

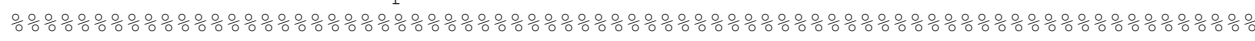

ㄴist of Oput files:

\% (1) CHT1 : HT concentration in primary side

\% (2) CHT2 : HT concentration in secondary side

(3) CHT3 : HT concentration in IHTL side

\% (4) CHT4 : HT concentration in product hydrogen

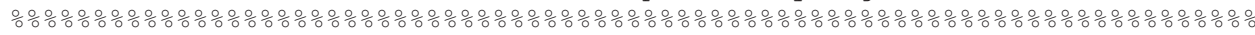

$\mathrm{CHT} 1=[] ;$

$\mathrm{CHT} 2=[] ;$

CHT3 $=[]$; 
$\mathrm{CHT} 4=[] ;$

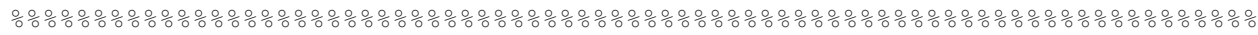

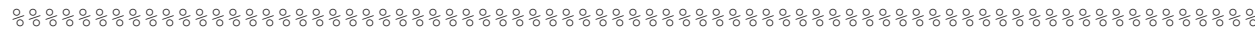

\% 3. Automatic Calculation of Simulink

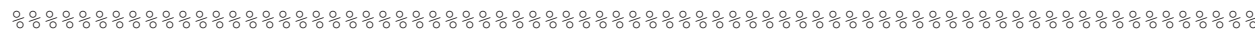

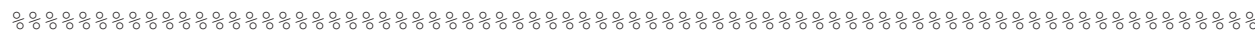

\% NI : number of iteration

: This number should be matched to be the same as the number of data

sets

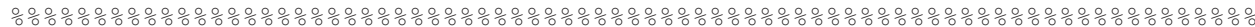

$\circ \mathrm{NI}=3$;

[NI NR] =size (DATA);

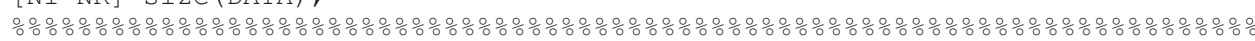
for $\mathrm{n}=1: \mathrm{NI}$

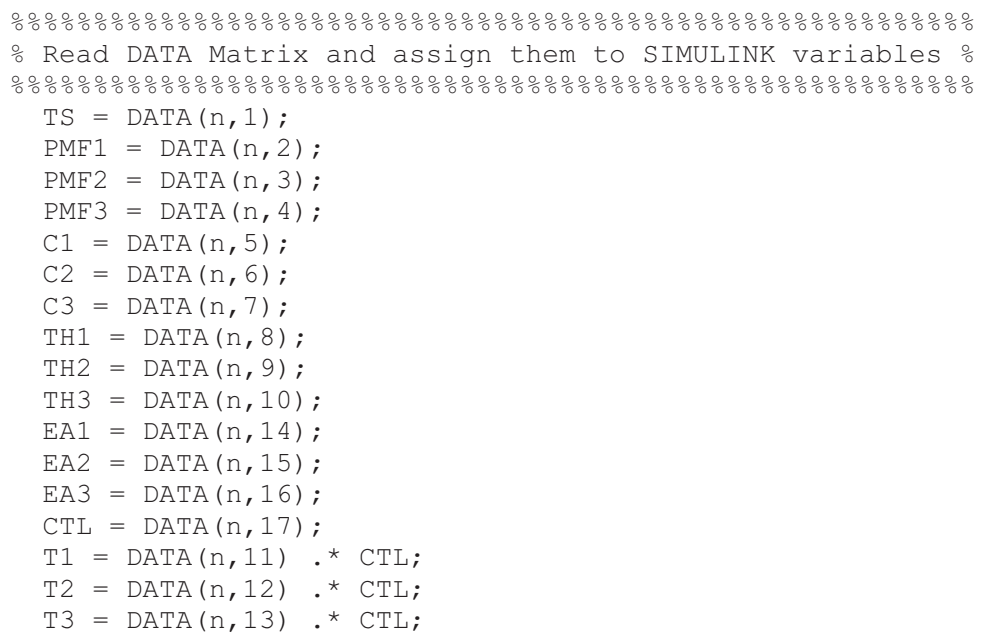

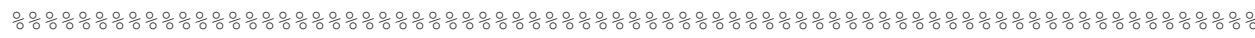
응응 END OF SCRIPT

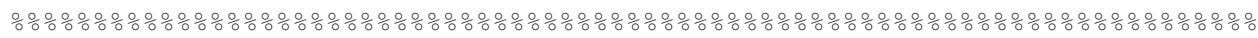




\title{
C. HTGR/MTG System (I)
}

\author{
MATLAB SCRIPT
}

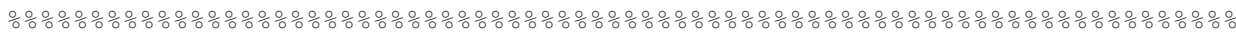

$\% \circ \% \circ \%$ Script for TPAC Running in the Matlab (S_TPAC_MTG.m)

$\% \% \% \%$ BY EUNG SOO KIM (Idaho National Laboratory)

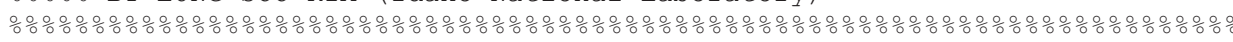

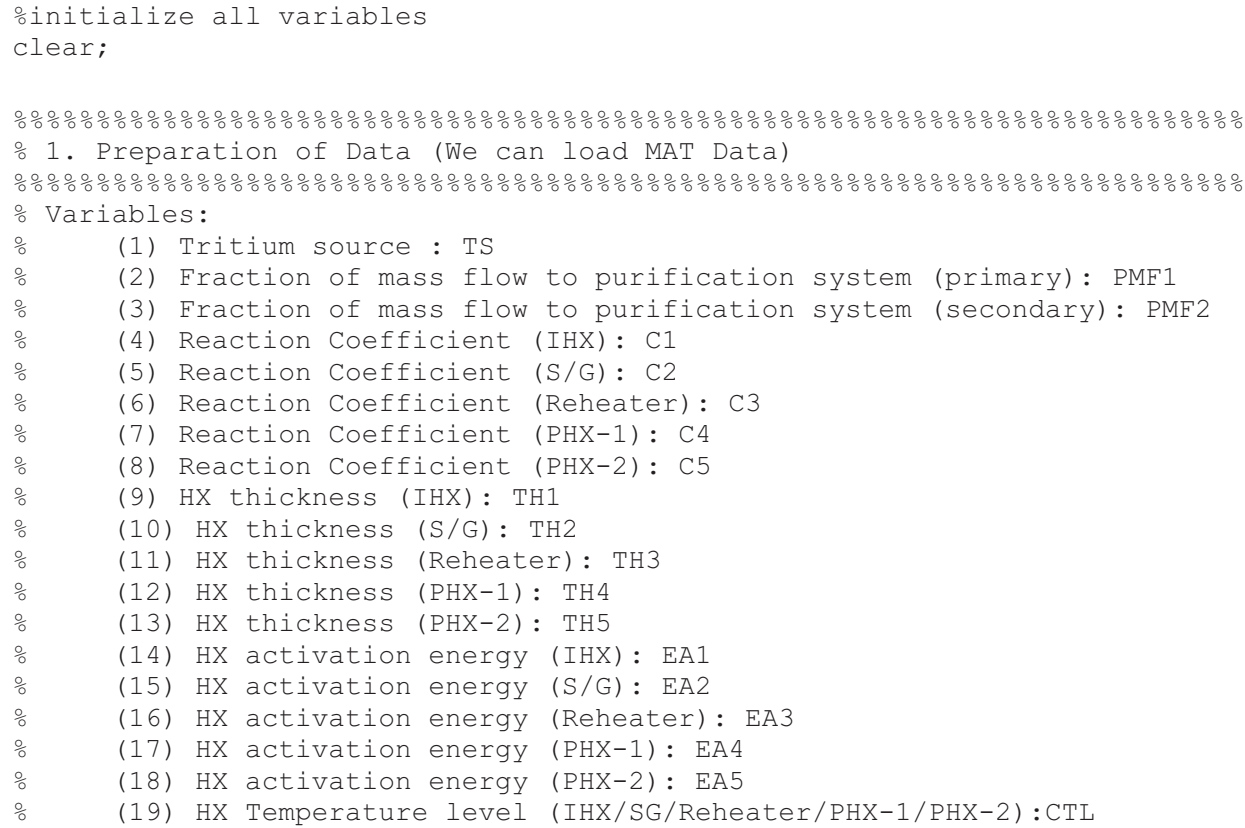

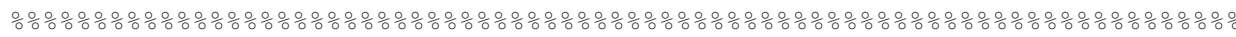
\% 2. Read Input Data

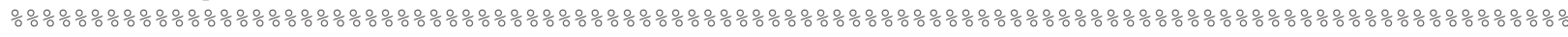

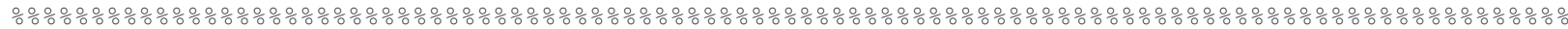
응

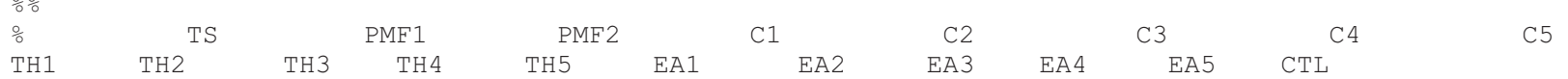

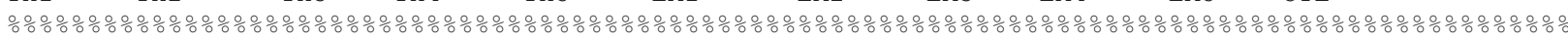

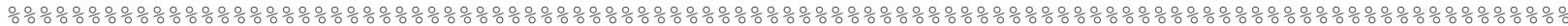
응

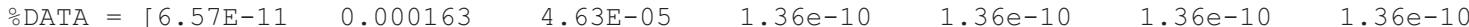

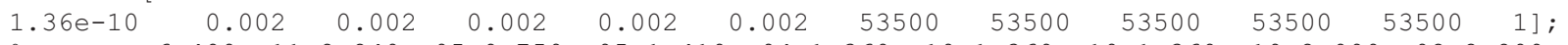
\% 6.490E-11 8.840E-05 9.750E-05 1.410E-04 1.360E-10 1.360E-10 1.360E-10 2.000E-02 2.800E$021.000 \mathrm{E}-02 \quad 1.060 \mathrm{E}+03 \quad 9.990 \mathrm{E}+02 \quad 9.810 \mathrm{E}+02 \quad 53.50 \mathrm{E}+03 \quad 53.50 \mathrm{E}+03 \quad 53.50 \mathrm{E}+03 \quad 1.0 ;$

\% 7.490E-11 7.840E-05 9.750E-05 1.410E-04 1.360E-10 1.360E-10 1.360E-10 2.000E-02 2.800E$021.000 \mathrm{E}-021.060 \mathrm{E}+03 \quad 9.990 \mathrm{E}+02 \quad 9.810 \mathrm{E}+0253.50 \mathrm{E}+03 \quad 53.50 \mathrm{E}+03 \quad 53.50 \mathrm{E}+03 \quad 1.0] ;$

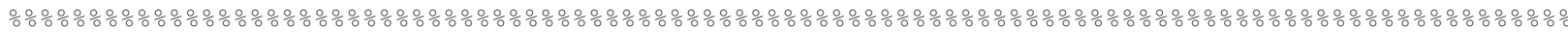

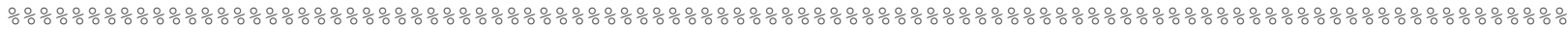
응

load ITPAC MTG C6:

○load iTPA $\bar{C}$ SEN

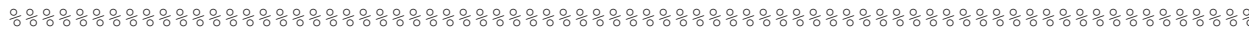

- Initialization of Output File

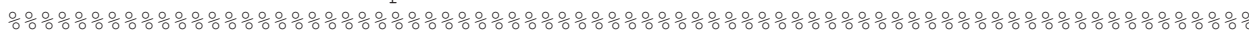

\% List of Oput files:

(1) CHT1 : HT concentration in primary side 


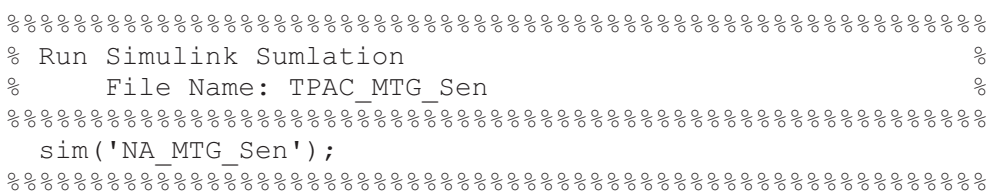




\title{
D. HTGR/MTG System (II)
}

\author{
MATLAB SCRIPT
}

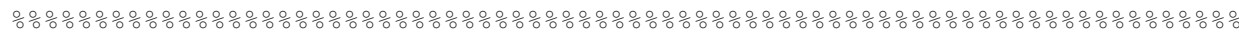

응응 Script for TPAC Running in the Matlab (S TPAC MTG Rev.m)

\%%ㅡ응 BY EUNG SOO KIM (Idaho National Laboratory)

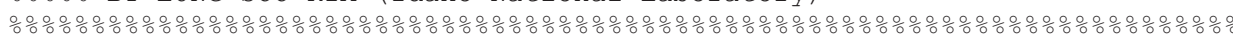

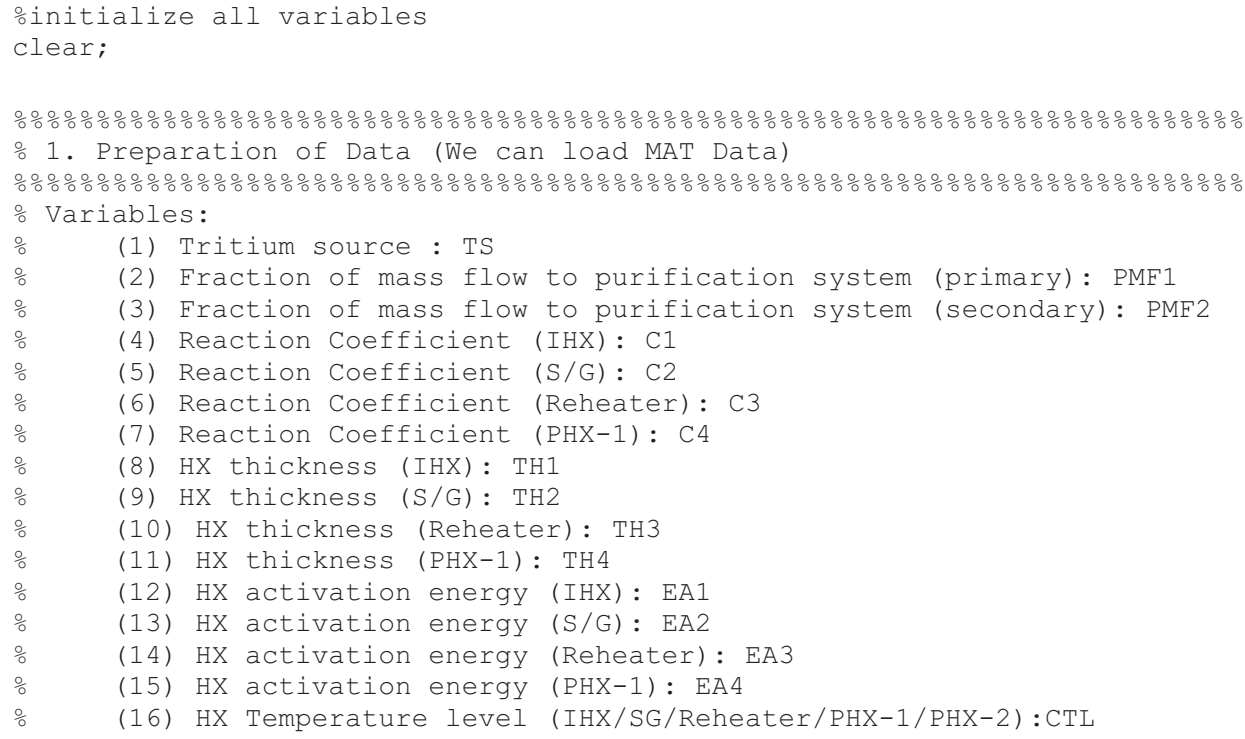




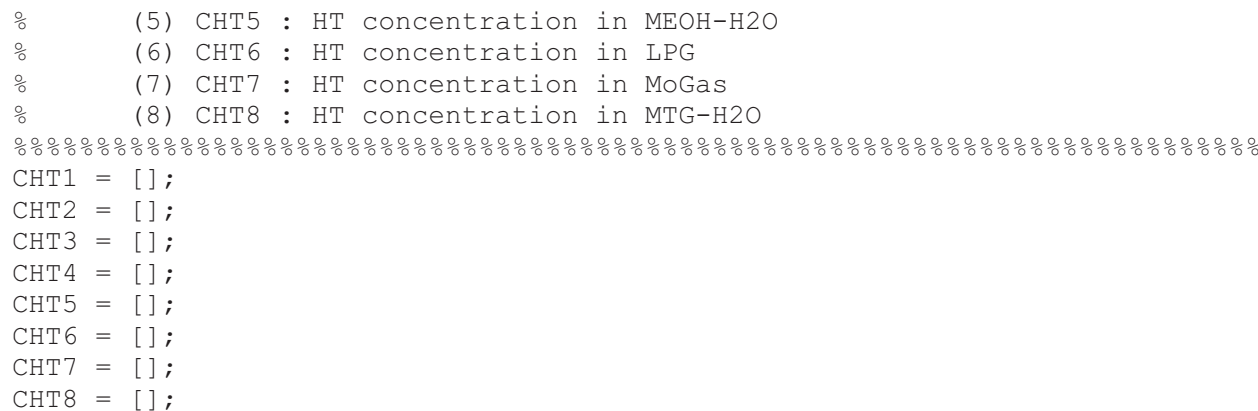

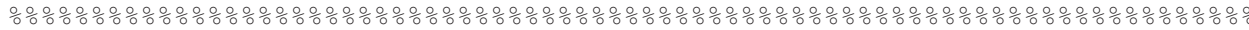

\% 3. Automatic Calculation of Simulink

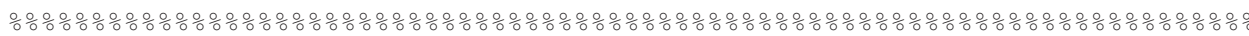

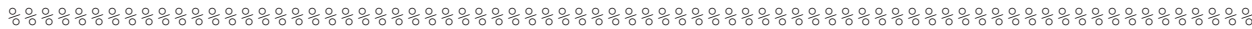

NI : number of iteration

\% This number should be matched to be the same as the number of data sets

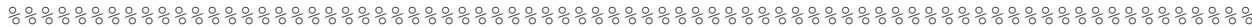

$\div \mathrm{NI}=1$

[NI NR] =size (DATA);

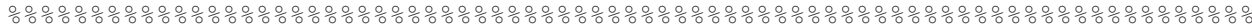

for $n=1: N I$

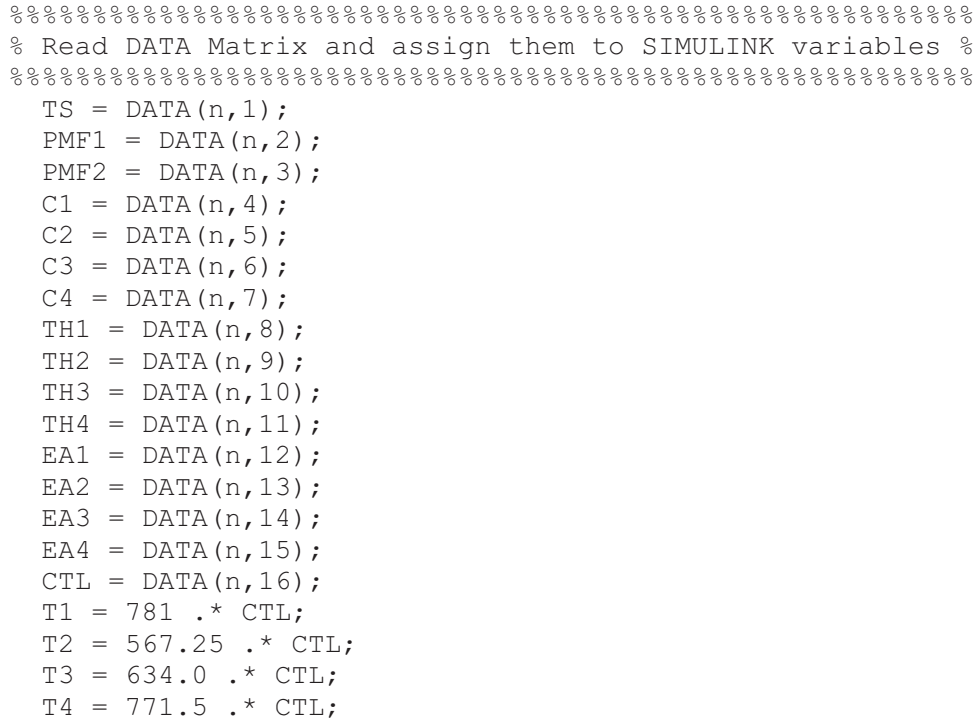

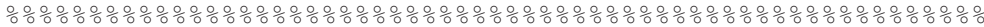




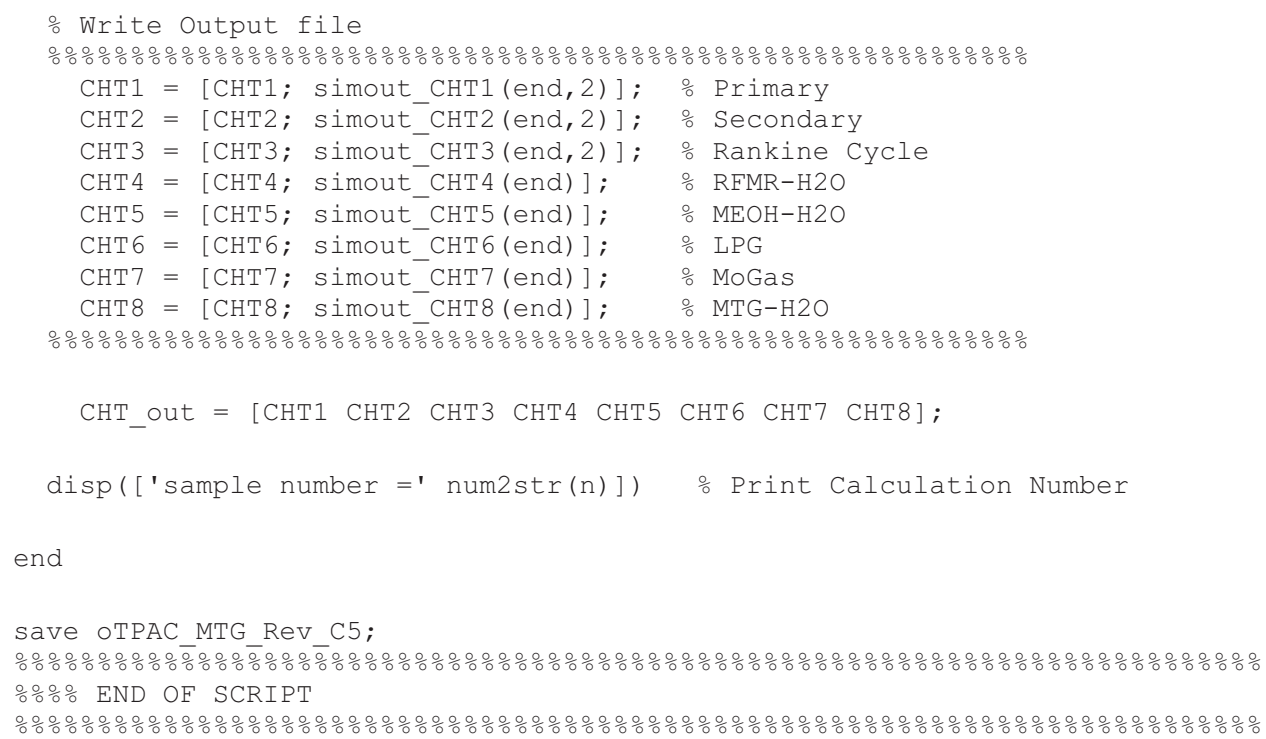

